\title{
Ontogeny of Hepatic Transporters and Drug-Metabolizing Enzymes in Humans and in Nonclinical Species ${ }^{\mathbb{\mathbb { S }}}$
}

B. D. van Groen, (D) J. Nicolaï, A. C. Kuik, S. Van Cruchten, E. van Peer, A. Smits, S. Schmidt, S. N. de Wildt, K. Allegaert, L. De Schaepdrijver, (DP. Annaert, ${ }^{1}$ and J. Badée ${ }^{1}$

Intensive Care and Department of Pediatric Surgery, Erasmus MC-Sophia Children's Hospital, Rotterdam, The Netherlands (B.D.v.G., K.A.); Development Science, UCB BioPharma SRL, Braine-l'Alleud, Belgium (J.N.); Leiden Academic Center for Drug Research, Leiden University, Leiden, The Netherlands (A.C.K.); Department of Veterinary Sciences, Faculty of Pharmaceutical, Biomedical and Veterinary Sciences, University of Antwerp, Wilrijk, Belgium (S.V.C.); Fendigo salnvbv, An Alivira Group Company, Brussels, Belgium (E.v.P.); Department of Development and Regeneration KU Leuven, Leuven, Belgium (A.S.); Neonatal intensive care unit, University Hospitals Leuven, Leuven, Belgium (A.S.); Department of Pharmaceutics, Center for Pharmacometrics and Systems Pharmacology, College of Pharmacy, University of Florida, Orlando, Florida (S.S.); Department of Pharmacology and Toxicology, Radboud Institute of Health Sciences, Radboud University Medical Center, Nijmegen, The Netherlands (S.N.d.W.); Departments of Development and Regeneration and of Pharmaceutical and Pharmacological Sciences, KU Leuven, Leuven, Belgium (K.A.); Department of Hospital Pharmacy, Erasmus MC, University Medical Center, Rotterdam, The Netherlands (K.A.); Nonclinical Safety, Janssen R\&D, Beerse, Belgium (L.D.S.); Drug Delivery and Disposition, Department of Pharmaceutical and Pharmacological Sciences, KU Leuven, Leuven, Belgium (P.A.); and Department of PK Sciences, Novartis Institutes for BioMedical Research, Basel, Switzerland (J.B.)

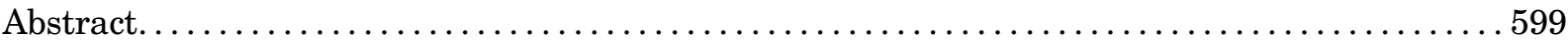

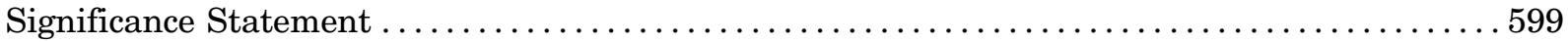

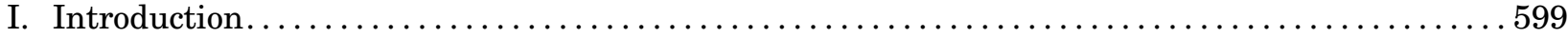

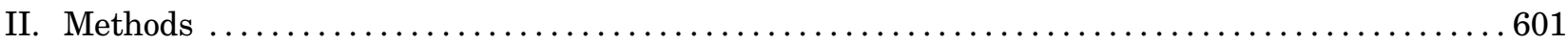

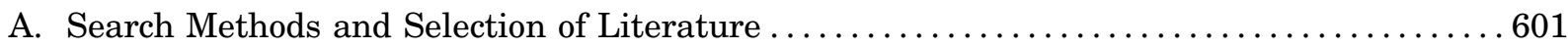

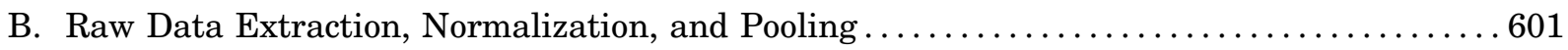

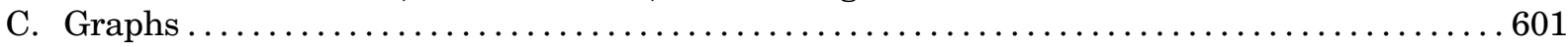

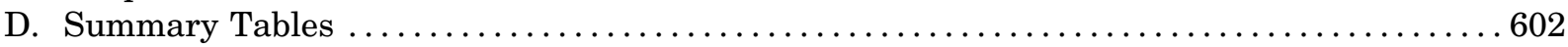

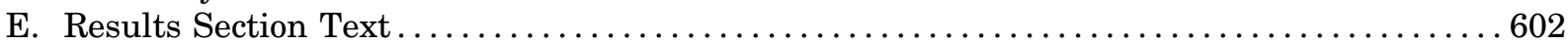

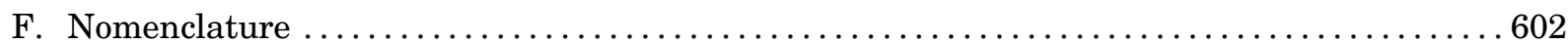

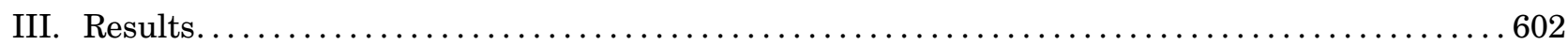

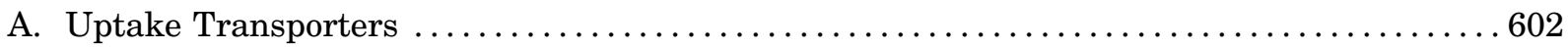

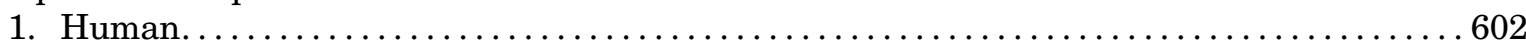

a. Age-related increase in activity/expression ............................ 602

b. Age-related decrease in activity/expression. ............................. 602

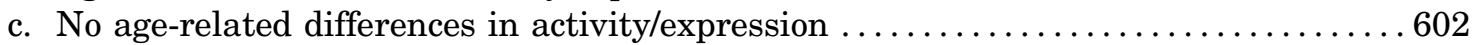

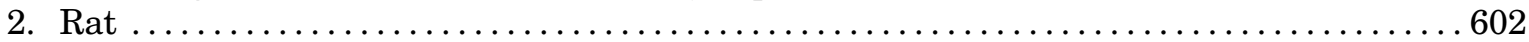

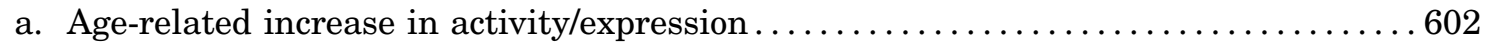

b. Age-related decrease in activity/expression........................... 605

Address correspondence to: P. Annaert, Campus Gasthuisberg, Herestraat 49-box 921, 3000 Leuven, Belgium. E-mail: pieter.annaert@ kuleuven.be

This manuscript received external funding from the Health and Environmental Sciences Institute (HESI) (https://hesiglobal.org). HESI is a publicly supported, tax-exempt organization that provides an international forum to advance the understanding of scientific issues related to human health, toxicology, risk assessment, and the environment through the engagement of scientists from academia, government, industry, nongovernmental organizations, and other strategic partners. This HESI scientific initiative is primarily supported by in-kind contributions from public and private sector participants of time, expertise, and experimental effort. These contributions are supplemented by direct funding that largely supports program infrastructure and management that was provided by HESI's corporate sponsors.

\$This article has supplemental material available at pharmrev.aspetjournals.org.

${ }^{1}$ P.A. and J.B. contributed equally to this work.

The research activities of A.S. are supported by the Clinical Research and Education Council of the University Hospitals Leuven.

Part of this work was previously presented in the following: van Groen BD (2020) From baby steps to mature strides: maturation of drug metabolism and transport studied using innovative approaches. Ph.D. thesis, Erasmus University Rotterdam.

https://doi.org/10.1124/pharmrev.120.000071. 


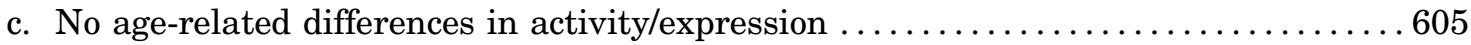

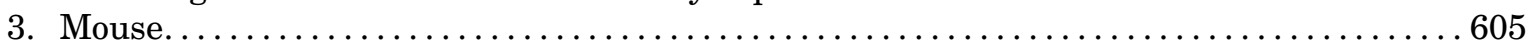

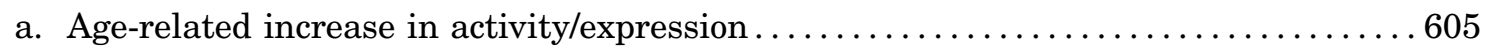

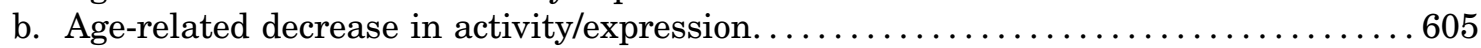

c. Complex and/or inconsistent ontogeny pattern in activity/expression $\ldots \ldots \ldots \ldots \ldots 67$

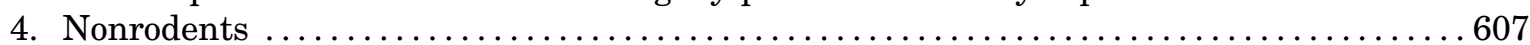

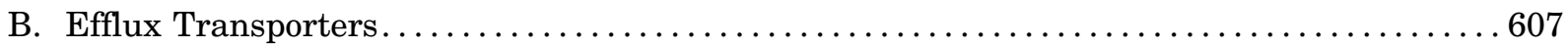

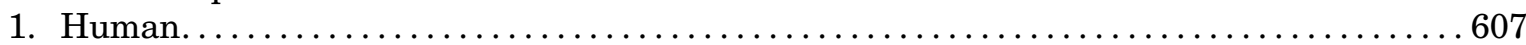

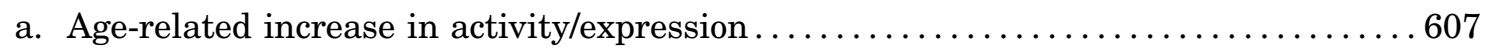

b. Complex and/or inconsistent ontogeny pattern in activity/expression $\ldots \ldots \ldots \ldots 607$

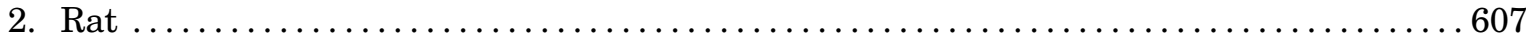

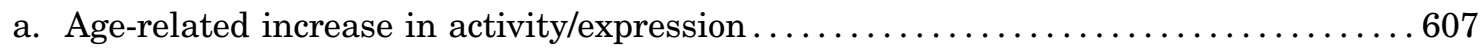

b. Age-related decrease in activity/expression.............................. 608

c. Complex and/or inconsistent ontogeny pattern in activity/expression $\ldots \ldots \ldots \ldots \ldots 608$

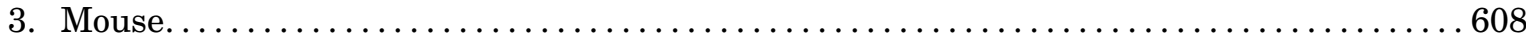

a. Age-related increase in activity/expression ............................. 608

b. Age-related decrease in activity/expression............................ 608

c. No age-related differences in activity/expression $\ldots \ldots \ldots \ldots \ldots \ldots \ldots \ldots \ldots \ldots \ldots$

d. Complex and/or inconsistent ontogeny pattern in activity/expression . . . . . . . 608

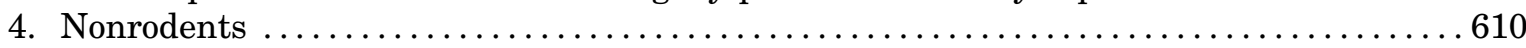

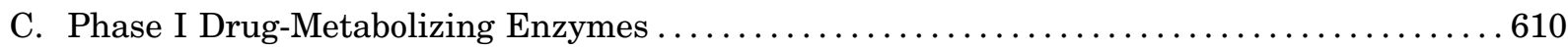

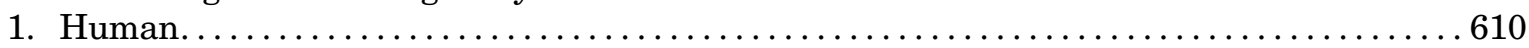

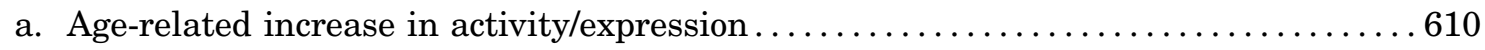

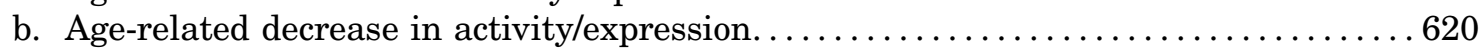

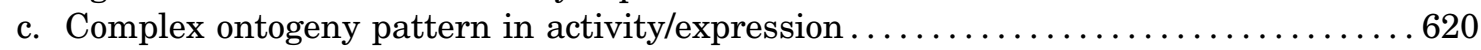

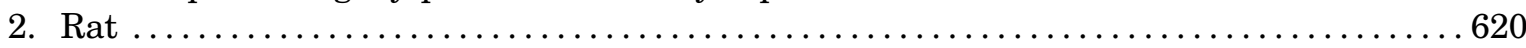

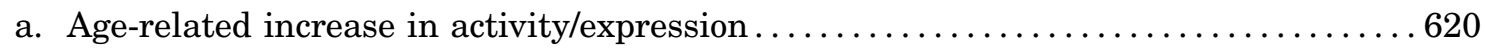

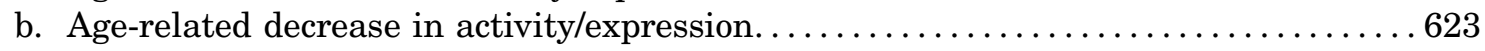

c. No age-related changes in activity/expression ..........................6623

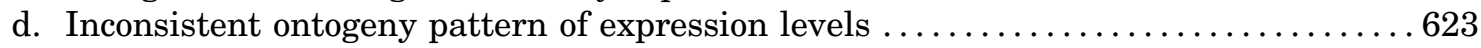

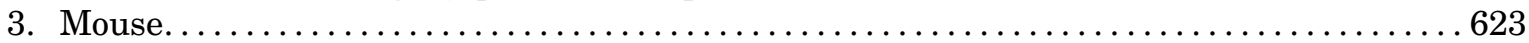

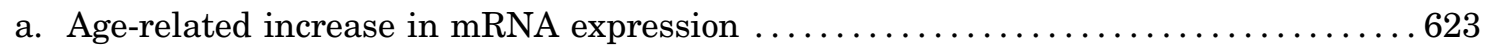

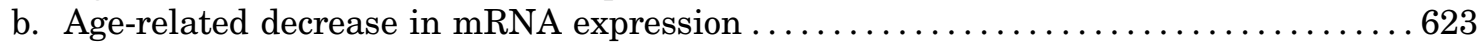

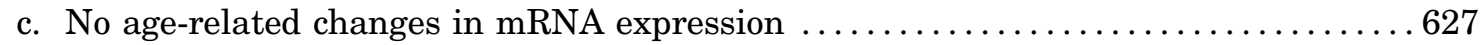

d. Complex and/or inconsistent ontogeny pattern of mRNA expression . . . . . . . . 627

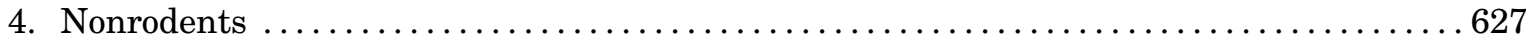

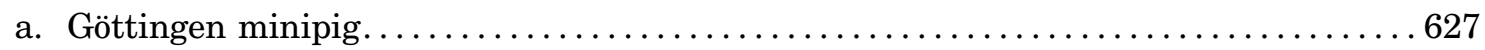

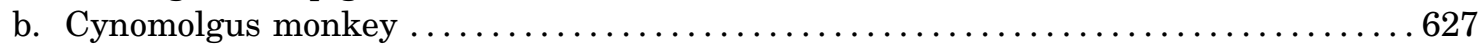

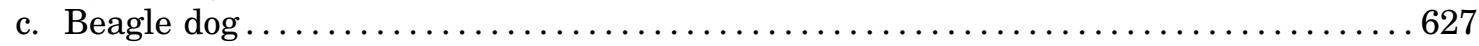

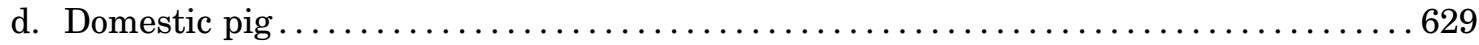

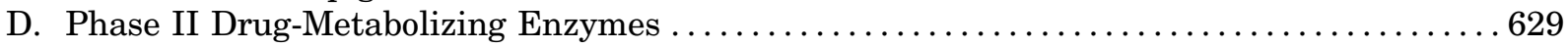

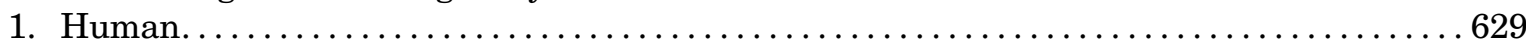

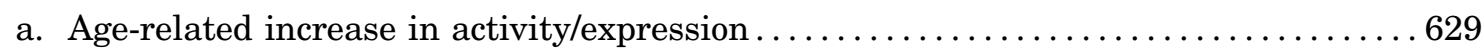

b. Age-related decrease in activity/expression........................... 629

c. No age-related changes in activity/expression ....................... 629

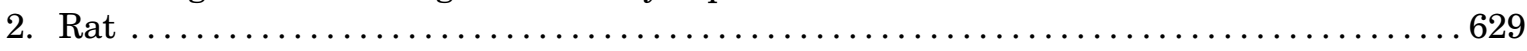

a. Age-related increase in activity/expression ........................ 629

\begin{abstract}
ABBREVIATIONS: ABC, ATP-binding cassette; ADH, alcohol dehydrogenase; ALDH, aldehyde dehydrogenase; BCRP, breast cancer resistance protein; BSEP, bile salt export pump; CES, carboxylesterase; COMT, catechol-O-methyltransferase; CNT, concentrative nucleoside transporter; DHEAS, dehydroepiandrosterone sulfate; DME, drug-metabolizing enzyme; DT, drug transporter; ENT, equilibrative nucleoside transporter; FMO, flavin-containing monooxygenase; GSH, glutathione; GST, glutathione-S-transferase; LC, liquid chromatography; MATE1, multidrug and toxin extrusion 1; MRP, multidrug resistance-associated protein; MS, mass spectrometry; NAT, $N$-acetyltransferase; NPT1, sodium-dependent phosphate transporter 1; NTCP, sodium taurocholate cotransporting polypeptide; OATP, organic anion-transporting polypeptide; OCT1, organic cation transporter 1; OCTN, organic cation/carnitine transporter; PBPK, physiologically based pharmacokinetic; PK, pharmacokinetics; PXR, pregnane X receptor; SNAT, system A amino acid transporter; SULT, sulfotransferase; UGT, uridine 5diphosphoglucuronic acid glucuronyltransferase.
\end{abstract}


b. Complex and/or inconsistent ontogeny pattern of activity/expression levels ......6635

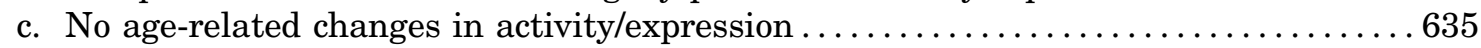

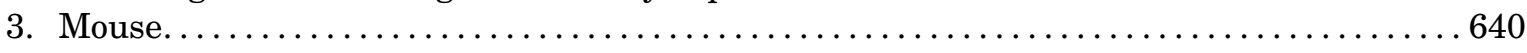

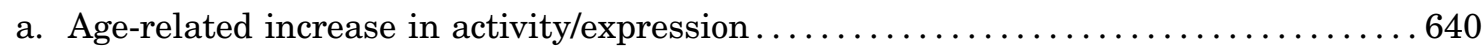

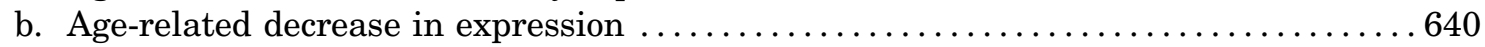

c. No age-related changes in expression ................................ 640

d. Complex and/or inconsistent ontogeny patterns in expression . . . . . . . . . . 640

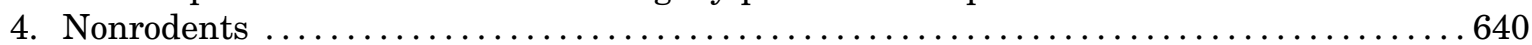

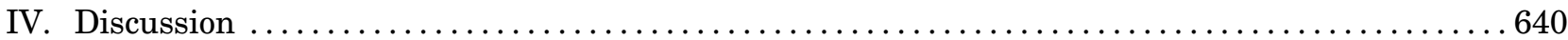

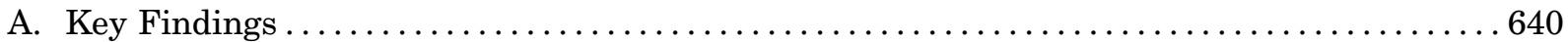

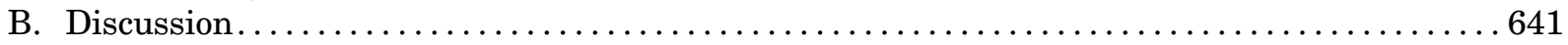

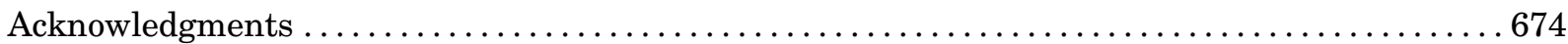

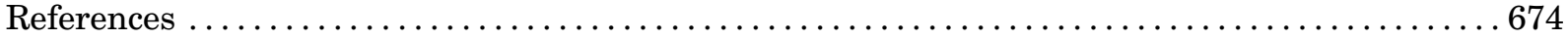

\begin{abstract}
The liver represents a major eliminating and detoxifying organ, determining exposure to endogenous compounds, drugs, and other xenobiotics. Drug transporters (DTs) and drug-metabolizing enzymes (DMEs) are key determinants of disposition, efficacy, and toxicity of drugs. Changes in their mRNA and protein expression levels and associated functional activity between the perinatal period until adulthood impact drug disposition. However, high-resolution ontogeny profiles for hepatic DTs and DMEs in nonclinical species and humans are lacking. Meanwhile, increasing use of physiologically based pharmacokinetic (PBPK) models necessitates availability of underlying ontogeny profiles to reliably predict drug exposure in children. In addition, understanding of species similarities and differences in DT/DME ontogeny is crucial for selecting the most appropriate animal species when studying the impact of development on pharmacokinetics. Cross-species ontogeny mapping is also required for adequate translation of drug disposition data in developing nonclinical species to humans. This review presents a quantitative cross-species compilation of the ontogeny of DTs and DMEs relevant to hepatic drug disposition. A comprehensive literature search
\end{abstract}

\section{Introduction}

Hepatic drug transporters (DTs) and drug-metabolizing enzymes (DMEs) are key players in the disposition of endogenous compounds, xenobiotics including drugs and their metabolites in human as well as in nonclinical species (Shi and $\mathrm{Li}, 2014$ ). The importance of DMEs has been recognized for many decades (Yamazaki, 2014). The impact of DTs has more recently received both scientific and regulatory attention, highlighting the increasing knowledge on their significance in drug disposition and on efficacy and safety (European Medicines Agency; Food and Drug Administration, 2020; International Council for Harmonisation, 2000; Ministry of Labor and Welfare, 2018; Petzinger and Geyer, 2006).

Numerous DTs are located on the apical and basolateral membranes of the hepatocyte and facilitate active transport of substrates into as well as out of hepatocytes to the bile canaliculi or blood was conducted on PubMed Central: Tables and graphs (often after digitization) in original manuscripts were used to extract ontogeny data. Data from independent studies were standardized and normalized before being compiled in graphs and tables for further interpretation. New insights gained from these highresolution ontogeny profiles will be indispensable to understand cross-species differences in maturation of hepatic DTs and DMEs. Integration of these ontogeny data into PBPK models will support improved predictions of pediatric hepatic drug disposition processes.

Significance Statement - Hepatic drug transporters (DTs) and drug-metabolizing enzymes (DMEs) play pivotal roles in hepatic drug disposition. Developmental changes in expression levels and activities of these proteins drive age-dependent pharmacokinetics. This review compiles the currently available ontogeny profiles of DTs and DMEs expressed in livers of humans and nonclinical species, enabling robust interpretation of age-related changes in drug disposition and ultimately optimization of pediatric drug therapy.

compartment (i.e., uptake DTs and efflux DTs, respectively) (Fig. 1) (Giacomini and Huang, 2013). Once a substrate enters the hepatocyte, it becomes available for metabolism by DMEs. DMEs are divided into two broad classes (i.e., phase I and phase II). Phase I enzymes catalyze oxidation, hydrolysis, and reduction reactions, whereas phase II enzymes carry out conjugation reactions (Lyubimov and Ortiz de Montellano, 2011).

Consequently, age-dependent variation in expression levels and activities of DTs and DMEs is one of the factors underlying variability in functional activities of DTs and DMEs and will influence homeostatic processes of endogenous substrates as well as pharmacokinetics (PK) and indirectly pharmacodynamics of drug substrates (Morrissey et al., 2013). A classic example is the case of fatal cardiovascular collapse (i.e., gray baby syndrome) due to toxic exposure to chloramphenicol in neonates as a result of underdevelopment of the phase II enzyme uridine 5-diphosphoglucuronic 


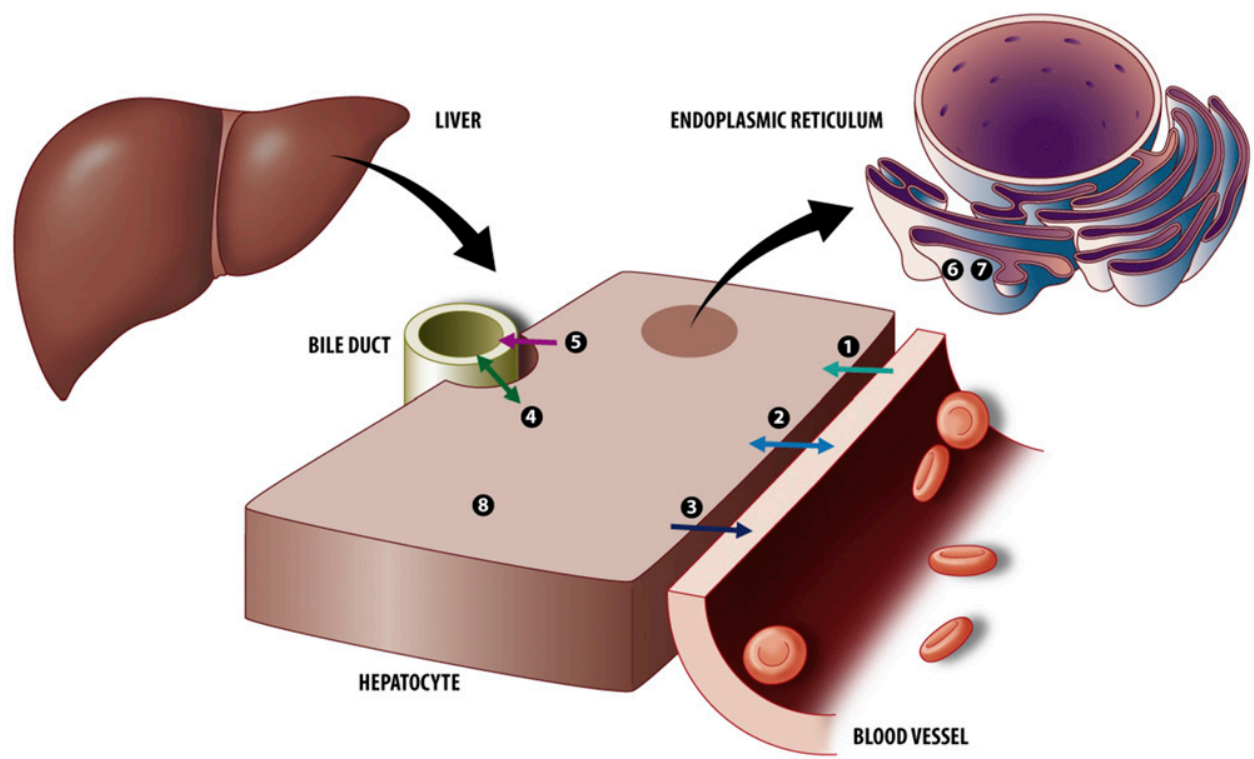

Fig. 1. Overview of localization of drug membrane transporters and drug-metabolizing enzymes in the hepatocyte. 1) Influx transporter (blood to hepatocyte), 2) bidirectional transporter (blood-hepatocyte), 3) efflux transporter (hepatocyte to blood), 4) canalicular bidirectional transporter (hepatocyte-bile), 5) canalicular efflux transporter (hepatocyte to bile), 6) phase I and 7) phase II drug-metabolizing enzymes, 8) cytosolic enzymes.

acid glucuronyltransferase (UGT) 2B7, mediating chloramphenicol glucuronidation (Weiss et al., 1960). More recently, DTs and their interplay with DMEs received attention in terms of drug disposition in children (Cheung et al., 2019). This is exemplified by the reduced hepatic clearance of the opioid morphine in newborns and young infants (Knibbe et al., 2009). Morphine is actively transported by the organic cation transporter 1 (OCT 1) (SLC22A1) and subsequently metabolized by UGT2B7. Significantly lower hepatic expression and activity of both OCT1 and UGT2B7 are reported in pediatric populations versus adults, which partly explains the relatively lower hepatic c'learance of morphine in newborns and infants $(\mathrm{Lu}$ and Rosenbaum, 2014; Prasad et al., 2016; Hahn et al., 2019). Developmental changes in hepatic DTs and DMEs and their impact on drug disposition and toxicity have also been reported for nonclinical species. For instance, neonatal rat hepatocytes are less sensitive to hepatotoxicity of phalloidin than adult rat hepatocytes (Petzinger et al., 1979; MeierAbt et al., 2004; Fattah et al., 2015). Phalloidin is a substrate for organic anion-transporting polypeptide (OATP) 1B2 (SLCO1B2 gene) (Csanaky et al., 2011). Because expression of OATP1B2 is lower in neonatal than in adult rat hepatocytes, there is relatively lower uptake of phalloidin in neonatal hepatocytes, leading to reduced sensitivity to phalloidin hepatotoxicity (Belknap et al., 1981).

These examples show how age-related changes in DT and DME activities can impact drug disposition. At present, to determine many pediatric dosing regimens, still the standard approach is to linearly adjust the adult dose to that of a child based on the child's body weight (Mahmood, 2016). However, this approach does not incorporate information on developmental physiology like age-related changes in DT and DME expression levels or activity and could therefore result in subtherapeutic or supratherapeutic doses. On the other hand, in silico methodologies, such as physiologically based pharmacokinetic (PBPK) models, allow integration of developmental changes of various aspects of $\mathrm{PK}$ and may improve prediction of pediatric drug disposition. The use of these in silico models has received much research interest in recent years (Johnson et al., 2014; Maharaj and Edginton, 2014), especially to better understand the effects of growth and maturation on drug disposition (Johnson et al., 2006; Krekels et al., 2012). However, the predictive performance is highly dependent on the availability and quality of the ontogeny profiles that are incorporated in these models (Zhou et al., 2018). Also, in terms of safety evaluation, extrapolation of drug disposition from nonclinical species to humans is common practice during drug development (Chen et al., 2012). This extrapolation relies heavily on our understanding of potential interspecies differences in ontogeny profiles of all pharmacological processes. More specifically, insights in the ontogeny profiles of DTs and DMEs across nonclinical species and humans may assist in selecting the appropriate juvenile animal model(s) for pediatric safety testing and to improve prediction of drug exposure in children.

Over the years, knowledge on developmental changes in hepatic DTs and DMEs in terms of mRNA expression levels, protein abundance, and functional activity has increased significantly (Cheung et al., 2019). 
Currently, the data that describe the developmental patterns of hepatic DTs and DMEs are dispersed across individual publications with small sample sizes, largely because of scarcity of pediatric samples. Hence, the reported insights are limited and fragmented. Descriptive reviews are available in literature yet are limited to qualitative description of developmental patterns and include limited information on nonclinical species (Brouwer et al., 2015; Elmorsi et al., 2016). The process of compiling available quantitative information on maturation profiles of hepatic DTs and DMEs in nonclinical species and humans and incorporating this into PBPK models is expected to increase the predictive performance of PBPK models for age-dependent hepatic drug disposition. Therefore, we aimed to compile the hepatic ontogeny profiles of individual DTs and DMEs in human as well as nonclinical species from literature based on search results of available in vitro data of these proteins at the level of mRNA expression, protein expression, and activity.

\section{Methods}

The workflow of the employed methodology is outlined in Fig. 2. The subsequent steps are explained in more detail below.

\section{A. Search Methods and Selection of Literature}

PubMed was searched by appropriate search terms with Medical Subject Headings and free text terms (see

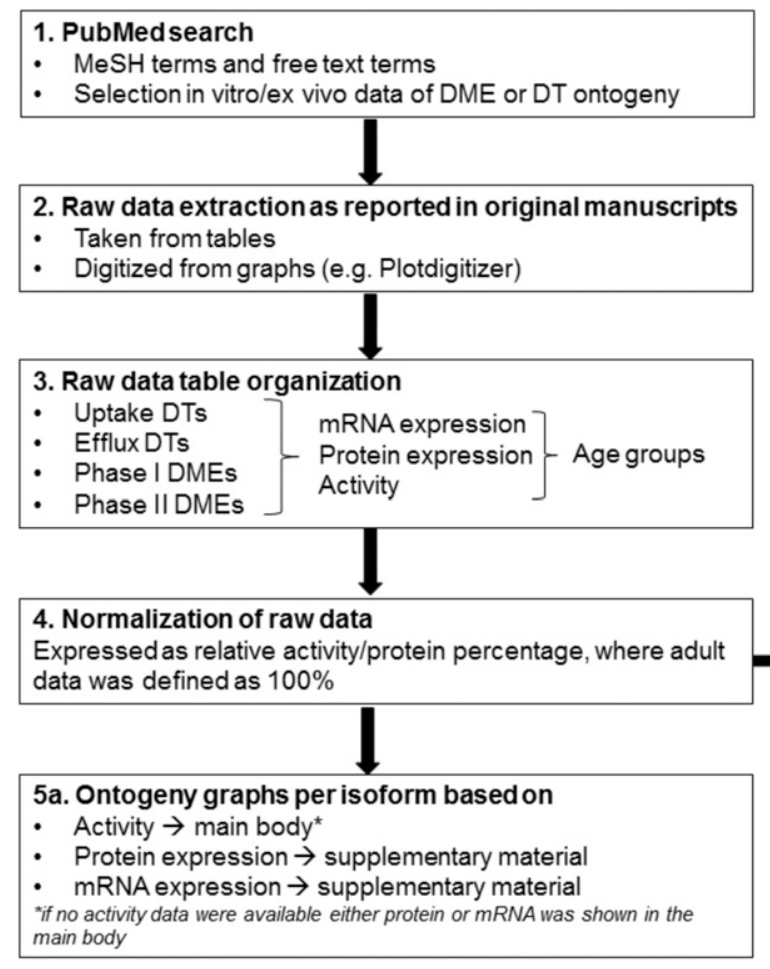

Supplemental Material 1) since creation up to June 2019. All articles were retained when they contained in vitro ontogeny data on DTs and DMEs, first based on the title or abstract and second based on the full text.

\section{B. Raw Data Extraction, Normalization, and Pooling}

We extracted the following data from the selected papers: age and the corresponding expression/activity levels, units of expression/activity level, method of quantification/semiquantification, race, sex, and substrate used to determine activity. The raw data were extracted from the selected articles and summarized in tables for individual isoforms. The data were subdivided by mRNA expression, protein abundance, and activity. Nonquantitative data (e.g., data obtained by immunoblotting) were also included in the raw data tables. If the raw data were not published in the article but only presented as graphs, they were extracted using Plotdigitizer. Data for individual studies were normalized to adult values, in which adult values were defined as $100 \%$. This was followed by pooling data of the various studies.

\section{Graphs}

Based on the pooled raw data tables, graphs were generated for each isoform (mRNA expression, protein abundance, and/or activity). If multiple values were obtained for the same age, average \pm S.D. values were used. Data from various publications were only pooled 5b. Summary tables

Divided in uptake DTs, efflux DTs, Phase I DMEs and Phase II DMEs

Information on

- Onset of expression/activity

- Developmental pattern

Age of adult expression/activity

- Additional information (rodent strains, gender differences, lab method, age of adult for preclinical species, substrates used to determine activity, other observations e.g. highly variable activity/expression)

Fig. 2. Workflow and methodology of the search strategy. 
when a similar developmental pattern was seen, and otherwise, individual developmental patterns obtained from separate publications were presented separately in the same graph. Graphs on the level of activity for a specific DT or DME are presented in the main body of the manuscript, and protein and mRNA expression graphs are included in the Supplemental Materials. In absence of activity data, protein expression graphs were presented in the main manuscript body as an alternative. In absence of both activity and protein expression data, mRNA expression graphs were presented in the main manuscript body.

\section{Summary Tables}

Based on the raw data tables containing quantitative and nonquantitative data and the graphs, a summary text table was created describing the onset of DT and DME expression/activity, the age at which adult expression was reached, and a description of the developmental pattern along with comments and references.

When feasible and depending on data availability, human pediatric samples were divided into subsets as defined by the International Conference on Harmonization E11 guidance (International Council for Harmonisation, 2000) as follows: neonates (birth to $<28$ days), infants ( 28 days to $<2$ years), young children ( 2 to $<6$ years), old children ( 6 to $<12$ years), adolescents (12-18 years), and adults ( $>18-65$ years). For nonclinical species, age was presented on a continuous scale.

\section{E. Results Section Text}

Throughout the Results section, ontogeny profiles in the summary tables are classified in the following order: 1) age-related increase in expression/activities, 2) agerelated decrease in expression/activities, 3) no agerelated changes, or 4) a more complex ontogeny pattern in activity/expression. References to the individual studies are provided in the summary tables and are not included in the Results section. Also, because the tables provide supporting information for the individual graphs, graphs and tables should be used together. The figure legends contain references to the corresponding tables.

\section{F. Nomenclature}

Throughout the manuscript upper-case protein names of DTs and DMEs have been consistently used; they have also been used when mRNA expression levels of the DTs and DMEs are discussed. This approach has been adopted for humans as well as for rodent and nonrodent animal species. Supplemental Table 1 provides an overview of all included DT isoforms with their corresponding gene names.

\section{Results}

\section{A. Uptake Transporters}

1. Human. The results (including references) are included in Fig. 3, Supplemental Fig. 1, and Table 1.

a. Age-related increase in activity/expression. Sodium taurocholate cotransporting polypeptide (NTCP) showed a pronounced increase early in life. In fetal tissue, mRNA and protein expression levels were $3 \%$ and $6 \%$ of adult, respectively, reaching full maturation at the age of 28 days. OCT 1 , on the other hand, showed a more gradual increase in its expression, with $54 \%$ of adult protein expression levels in fetal tissue and adult values from adolescent age onward.

b. Age-related decrease in activity/expression. Three transporters showed high abundance in fetal tissue, with a subsequent decrease with increasing age. The glucose transporter 1 transporter showed the most distinct decrease, with 45 -fold higher protein expression in fetal tissue than in adult tissue, whereas organic cation/carnitine transporter (OCTN) 2 expression appeared 2 -fold higher in fetal tissue and decreased slowly toward adult levels during childhood. OATP1B1 is the third transporter that showed an overall decline in protein expression. However, the results on OATP1B1 protein expression were conflicting, as fetal values corresponding to $50 \%-165 \%$ of adult values were reported.

c. No age-related differences in activity/expression. Protein expression of the transporters monocarboxylate transporter 1, OATP2B1, and OATP1B3 did not show age-related changes. However, data on mRNA expression of OATP1B3 are conflicting, as one study reported no age-related changes, whereas another study found $5 \%$ in fetal tissue and $1 \%$ in infant tissue compared with adult values.

2. Rat. The results are depicted in Fig. 4, Supplemental Figs. 2 and S3, and Table 2.

a. Age-related increase in activity/expression. The literature contained activity data for four hepatic uptake transporter(s) (families) [i.e., OATP, NTCP, OCT1, and concentrative nucleoside transporter (CNT) 1/2] in juvenile rats. The ontogeny of other hepatic uptake transporters was established based on either protein expression levels [i.e., system A amino acid transporter (SNAT) 1] or mRNA expression levels (i.e., OATP1A1, OATP1A4/OATP2, OATP1A5, OATP1B2/OATP4, OATP2, OATP2B1, and OATP4A1).

OATP and NTCP activity levels rose progressively from birth $(10 \%-50 \%)$ to achieve maximal activity levels at 21 and 29 days of age in male rats based on the uptake activity levels using sodium fluorescein and taurocholate $(1-200 \mu \mathrm{M})$, respectively.

The ontogeny profiles of distinct OATP transporters were characterized based on protein and mRNA expression levels. Percentage of maximal 
A

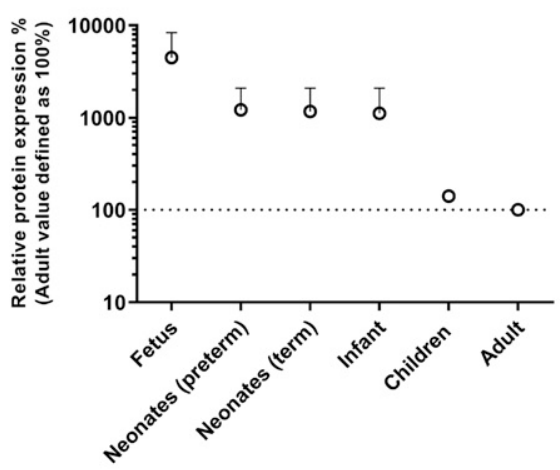

C

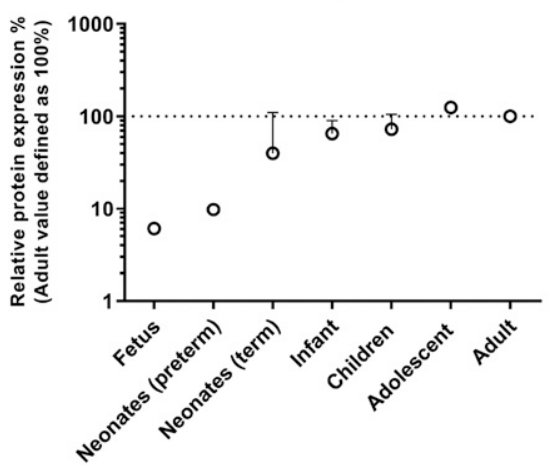

E

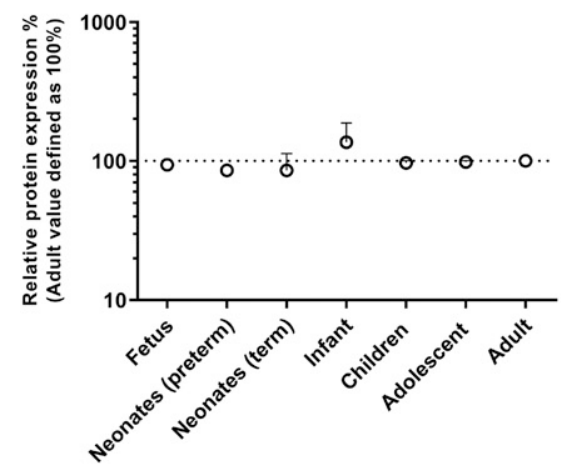

G

OCT1

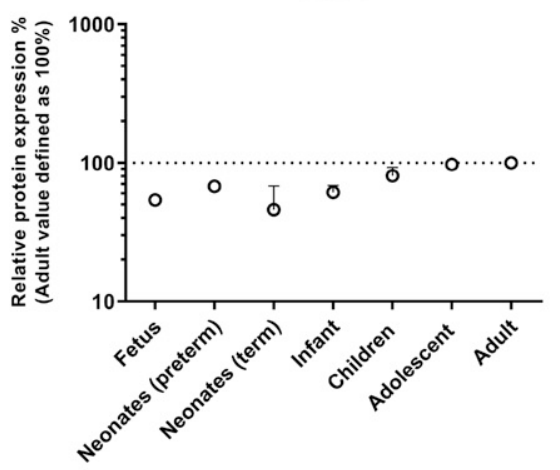

B

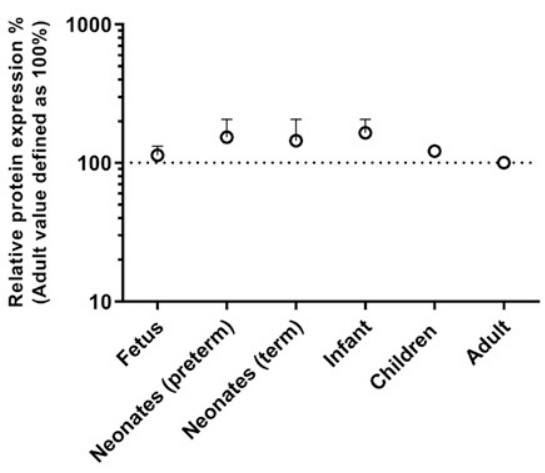

D

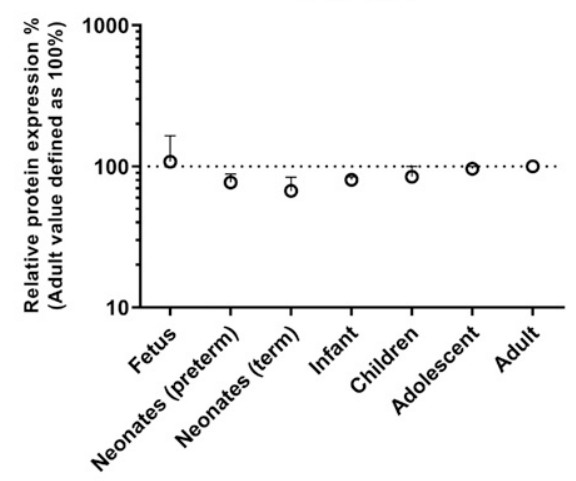

$\mathbf{F}$

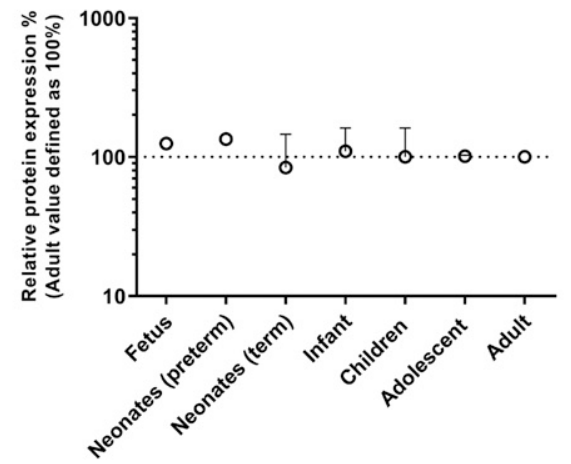

H

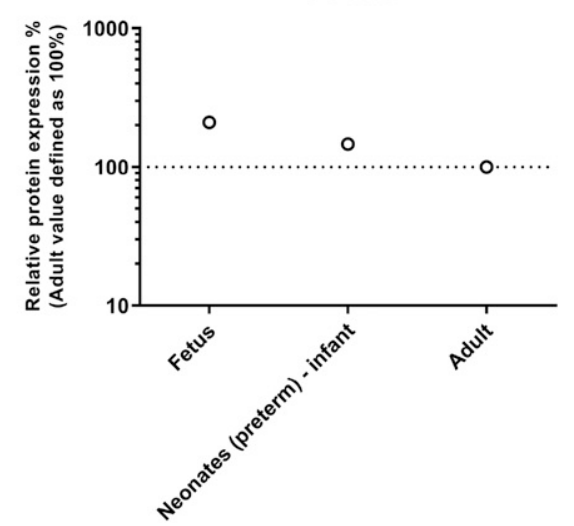

Fig. 3. Pooled literature data on the ontogeny of protein expression of hepatic uptake transporters in humans: GLUT1 (A), MCT1 (B), NTCP (C), OATP1B1 (D), OATP2B1 (E), OATP1B3 (F), OCT1 $(\mathrm{G})$, and OCTN2 $(\mathrm{H})$. The symbols represent the relative protein expression in each age group and the dotted line indicates the adult value defined as $100 \%$. If multiple values were obtained for the same age group, the symbols represent the average relative protein expression, and the error bars show the S.D. See Table 1 for explanation on the ontogeny profiles and literature references. GLUT1, glucose transporter 1; MCT1, monocarboxylate transporter 1. 


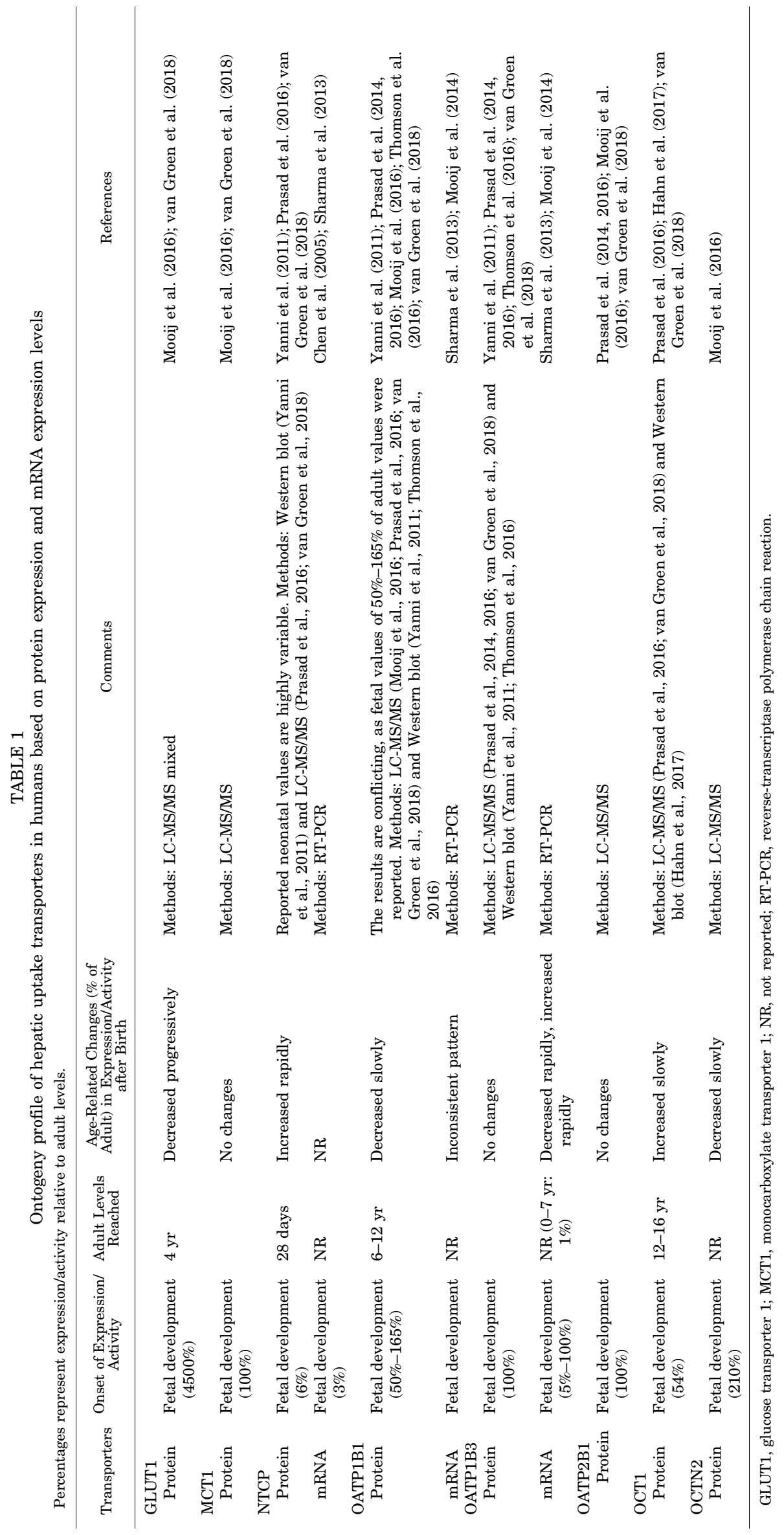


A

OATP

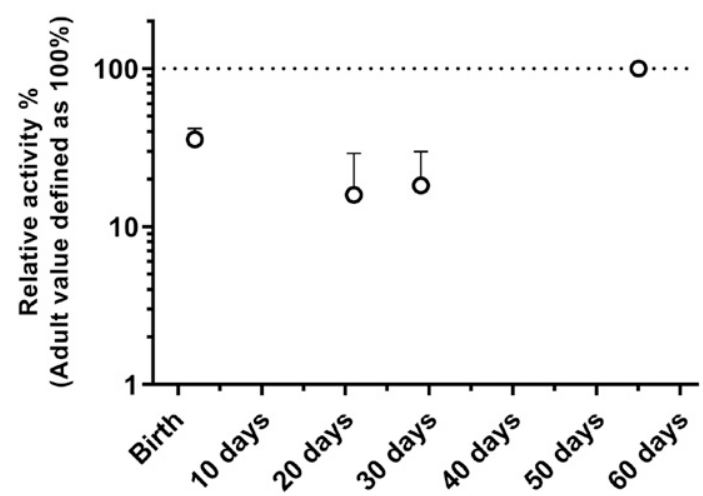

C

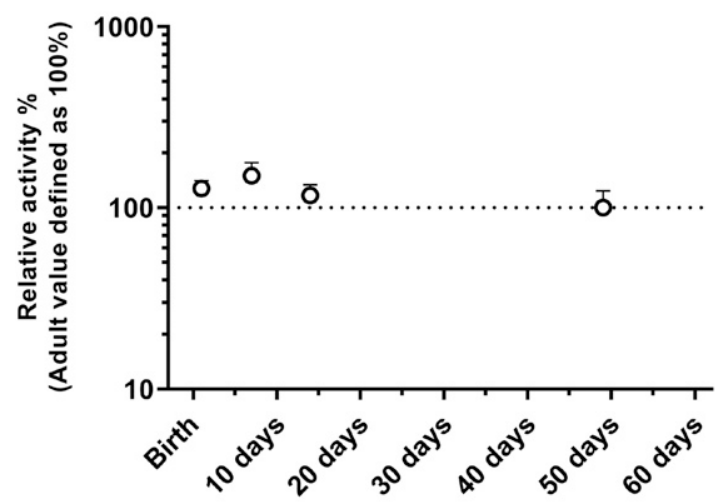

B

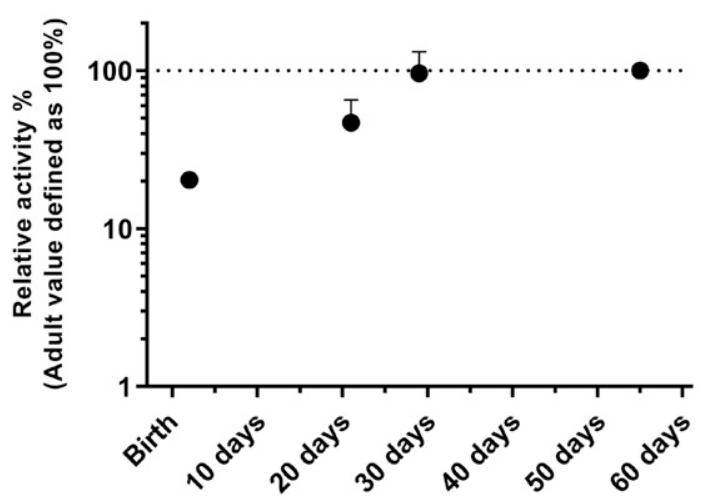

D

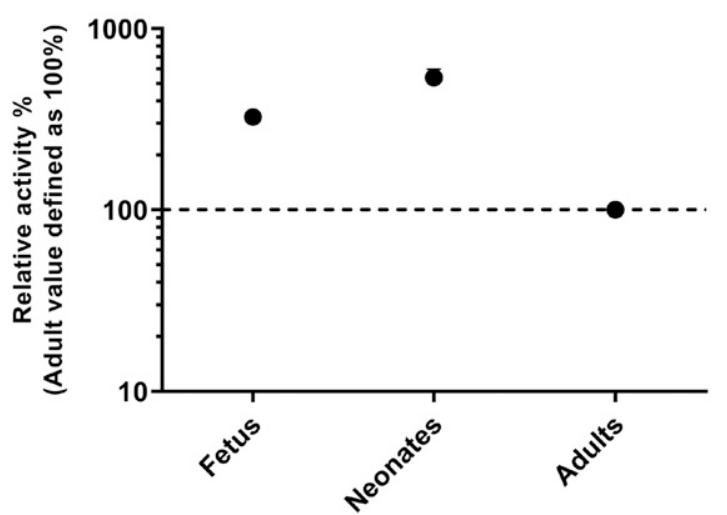

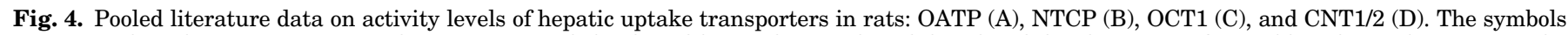

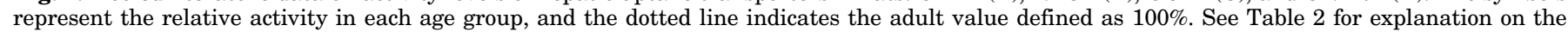
ontogeny profiles and literature references.

mRNA levels during fetal development compared with adults represented $<10 \%$ for OATP1A1, OATP1A4, and OATP1B2; up to 30\% for OATP1A5 and OATP2B1; and $100 \%$ for OATP4A1. Based on one study, OATP2 (OATP1A4) adult values were reached at 25 days (male) and 30 days (female). For the other OATP transporters, adult values were reached only at adulthood. Notably, a 55\% decrease in protein abundances of OATP1A1, OATP1A4, and OATP1B2 in elderly rats was observed in comparison with those of adult levels.

b. Age-related decrease in activity/expression. The developmental patterns of CNT1/2 and SNAT1 suggested that CNT1/2 and SNAT1 are fetal uptake transporters. Maximal uptake activity levels of uridine mediated by CNT1/2 were achieved during fetal development (300\% of adult levels) and then rapidly decreased in neonates (200\% of adult levels). Similarly, fetal protein expression levels of SNAT1 were up to 2.5-fold and 5-fold greater than those reported in very young and adult rats, respectively.

c. No age-related differences in activity/expression. OCT1 activity was stable from birth to adulthood. This is supported by maximal uptake activity levels of OCT 1 that were rapidly reached at 1 day after birth using 1-methyl-4-phenylpyridinium as test substrate.

3. Mouse. The results are depicted in Fig. 5, Supplemental Fig. 4, and Table 3 and are further explained below.

a. Age-related increase in activity/expression. The majority of the uptake transporters showed a lower expression in younger versus older age groups. Most data were available for mRNA expression of the OATP family. OATP1A1 and OATP1A4 showed a slow rise in expression over age, whereas OATP1A6, OATP1B2, OATP2A1, and OATP2B1 increased more rapidly. The amount in fetal tissue was transporter-dependent (e.g., only $1 \%$ of adult values was detected for OATP1B2 compared with $32 \%-57 \%$ of adult values for OATP1A6). The OCT 1 and apical sodium-dependent bile acid transporters both showed a very low expression in fetal tissue, with adult values reached at day 22 and at adult age, respectively.

b. Age-related decrease in activity/expression. The transporters that showed a decrease in expression all declined very rapidly from fetal age. OAT3 showed very high fetal levels, and adult levels were reached between day 25 and day 30 . OCTN1 showed 


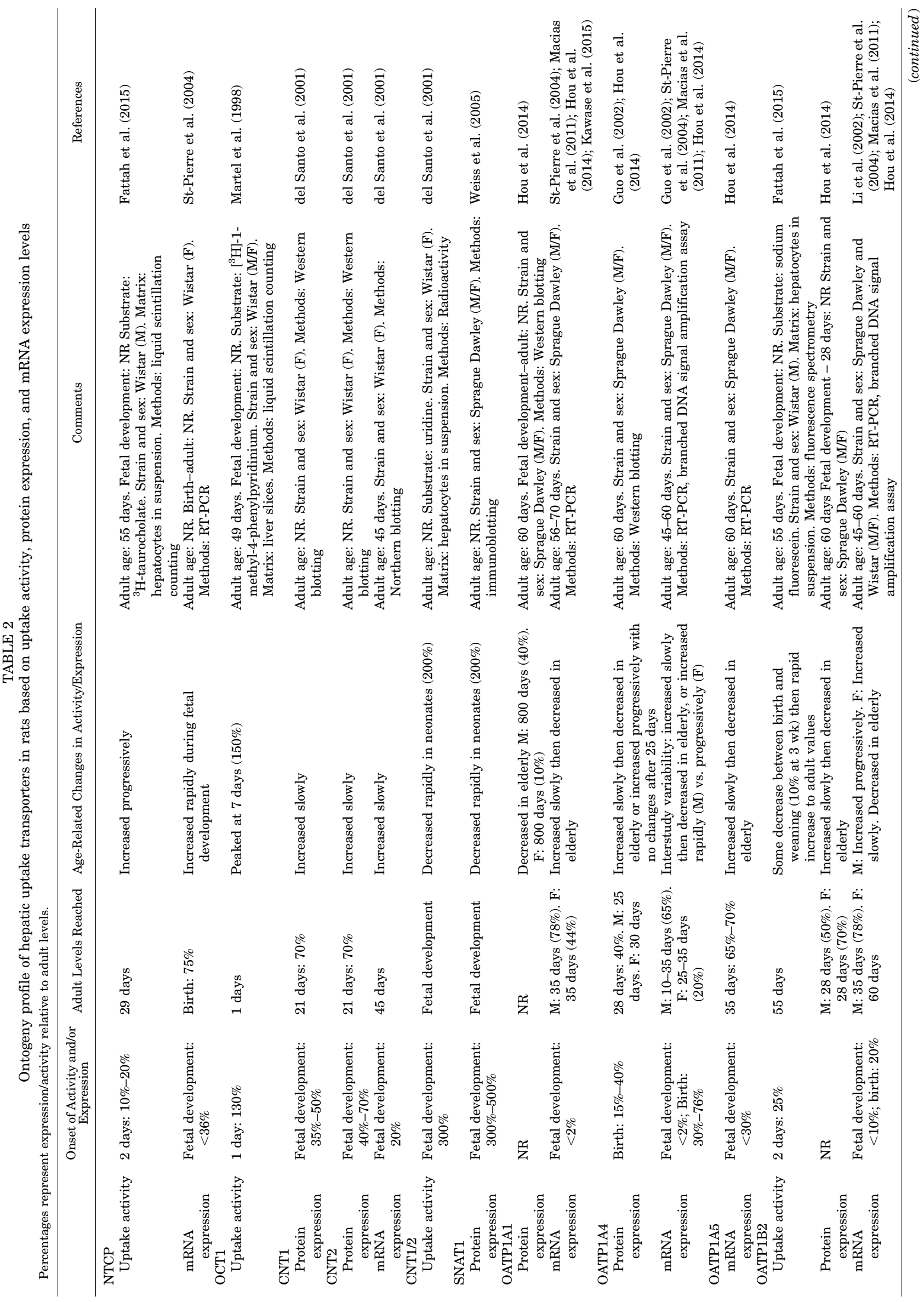


similarly high fetal values, which were followed by a more gradual decrease toward adult values.

c. Complex and/or inconsistent ontogeny pattern in activity/expression. For NTCP, mRNA expression data from four studies as well as protein expression data from one study were available. mRNA expression was clearly present in fetal tissue. No distinct ontogeny profile could be defined, as the studies reported varying results. The transporters equilibrative nucleoside transporter (ENT) 1, OAT2, and OCTN2 fluctuated between age groups because they had an overall increased developmental pattern from fetal age onward but also showed a decrease in expression between various age groups. ENT3 had relatively high fetal levels, and adult levels were reached at day 25 .

4. Nonrodents. Data on ontogeny profiles of hepatic uptake transporters were lacking for nonrodent species, including Beagle dog, cynomolgus monkey, Göttingen Minipig, and the domestic pig.

\section{B. Efflux Transporters}

1. Human. The results are depicted in Fig. 6, Supplemental Fig. 5, and Table 4 and are further explained below.

a. Age-related increase in activity/expression. Most efflux transporters showed a developmental pattern with rise in expression with increasing age. For all studies that included fetal tissue, the transporters were detectable at fetal age, yet maturation rates differed. For example, bile salt export pump (BSEP), multidrug resistance-associated protein (MRP) 3, and multi-resistance protein (MDR) 1 (or P-glycoprotein) showed a rapid increase from fetal tissue to neonatal tissue. In contrast, MRP1 and MRP2 increased more gradually, with $50 \%$ of adult values in neonates and $30 \%-100 \%$ of adult values in infants, respectively. Data on MDR3 were scarce, but fetal tissue showed $6 \%$ of adult values.

b. Complex and/or inconsistent ontogeny pattern in activity/expression. The breast cancer resistance protein (BCRP) transporter ontogeny is well described in literature, yet results are inconsistent. Fetal values were reported to be between $94 \%$ and $235 \%$, and adult values were likely reached at neonatal age. However, higher values than those of adults were detected at infant age, which decrease again thereafter to adult values.

2. Rat. The results are depicted in Fig. 7, Supplemental Fig. 6, and Table 5 and are further explained below.

a. Age-related increase in activity/expression. No activity data for hepatic efflux transporters in juvenile rats were found in literature. The ontogeny of hepatic efflux transporters was established based on either protein expression levels (MRP2 and BSEP) or mRNA expression levels (MRPs, BCRP, and BSEP). 
A

NTCP

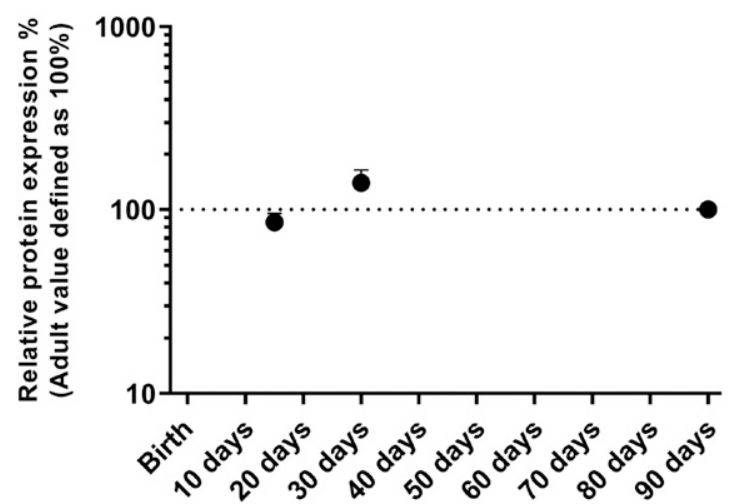

B

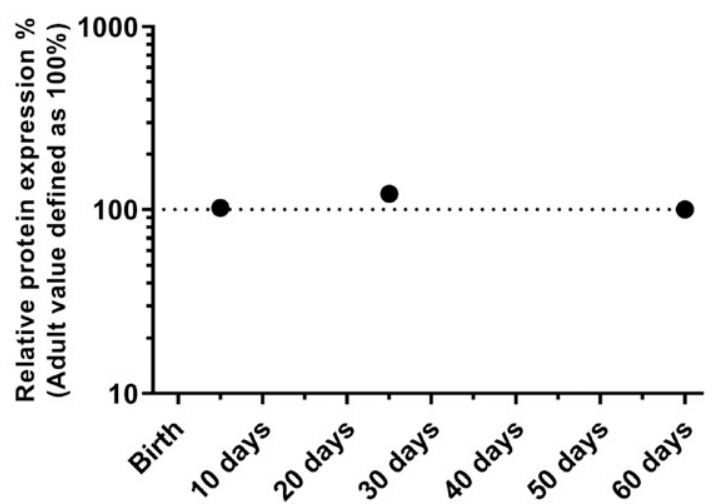

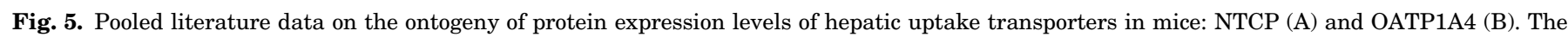

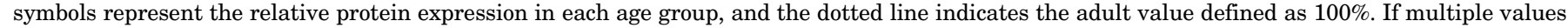

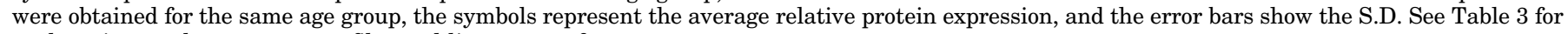
explanation on the ontogeny profiles and literature references.

Protein and mRNA expression levels of BSEP represented $<10 \%$ of adult levels during fetal development, suggesting an onset of expression after birth. Maturation of BSEP rapidly increased after birth, with $50 \%$ of maximal protein expression levels achieved at 1 day and maximal levels achieved at 21 days in rats. Onset of MRP2 and MRP3 expression started during fetal development as fetal mRNA expression levels reached up to $60 \%$ of maximal levels in female and male rats. However, maximal levels of MRP2 were achieved at different maturational age: within the first week in male rats and at adulthood in female rats.

b. Age-related decrease in activity/expression. Adult mRNA expression levels of MRP1 and BCRP were high during the fetal development and decreased progressively to adult levels after birth.

c. Complex and/or inconsistent ontogeny pattern in activity/expression. mRNA expression levels of MRP6 corresponded to $20 \%$ and $40 \%$ of adult levels during fetal development and at birth, respectively. mRNA expression levels of MRP4 rose progressively to reach adult levels at 28 days in male rats, whereas no changes in mRNA expression levels were observed in female rats. Fetal expression levels of MRP4 ranged from $30 \%$ in male rats to more than $200 \%$ in female rats.

3. Mouse. The results are depicted in Fig. 8, Supplemental Fig. 7, and Table 6 and are further explained below.

a. Age-related increase in activity/expression. The mRNA expression of BSEP and MRP2 is well studied compared with other transporters. Both transporters showed 30\% expression in fetal tissue compared with adults and an increase in expression up to birth, with higher expression than adult levels for BSEP and similar expression to adult levels for MRP2. After birth, the expression of both transporters fluctuated until adult values were reached at adult age, with 46\%-153\% for BSEP and 40\%-90\% for MRP2.
Interestingly, not only BSEP and MRP2 had $\pm 30 \%$ expression at fetal age, as this was also observed for MRP3 and MRP6. MRP3 expression showed a gradual increase from fetal to adult levels, whereas MRP6 mean adult levels were reached at day 3 .

In one study, mRNA expression of MDR2/3, sodiumdependent phosphate transporter 1 (NPT1), and multidrug and toxin extrusion 1 (MATE1) was measured by RNA sequencing (Cui et al., 2012a). Both MATE1 and NPT1 showed a steep increase in expression from birth to day 1 with a more gradual increase thereafter.

b. Age-related decrease in activity/expression. The mRNA expression of MRP1 and MRP5 was measured by RNA sequencing in one study (Cui et al., 2012a) and showed high expression in fetal tissue (558\%-1200\% of adult values), which was followed by an overall decrease in expression. The age at which adult values were reached was transporter-dependent and varied between day 25 and day 30 .

For MRP4, a high mRNA expression in fetal tissue (200\%) was captured, and a more rapid decrease in expression was observed, reaching adult values at day 10. Interestingly, there was a slightly higher expression in females than in males.

c. No age-related differences in activity/expression. Protein and mRNA expression of MDR1b showed no age-related changes.

d. Complex and/or inconsistent ontogeny pattern in activity/expression. MDR1 [ATP-binding cassette (ABCB1)] expression was higher in fetal tissue than at birth, and the overall developmental pattern showed an increase from birth up to 15 days of age (160\%-250\%) with a subsequent decrease up to adult age. In addition, for MDR2/3 a complex pattern was observed. Onset of expression was in fetal tissue and increased to $156 \%$ at birth. At day 5, a steep decrease to $48 \%$ was observed, and this was followed by an increase to adult levels at day 30. For the ABCG5 and the ABCG8 transporter, 


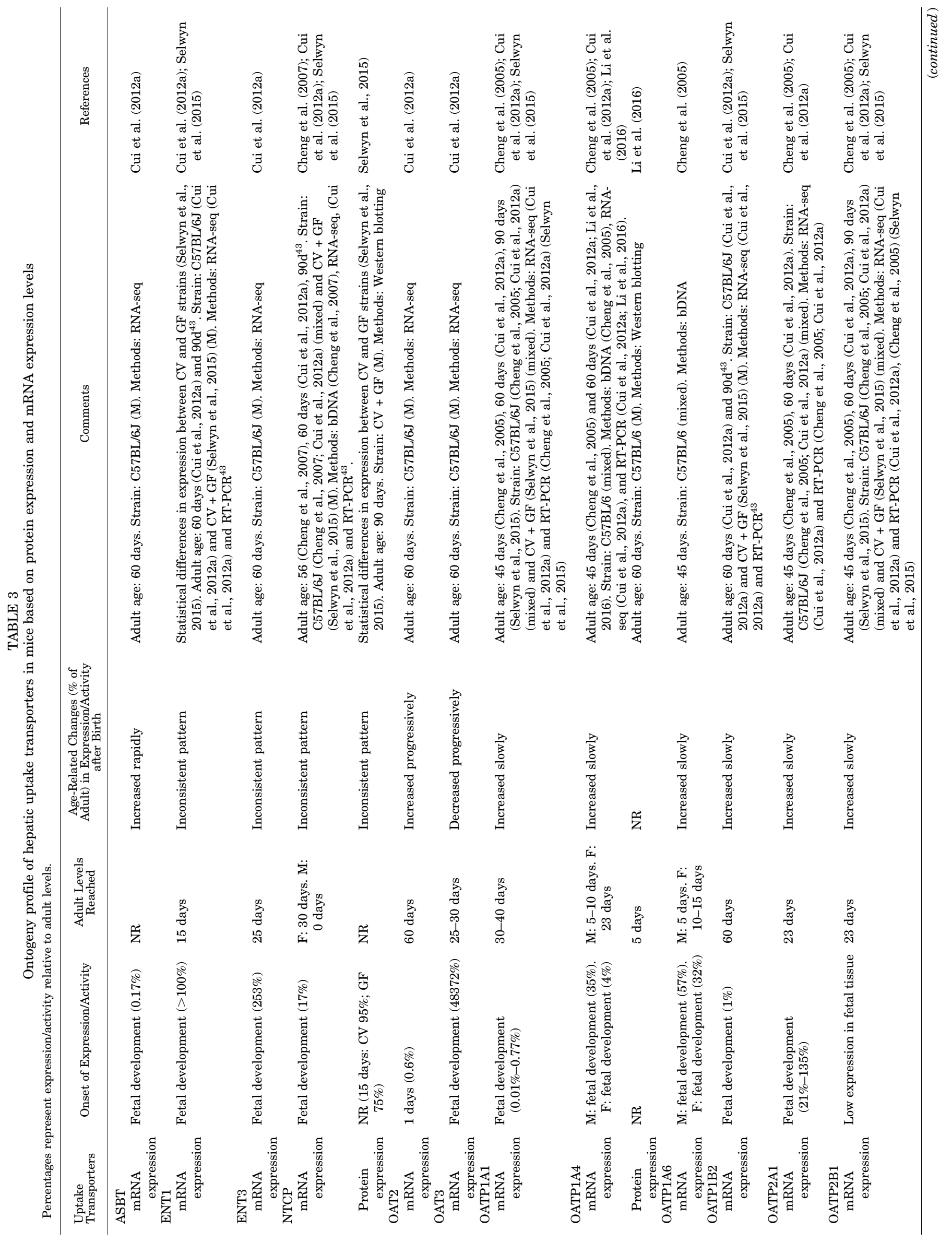


protein expression levels were available for mice at days 15, 30, and 90, and statistical difference in expression was found between the strains. For both transporters, protein expression was very high at day 15 , and a distinct decrease was captured thereafter. This was supported by mRNA expression data that also showed a decrease in expression from day 15 onward. Interestingly, mRNA expression was available from younger mice, and an increase was seen from fetal tissue up to day 15. The mRNA expression of the copper-transporting P-type ATPase (ATP) 7B and BCRP (ABCG2) showed high expression in fetal tissue (280\% of adult values) followed by an overall decrease in expression. The age at which adult values were reached was transporter-dependent and varied between day 25 and adult age.

4. Nonrodents. Data on ontogeny profiles of hepatic efflux transporters were lacking for the Beagle dog, cynomolgus, monkey and domestic pig. For the Göttingen minipig, a semiquantitative assessment of P-glycoprotein showed no difference between livers from 84 days of gestation versus adult animals (1.5-3 years of age).

\section{Phase I Drug-Metabolizing Enzymes}

1. Human. The results are depicted in Fig. 9, Supplemental Figs. 9 and S10, and Table 7 and are further explained below.

a. Age-related increase in activity/expression. Except cytochrome P450 (CYP) enzymes, very few data about ontogeny of phase I enzymes in human liver could be found in literature. Among the non-CYP phase I enzymes, all showed a lower expression in neonates and pediatrics than in adults $(\mathrm{ADH} 1 \mathrm{~A}, \mathrm{ADH} 1 \mathrm{~B}, \mathrm{ADH} 1 \mathrm{C}$, ALDH1A1, CES1, CES2, and FMO3). Activity was reported only for CES1 and was lower in neonates and pediatrics than in adults. For most of the CYP enzymes, data on catalytic activity in various age groups were available. The isoforms CYP2D6, CYP2E1, and CYP1A2 had low activity during fetal age $<30$ weeks of gestation and reached adult levels between neonatal and infant age. For CYP2C18, only data on fetal age $>30$ weeks of gestation were available, showing a low mRNA expression that reached adult levels between neonatal and infant age. The best-characterized CYP enzyme in terms of ontogeny is CYP2D6, for which onset of expression and activity is captured during fetal life, with a rapid increase during neonatal development. The patterns for CYP2D6 activity, protein expression, and mRNA expression lack similarity other than that they all increase with increasing age. Similar to CYP2D6, CYP1A2 showed very low activity and protein/mRNA expression in fetuses. Adult values of activity and protein expression were reached at 5-15 years and 1-5 years of age, respectively. The catalytic activity of CYP2E1 showed low activity in fetuses $<30$ weeks of gestation (3\%-20\% of adult values) and increased to 
A

BCRP

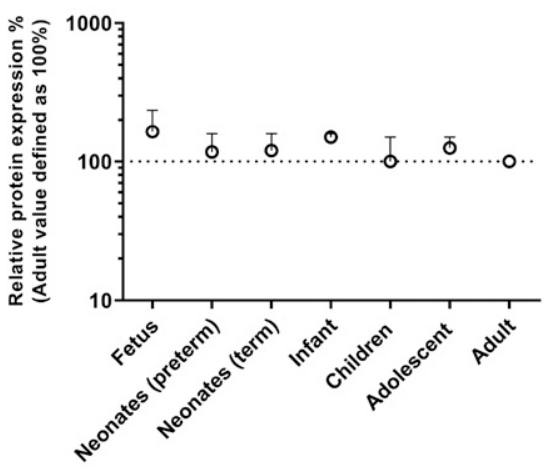

C

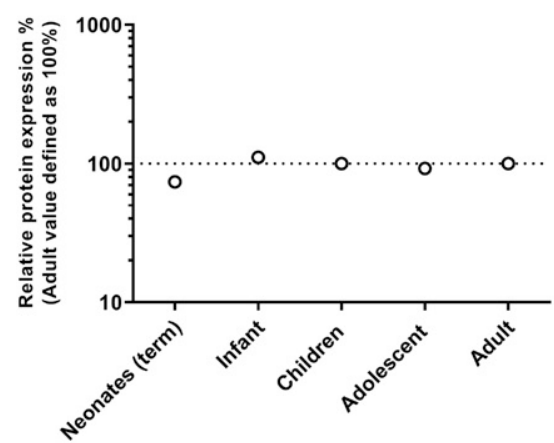

E

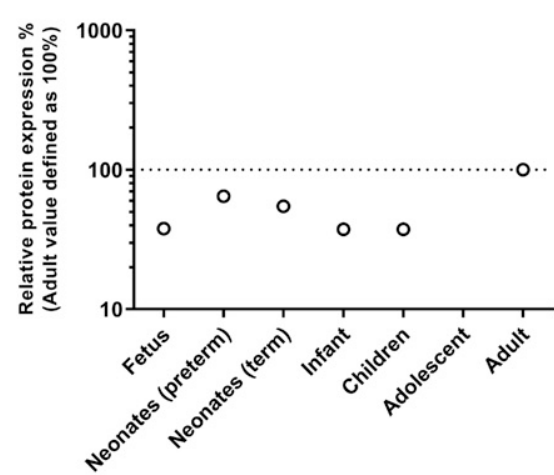

G

MRP3

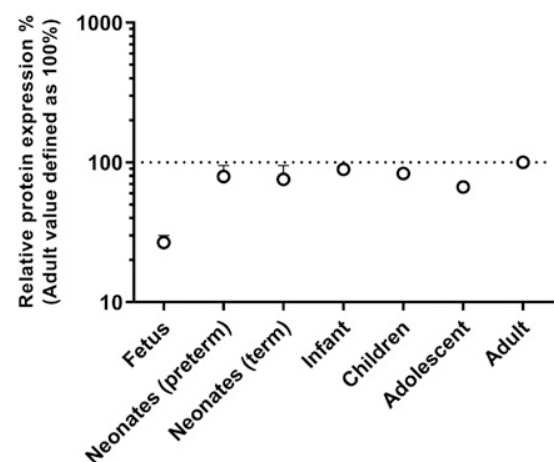

B

BSEP

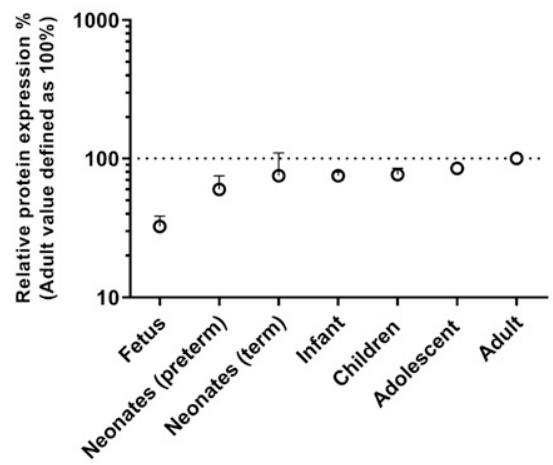

D

MDR1

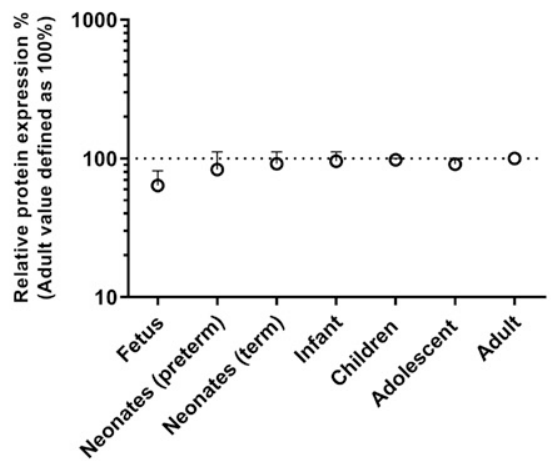

$\mathbf{F}$

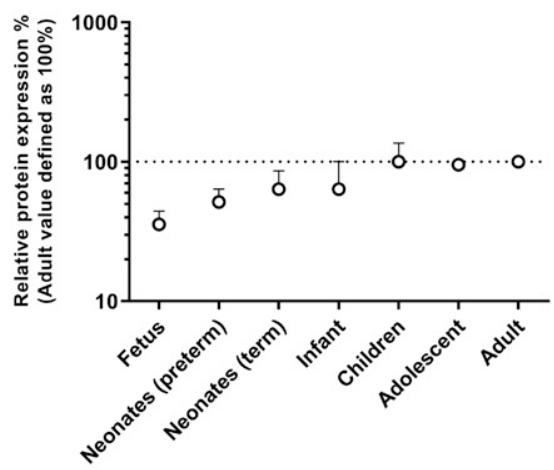

Fig. 6. Pooled literature data on the ontogeny of protein expression of hepatic efflux transporters in humans: BCRP (A), BSEP (B), MATE1 (C), MDR1 (D), MRP1 (E), MRP2 (F), and MRP3 (G). The symbols represent the relative protein expression in each age group, and the dotted line indicates the adult value defined as $100 \%$. If multiple values were obtained for the same age group, the symbols represent the average relative protein expression, and the error bars show the S.D. See Table 4 for explanation on the ontogeny profiles and literature references. 


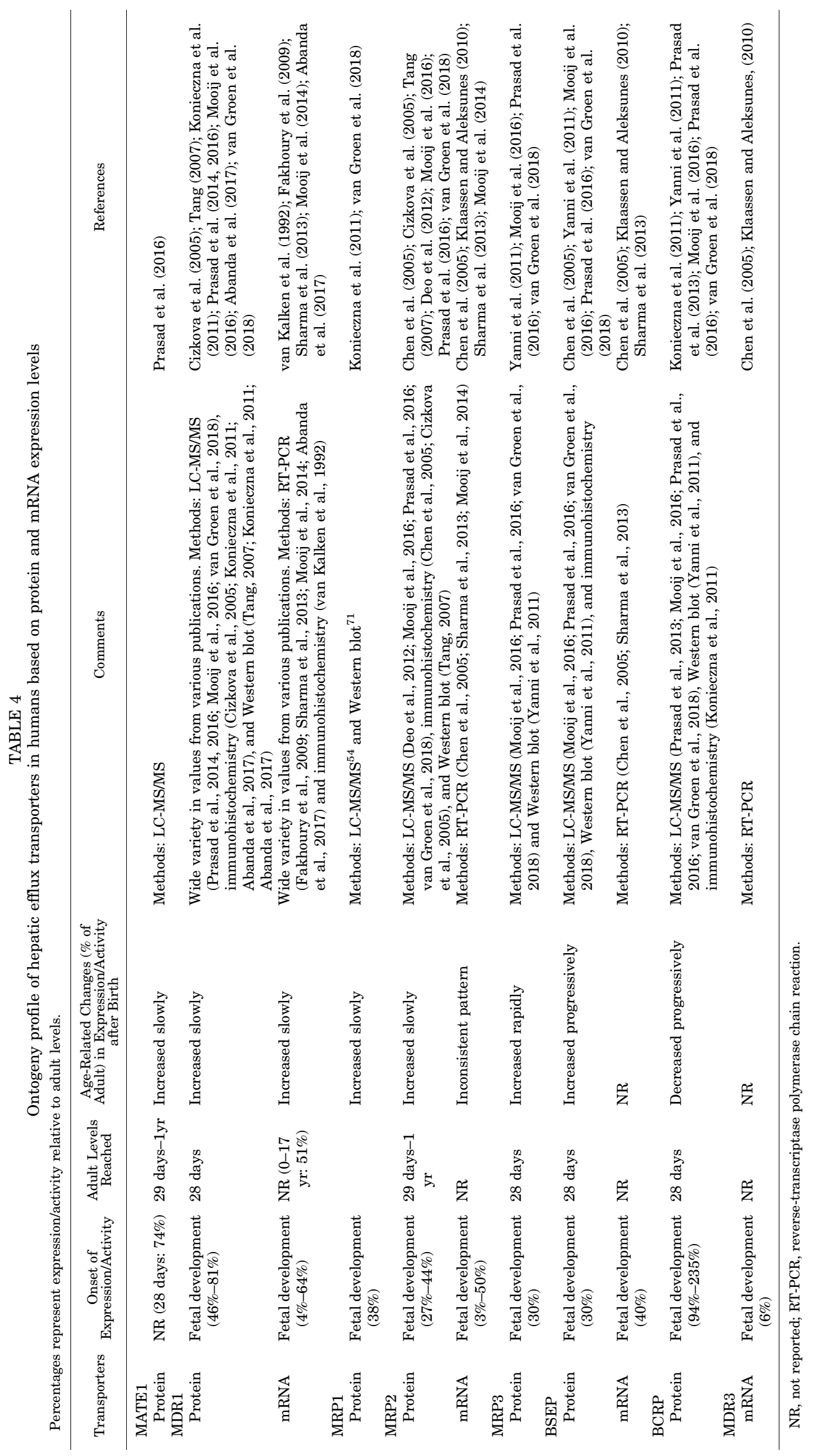


A

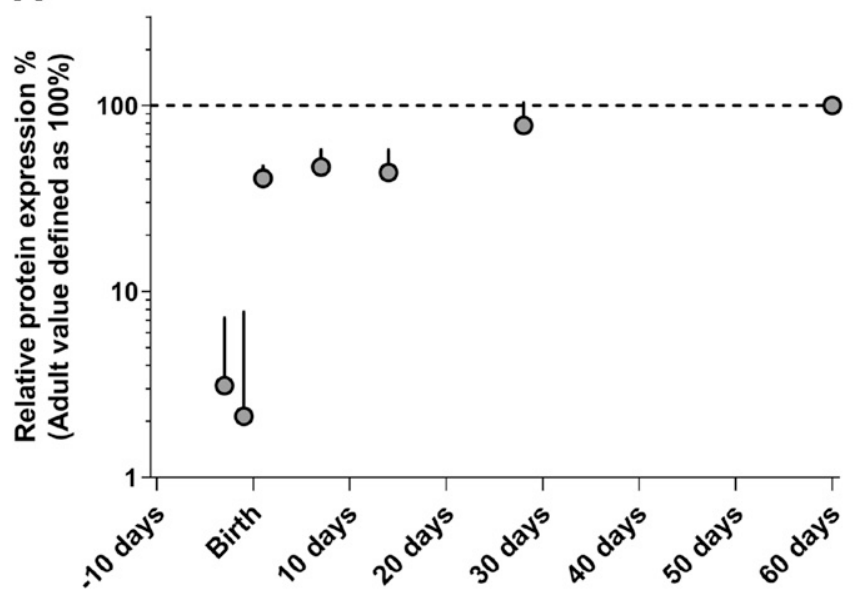

B

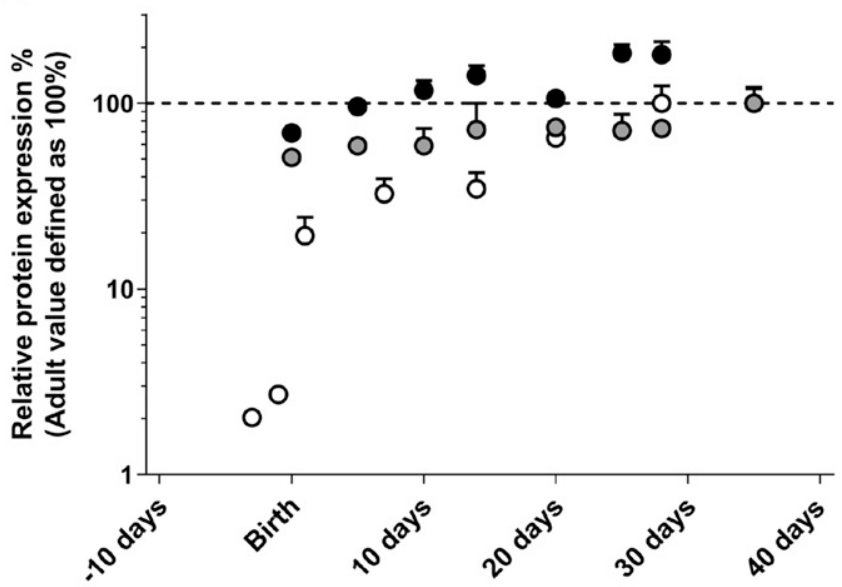

Fig. 7. Pooled literature data on the ontogeny of protein expression levels of hepatic efflux transporters in rats: BSEP (A) and MRP2 (B). The symbols represent the relative protein expression in mixed-sex rat population (open), male rats (gray), and female rats (black). If multiple values were obtained for the same age group, the symbols represent the average relative protein expression, and the error bars show the S.D. See Table 5 for explanation on the ontogeny profiles and literature references.

$50 \%$ activity of adult values in infants. The results on protein expression show a wide interstudy range in fetal CYP2E1 expression (1.5\%-70\% of adult values), and adult values were reached at $1-5$ years of age. The pattern of low activity/protein expression in fetuses is also seen for mRNA expression, with concordant expression of $50 \%$ in infants.

For the isoforms CYP3A4, CYP2A6, and CYP2C8, a more gradual increase in activity and expression was seen. The CYP3A family consists of the isoforms

\section{A}

ABCG5

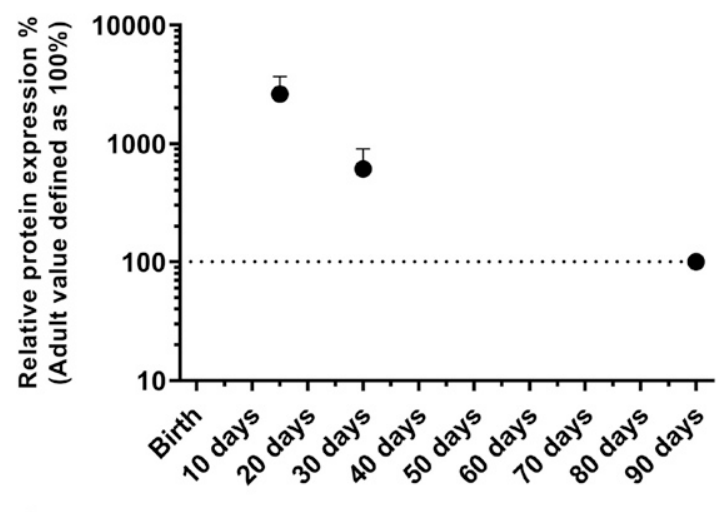

C

MDR1

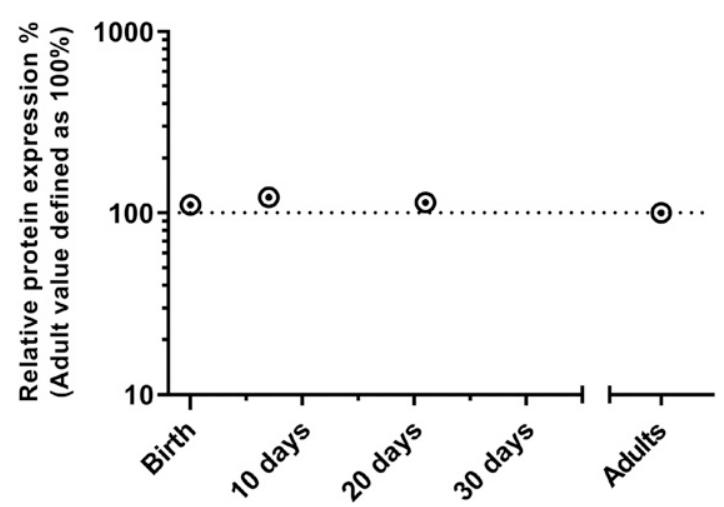

B

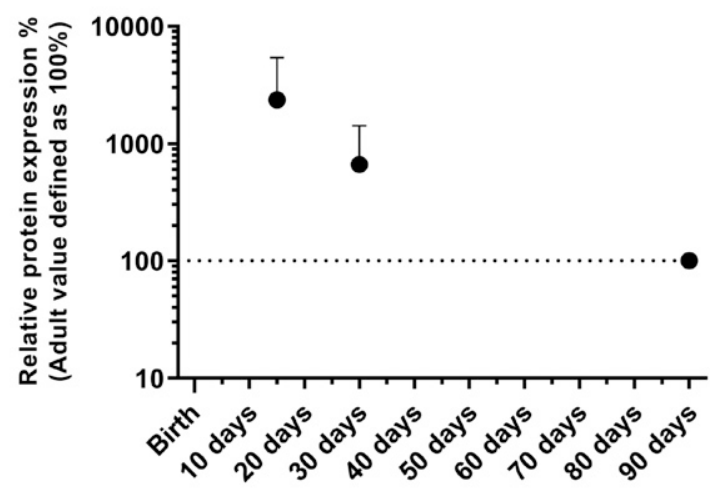

D

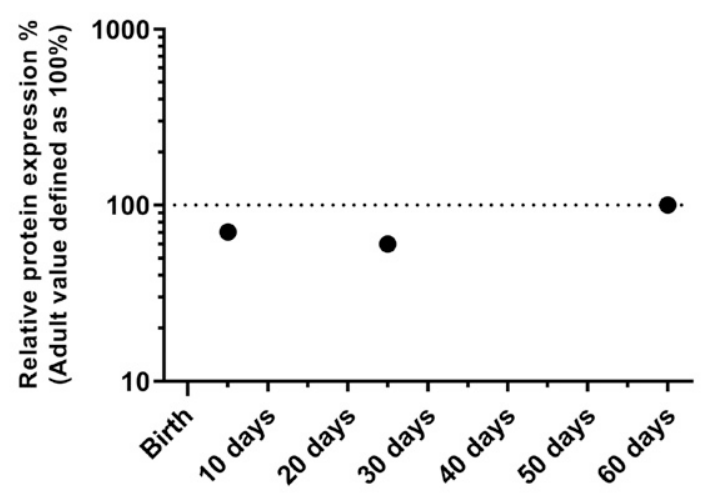

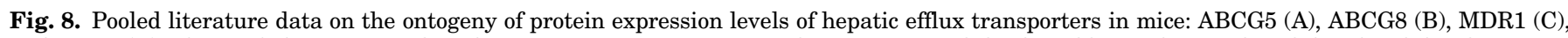

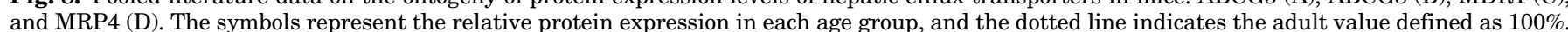

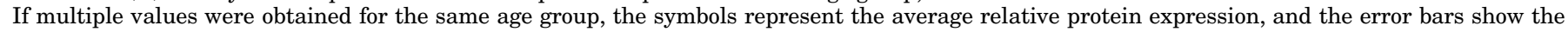
S.D. See Table 6 for explanation on the ontogeny profiles and literature references. 


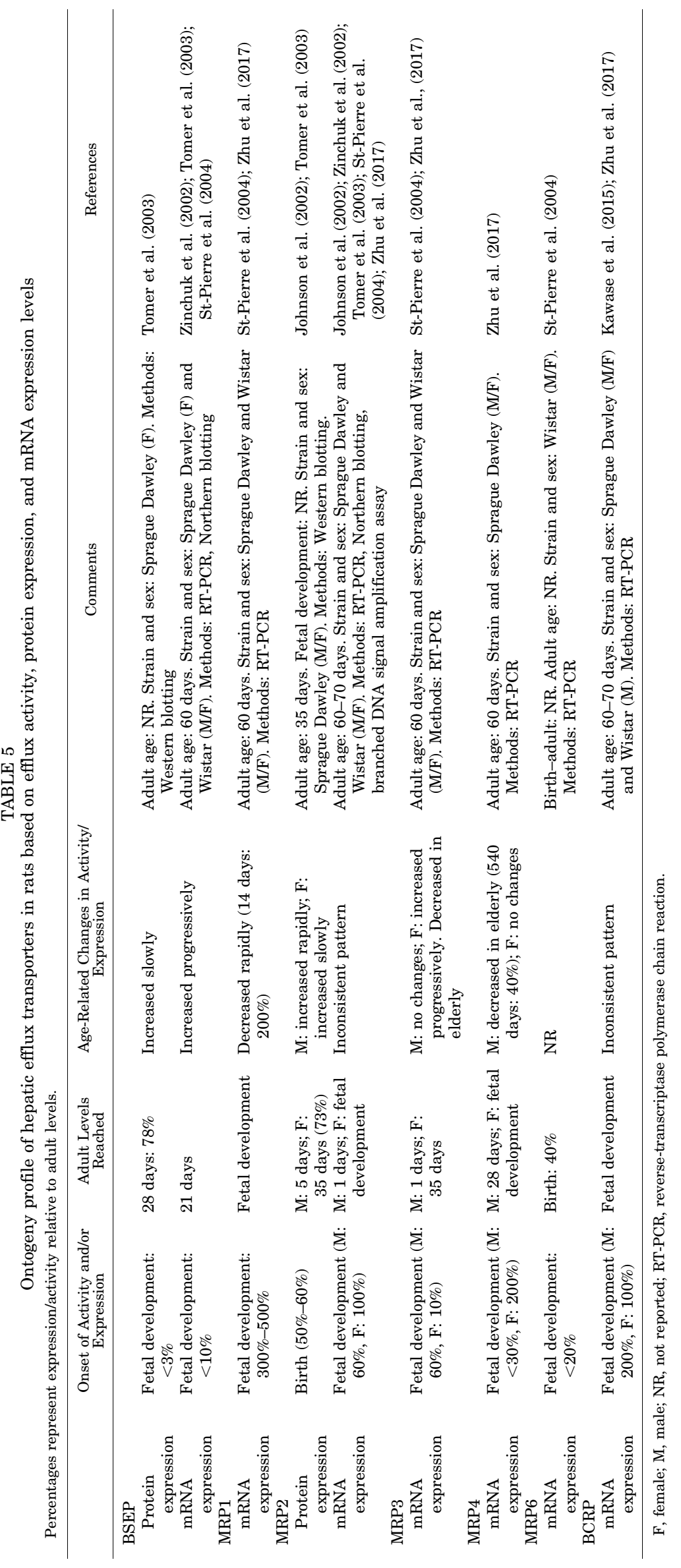




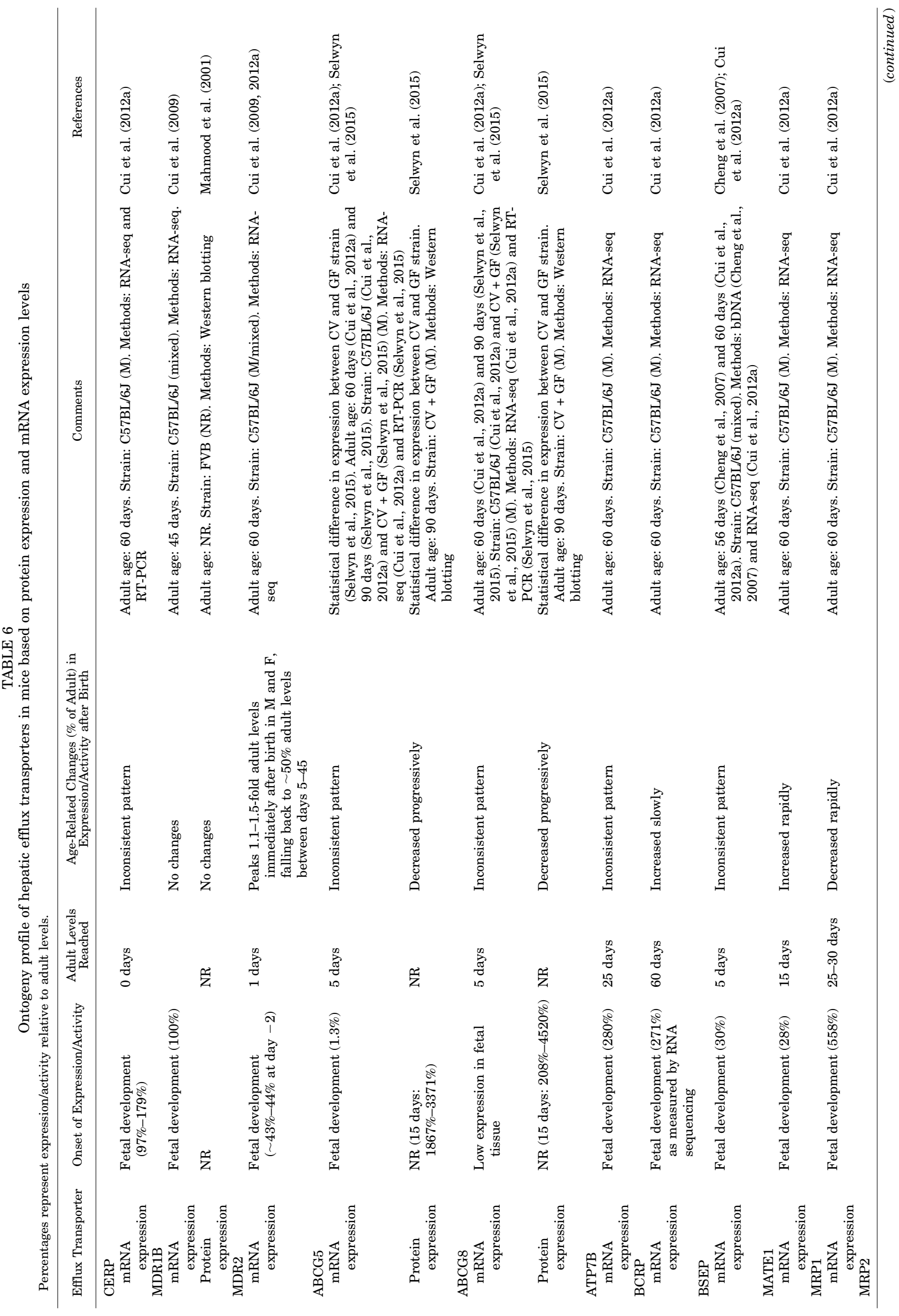




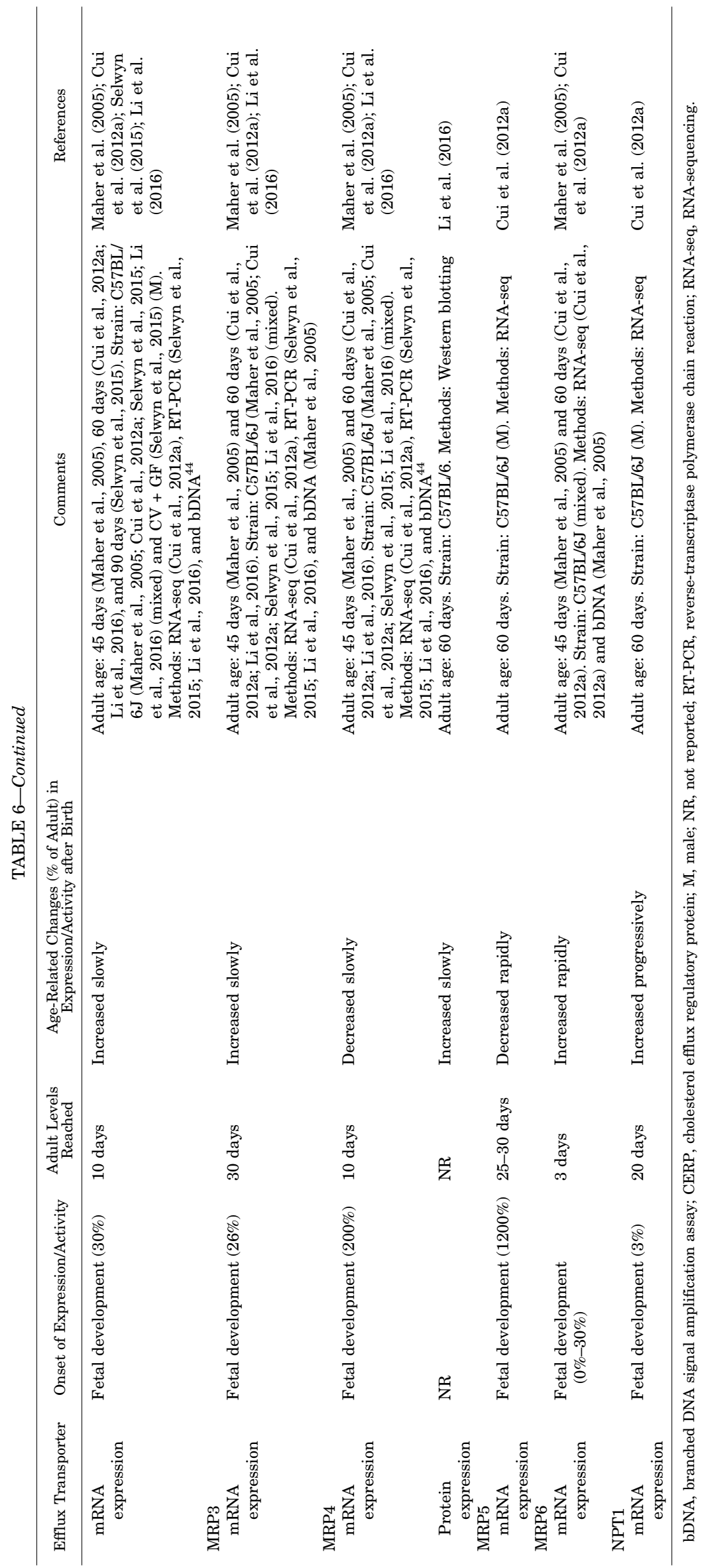


A

CYP1A2

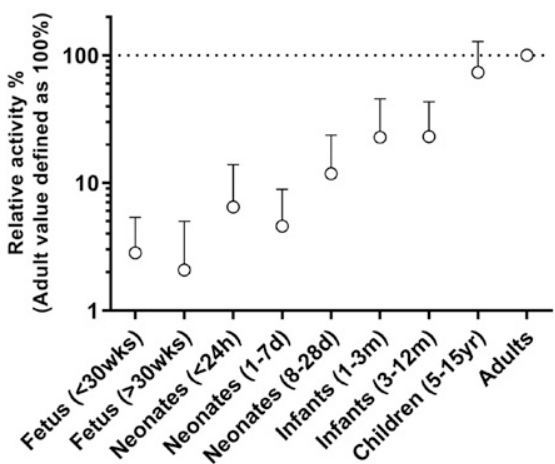

C

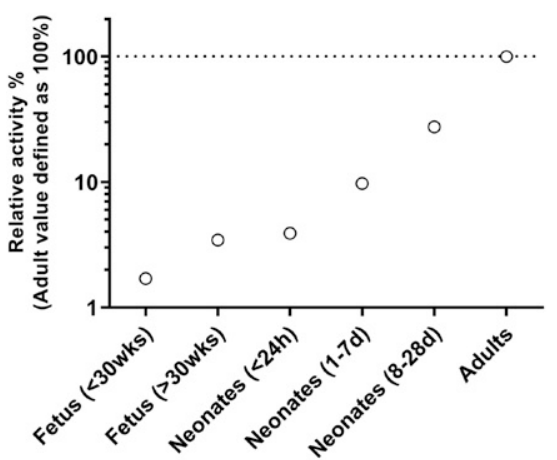

E

CYP3A4

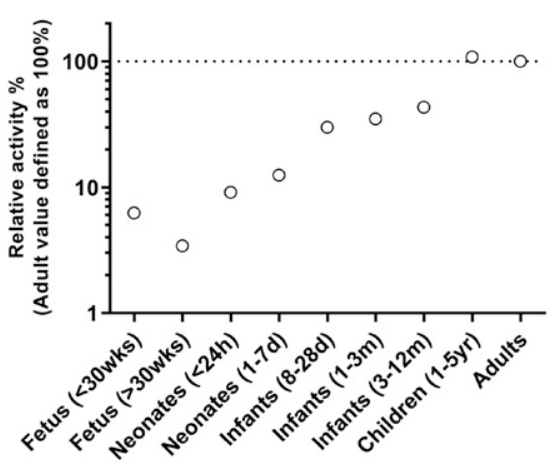

G CES1

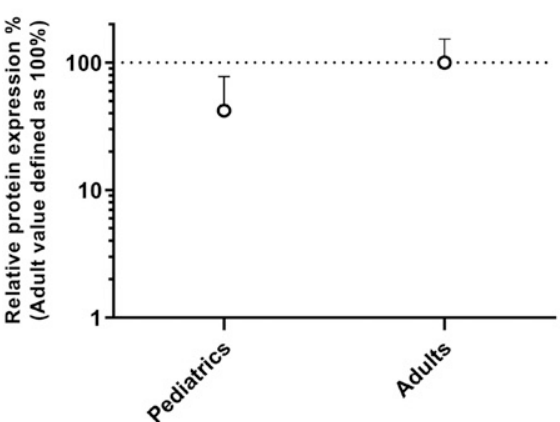

B

CYP2A6

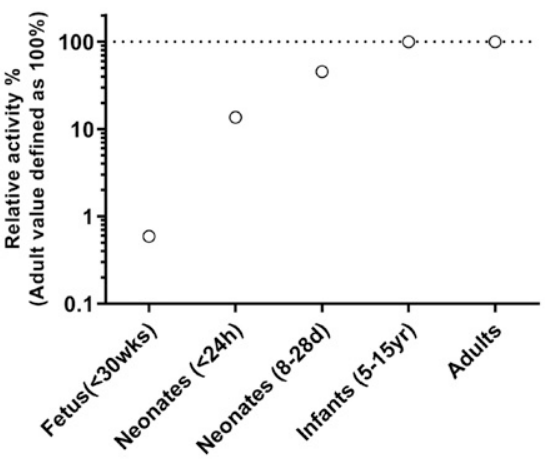

D

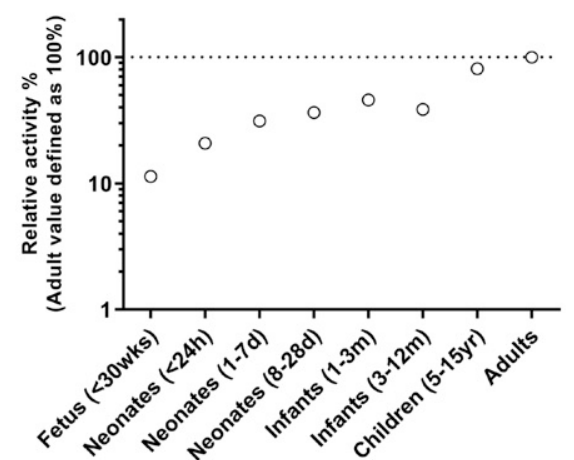

F

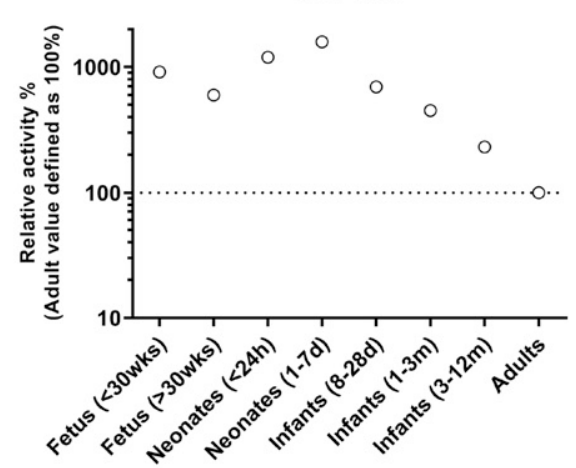

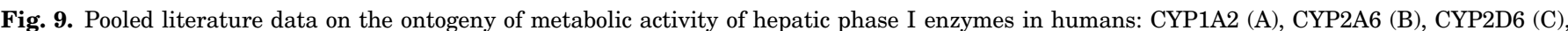

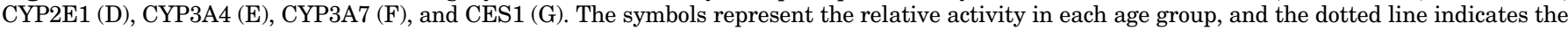

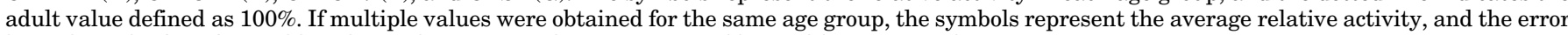
bars show the S.D. See Table 7 for explanation on the ontogeny profiles and literature references. 


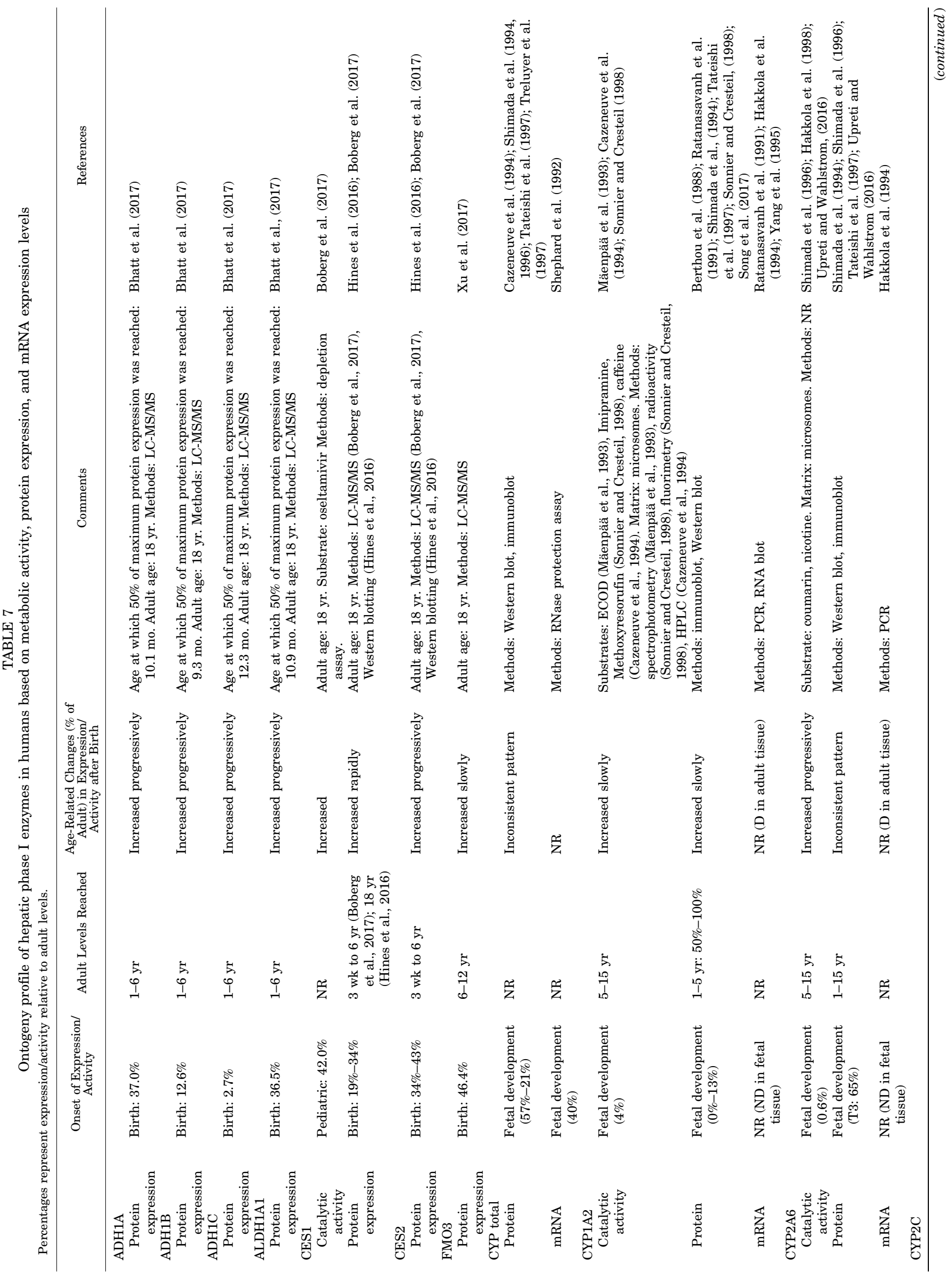




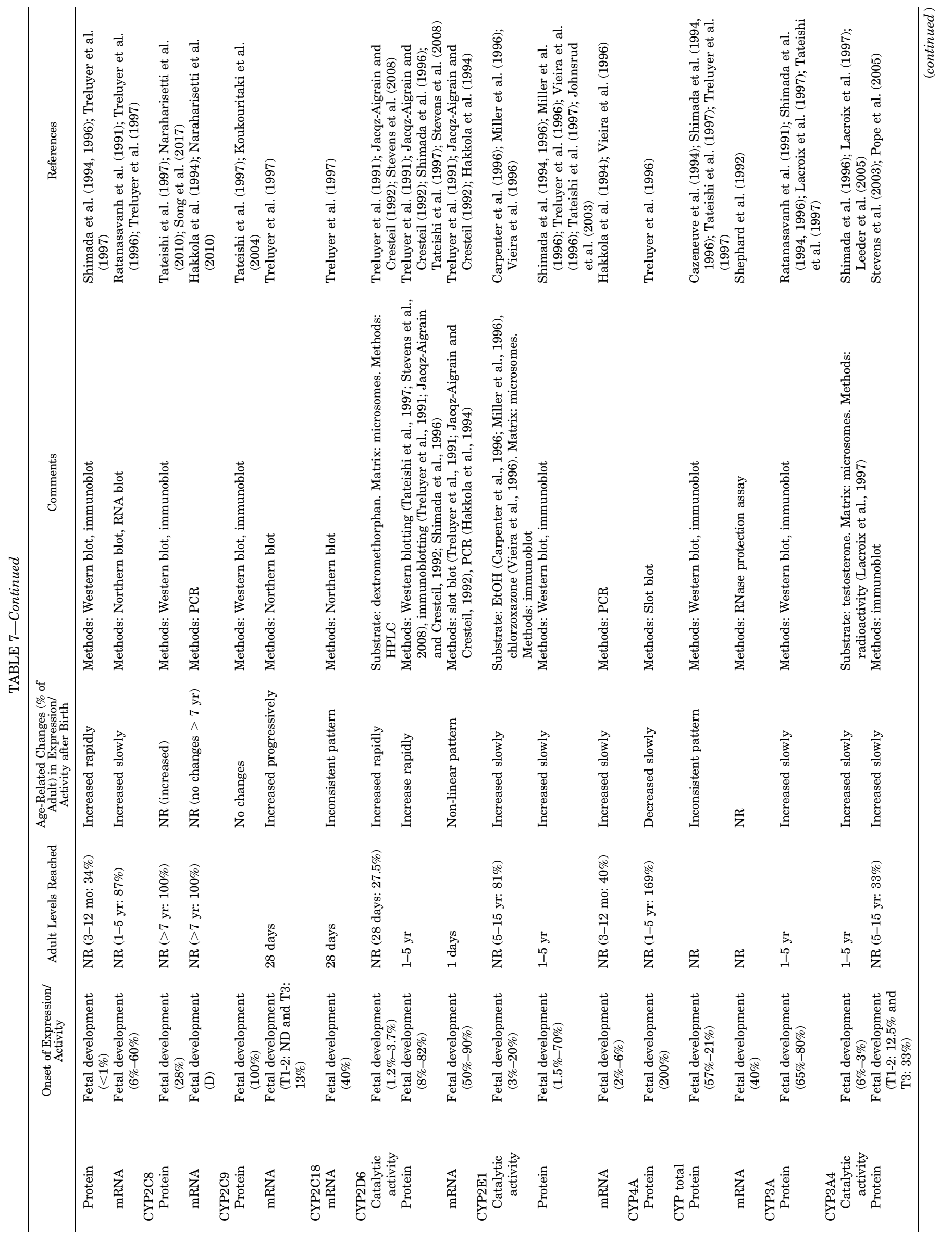


CYP3A4, CYP3A5, and CYP3A7. The total CYP3A protein expression was $65 \%-80 \%$ in fetuses but appeared to be relatively constant across other age groups. CYP3A4 is an extensively studied enzyme that shows low activity in fetuses, with $50 \%$ of adult levels in children up to 1 year old. Adult levels are reached in children between 1 and 5 years old. Protein expression data showed an increase, but activity data showed a decrease during fetal life. The activity of CYP2A6 is very low during fetal age $(<1 \%$ of adult values $)$ but reaches $50 \%$ activity of adult values at neonatal age. This is also reported for protein expression of CYP2A6. Activity and protein expression both reach adult values between 1 and 15 years of age. For CYP2C8, activity data are missing, but the maturational pattern is delayed compared with CYP2A6. Protein expression of CYP2C8 in fetuses shows $28 \%$ of adult values, with adult values reached in children $>7$ years.

b. Age-related decrease in activity/expression. The CYP3A family consist of various isoforms as noted before, of which CYP3A7 is known as the fetal isoform. This is confirmed by literature data, as CYP3A7 is highly active in fetuses. Also, the protein expression is $2000 \%$ of adult expression. However, mRNA expression in fetuses was found to be only $185 \%$ of adult values. For CYP4A, only data on protein expression were available. From neonates to children, protein expression was higher than in adults (130\%-200\% of adult values). Expression data for age groups between children (1-5 years) and adults were lacking.

c. Complex ontogeny pattern in activity/expression. Total CYP enzyme protein levels and mRNA expression in fetuses were $21 \%-57 \%$ and $40 \%$ of adult values, respectively. Adult values are not yet reached at infant age, and data were lacking between infant and adult age. The CYP2C9 maturational pattern was discrepant between protein and mRNA expression. Protein expression did not show age-related differences. In contrast, mRNA expression was not detected in fetuses and showed neonatal development with $60 \%$ of adult values 1 week postnatally. Adult values were reached 1 month postnatally. For the enzyme CYP2C18, only mRNA expression is available, with $40 \%$ in fetuses, and rapid neonatal development to adult levels decreasing to $87 \%$ of adult levels 1 week postnatally. CYP3A5 is polymorphic and is only expressed in $23 \%$ of the adult population. The expression shows no clear developmental pattern.

2. Rat. The results are depicted in Fig. 10, Supplemental Fig. 11 and S12, and Table 8 and are further explained below.

a. Age-related increase in activity/expression. Metabolic activity gradually increased with age, reaching maximal activity levels from 3 to 4 days (CYP2E and CYP2B1/2), 7 days (CYP4A1), and 21 days of age (CYP1A and CYP3A). For CYP2C11, a sex-related pattern was 
Ontogeny of Hepatic Transport and Drug Metabolism

621

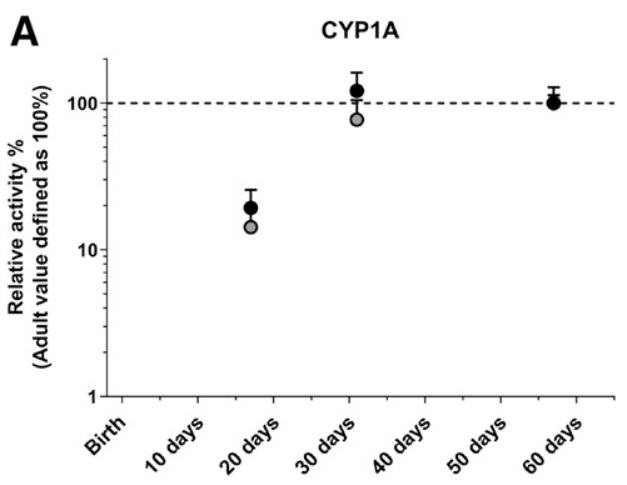

C

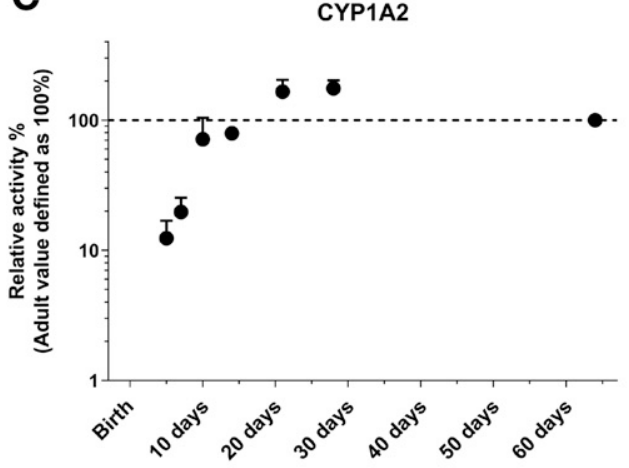

E
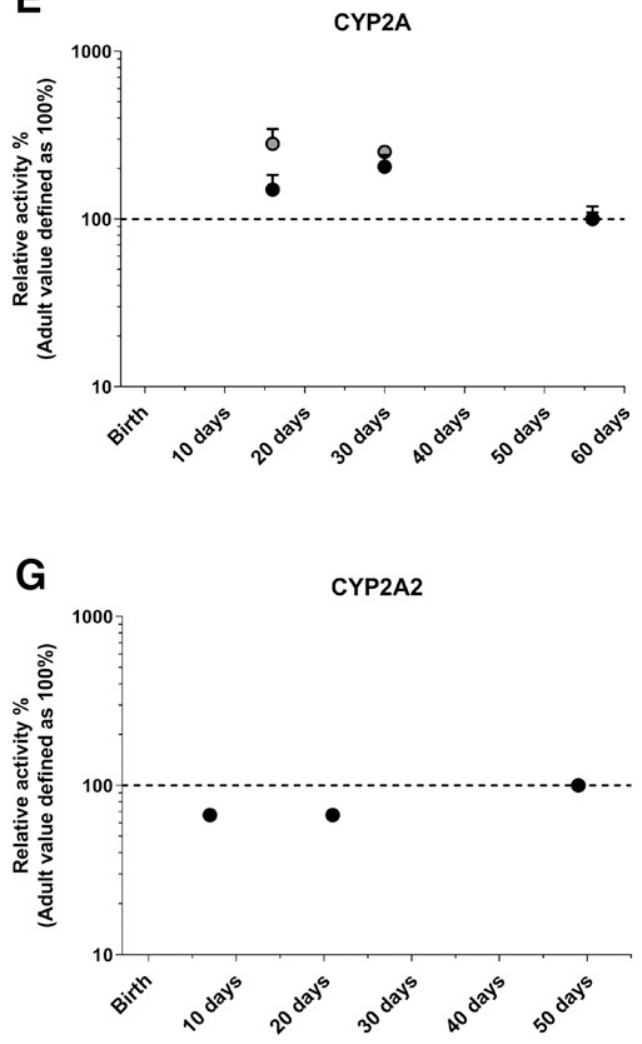

B

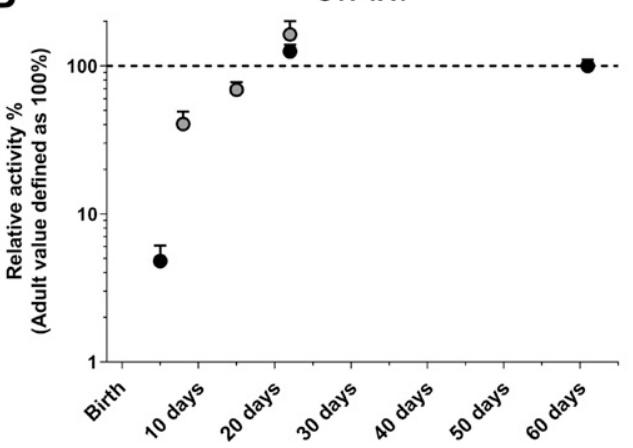

D

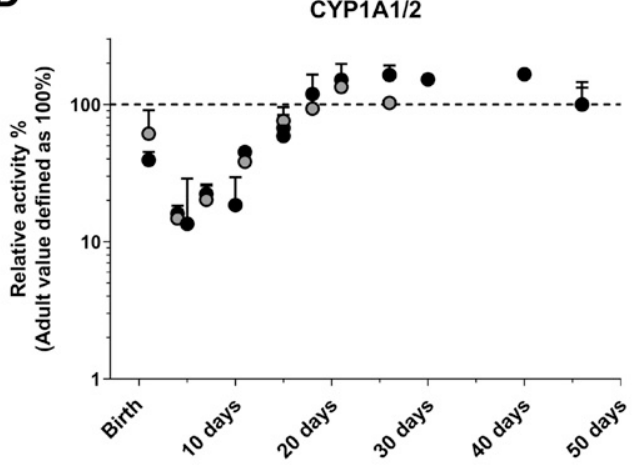

$\mathbf{F}$
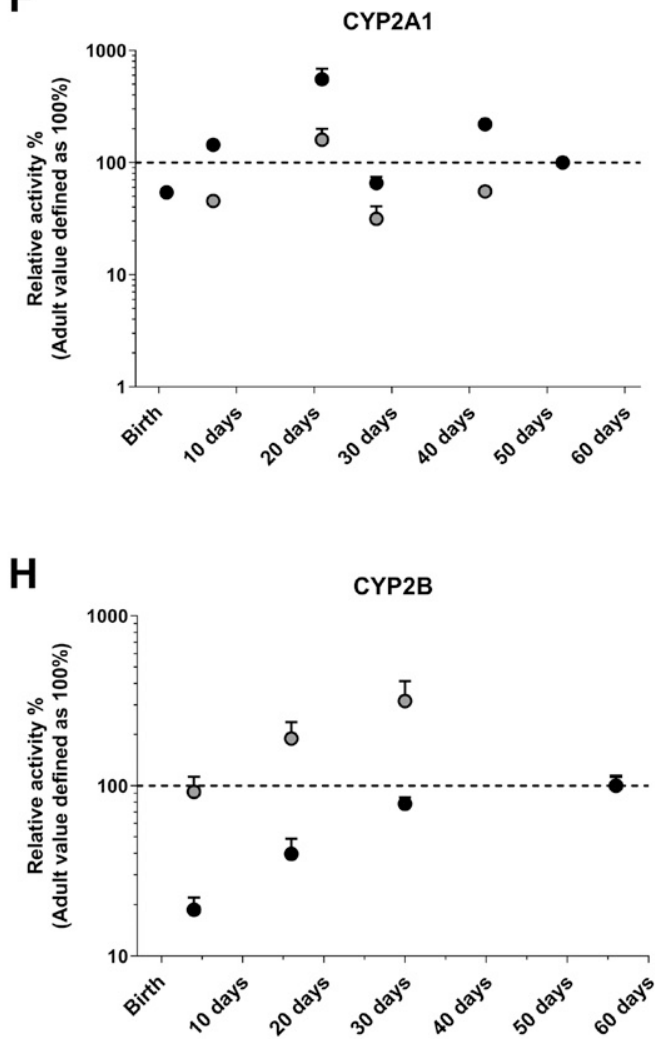

Fig. 10. Pooled literature data on the ontogeny of metabolic activity of hepatic CYP enzymes in rats: CYP1A (A), CYP1A1 (B), CYP1A2 (C), CYP1A1/2 (D), CYP2A (E), CYP2A1 (F), CYP2A2 (G), CYP2B (H), CYP2B1 (I), CYP2B1/2 (J), CYP2C (K), CYP2C6 (L), CYP2C11 (M), CYP2D (N), CYP2E1 (O), line indicates the adult value defined as $100 \%$. If multiple values were obtained for the same age group, the symbols represent the average relative activity, and the error bars show the S.D. See Table 8 for explanation on the ontogeny profiles and literature references. 

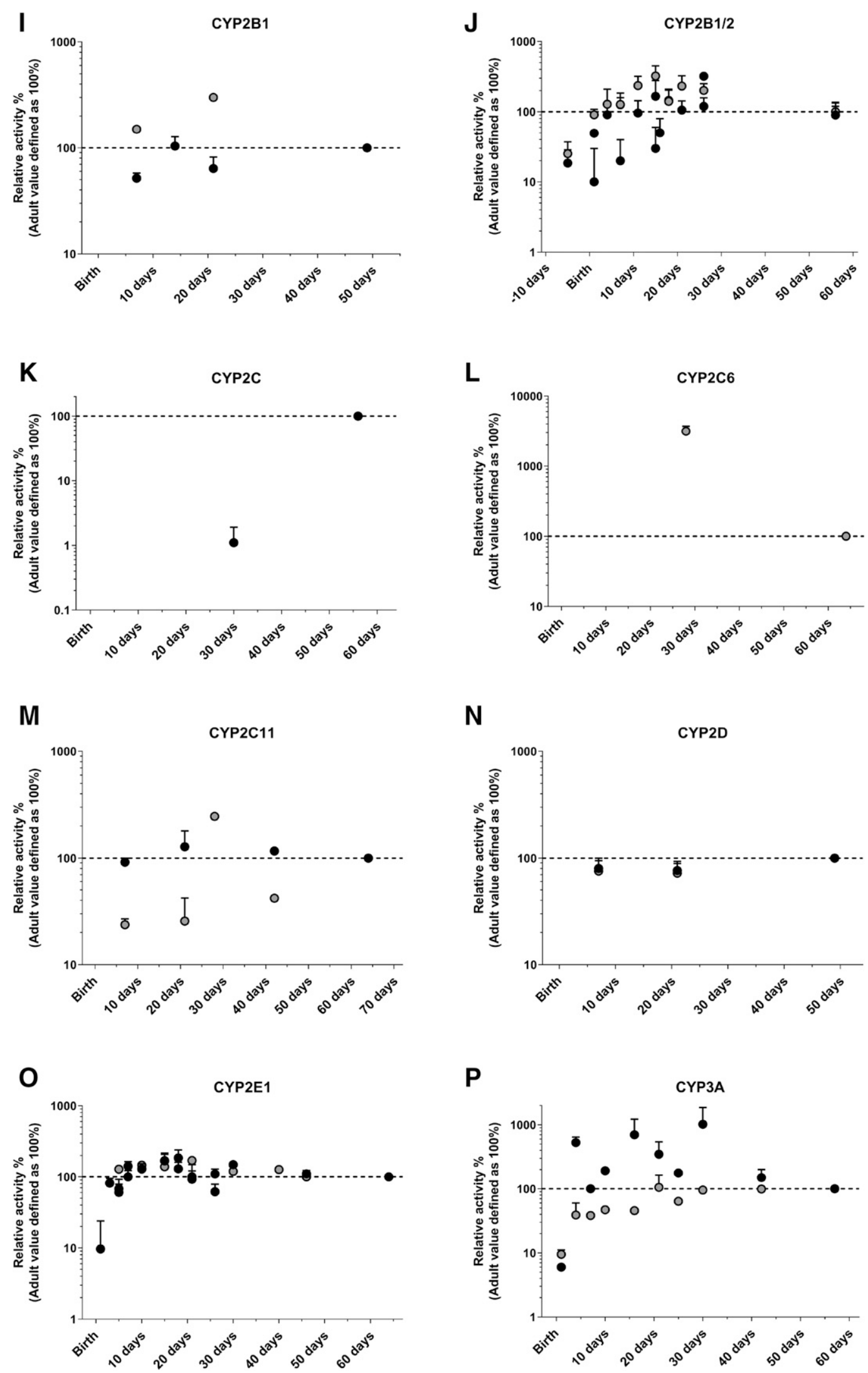

Fig. 10. Continued. 

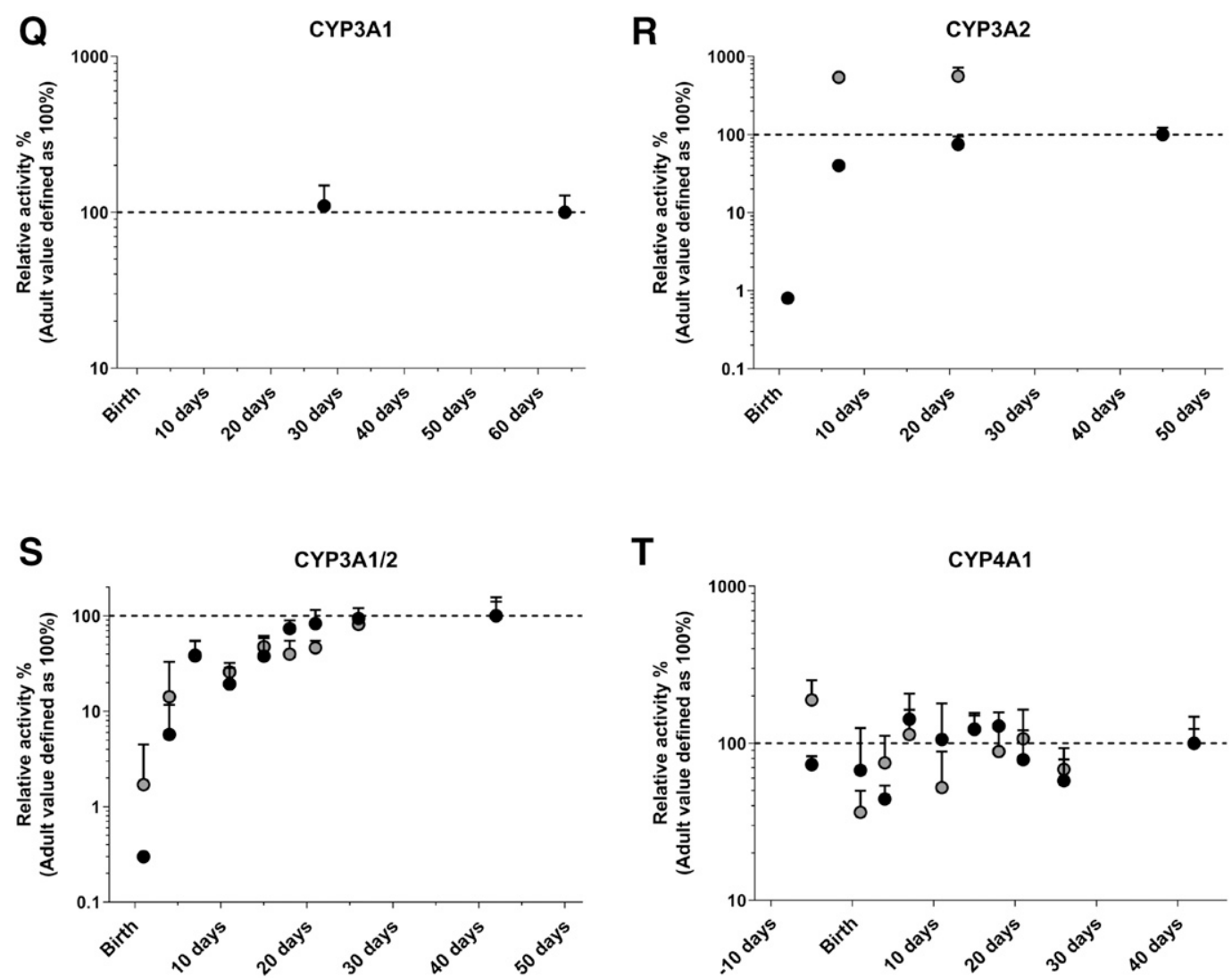

Fig. 10. Continued.

observed, reaching adult levels of activity at 7 days for female rats and 21 days for male rats.

Activity of CYP4A2 and CYP4A3 rose from $20 \%$ at birth until adulthood, except for female rats showing $>100 \%$ of adult CYP4A2 activity at 7 days after birth.

Age- and sex-dependent increase in mRNA expression levels of CYP3A9, CYP3A11, CYP3A18, CYP3A23, CYP2D3, CYP7A1, CYP8B1, and CYP27 was reported. Maximal mRNA expression levels were achieved after 7 days of age for CYP3A11 and CYP3A23 or during adulthood for CYP3A9. Interstudy discrepancies exist with regard to the ontogeny of CYP3A18 reaching maximal mRNA expression levels at various ages, from 7 days in both female and male rats to 4 days in female rats and adulthood in male rats.

b. Age-related decrease in activity/expression. The ontogeny of CYP2C6 activity levels was not reported in juvenile rats below 28 days of age, but a 50-fold decrease in activity from 28 days to adult rats was seen. However, CYP2C6 protein and mRNA expression levels were inconsistent with activity levels: The more detailed ontogeny of CYP2C6 mRNA/protein levels revealed an age-related increase in expression from birth until adulthood in both male and female rats.

c. No age-related changes in activity/expression. Little to no change in metabolic activity of CYP2A, CYP2C12, and CYP2D isoforms was observed with advancing age in rats. No apparent sex differences in activity were associated with ontogeny of CYP2A, whereas only male rats were studied for other CYP isoforms.

d. Inconsistent ontogeny pattern of expression levels. Fetal mRNA values of CYP7A1 and CYP8B1 represented $>30 \%$ of adult levels. However, their mRNA expression levels rapidly declined after birth $(<25 \%$ of adult levels after 7-14 days) and then increased throughout adulthood and peaked in elderly rats $(>300 \%)$. However, mRNA protein levels of CYP27 reached maximal values after birth and remained unchanged until adulthood.

3. Mouse. The results are depicted in Fig. 11 and Table 9 and are further explained below.

a. Age-related increase in $m R N A$ expression. The majority of the phase I enzymes showed a lower mRNA expression in younger age groups than in older age groups, and an important number of these enzymes reached adult levels at 20 days postnatal, including CYP1A2, CYP2A4, CYP2A5, CYP2B26, CYP2C50, CYP2D22, CYP3A11, CYP3A25, CYP4F14, and ALDH1. All but CYP1A1, CYP1A2, CYP2B10, CYP2B13, CYP2B23, CYP2F2, CYP4A10, CYP4A32, FMO2, and alternative oxidase were expressed in fetal tissue.

b. Age-related decrease in mRNA expression. CYP3A16 was the only isoform that showed a clear decrease in expression with a slow decrease from fetal life until adult values were reached at 25 days. 


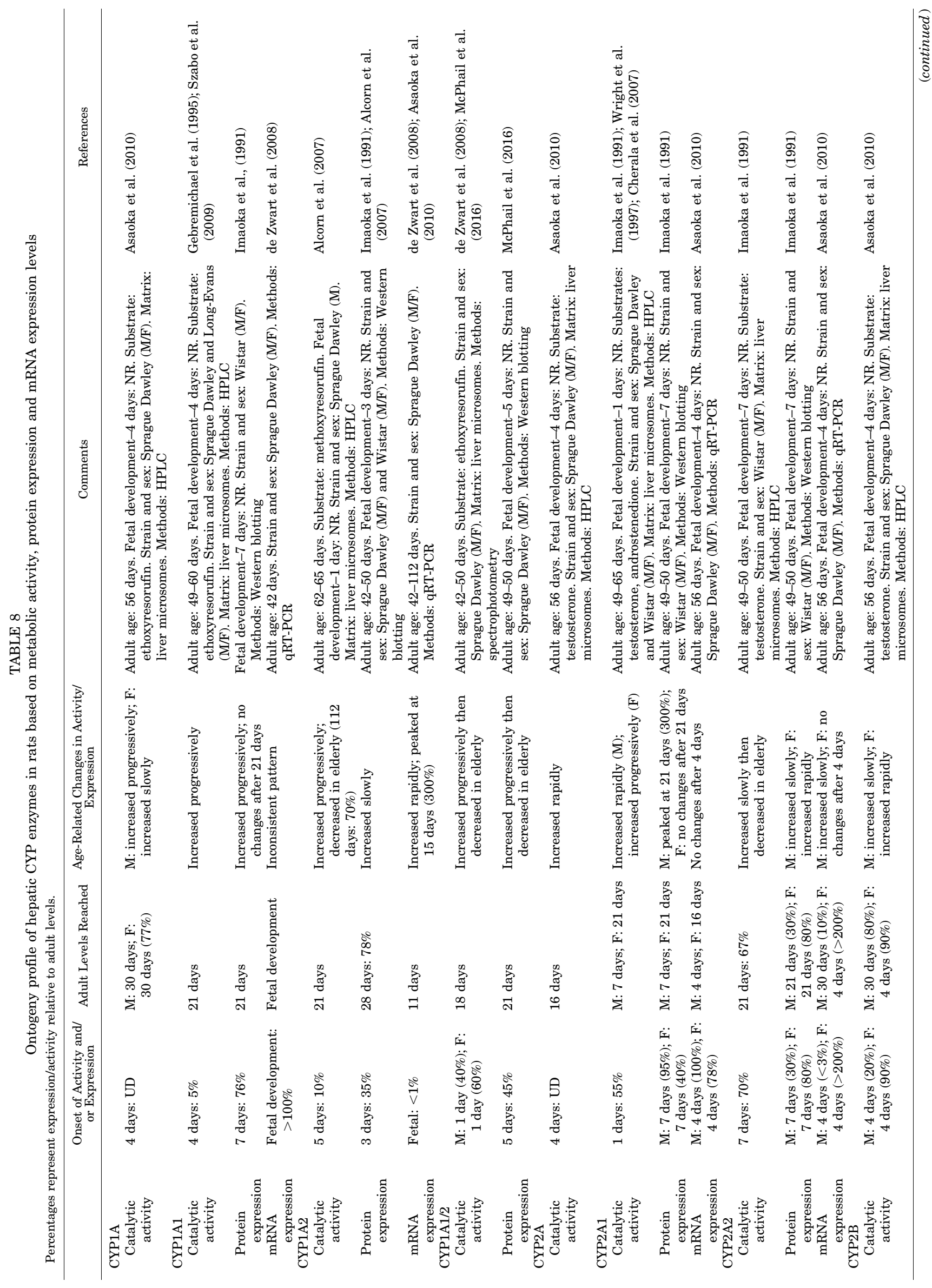




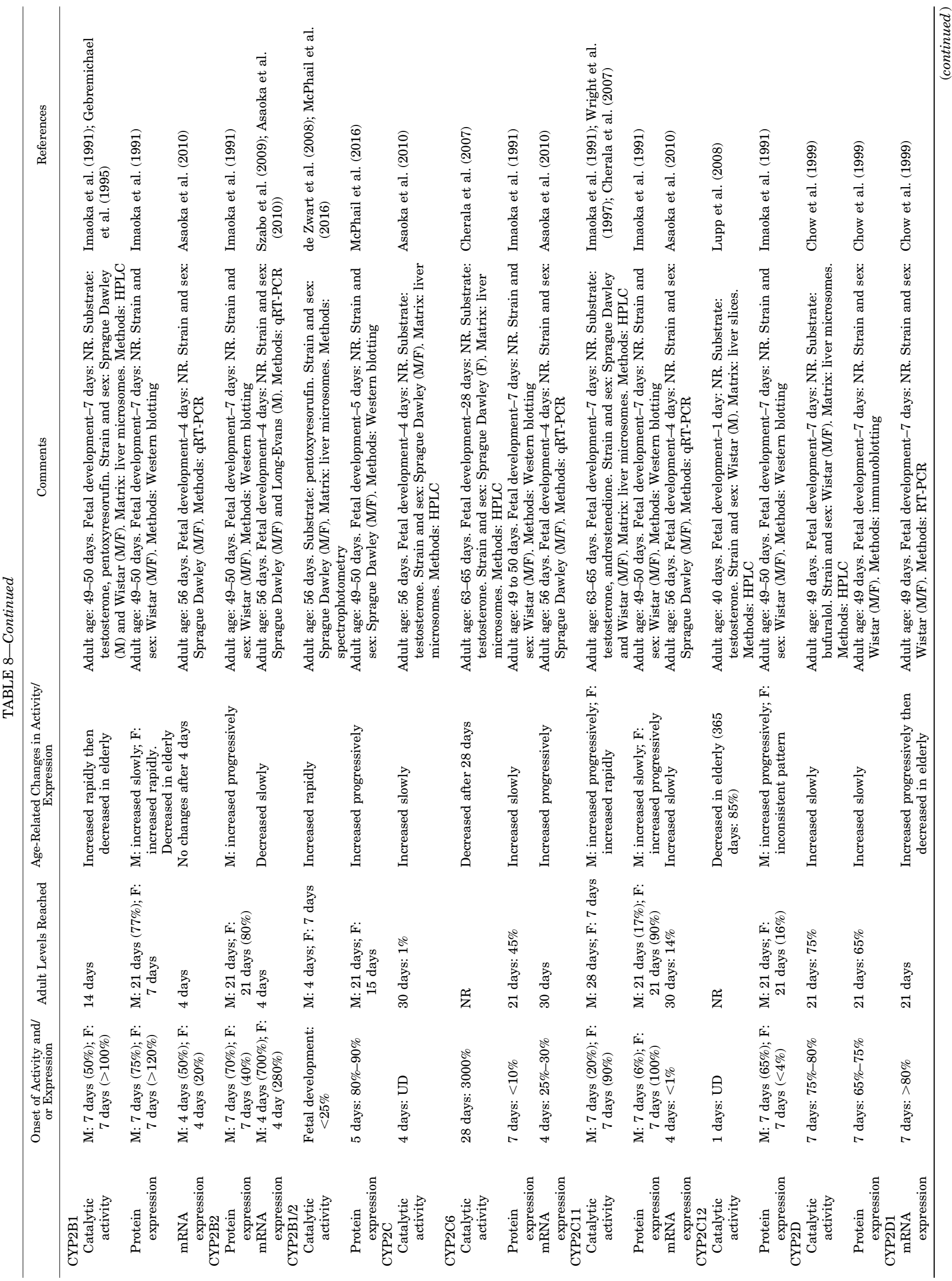


van Groen et al.

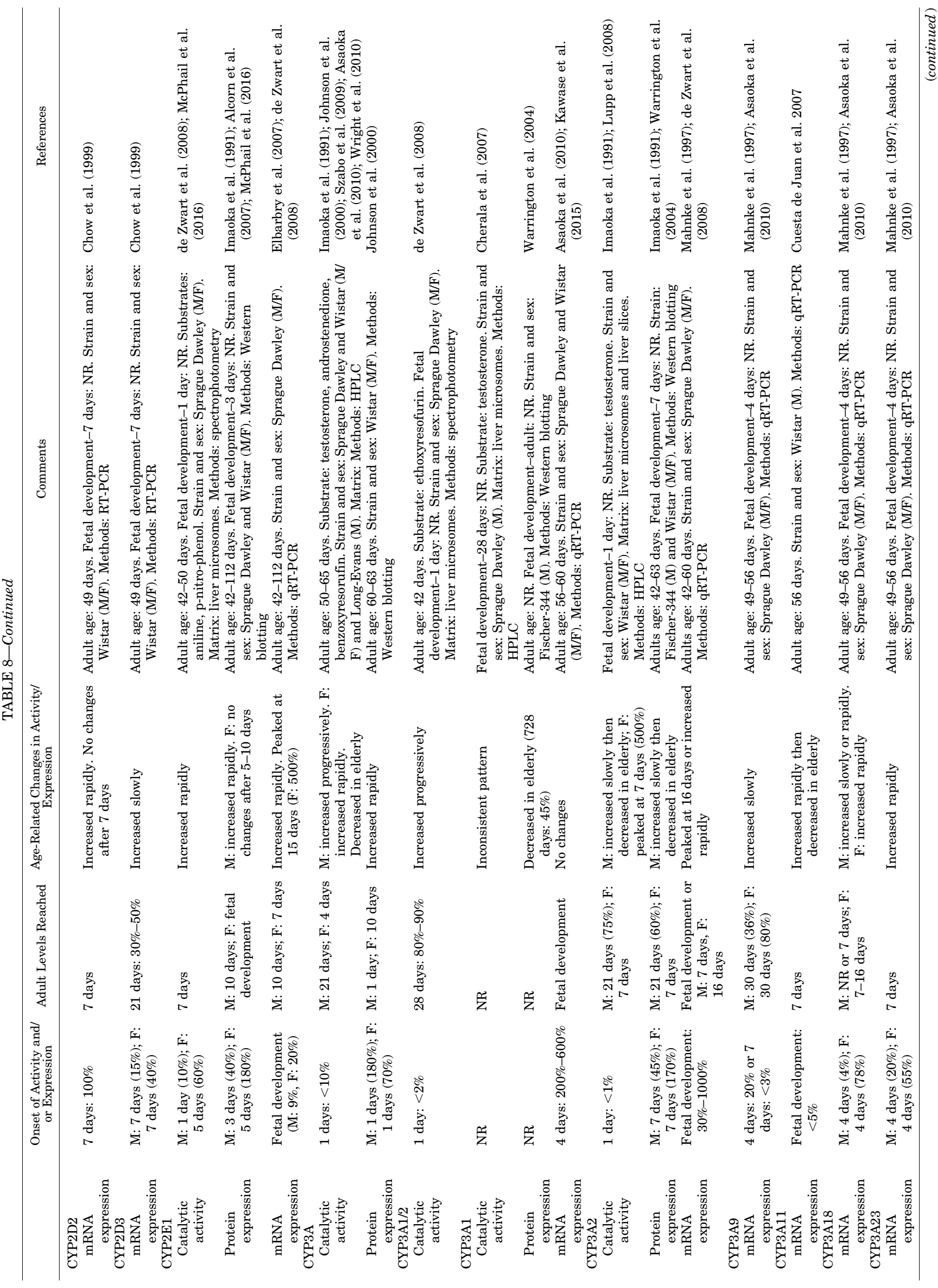


c. No age-related changes in mRNA expression. CYP2D26 did not show age-related changes in its ontogeny profile.

d. Complex and/or inconsistent ontogeny pattern of $m R N A$ expression. For the isoforms CYP2B13, CYP2B23, CYP2B9, CYP3A41B, CYP3A59, CYP4A31, CYP4A32, and CYP4F16, no clear developmental pattern could be distinguished. CYP2B13 and CYP2B23 were not expressed in fetal tissue. CYP2B13 and CYP2B9 expression was higher in male mice than in female mice. Expression of CYP2B23 increased from birth to 10 days and subsequently decreased.

\section{Nonrodents.}

a. Göttingen minipig. The results are depicted in Fig. 12, Supplemental Fig. 13, and Table 10. The metabolic activity of CYP1A2 and CYP2D6 showed a rapid increase, with adult levels reached at 28 days of age. CYP2C9 and CYP3A4 showed a more gradual increase with lower activity at 28 days of age compared with adults. All CYPs mentioned above showed detectable albeit very low $(0.2 \%-3 \%)$ fetal activity.

Only CYP3A protein expression has been reported. It was low (about $20 \%$ of adult) during the late fetal stages and gradually increased postnatally with still a lower expression at 28 days of age compared with adults.

b. Cynomolgus monkey. Results are depicted in Fig. 13 and Table 11. For this species, only mRNA data are reported. Several CYPs show a rapid increase and normalize at adult values (CYP2A23, CYP2A24, CYP2B6, CYP2C9, CYP2C19, CYP2C76, CYP2D17, CYP2E1, CYP3A4, and CYP4F2). CYP2C18 mRNA levels, on the other hand, increase very slowly. Others show a more particular profile that either increases well above adult expression levels before declining (CYP1A1, CYP2C8, CYP2J2, CYP3A5, CYP4A11, CYP4F3, and CYP4F11) or starts above adult values to first fluctuate and eventually decrease toward adult age (CYP3A43). CYP4F12 was the only enzyme with a more or less stable profile from fetal to adult age. No sex differences were reported.

c. Beagle dog. The results are depicted in Fig. 14, Supplemental Fig. 14, and Table 12. The data need to be interpreted with caution because they are derived from animals of 7 days and older, and CYP activity already reached values around $50 \%$ of adult levels at this young age. CYP1A1 activity and metabolism mediated by CYP3A and CYP2B already showed adult levels in male Beagle dogs at 1 week of age, whereas CYP1A2 increased after birth and reached adult values at 30 weeks of age. Combined activity of CYP2C, CYP2E1, and CYP3A was higher at 3 weeks of age, whereas the older age groups showed similar levels as dogs at 1 week of age. Activity levels of especially CYP2C9 and also CYP2E1 increased from 7 days and valued well above adult values around 100 days, after which they steadily declined to adult values. CYP3A4/5 activity decreased between 7 days and 50 days, after which it increased 
A

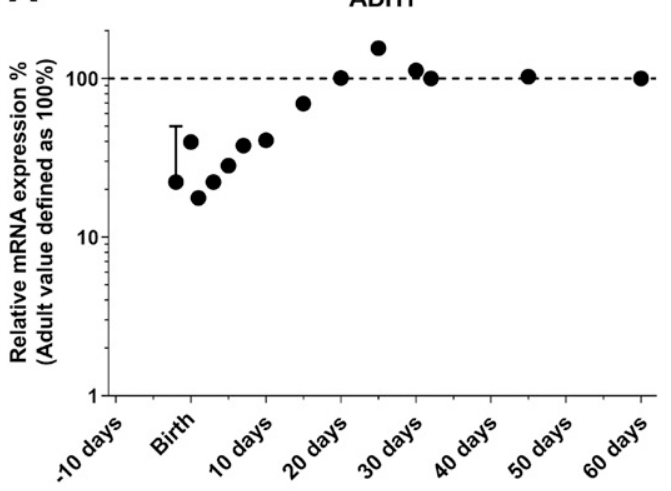

C

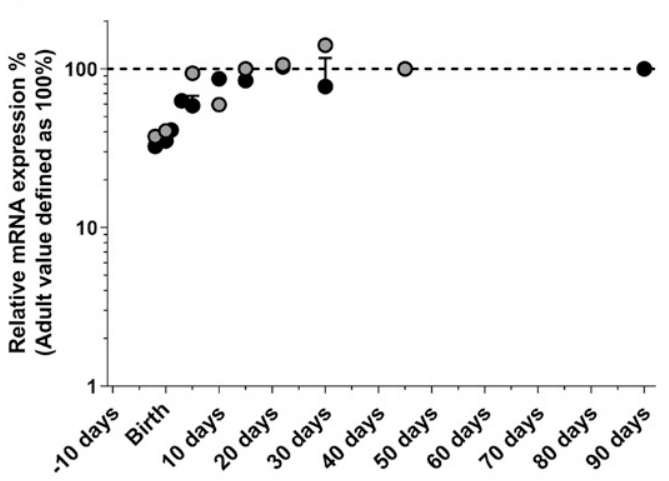

E

ALDH1A7

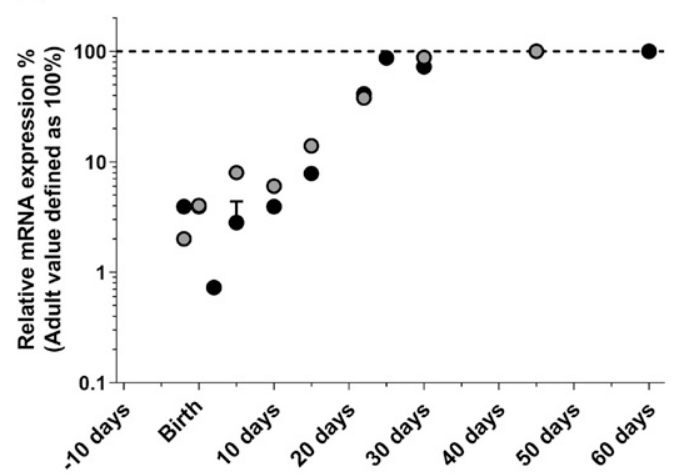

G

AOX

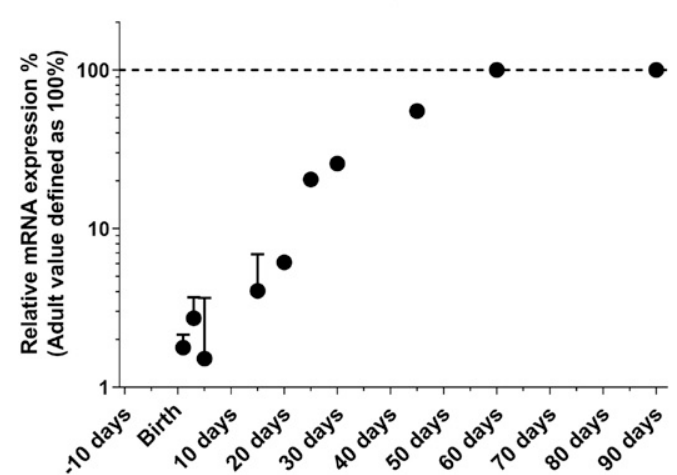

B

ALDH1A1

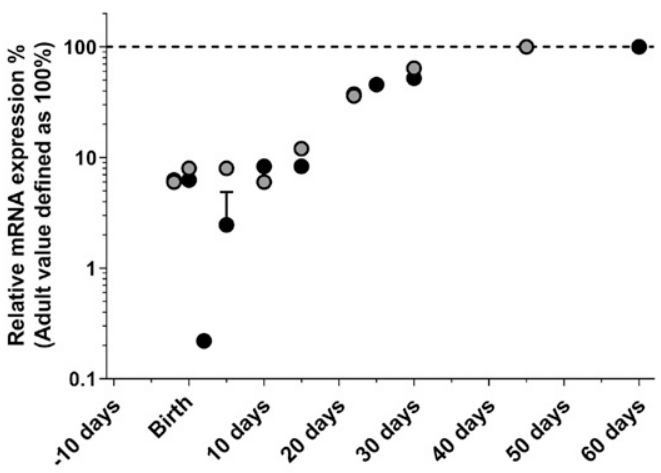

D

ALDH3A2

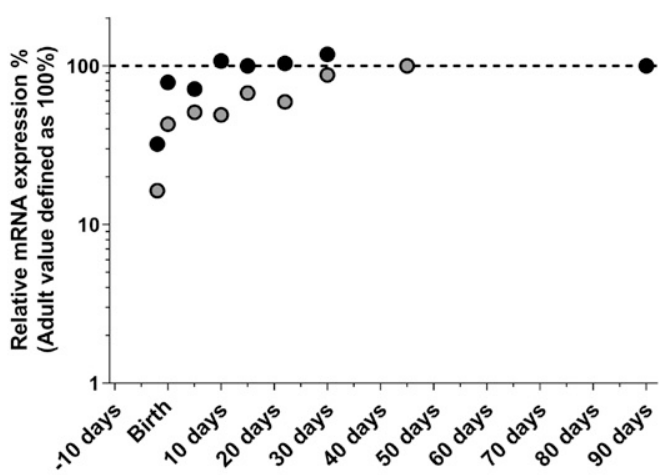

F

ALDH7A1

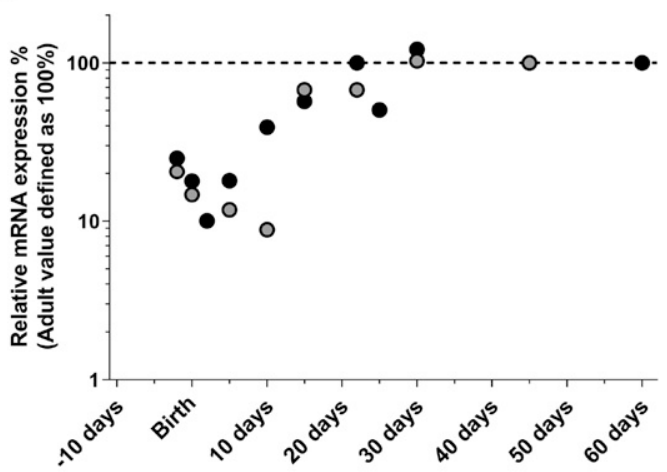

H

CES2A

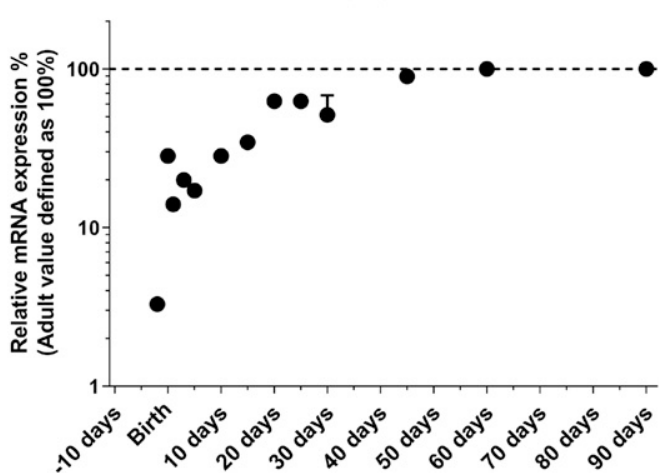

Fig. 11. Pooled literature data on the ontogeny of hepatic mRNA expression of phase I drug-metabolizing enzymes in mice: ADH1 (A), ALDH1A1 (B), ALDH1B1 (C), ALDH3A2 (D), ALDH1A7 (E), ALDH7A1 (F), AOX (G), CES2A (H), CYP1A2 (I), CYP2A4 (J), CYP2A5 (K), CYP2B10 (L), CYP2B13 (M), CYP2B23 (N), CYP2B9 (O), CYP2C29 (P), CYP2C37 (Q), CYP2C40 (R), CYP2C44 (S), CYP2C50 (T), CYP2C54 (U), CYP2C67 (V), CYP2C69 (W), CYP2C70 (X), CYP2D10 (Y), CYP2D22 (Z), CYP2D26 (AA), CYP2D9 (AB), CYP2E1 (AC), CYP2F2 (AD), CYP3A11 (AE), CYP3A13 (AF), CYP3A16 (AG), CYP3A25 (AI), CYP3A41A (AJ), CYP3A41B (AK), CYP3A44 (AL), CYP3A59 (AM), CYP4A10 (AN), CYP4A14 (AO), CYP4A31 (AP), CYP4A32 
gradually to adult values. No mRNA or protein expression level data were available.

d. Domestic pig. The results are depicted in Fig. 15, Supplemental Figs. 15 and S16, and Table 13. Activity data were available from male and female animals 2,28 , 56 , and 180 days of age. Female CYP2C as well as male/ female CYP2E activity levels were high at birth $( \pm 50 \%)$ and gradually increased to adult values. Male CYP2E and male/female CYP3A activity levels were low at birth and rapidly increased to $\pm 75 \%$ of adult values, which was followed by a gradual increase to adult values (180 days). Microsomal protein content was high at birth and gradually decreased to adult values at 30 days.

Protein expression levels as determined by LC-MS/ MS were reported for male and female animals at 2, 28, 56, and 180 days of age. Expression levels of CYP1A2, CYP2C34, and CYP2C49 increased rapidly after birth. A sex difference was observed for CYP1A2, with female expression reaching well above adult levels before declining back to adult levels. A more gradual increase without sex differences was observed for CYP2A19, CYP2D6, CYP3A22, CYP3A46, CYP4A21, CYP20A1, and CYP51A1. Protein expression levels of CYP2B22, CYP2C33, male CYP2C36, and female CYP2E1 and CYP4A24 were stable postnatal until 56 days of age, and then this was followed by an increase to adult levels at 180 days of age. Female CYP2C36 and male CYP2E1 levels were stable from birth to adulthood.

\section{Phase II Drug-Metabolizing Enzymes}

1. Human. The results are depicted in Fig. 16, Supplemental Fig. 17 and S18, and Table 14 and are further explained below.

a. Age-related increase in activity/expression. Metabolic conjugating activity gradually increased with age, reaching maximal levels at various ages from infancy $[<2$ years, for $N$-acetyltransferase (NAT) and UGT1A9], early childhood [7 years, for glutathione-Stransferase (GST) $\zeta 1$ ], or adulthood [ $>18$ years for catechol-O-methyltransferase (COMT), sulfotransferase (SULT) 1E1, UGT2B7, UGT2B15, and UGT2B17]. Activity was readily apparent by either the fetal period for COMT, GSTZ1, NAT, UGT2B7, UGT2B17, and SULT1E1 or at least within a few days after birth for UGT1A9 and UGT2B15-there was no fetal activity data available.

The developmental pattern of several phase II enzymes has been characterized only based on either protein expression levels [GSTA2, GSTM, and SULT2A1] or mRNA expression levels (UGT2B4). Protein abundance levels of GSTA2, GSTM, and SULT2A1 gradually increased with advancing age, reaching maximal levels within 2 years of age and with onset of protein expression started during fetal life. Although no data were reported below 6 months of age, $50 \%$ of adult mRNA expression levels of UGT2B4 was achieved after 6 months and remained unchanged until adulthood.

b. Age-related decrease in activity/expression. SULT1A3 activity levels and GSTP1 protein abundances decreased by 2.5- and 20-fold from fetal to neonatal population, respectively. Although no data were reported during childhood, SULT1A3 activity levels increased by 10-fold, whereas GSTP1 protein levels further decreased by 10 -fold from neonates to adulthood.

c. No age-related changes in activity/expression. Little to no change in SULT1A1 activity levels was observed during fetal life, being more than $80 \%$ of adult levels. However, activity data were not reported between 6 months and adult age, with 3 -fold higher activity at 6 months of age compared with adult levels. Similar results were observed in protein abundance levels of SULT1A1 and GSTA1.

2. Rat. The results are depicted in Fig. 17, Supplemental Figs. 19 and S20, and Table 15 and are further explained below.

a. Age-related increase in activity/expression. Activity of UGT1A1, UGT1A6, and UGT2B1 was present at 1 to 2 weeks before birth and rapidly increased to adult levels around 3 weeks postnatally. The mRNA profile of UGT2B2 followed a similar pattern. Although increasing, UGT1A6 activity was variable and fluctuated in three distinct ages, namely 0-15 days, 15-45 days, and 45-300 days. This was also observed for the mRNA maturation profile of UGT1A6. UGT1A1 mRNA expression showed a marked peak after birth that rapidly declined during the first week of life and gradually increased until 56 days.

SULT1A1 (activity and mRNA), SULT2A1 (activity and mRNA), SULT-40/41 (mRNA) bile-salt sulfotransferase (activity), and 3 $\beta$-hydroxy-5-cholenoate sulfotransferase (activity) increased gradually after birth, reaching a maximum around 20 (SULT2A1, bile-salt sulfotransferase, and $3 \beta$-hydroxy-5-cholenoate) to 40 (SULT1A1) days postnatally. SULT1A1 activity and mRNA levels remained stable through adolescence and adulthood. However, for SULT2A1, bile-salt sulfotransferase, and $3 \beta$-hydroxy-5-cholenoate, activity in male livers decreased between day 20 and days $60-80$ postnatally, whereas activity in female livers remained stable. The decrease in SULT2A1 levels was also observed in the corresponding mRNA levels (SULT-20/ 21). SULT-40/41 mRNA levels also showed a decrease after 20 days of age, which was observed in both sexes.

(AQ), CYP4F13 (AR), CYP4F14 (AS), CYP4F15 (AT), CYP4F16 (AU), FMO1 (AV), FMO2 (AW), FMO5 (AX), NQO1 (AY), and POR (AZ). The symbols represent the relative mRNA expression in each age group, and the dotted line indicates the adult value defined as $100 \%$. See Table 9 for explanation on the ontogeny profiles and literature references. AOX, alternative oxidase; NOR, nitric oxide reductase; NQO1, NAD(P)H:quinone acceptor oxidoreductase. 
I

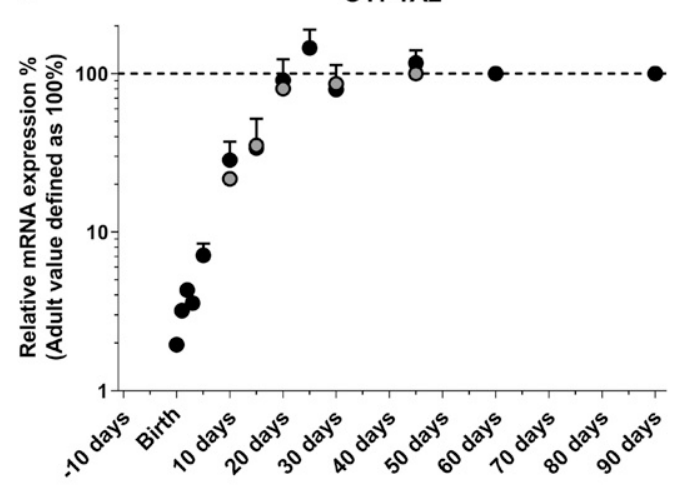

K

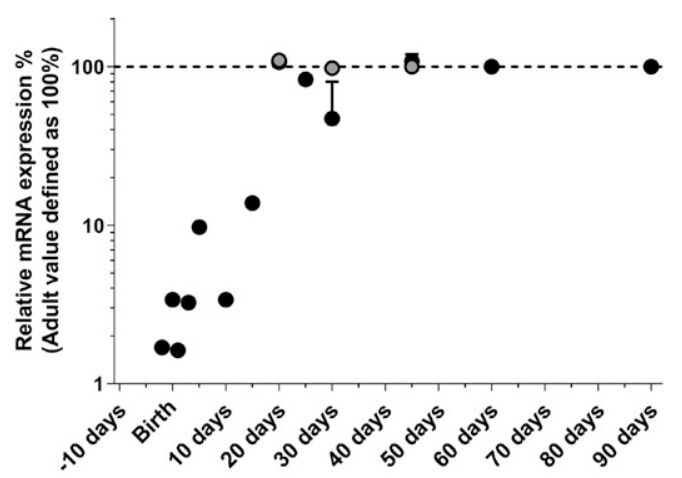

M

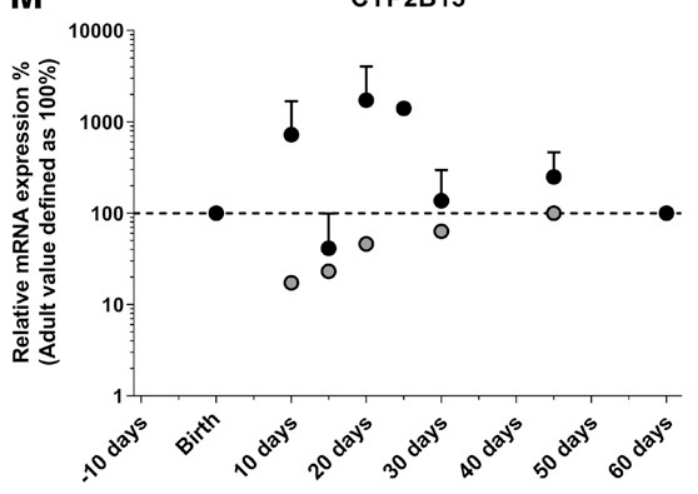

0

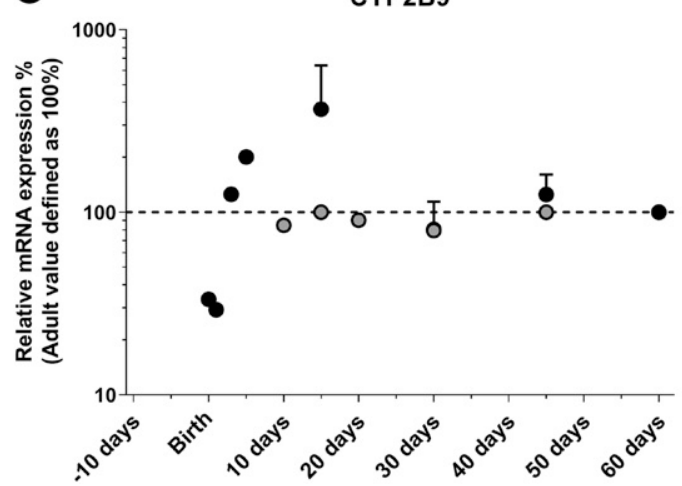

J

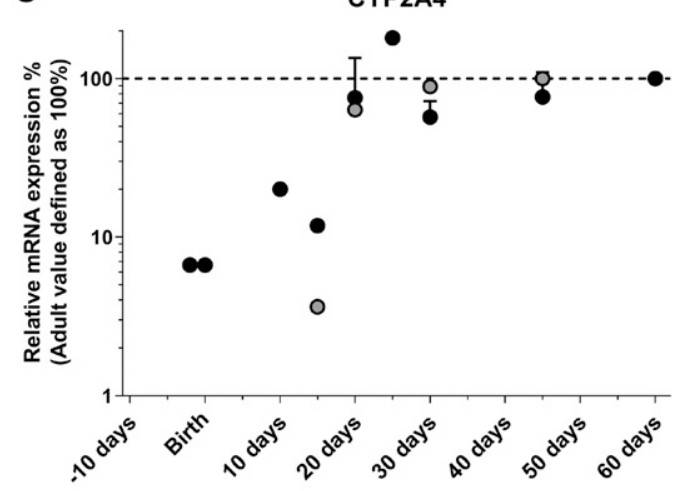

L

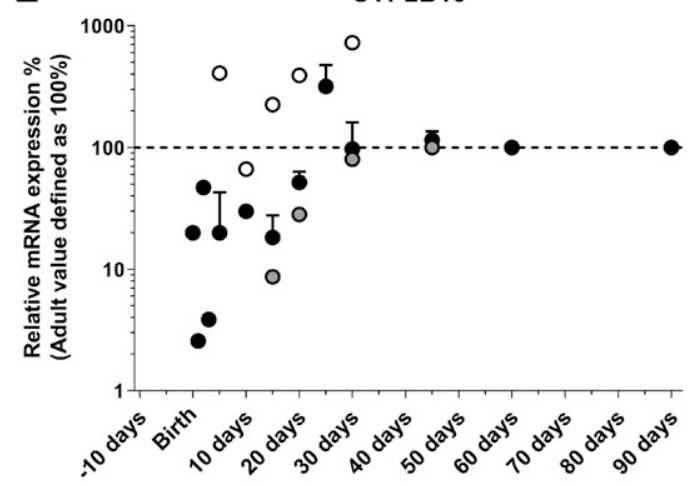

N

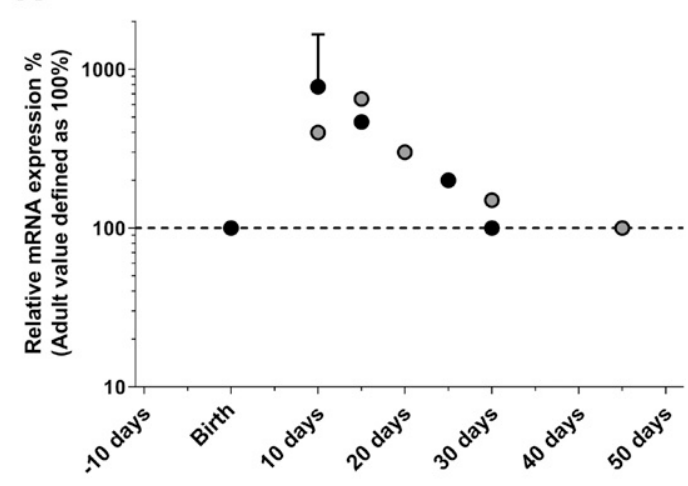

$\mathbf{P}$

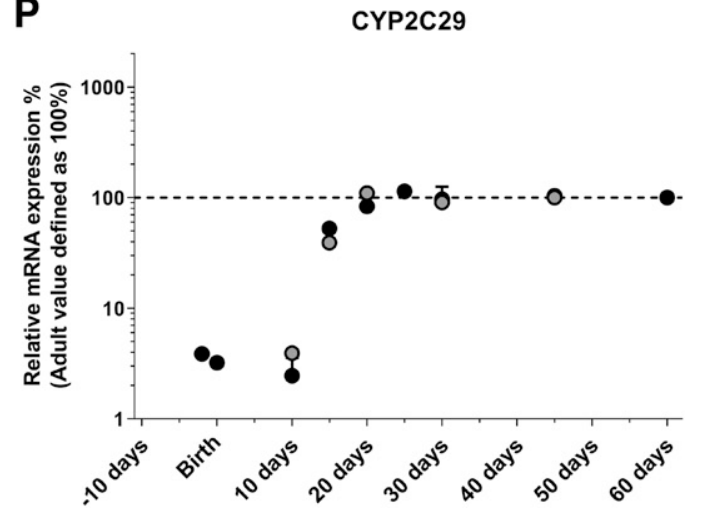

Fig. 11. Continued. 
Q

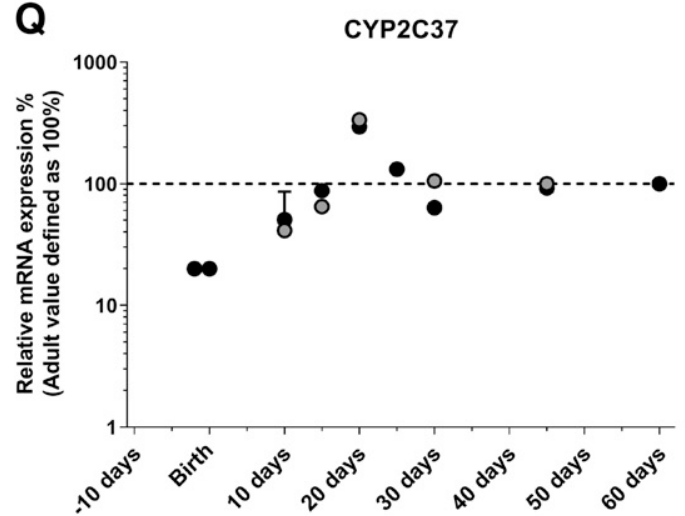

S

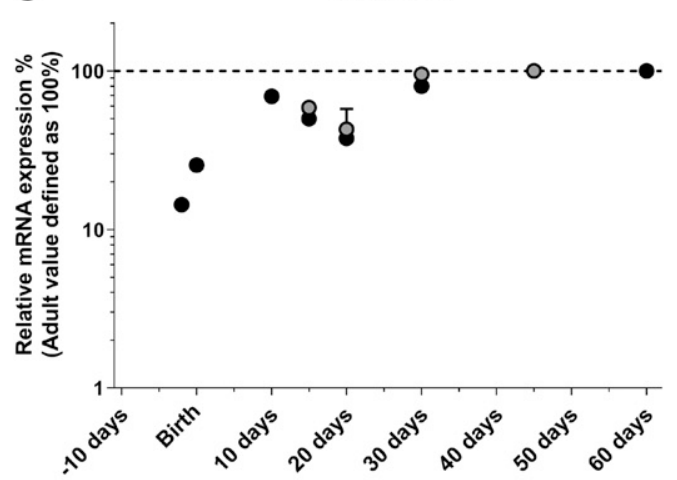

U

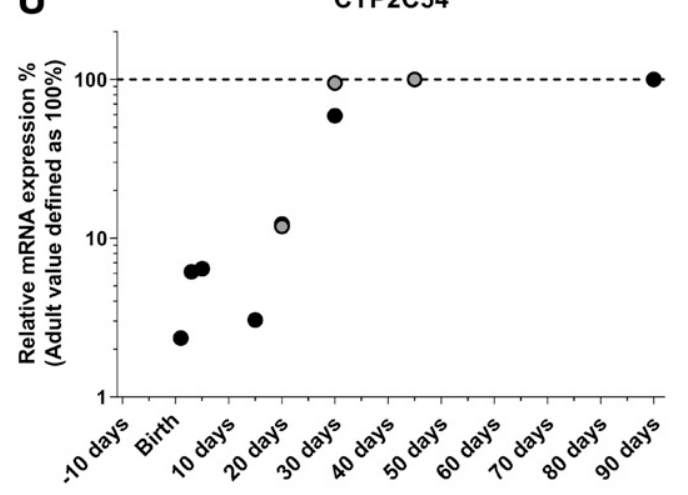

W

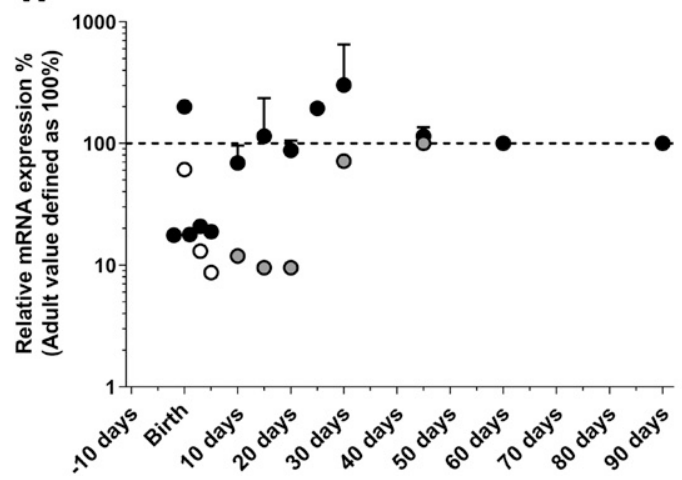

R
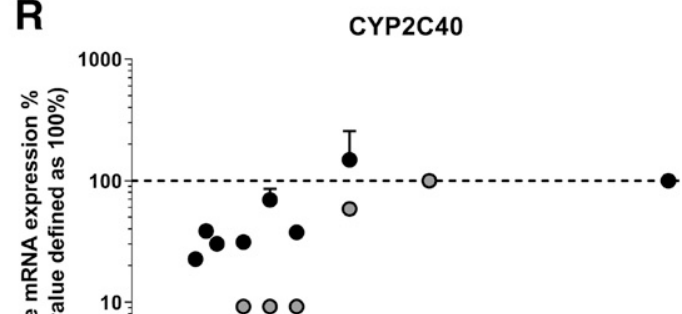

娄专

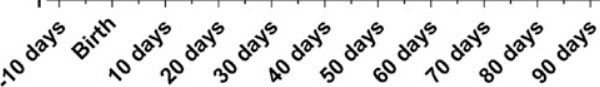

T

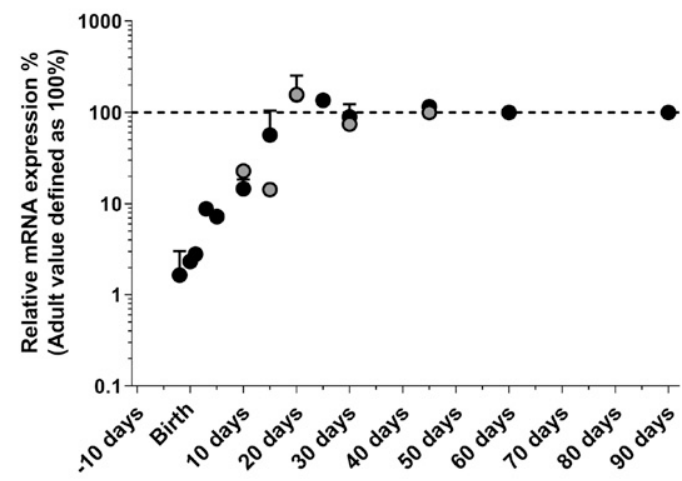

V

CYP2C67

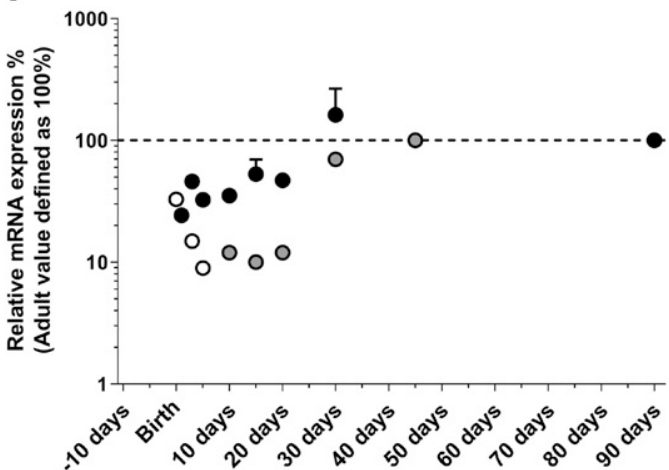

X

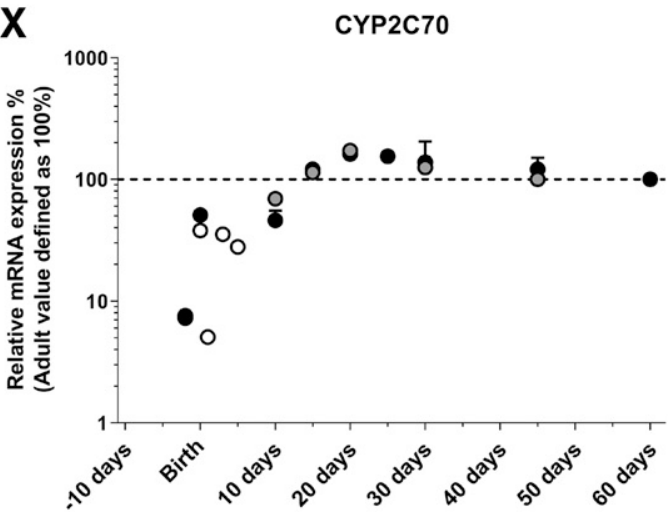


Y

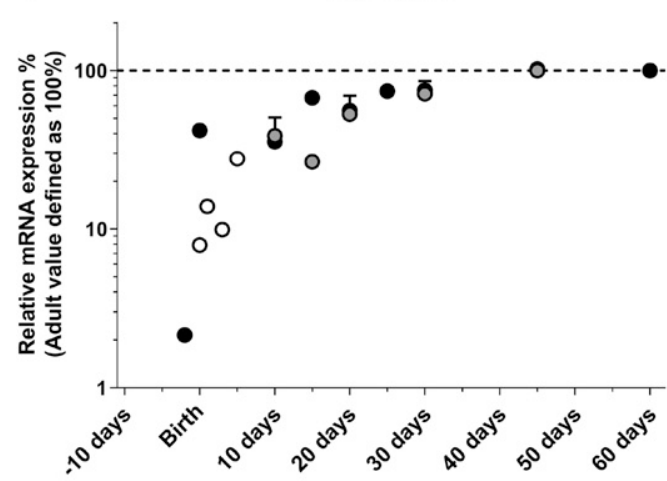

AA

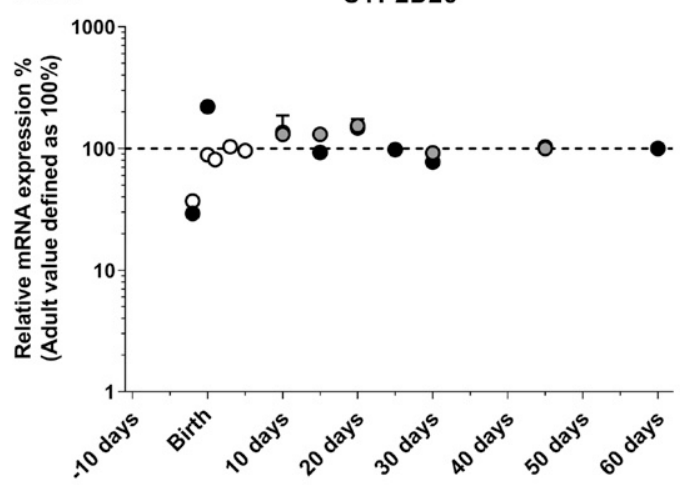

AC

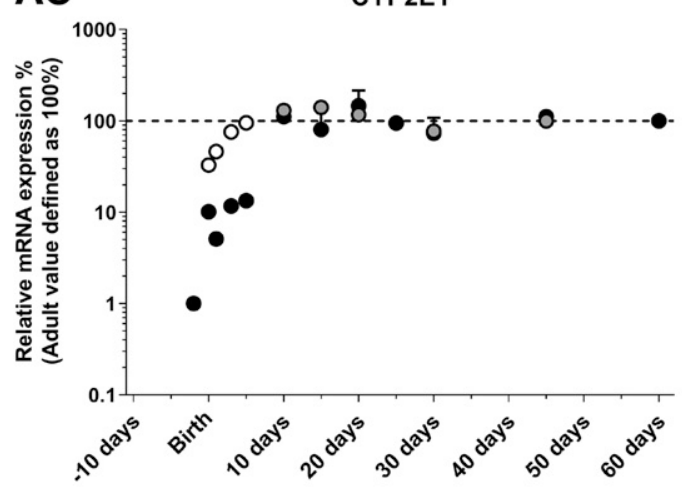

AE

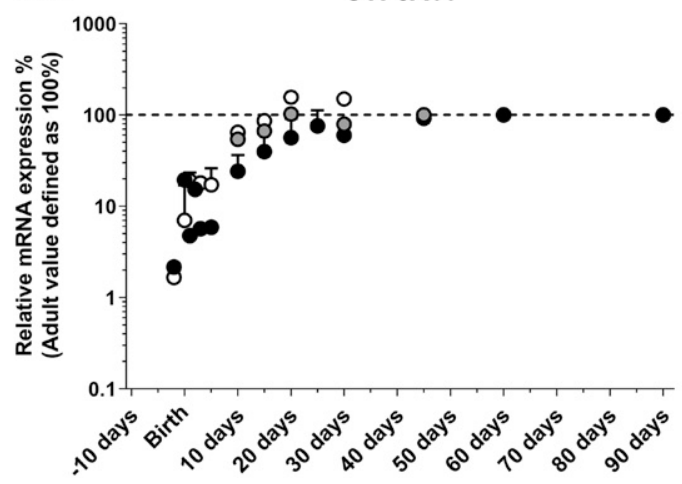

Z

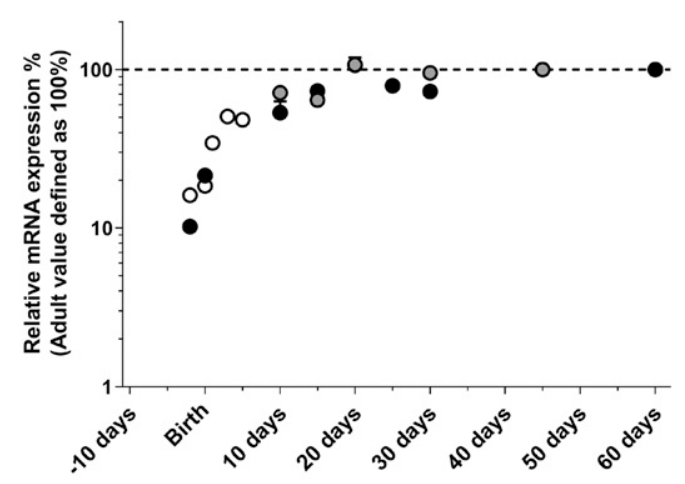

$A B$

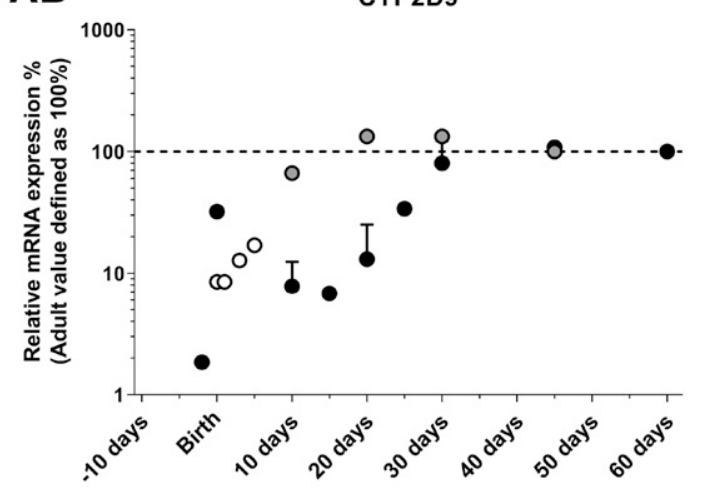

AD

CYP2F2

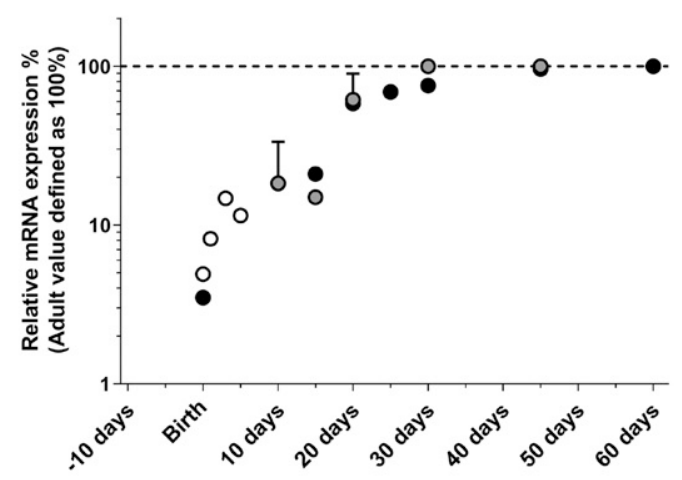

AF CYP3A13

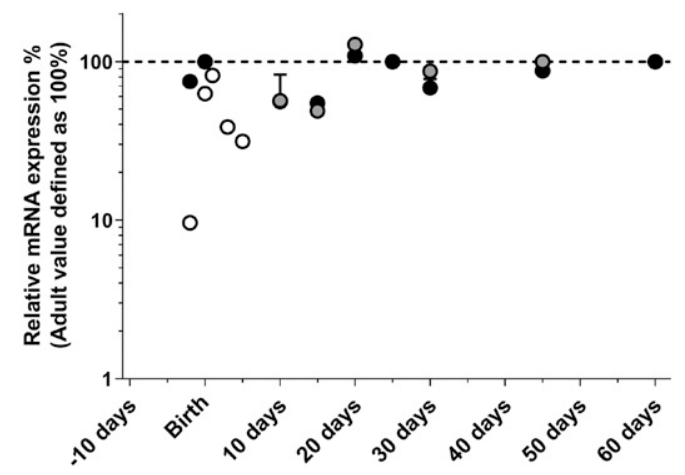

Fig. 11. Continued. 
AG

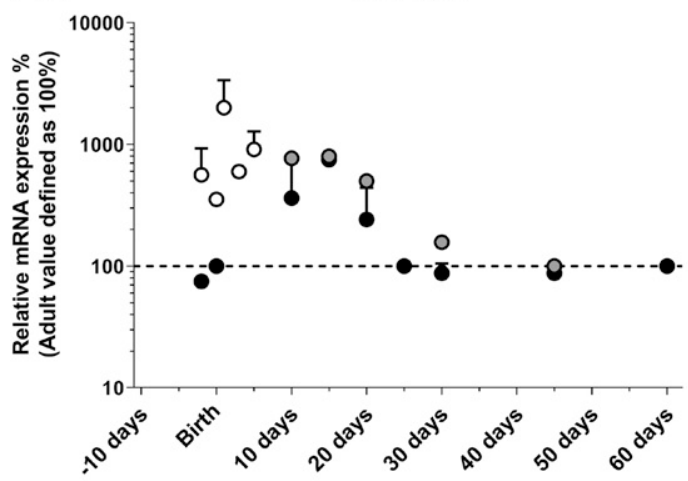

AJ

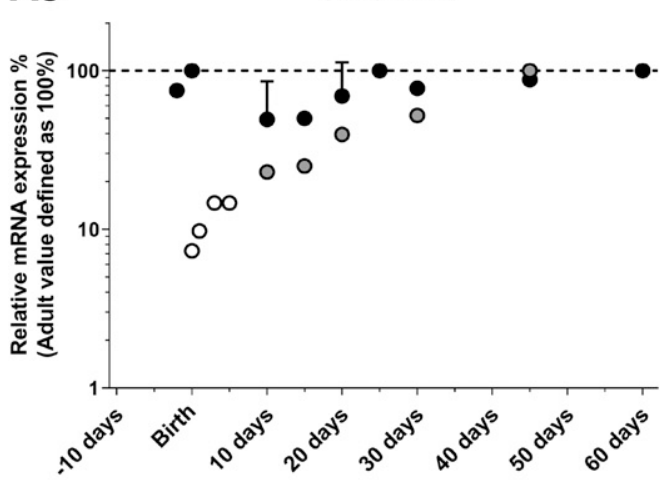

AL

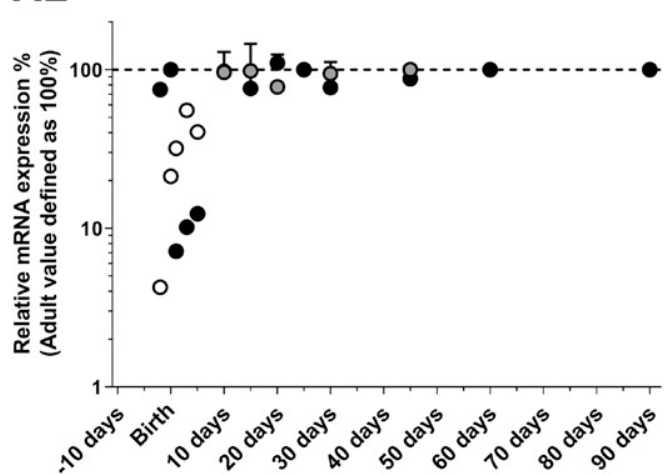

AN

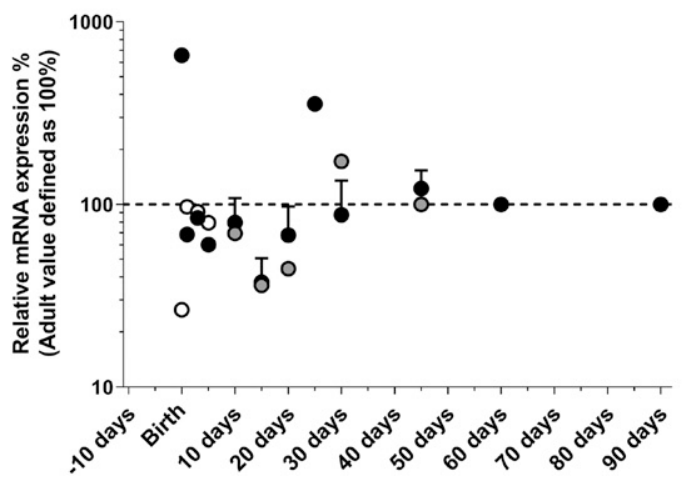

Al

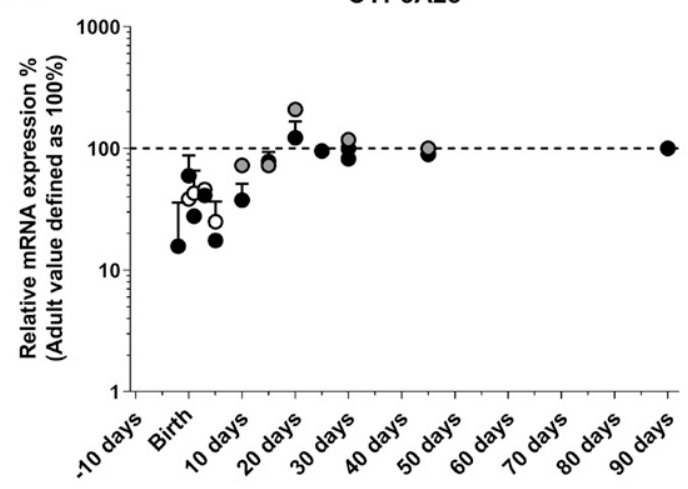

AK

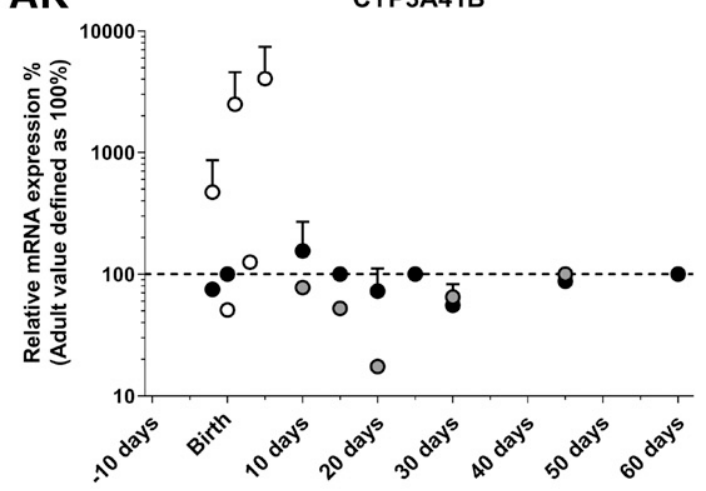

AM

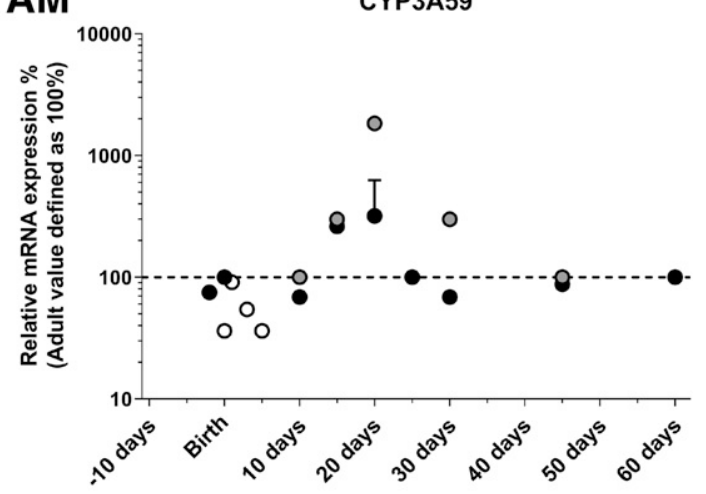

AO

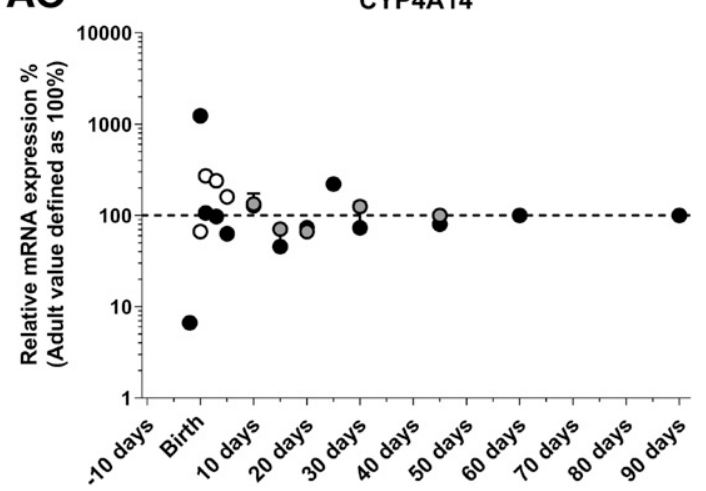

Fig. 11. Continued. 
AP

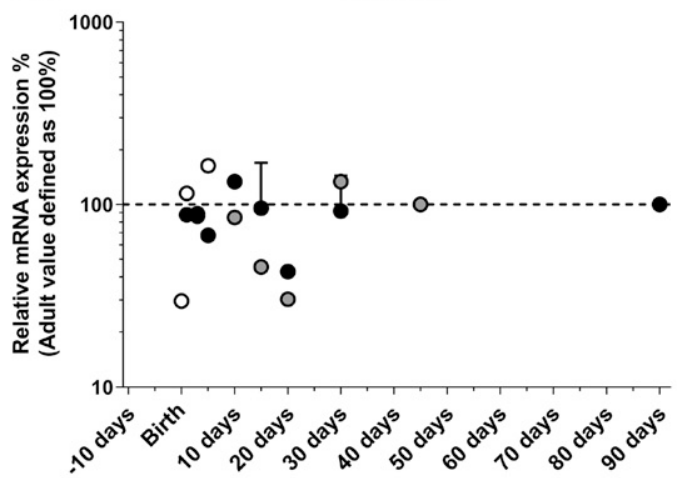

AR

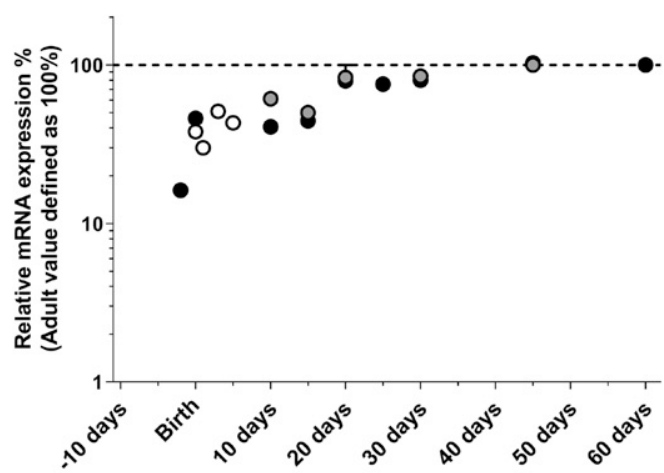

AT

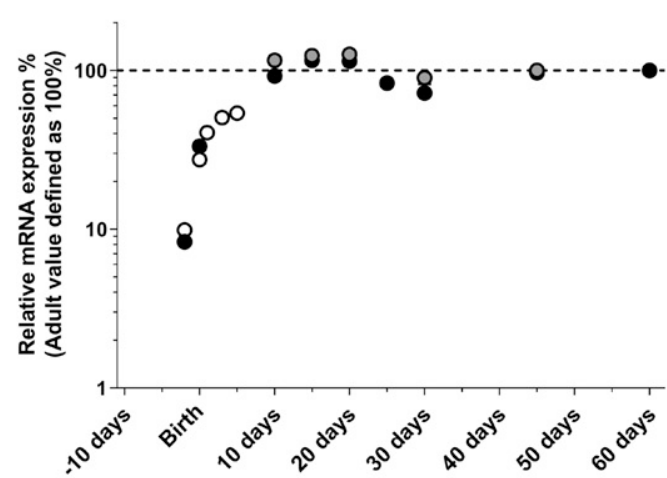

AV

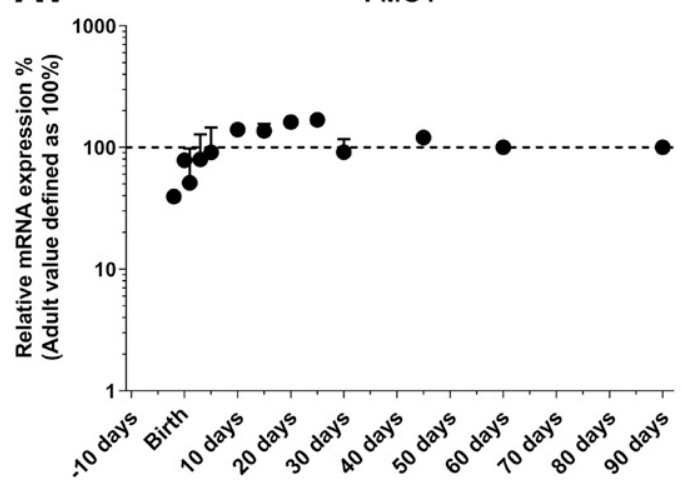

AQ

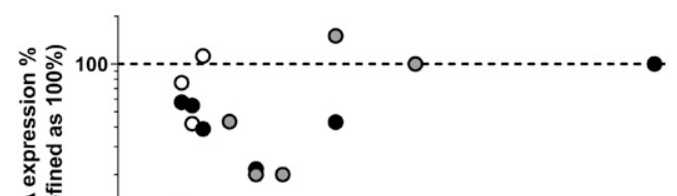

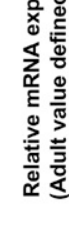

0

(1)

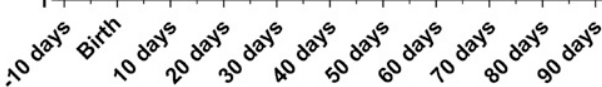

AS CYP4F14

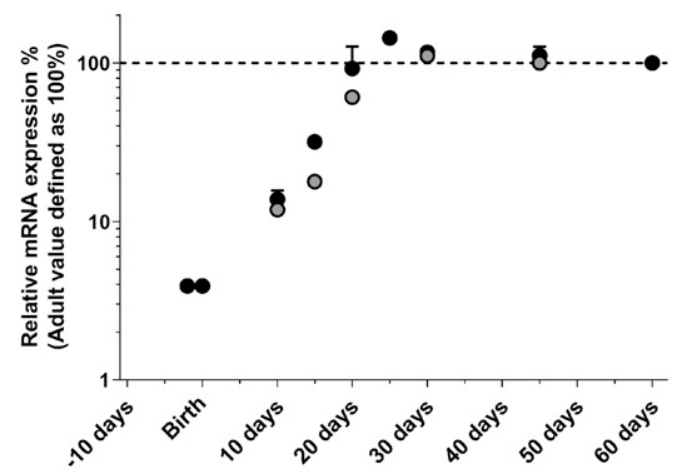

AU

CYP4F16

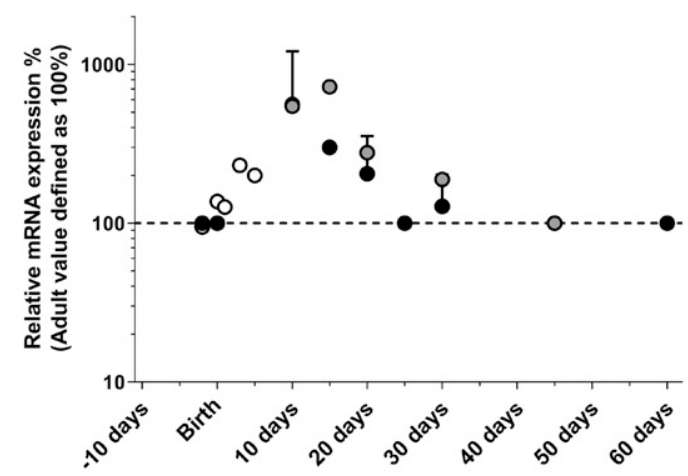

AW

FMO2

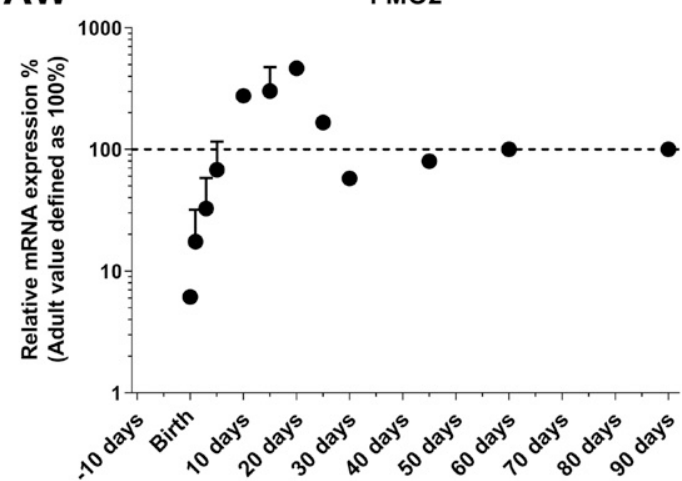

Fig. 11. Continued. 
AX
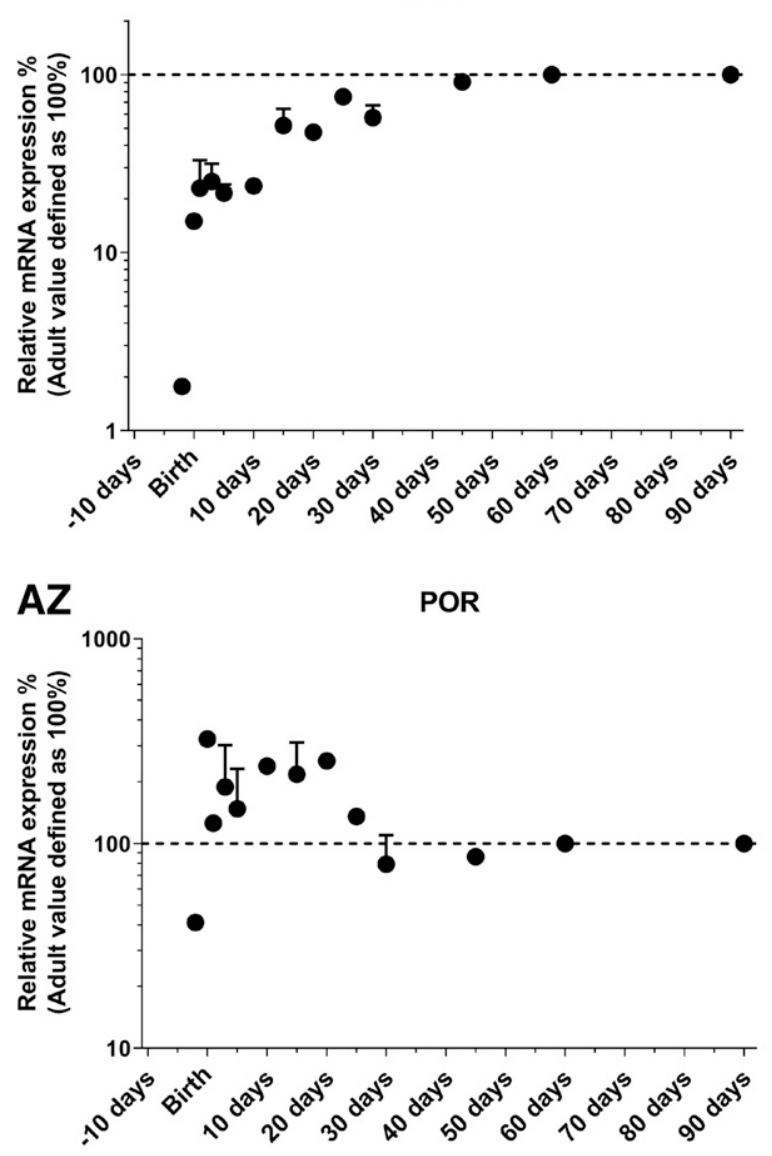

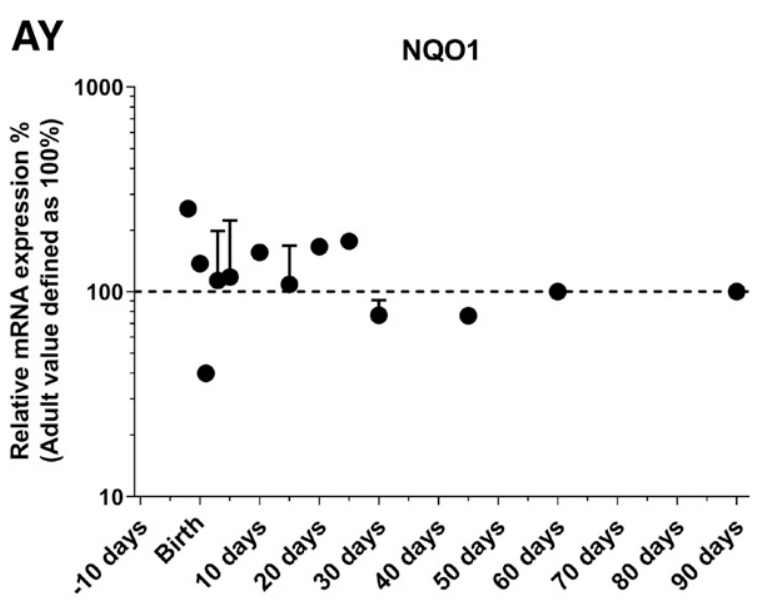

Fig. 11. Continued.

Glutathione-S-transferase, GSH peroxidase, and GSH reductase activity steadily increased from several days before birth and reached adult levels around 30 days of age, after which activity became variable. GSH reductase activity appeared to gradually decline between 60 and 800 days of age. Cytosolic GST activity comprised a conglomerate of GST activity of different classes of GST. For GSTA1, GSTM1, and GSTP1, both mRNA and protein expression levels were determined. GSTA1 and GSTP1 mRNA levels reached adult values a few days after birth and remained stable until 180 days postpartum, which was followed by a gradual increase until 800 days. GSTA1 and GSTP1 protein expression levels differed from mRNA expression levels in that they steadily increased from birth until 800 days. For GSTM1, the maturation profile of mRNA expression levels increased gradually from birth until 60 days, after which it steadily declined until reaching $30 \%$ of maximum levels. Protein expression levels followed a similar trend. GSTA4, GSTM3, GSTK1, GSTO1, GSTT1, and GSTT2 mRNA expression levels all showed a similar maturation profile with a start around birth, a steady increase until 60 days of age, and a gradual decline until 800 days. The latter decline did differ between different classes of GST. b. Complex and/or inconsistent ontogeny pattern of activity/expression levels. UGT1A5 mRNA expression was observed at birth and persisted during the first 10 days of life, after which mRNA levels decreased until 30 days and remained stable until 56 days of age.

Rat hepatic SULT1B1 activity appeared stable between 2 days and 25 days of age with a gradual decline until 25 days. At 50 days, a $2-4$-fold increase in activity was observed in liver samples from male and female rats, respectively. SULT1C1 and SULT1E1 mRNA profiles shared a similar pattern with low male and female levels at birth until 20 days of age. Subsequently, male levels increased markedly, reaching a maximum around 40 days of age. A comparable maturation profile was reported for male and female SULT-60 mRNA levels; however, the sex difference was inversed as compared with SULT1C1 and SULT1E1.

NAT1 activity was high during fetal development and gradually decreased until birth, after which it stabilized, whereas NAT1 mRNA levels increased suddenly at 15-20 days and remained stable.

c. No age-related changes in activity/expression. NAT2 (mRNA) levels were stable across all age ranges. 


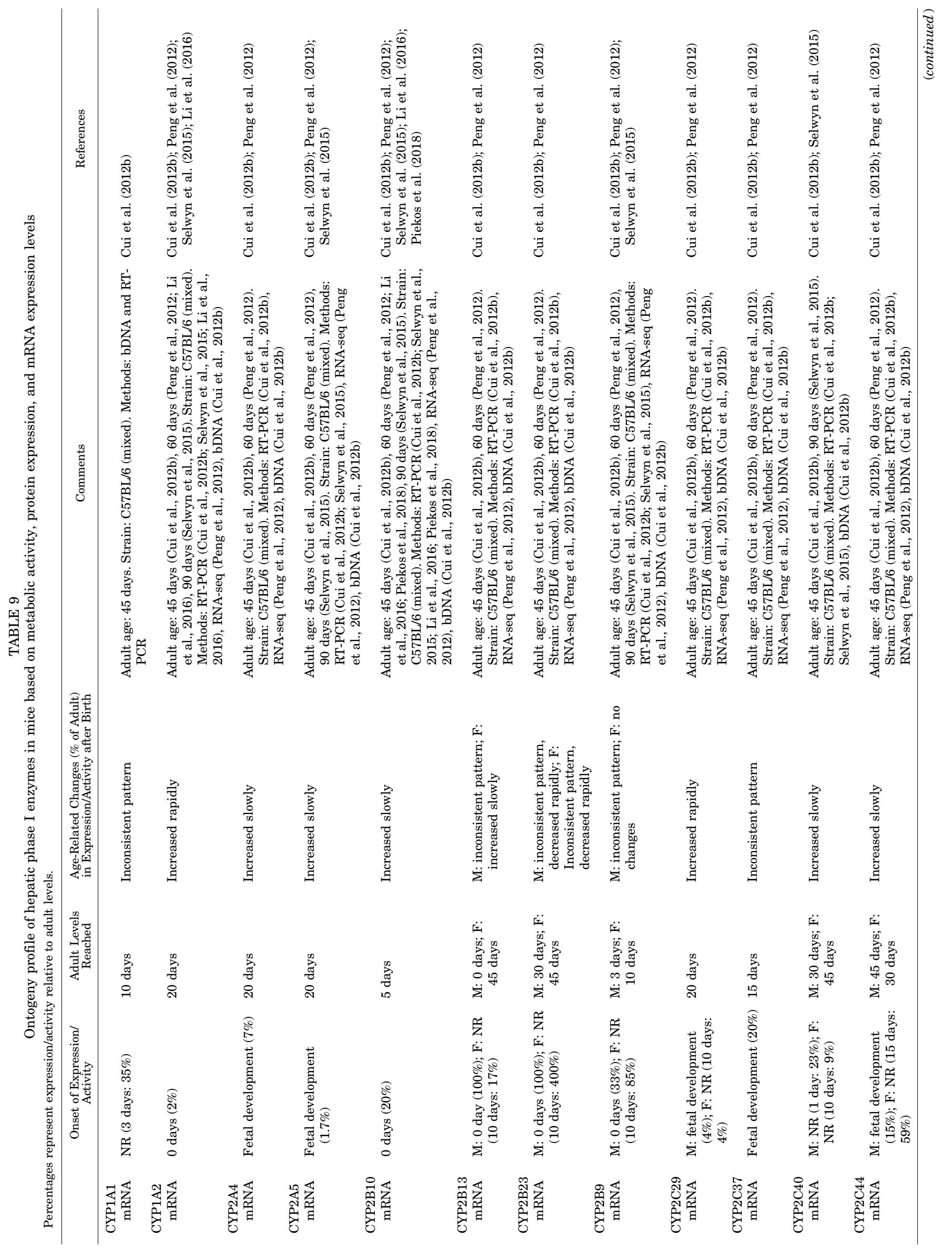




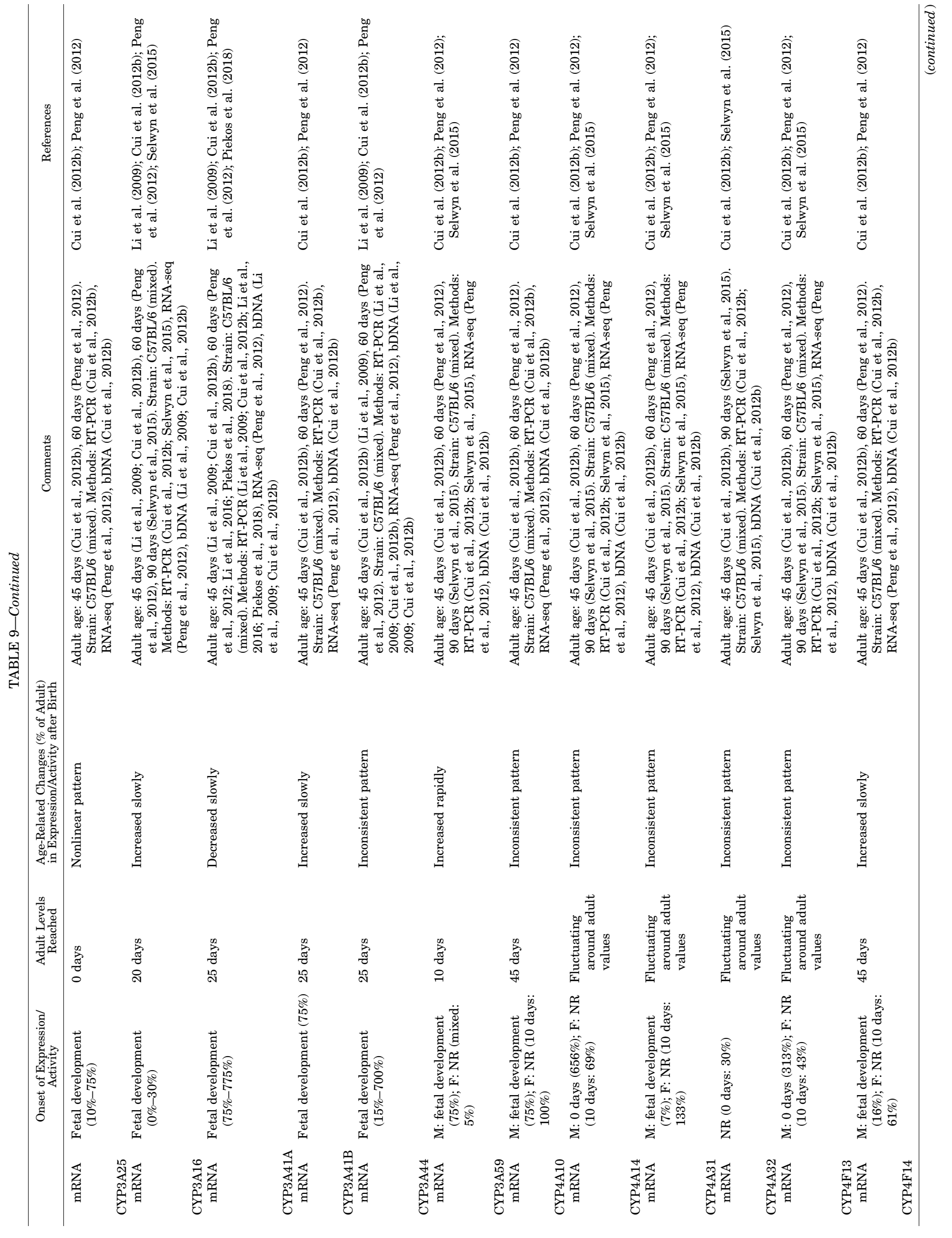




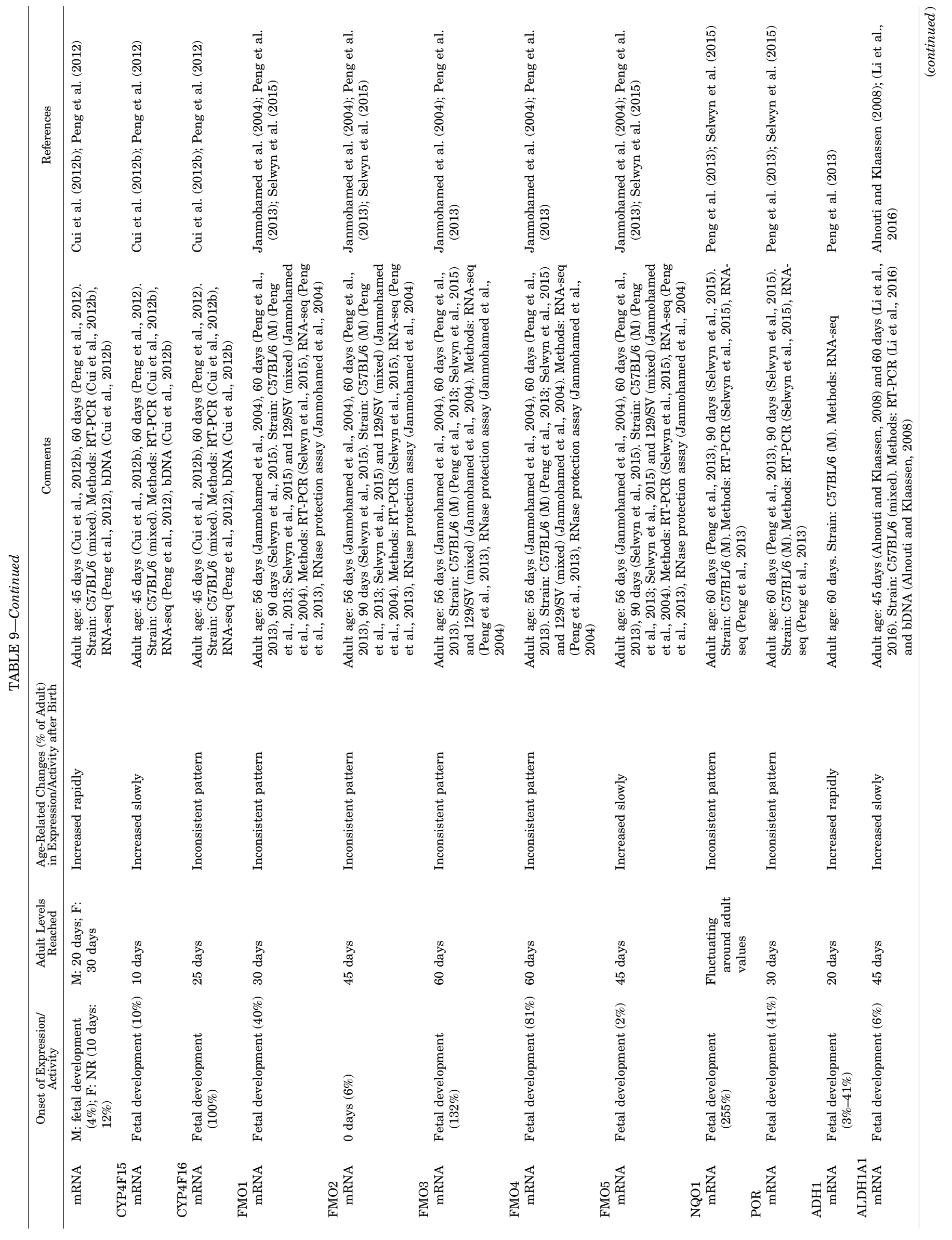


3. Mouse. The results are depicted in Fig. 18, Supplemental Fig. 21, and Table 16 and are further explained below.

a. Age-related increase in activity/expression. The majority of phase II enzymes showed a lower expression in younger age groups than in older age groups. For some enzymes, the expression increased progressively directly after birth, often reaching adult values before or at 22 days postnatal age (PNA) [CES1B, CES1C, CES1G, CES2E, CES5, GSTA3, GSTA4, GSTK1, GSTM1, GSTM2, GSTM3, GSTM4, GSTT1, GSTT3, GSTZ1, NAT1, NAT12, SULT1B1, and UGT1A1 (male)], whereas for other enzymes the expression increased more gradually, reaching adult levels after 22 days PNA [CES1A, CES1D, CES1E, CES1F, CES2A, CES3B, CES6, CES7, microsomal glutathione S-transferase (MGST1), NAT2, NAT6, SULT3A1 (female), UGT1A1 (female), and UGT3A2].

b. Age-related decrease in expression. Only a few phase II enzymes showed a consistently higher expression at younger age groups than in older age groups (GSTCD, GSTM5, MGST2, NAT5, NAT11, NAT13).

c. No age-related changes in expression. There are few phase II enzymes that show no age-related changes in expression [CES2G, GSTT2, GSTM7, and SULT3A1 (male)].

d. Complex and/or inconsistent ontogeny patterns in expression. A number of phase II enzymes showed particular patterns of age-related changes in expression. These enzymes showed low expression at fetal age, which was followed by a peak in expression generally between 5 and 30 days PNA, after which expression dropped back to adult levels (SULT1A1, SULT1C2, SULT1D1, SULT2A1, SULT2A12, SULT2A2, SULT2A3, SULT2A4, SULT2A5, SULT2A6, and UGT1A9).

A few enzymes showed peaks and troughs in expression between younger and older age groups with an overall increasing trend (CES2B, CES2C, CES2D, CESPS, CES2F, CES3A, CES4A, GSTA1, GSTA2, GSTP1, GSTP2, NAT8, SULT2A7, SULT5A1, UGT1A2, UGT1A5, UGT1A6A, UGT1A6B, UGT1A10, UGT2B1, UGT2B5, UGT2B34, UGT2B35, UGT2B36, UGT2B37, UGT2B38, UGT3A1, and UGT3A2), whereas others did so with a general decreasing trend (SULT1E1, SULT2B1, and UGT1A7C).

Some enzymes showed contradictory (i.e., study-dependent) age-related expression profiles (MGST3, SULT1C1, GSTO1, and NAT10).

4. Nonrodents. The results are depicted in Fig. 19 and Table 17. For Göttingen minipig only, general UGT activity was studied. UGT activity gradually increased as a function of age, although only three data points are reported in literature.

\section{Discussion}

\section{A. Key Findings}

- Multilevel and cross-species compilation of published ontogeny profiles of hepatic DTs and DMEs 
A

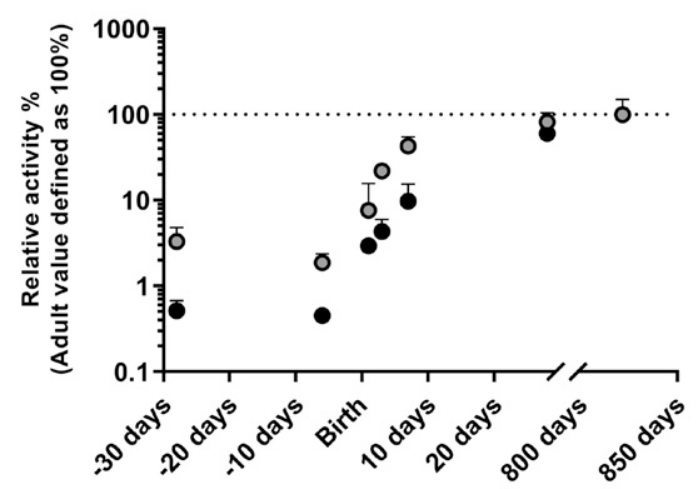

C

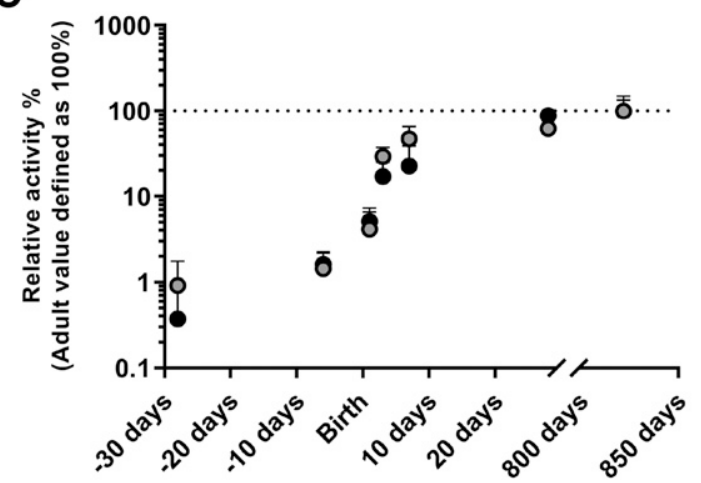

B

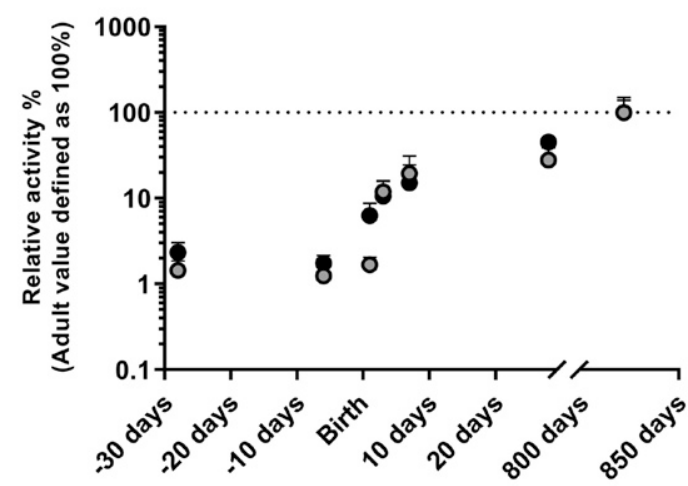

D

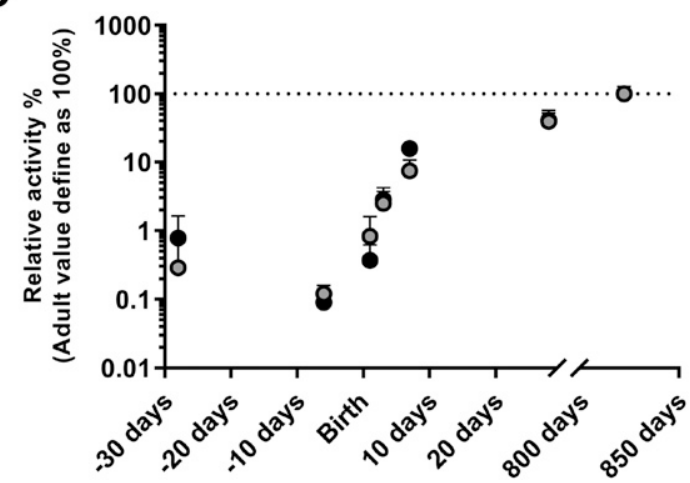

Fig. 12. Pooled literature data on the ontogeny of metabolic activity of hepatic phase I enzymes in Göttingen minipig: CYP1A2 (A), CYP2C9 (B), CYP2D6 (C), and CYP3A4 (D). The symbols represent the relative activity in each age group, and the dotted line indicates the adult value defined as $100 \%$. If multiple values were obtained for the same age group, the symbols represent the average relative activity, and the error bars show the S.D. See Table 10 for explanation on the ontogeny profiles and literature references.

was used to obtain a quantitative understanding of the developmental biology of drug metabolism and transport.

- Most DTs and DMEs undergo substantial maturation after birth, typically showing developmental patterns with either significant increase or decrease in expression or activity levels with progressing age.

- The limitations associated with interpretation and application of ontogeny profiles across multiple studies should be acknowledged: technical, methodological, and analytical sources of variability confound accurate registration of interindividual variability in activity or expression levels. Examples of study-specific sources of variability include postmortem versus surgical biopsies, lack of subject demographic information, Western blotting versus LC-MS/MS-based proteomic quantitative methods, and different units of normalization or expression.

- Substantial knowledge gaps regarding the ontogeny of hepatic DTs/DMEs remain to be addressed. A notable example is the clear lack of information regarding ontogeny of DTs and DMEs in monkeys despite their frequent use in ontogeny-related studies. Also, no sex- or ethnicity-related differences in ontogeny profile of human hepatic DTs and DMEs could be identified based on the currently available data.

\section{B. Discussion}

The overarching goal of this review was to compile multilevel (i.e., at mRNA expression, protein expression, and activity levels) ontogeny profiles of hepatic DTs and DMEs in humans and in nonclinical species. For many isoforms, data from multiple studies were combined, thus frequently yielding high-resolution ontogeny profiles sometimes at the protein activity level as well as the mRNA/protein expression levels. Subsequent interpretation of these profiles allowed obtaining more complete quantitative insight into the developmental changes in expression and activity levels of these pivotal hepatic DTs and DMEs.

Various developmental patterns emerged, which were classified as follows: 1) age-associated increase in activity/expression; 2) age-associated decrease in activity/expression; 3) no obvious associations of age with activity/expression; and 4) complex and/or inconsistent ontogeny profile(s). For those that showed an agerelated change in activity/expression, developmental patterns were particularly isoform-dependent and 


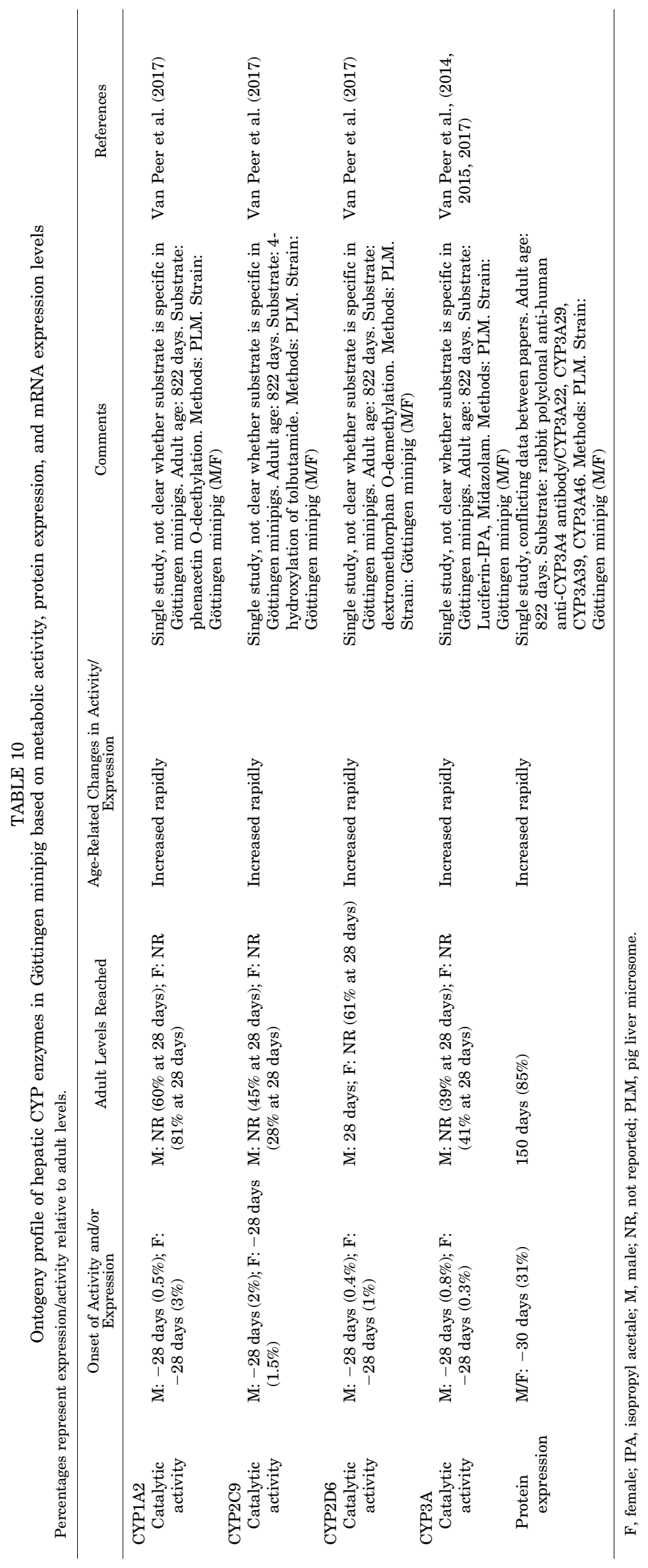


A

CYP1A1

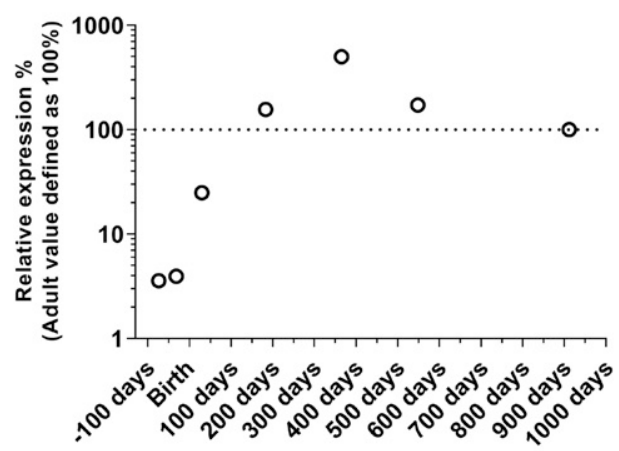

C

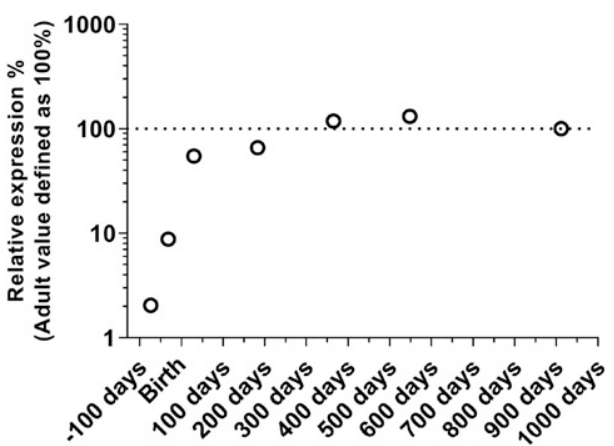

E

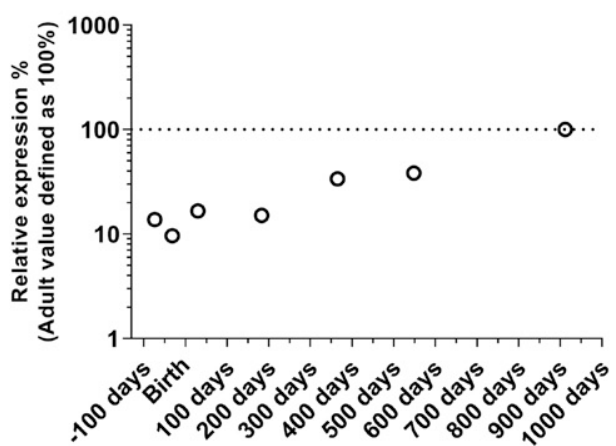

G

CYP2C9

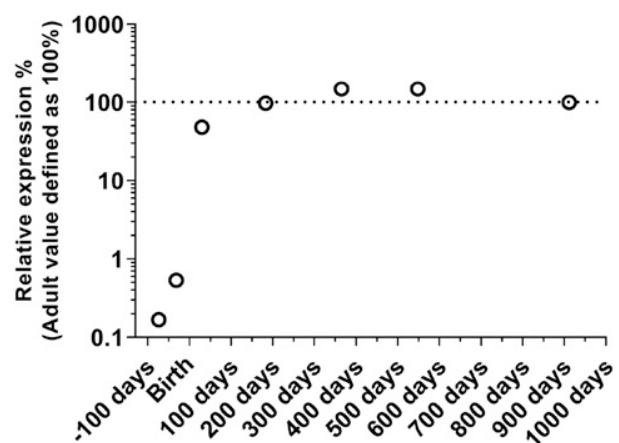

B

CYP2A23

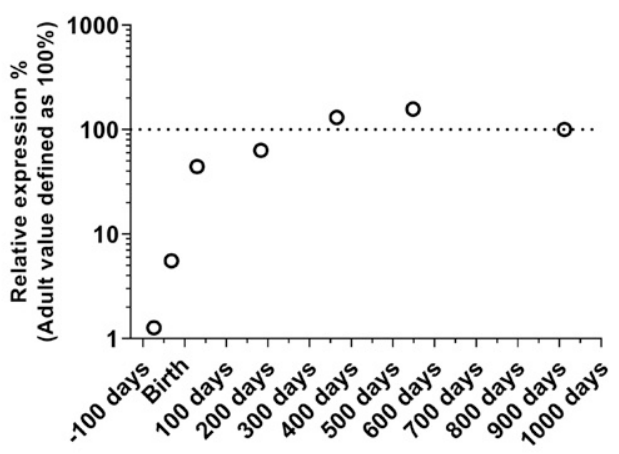

D

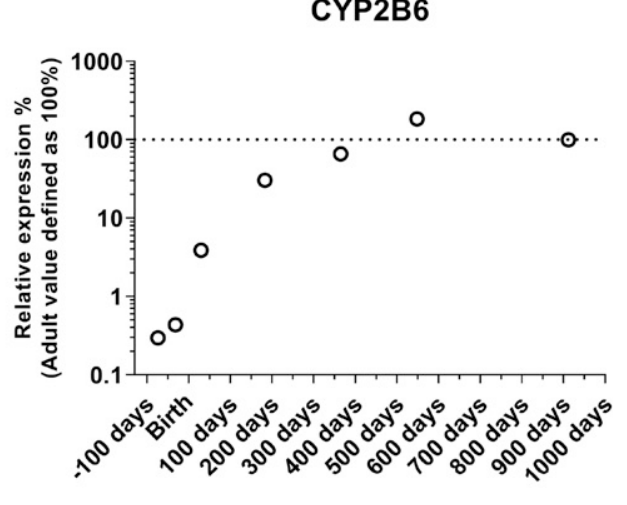

F

CYP2C8

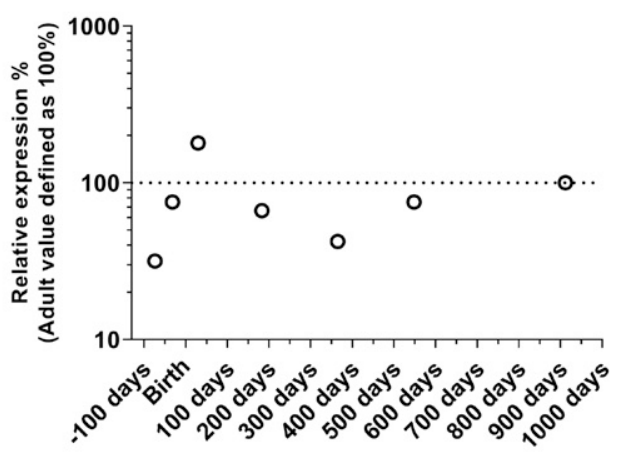

H

CYP2C19

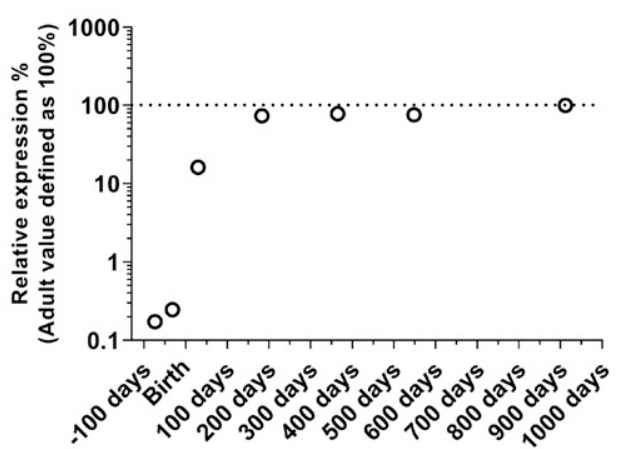

Fig. 13. Pooled literature data on the ontogeny of hepatic mRNA expression of hepatic phase I enzymes in cynomolgus monkey: CYP1A1 (A), CYP2A23 (B), CYP2A24 (C), CYP2B6 (D), CYP2C18 (E), CYP2C8 (F), CYP2C9 (G), CYP2C19 (H), CYP2C76 (I), CYP2D17 (J), CYP2E1 (K), CYP2J2 (L), CYP3A4 (M), CYP3A5 (N), CYP3A43 (O), CYP4A11 (P), CYP4F3 (Q), CYP4F11 (R), CYP4F12 (S), and CYP4F2 (T). The symbols represent the relative mRNA expression in each age group, and the dotted line indicates the adult value defined as $100 \%$. See Table 11 for explanation on the ontogeny profiles and literature references. 
644

van Groen et al.

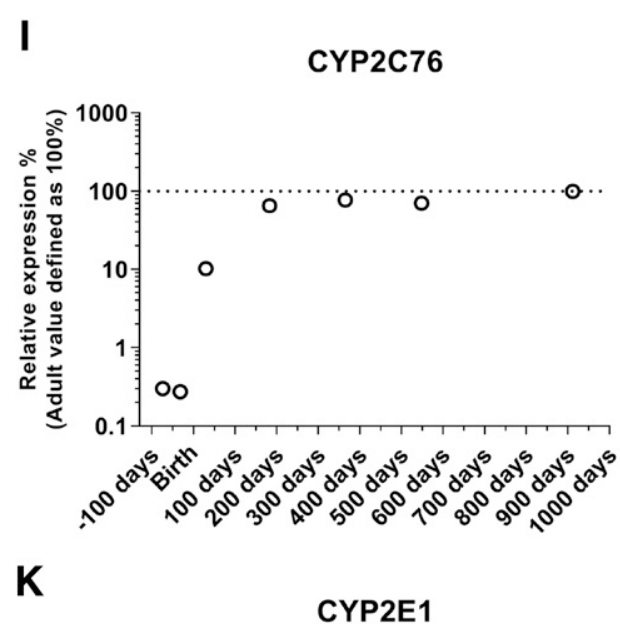

CYP2E1

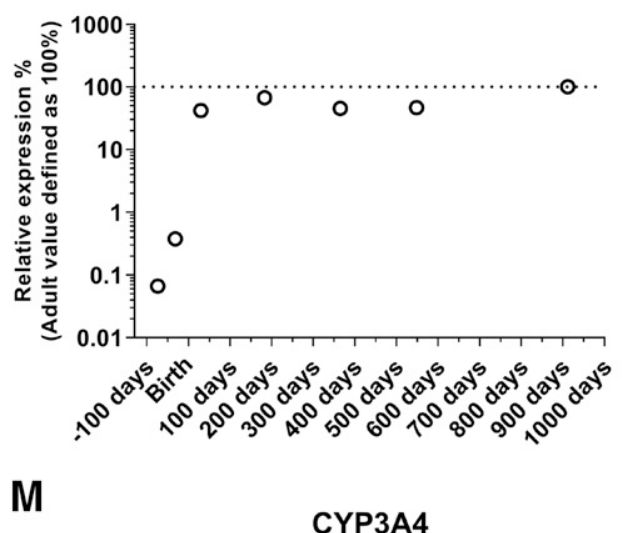

CYP3A4

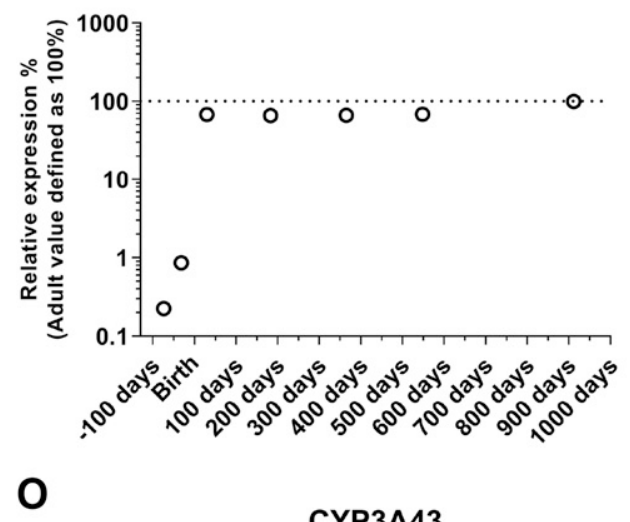

CYP3A43

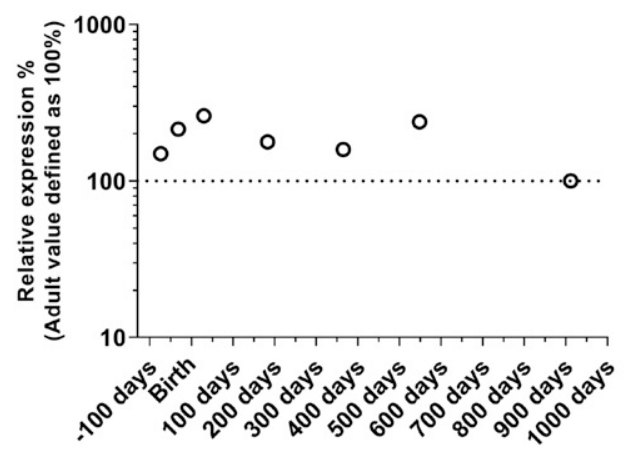

J

CYP2D17

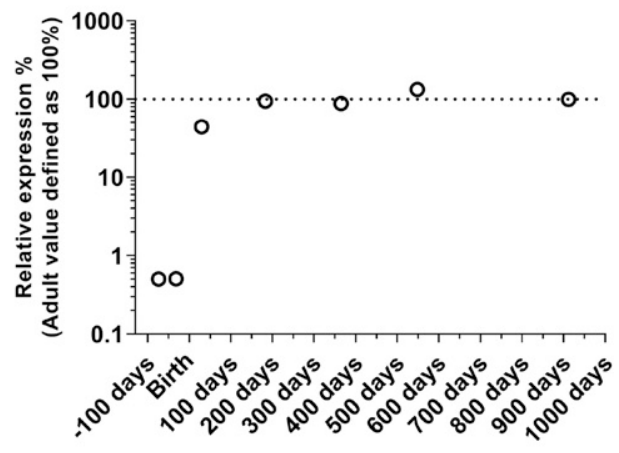

L

CYP2J2
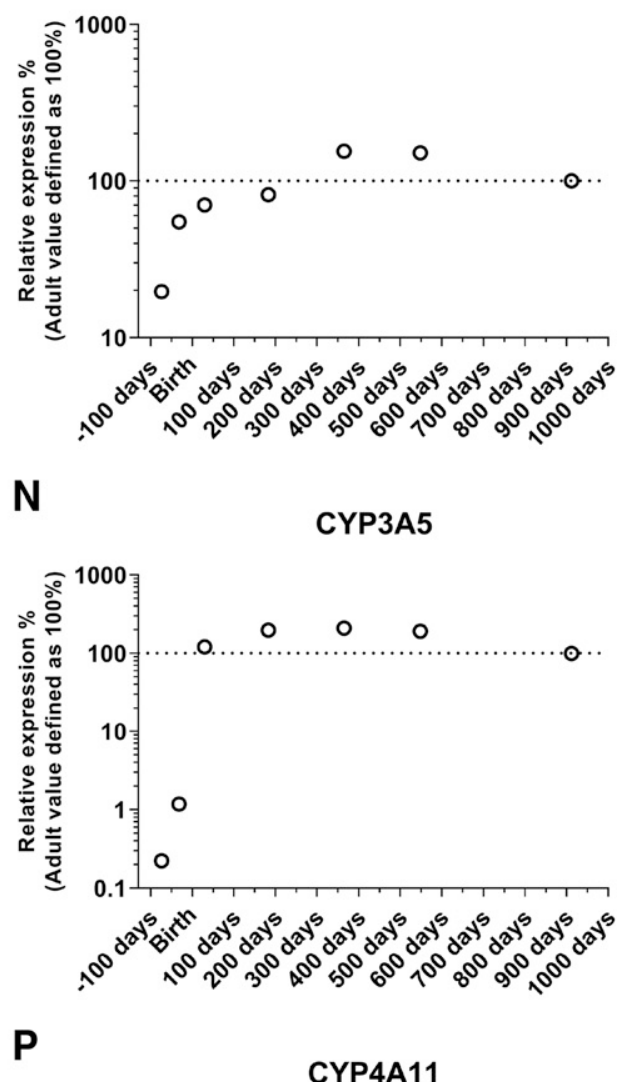

CYP4A11

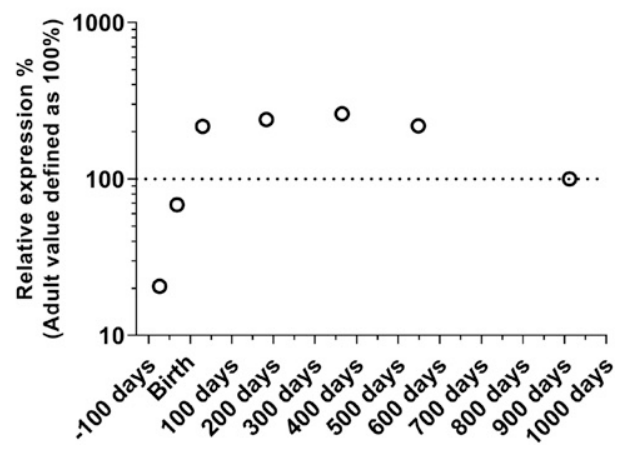

Fig. 13. Continued.

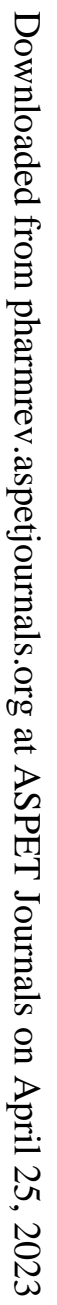


Q

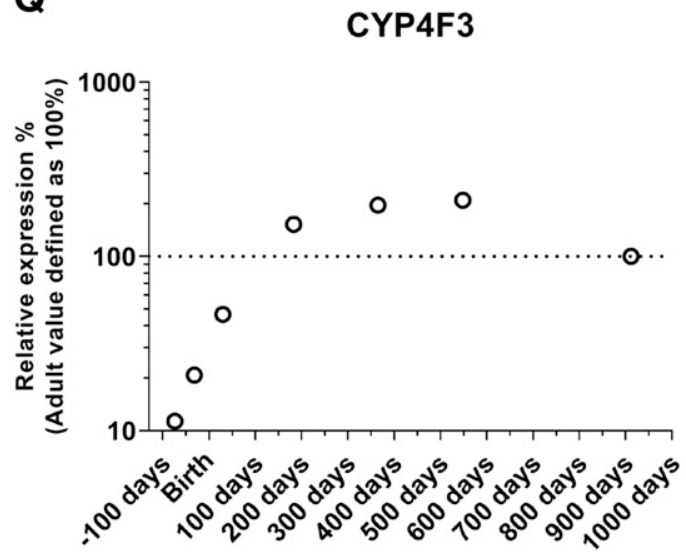

S

CYP4F12

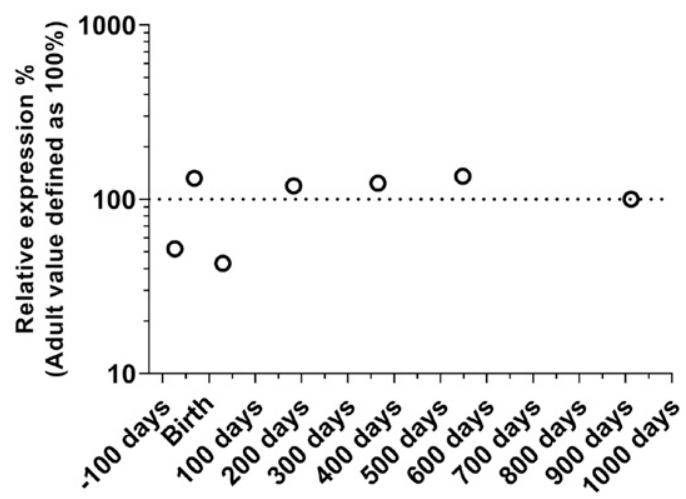

$\mathbf{R}$

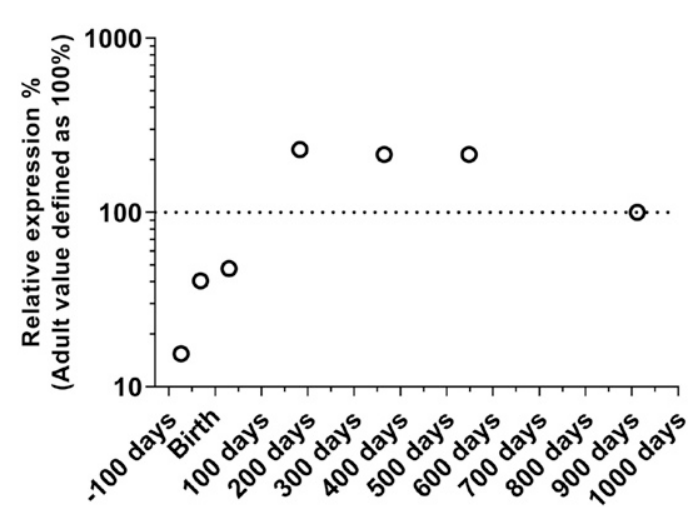

T

CYP4F2

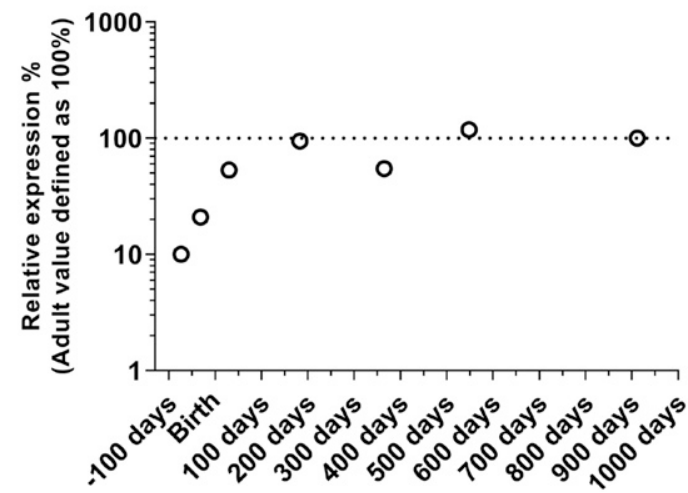

Fig. 13. Continued.

emerged at various rates. This resulted in identification of DTs and DMEs that reached adult levels shortly after birth [e.g., mRNA expression of MRP6 in mice (Table 6) or CYP27 in rats (Table 8) both increased rapidly], whereas others showed a more gradual increase/decrease [e.g., mRNA expression of CYP2A5 in mice increased slowly from fetal age until adult values were reached at 20 days of age (Table 9 )].

Despite the increase in literature data, important knowledge gaps were identified while compiling these ontogeny data. One of the reasons is the scarcity of pediatric liver tissue, especially neonates (Brouwer et al., 2015). Human protein expression data remain limited for CYP2A6, CYP2C8, CYP2C9, CYP2C19, GSTP1, and SULT1A1, as data on older age groups were missing. The same holds true for mRNA expression of CYP3A7 and SULT2A1. In mice and cynomolgus monkey, all ontogeny profiles on CYP enzymes were derived from mRNA data only, and several CYP enzymes lack activity data in all other nonclinical species. In mice, most ontogeny profiles of phase II enzymes were derived from mRNA expression, whereas no phase II ontogeny data were available in nonrodent species. Finally, the mechanisms underlying the ontogeny of DTs and DMEs are largely unknown. A potential mechanism is that nuclear transcription factor activity/ expression involved in the expression of DTs and DMEs is also subject to age-related changes. For example, the mRNA expression of the nuclear transcription factor pregnane $\mathrm{X}$ receptor (PXR) was correlated with age in human livers (0-25 yr of age) (Neumann et al., 2016). In mouse livers the induction potential using substrates for aryl hydrocarbon receptor, PXR, and constitutive androstane receptor was age-specific ( $\mathrm{Li}$ et al., 2016). The same was seen in rat livers for aryl hydrocarbon receptor, PXR, and constitutive androstane receptor mRNA expression (Xu et al., 2019). However, how these findings relate to DT and DME ontogeny should be further studied. The same considerations can be made for cofactors involved in metabolism, such as uridine diphosphate glucuronic acid, which supports compound glucuronidation. However, to the best of our knowledge, no literature is available on age-related changes in these cofactors levels.

Interestingly, in the case of DTs, data on mRNA expression were more limited than data on protein expression, whereas for DMEs, this was the other way around. A potential explanation is that the impact of DTs on drug disposition was recognized later than that of DMEs. In the earlier days, information on DMEs 


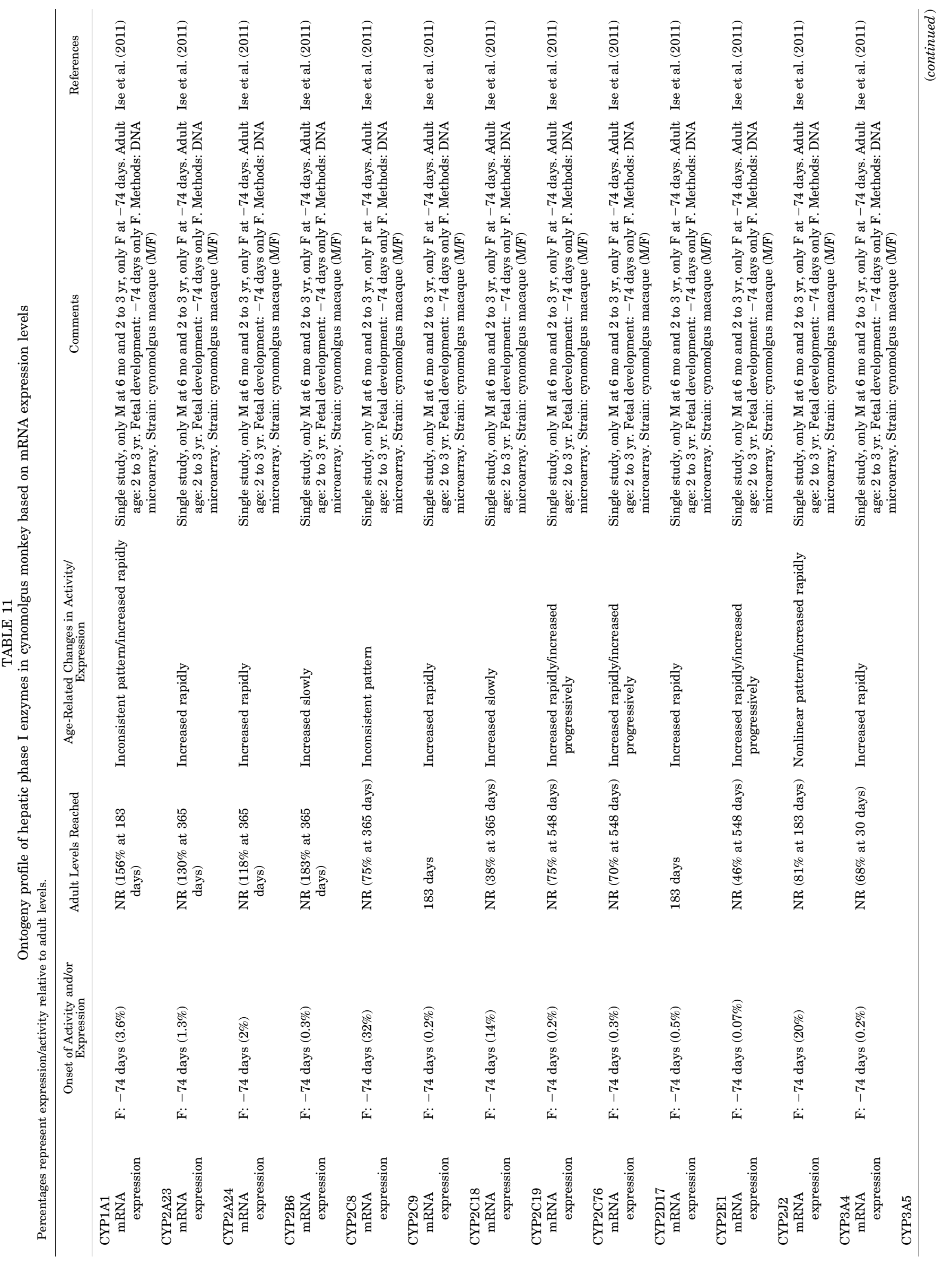



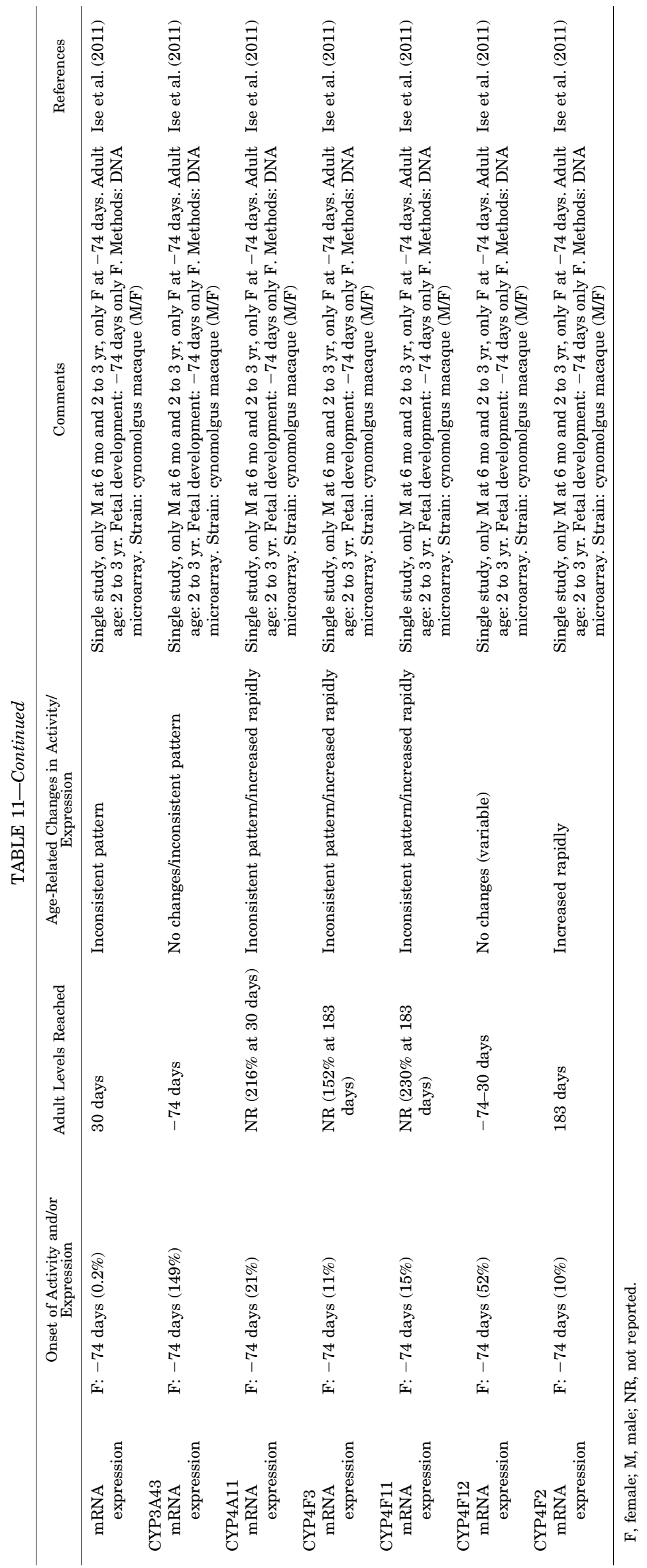
A

CYP1A1

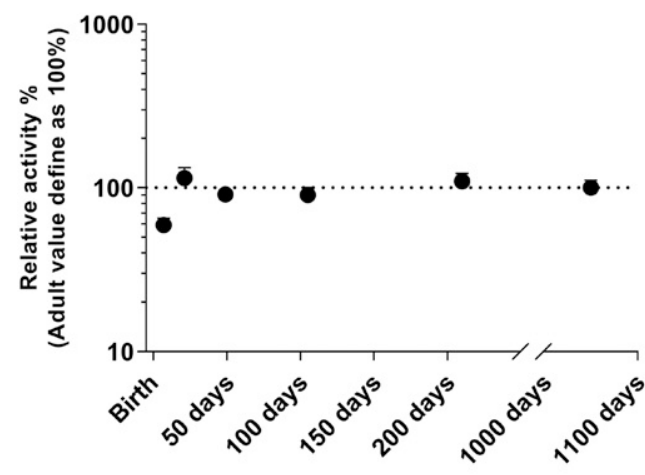

C

CYP2C9

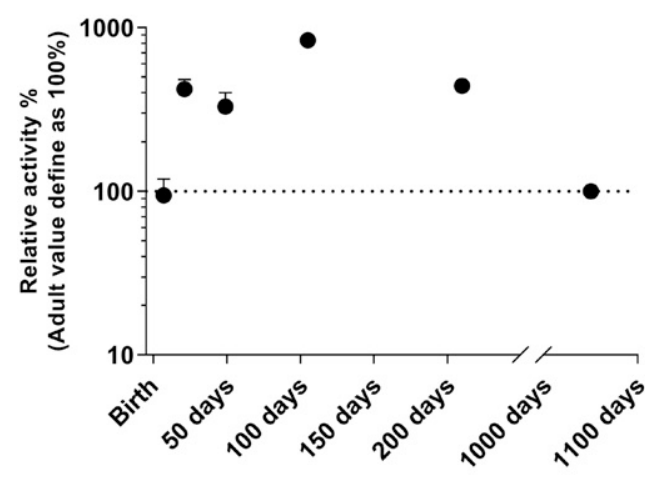

E

CYP2E1

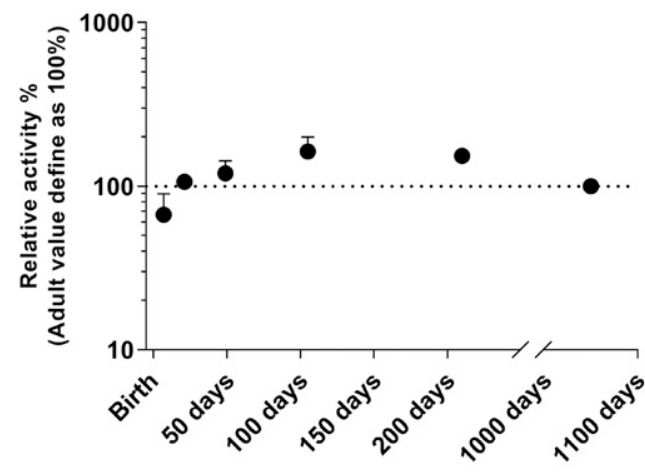

G

CYP3A4/5

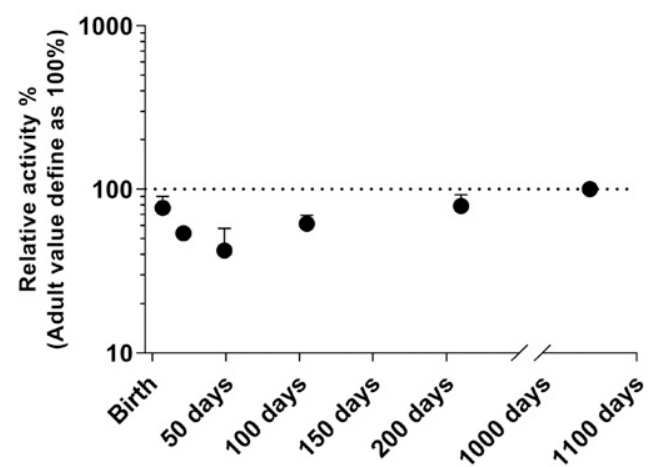

B

CYP1A2

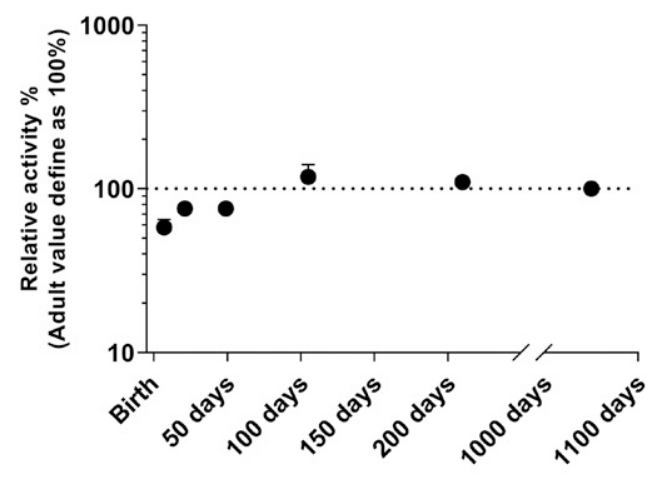

D

CYP 2C/ 2E1 / 3A

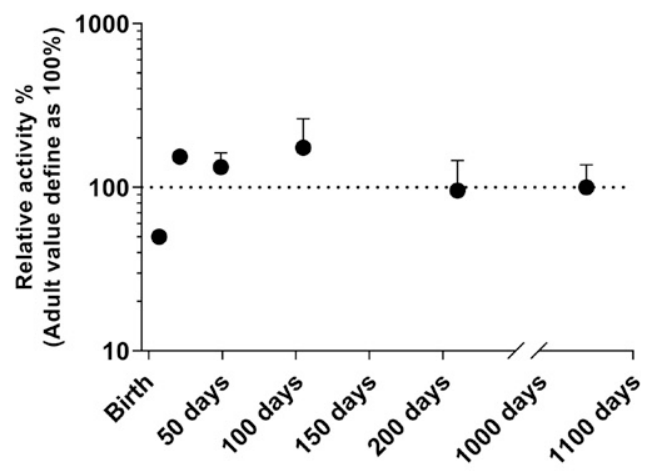

F

CYP 3A / 2B

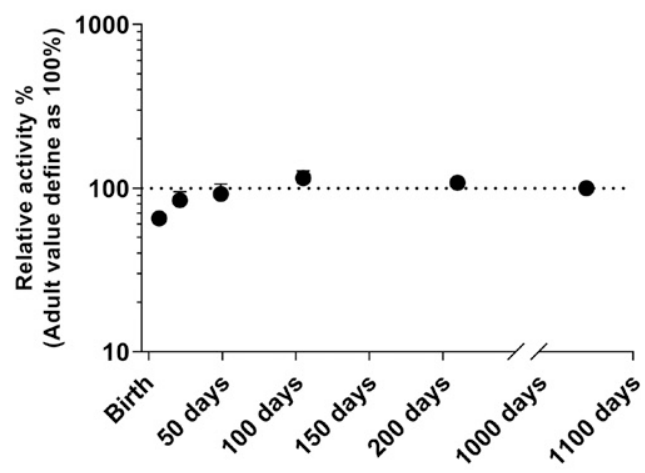

H

P450 Content

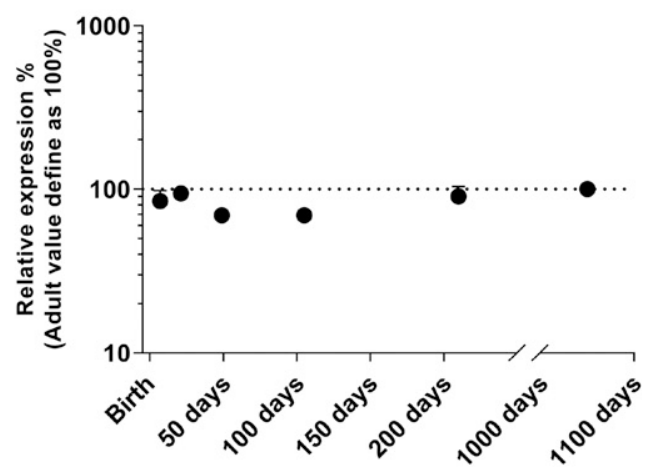

Fig. 14. Pooled literature data on the ontogeny of hepatic metabolic activity of phase I enzymes in Beagle dogs: CYP1A1 (A), CYP1A2 (B), CYP2C9 (C), CYP2C/2E1/3A (D), CYP2E1 (E), CYP3A/2B (F), CYP3A4/5 (G), and P450 content (H). The symbols represent the relative activity in each age group, and the dotted line indicates the adult value defined as $100 \%$. If multiple values were obtained for the same age group, the symbols represent the average relative activity, and the error bars show the S.D. See Table 12 for explanation on the ontogeny profiles and literature references. P450, cytochrome P450. 


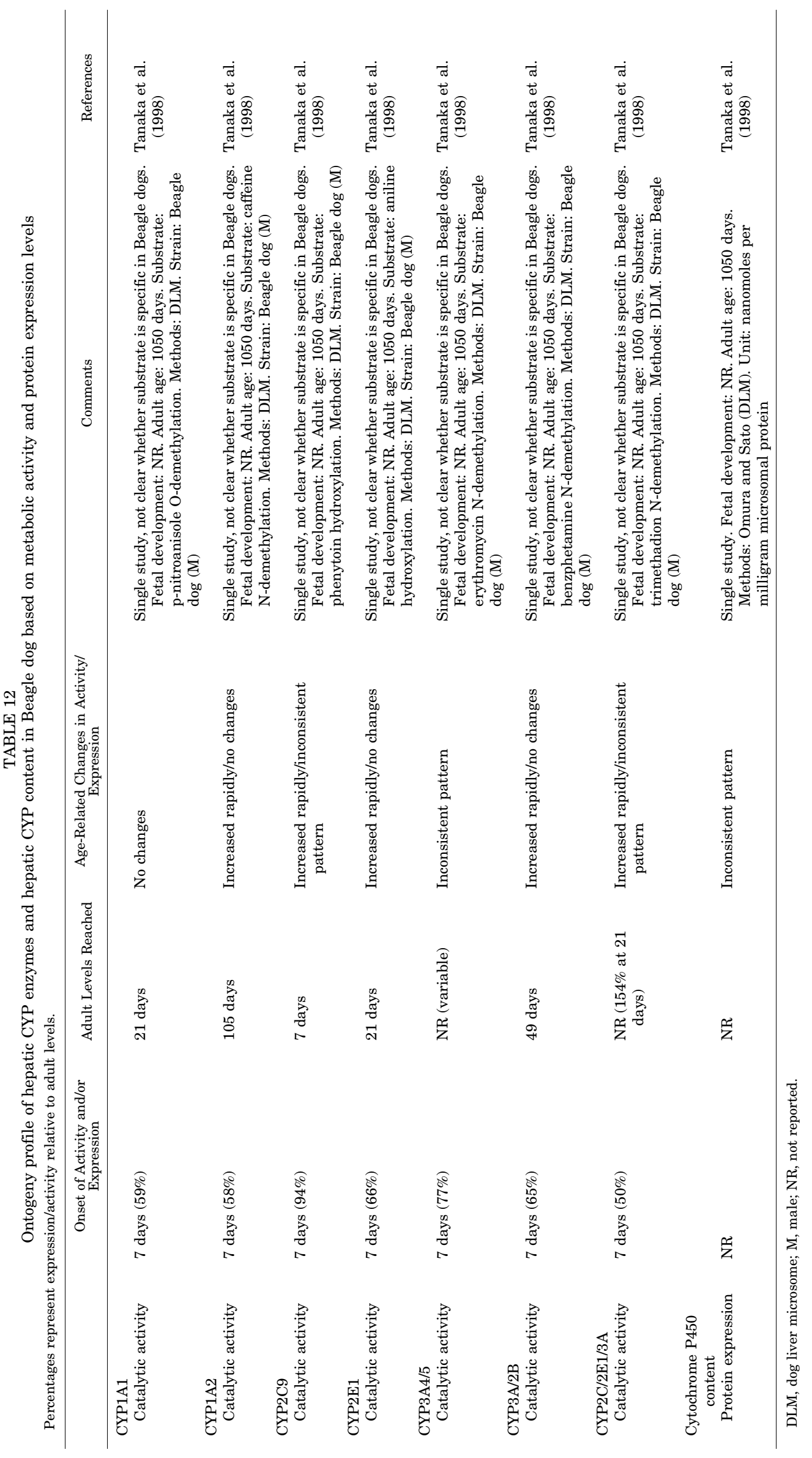


A

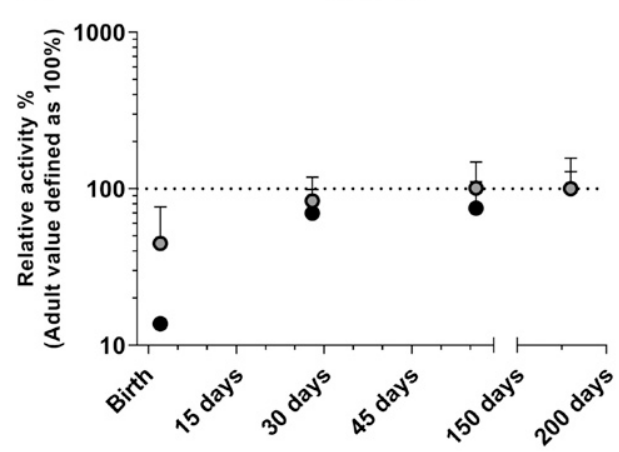

C

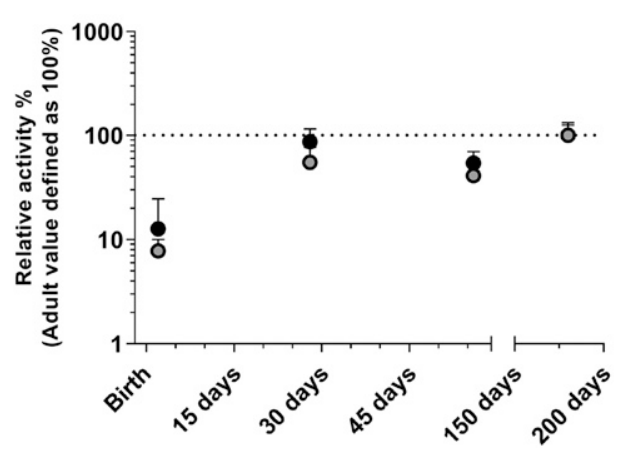

B

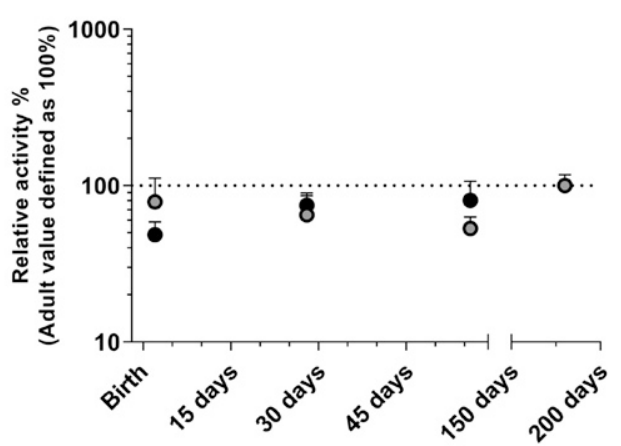

Fig. 15. Pooled literature data on the ontogeny of hepatic metabolic activity of phase I enzymes in the domestic pig: CYP2C (A), CYP2E (B), and CYP3A (C). The symbols represent the relative activity in each age group and the dotted line indicates the adult value defined as $100 \%$. If multiple values were obtained for the same age group, the symbols represent the average relative activity and the error bars show the S.D. See Table 13 for explanation on the ontogeny profiles and literature references.

mostly came from mRNA expression data because analytical methods for protein quantification became more advanced just recently. There is still a major lack of knowledge on transporter ontogeny in all species. At the activity level, few studies were published on agedependent activity of OATP, OCT1, and NTCP in suspended rat hepatocytes. This represents a critical gap because gene expression or protein abundance rarely correlates well with transporter activity. Hence, activity data are essential to accurately predict the impact of age-related changes on drug disposition (Brouwer et al., 2015). For several DMEs, validated in vivo markers are available, as exemplified by the drug midazolam that is often used for CYP3A activity (de Wildt et al., 2009) or dextromethorphan for CYP2D6 activity (Leeder et al., 2008). However, transporter substrates most often rely on multiple DTs; hence validated markers are lacking, which makes it challenging to fill this knowledge gap. Furthermore, the lack of data on hepatic DTs in nonclinical species precludes straightforward translation of in vivo data animal with a transporter substrate from nonclinical species to humans. Still, DTs and DMEs in animals that are orthologs of human isoforms do not always recognize the same substrates. This adds another layer of complexity to translating nonclinical animal data to humans.
Filling the knowledge gaps on ontogeny of human DT and DME activity remains challenging. Even if biologic material were available to perform in vitro experiments, the in vitro-to-in vivo extrapolation would not be straightforward. The isolation process of cells or enzymes from biologic material is known to impact enzyme and transporter activity. Even the isolation efficiency of enzymes from donor material from different age groups can be subject to age (unpublished observation). The importance of age-specific scaling is also reflected by the reported age dependency of hepatocellularity (i.e., the number of hepatocytes per gram liver in rat liver). Standard (i.e., age-independent) scaling factors to extrapolate catalytic activity from in vitro to in vivo could therefore introduce bias to the data and skew predictions of in vivo drug disposition. More studies should attempt to translate in vitro observations to the clinical setting to better understand how these ontogeny profiles, which are often determined in vitro, can aid in clinical dose predictions. In this context, it also needs to be emphasized that reliable prediction and understanding of the effect of age on the disposition of a given drug require consideration and integration of combined influences of ontogeny of all enzymes/transporters mediating the disposition of said drug. Consistently, developmental patterns based on in vitro activity measurements should also be validated 
Ontogeny of Hepatic Transport and Drug Metabolism

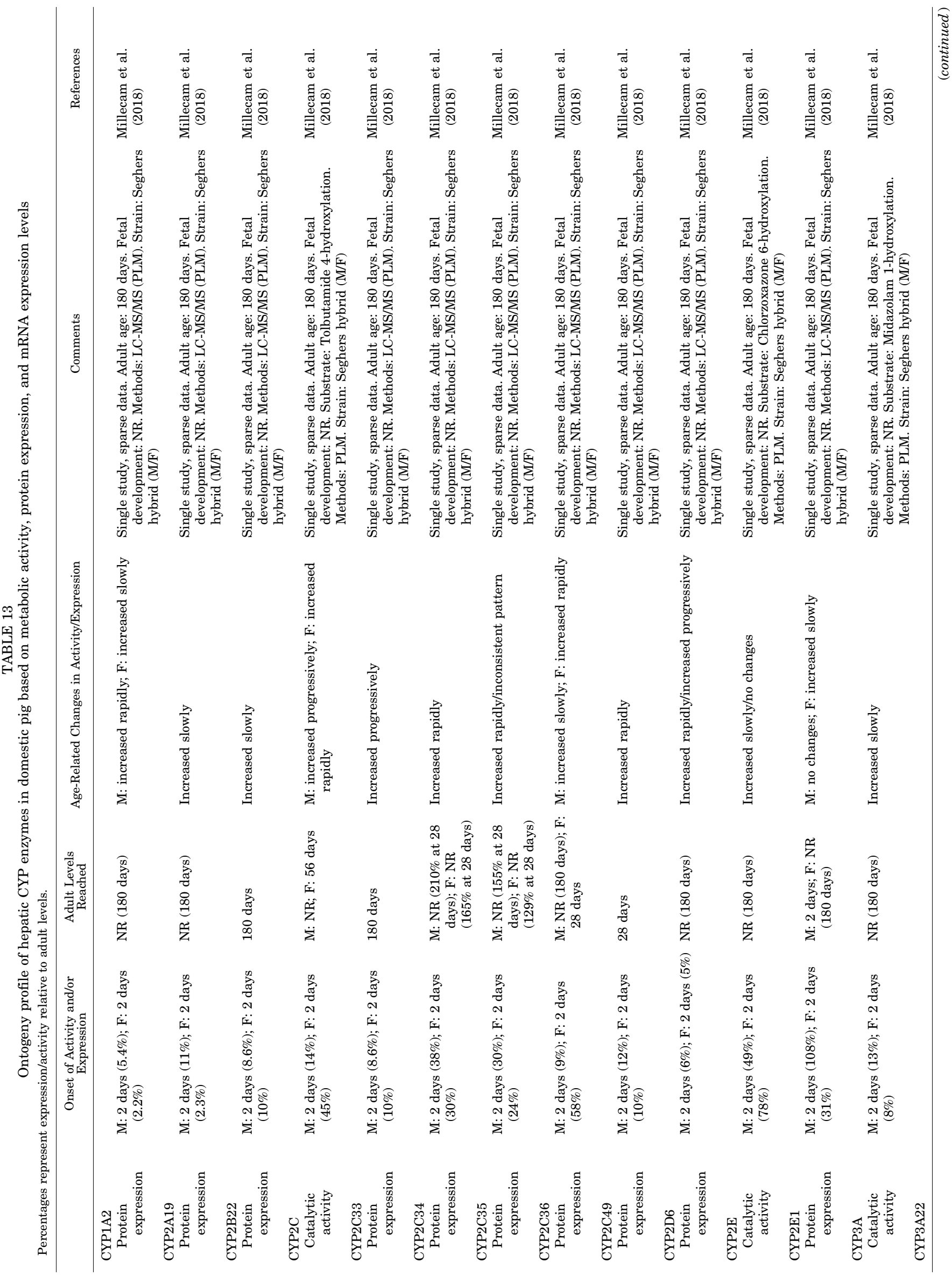

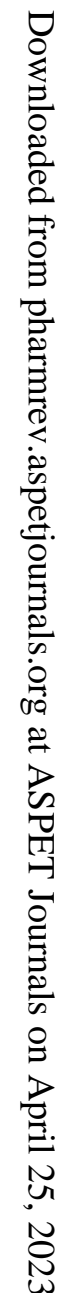


because, for example, the isolation process of cells or subcellular fractions from biologic material could impact protein activity. Moreover, since substrates differ in their affinity for DT and/or DME isoforms, the results from one substrate may not be translated directly to another drug substrate. Understanding the disposition kinetics of the substrate itself is therefore a crucial step in the interpretation of age-dependent activities. Exemplar of this is the interplay between different individual DTs and/or, subsequently, with DMEs, which hampers reliable deconvolution and extraction of individual DT and DME ontogeny profiles from population PK data (Nigam, 2015). However, PBPK models allow incorporation of multiple ontogeny profiles and can be used for hypothesis-driven exploration and ultimately verification of developmental patterns against pediatric PK data (Emoto et al., 2018; Zhou et al., 2018; Cheung et al., 2019). Also, PBPK models are increasingly used for pediatric dose finding-for example, for oseltamivir for pediatric clinical trials (Parrott et al., 2011).

Currently, an opportunity lies in the fact that endogenous substrates/metabolites have been identified as potential markers to phenotype the activity of DTs and DMEs in vivo. Examples include the use of the urinary 6- $\beta$-hydroxycortisol/cortisol ratio for CYP3A activity, thiamine for OCT1 activity, and dehydroepiandrosterone sulfate (DHEAS) for OATP1B1/3 activity (Muller et al., 2018). Recently, testosterone glucuronide normalized by andosterone glucuronide was shown to be promising as a urinary biomarker to phenotype UGT2B17 activity in children 7-18 years (Zhang et al., 2020). Using endogenous substrates to phenotype DTs and DMEs does not require administration of an exogenous probe, thereby overcoming one of the challenges in pediatric research. However, pediatric homeostatic levels may differ from those in adults, and reference values of endogenous substrate levels in children are lacking. For example, DHEAS levels at birth are high and decrease drastically over the first month of life, which is then followed by a more progressive decrease until reaching 6 months of age (de Peretti and Forest, 1978). Hence, specific reference values for these endogenous substrates/metabolites in various age groups should be obtained in the near future.

Our data compilation effort also revealed notable inconsistencies between results obtained in different studies on the same protein isoforms. Clearly, understanding differential contributions of technical, methodological, analytical, and interindividual variability in activity or expression levels remains challenging. First, several studies that were included in this review used human pediatric liver tissue-mostly postmortem tissue-obtained from biobanks. Not all biobanks collect data on the primary diagnosis, age, and sex. Moreover, it is challenging to determine the severity of disease, comedication, ethnicity, feeding status, smoking, drug 
A

сомт

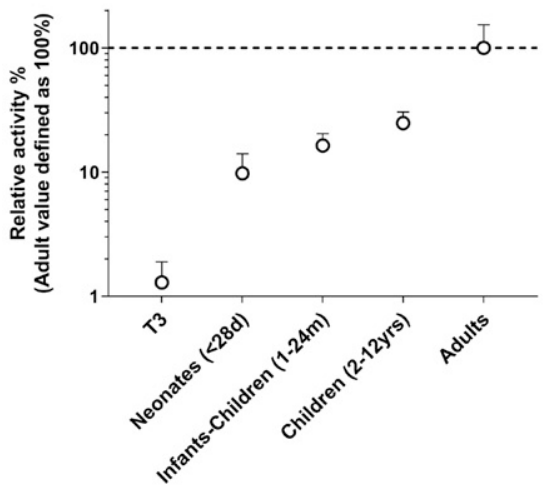

C

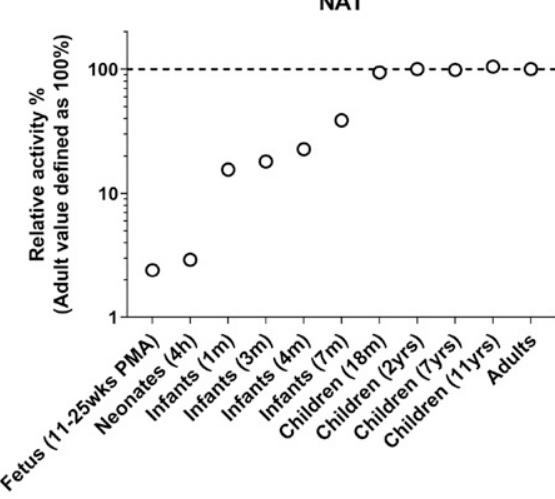

E

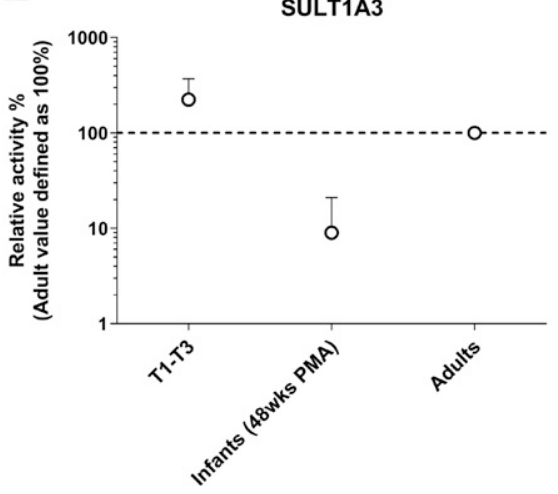

G

TMPT

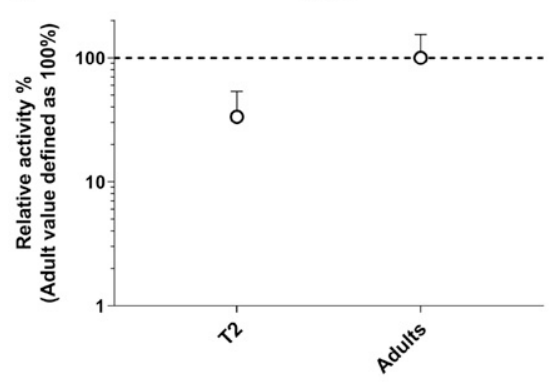

B

GSTZ1

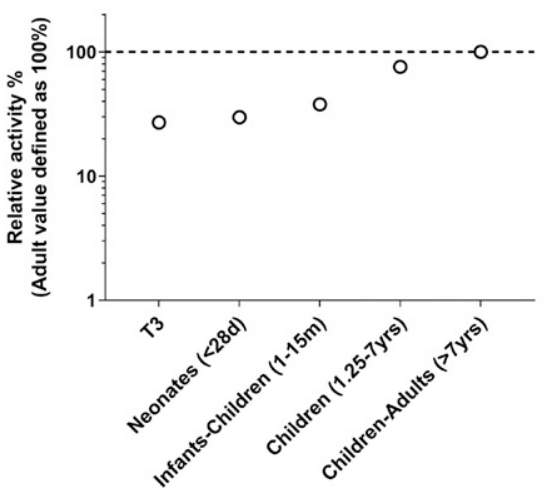

D

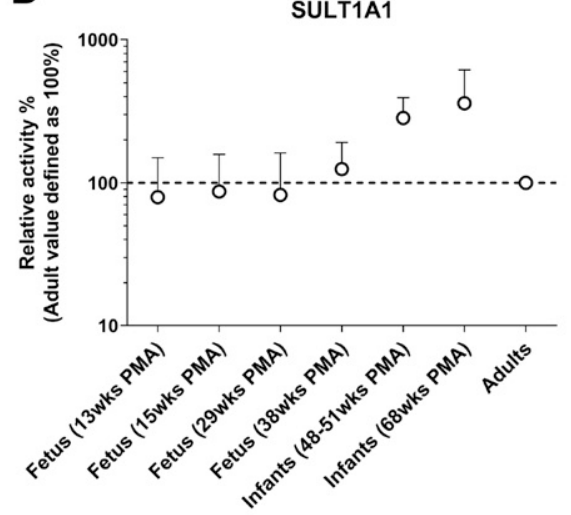

F

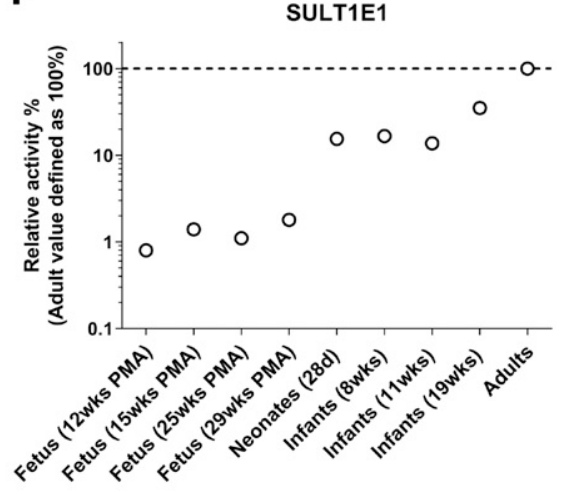

H

UGT1A1

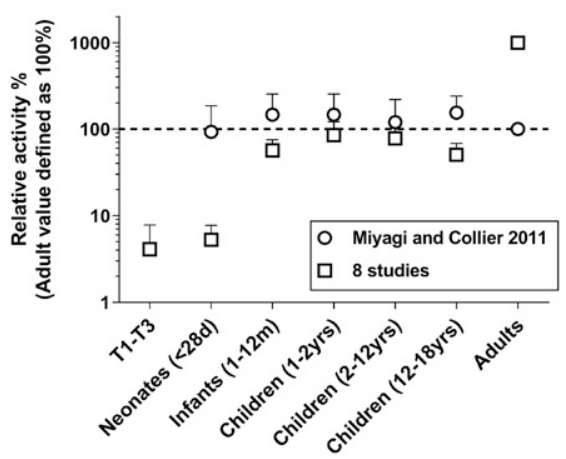

Fig. 16. Pooled literature data on the ontogeny of metabolic activity of hepatic phase II enzymes in humans: COMT (A), GSTZ1 (B), NAT (C), SULT1A1 (D), SULT1A3 (E), SULT1E1 (F), TMPT (G), UGT1A1 (H), UGT1A4 (I), UGT1A6 (J), UGT1A9 (K), UGT2B7 (L), UGT2B15 (M), and UGT2B17 (N). The symbols represent the relative activity in each age group, and the dotted line indicates the adult value defined as $100 \%$. If multiple values were obtained for the same age group, the symbols represent the average relative activity, and the error bars show the S.D. See Table 14 for explanation on the ontogeny profiles and literature references. TMPT, thiopurine-methyltransferase. 
I

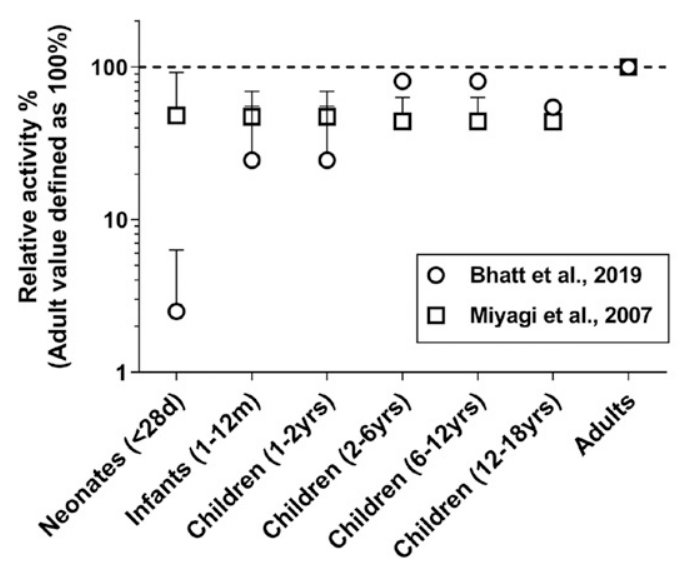

K

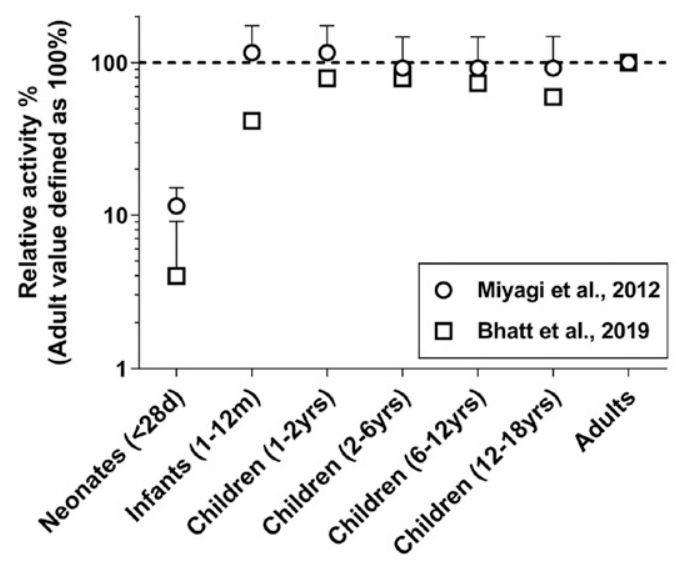

M

UGT2B15

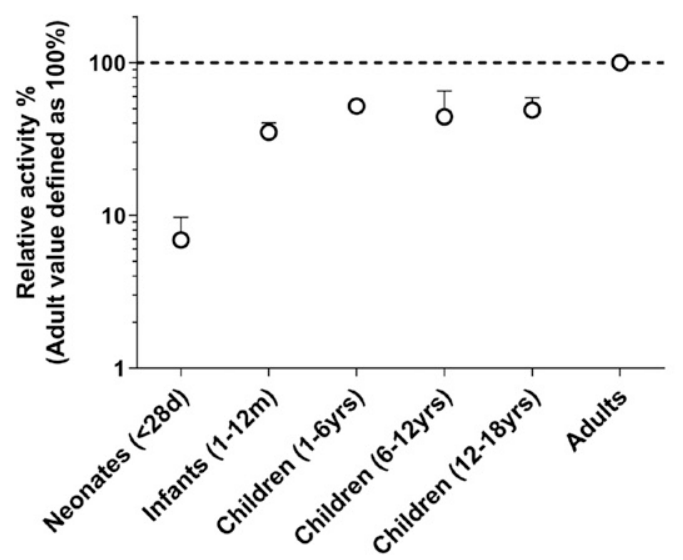

$\mathbf{J}$
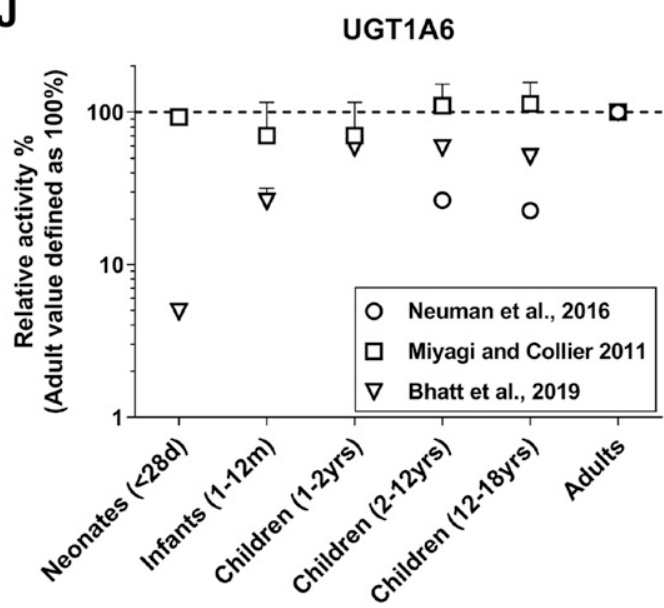

L

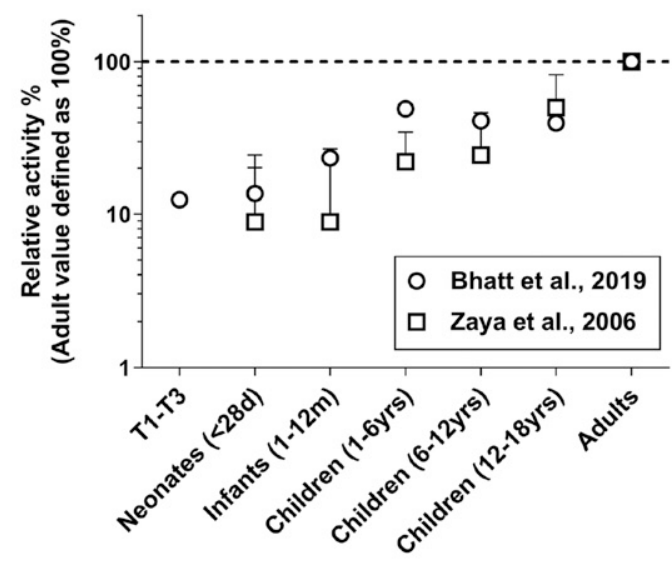

N

UGT2B17

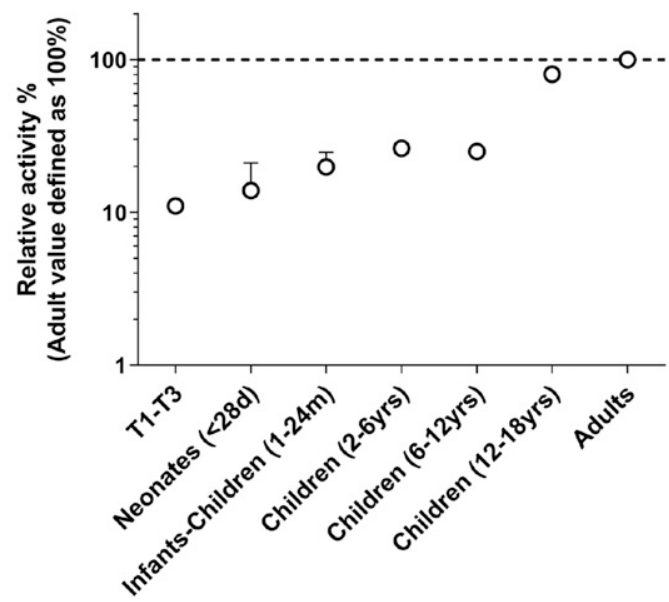

Fig. 16. Continued.

history, or alcohol intake and the impact of these factors. For data obtained in tissues from nonclinical animals, strain differences may have an especially significant impact apart from housing conditions and diet. Taken together, this implies that data compiled in this review were obtained in various subpopulations. Second, the exact experimental conditions and specific analytical methods used to quantify mRNA expression, protein abundance, or activity may differ between studies and may thus complicate the meta-analysis of 


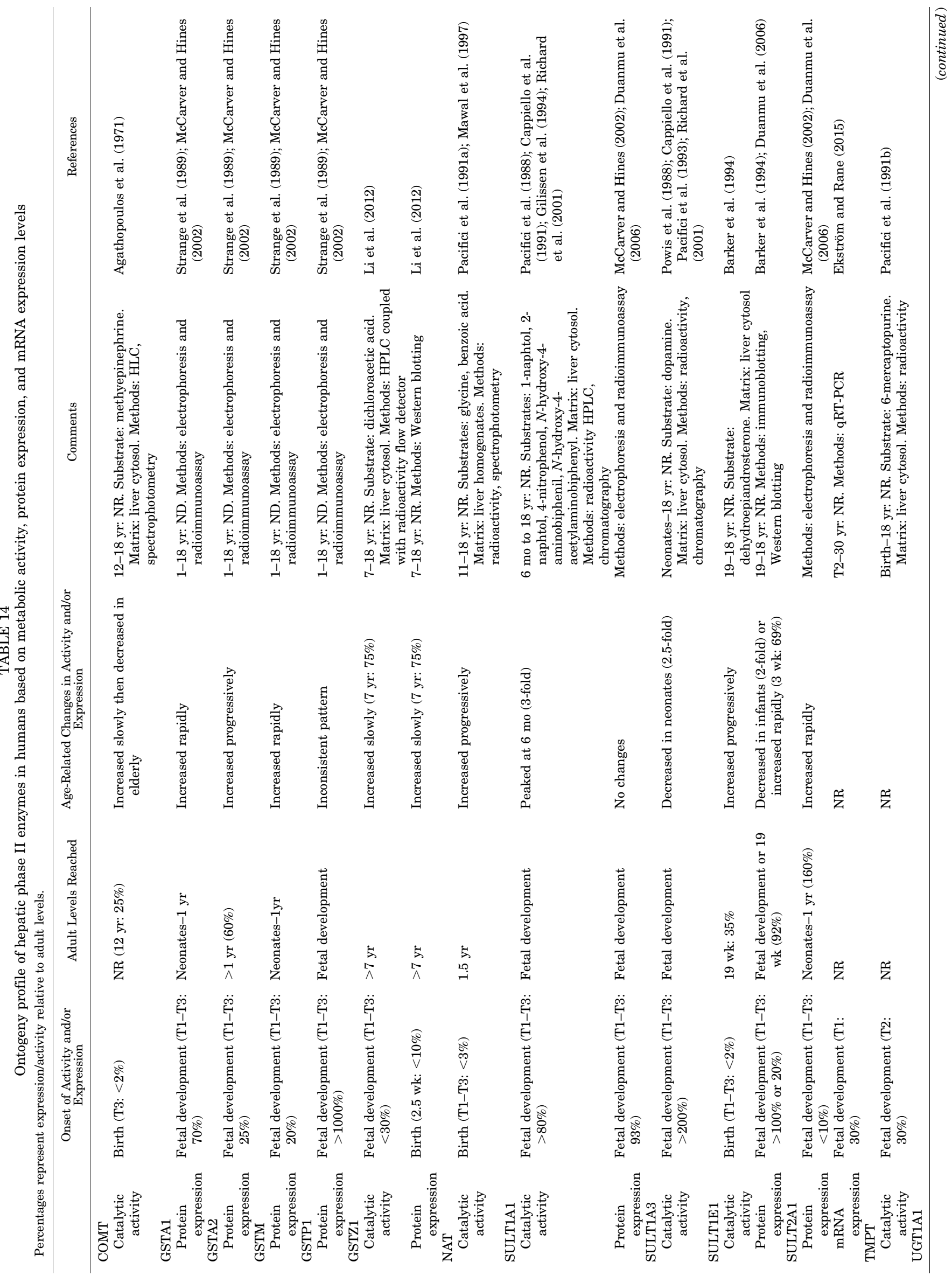




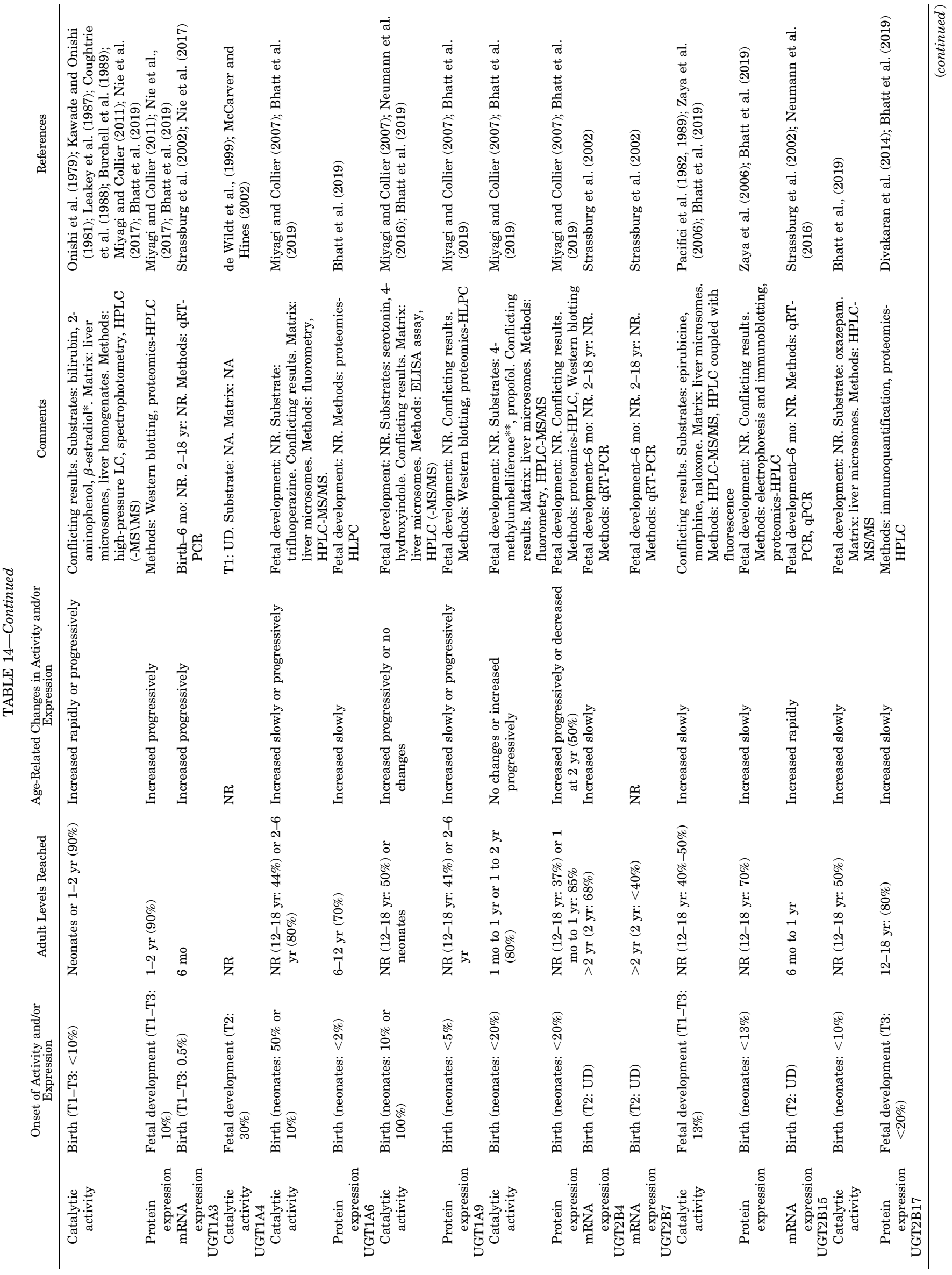


ontogeny profiles. This is most obvious for protein abundance, wherein Western blot and LC-MS/MS do not necessarily give the same results (Aebersold et al., 2013; Achour et al., 2017). Third, for LC-MS/MS-based quantification, there is a significant interlaboratory variability in absolute protein levels (Wegler et al., 2017; Prasad et al., 2019). Sources of variability include type of membrane fractionation, tissue homogenization, degree of protein solubility, digestion conditions of proteins (e.g., type of digestion enzyme), digestion time, and temperature and amount of enzymes per total protein, quantification method, and choice of specific peptides and probe substrate (Badée et al., 2019). In addition, the units to express protein abundance are of importance when comparing between studies and when extrapolating normalized values for protein abundance to, for instance, the organ level. One example is that Prasad et al. (2016) used protein abundance in relation to "microgram membrane protein," whereas van Groen et al. (2018) used protein abundance in relation to "gram liver tissue." The reason for the latter is that membrane protein yield per gram tissue showed an age-related pattern and needed a correction factor to scale up to total organ expression (van Groen et al., 2018). Consistently, the number of isolated liver cells per gram liver (i.e., hepatocellularity) was also shown to be agedependent in rats, necessitating the use of age-specific values for hepatocellularity, such as, for instance, when extrapolating in vitro hepatocytic uptake data to the in vivo level (Fattah et al., 2016). Despite the fact that we have normalized the results presented in this review to adult levels in an attempt to correct for interstudy variability, readers should consider the implications of these differences in data generation when using the data (e.g., for PBPK modeling). Moreover, because consensus is lacking on standard practice for performing LC-MS/MS-based protein quantitation studies (Prasad et al., 2019), the scientific community should harmonize guidelines in these areas to further improve use of the quantitative data presented in this review.

Not surprisingly, we identified several asynchronous ontogeny profiles of DTs and DMEs when comparing mRNA expression, protein expression, and activity levels. This was, for instance, the case for protein and mRNA expression levels of CNT2 in rats that increased with age, reaching maximal levels at either 21 or 45 days, respectively (Supplemental Fig. 3), whereas maximal uptake activity levels of uridine mediated by CNT1/2 were achieved during fetal development and then rapidly decreased in neonatal animals (Fig. 4C) (del Santo et al., 2001). In addition, UGT2B7 mRNA expression levels decreased with increasing age in humans, showing maximal levels during fetal life and reaching adult levels in older children of 12 years of age (Supplemental Fig. 18B), but this expression profile was inconsistent with the respective protein (Supplemental Fig. 17B) and activity (Fig. 16L) levels. Taken together, 
A

UGT1A1

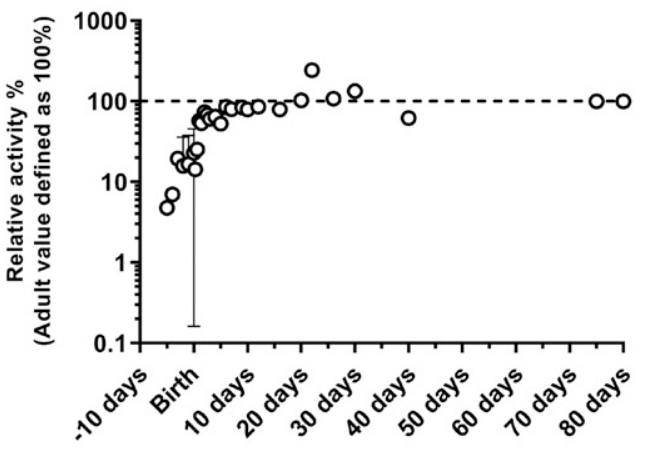

C

UGT2B1

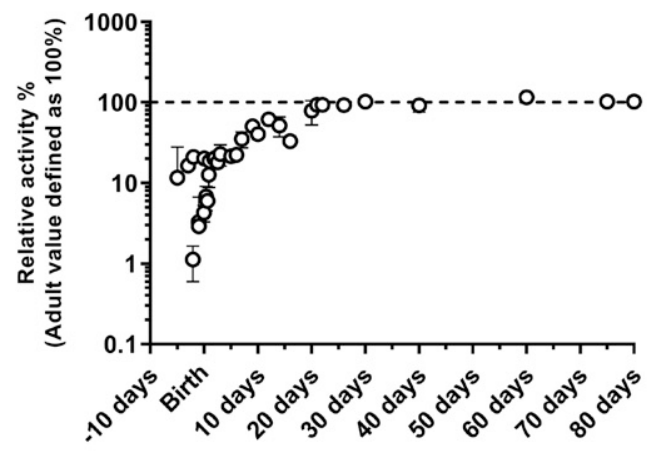

E

SULT1B1

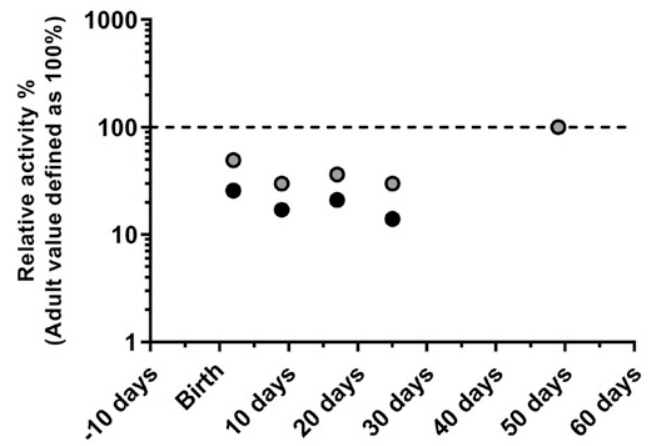

G

3b-hydroxy-5- cholenoate sulfotransferase

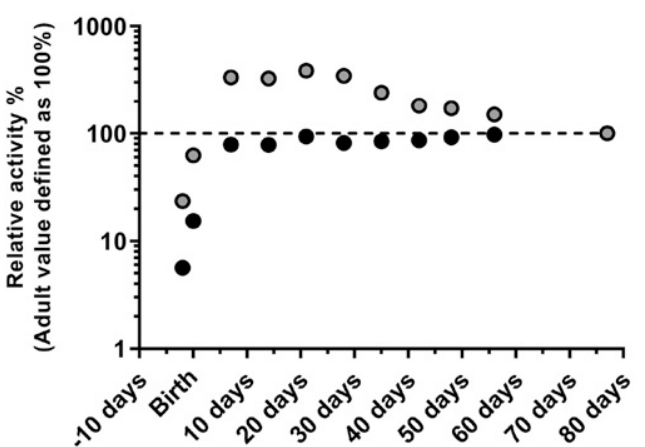

B

UGT1A6

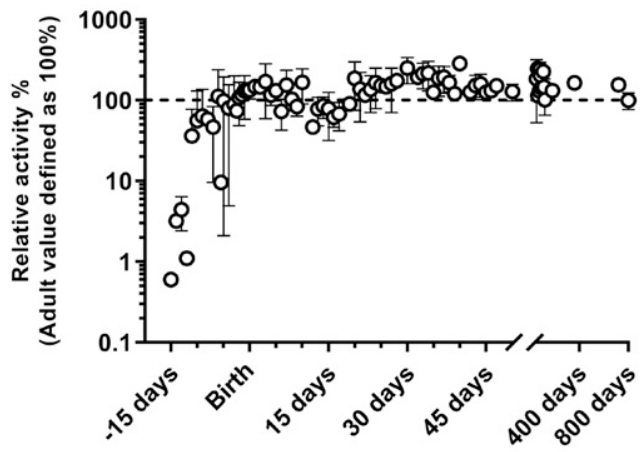

D

SULT1A1

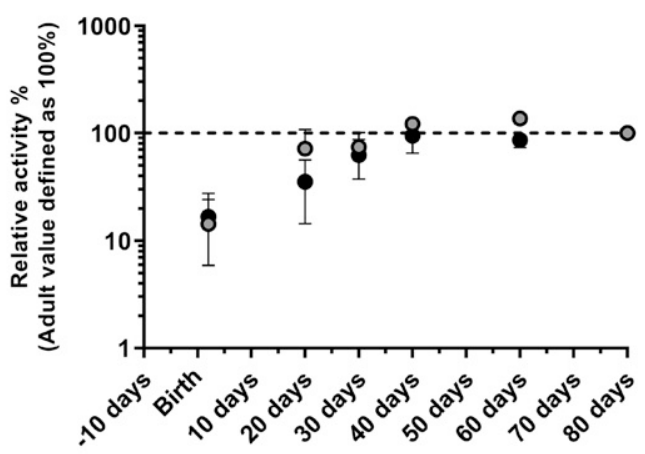

F

Bile salt sulfotransferase

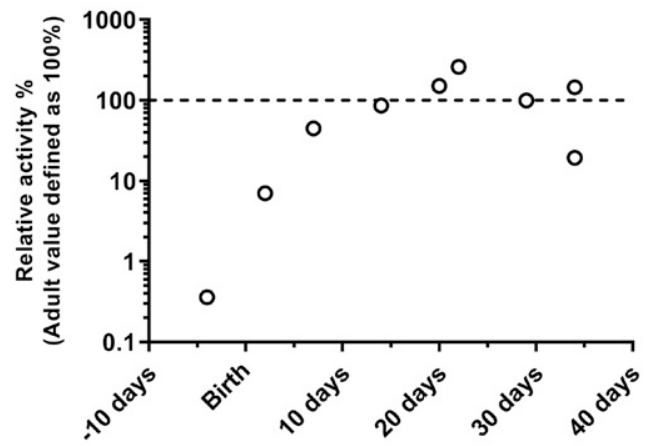

H

Thiaridamide O-sulfation

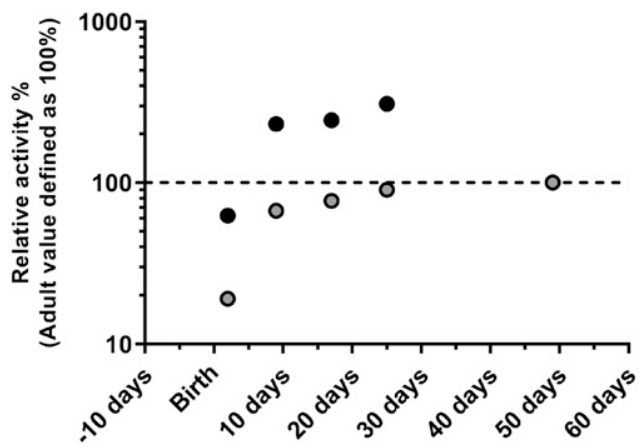

Fig. 17. Pooled literature data on the ontogeny of metabolic activity of hepatic phase II enzymes in rats: UGT1A1 (A), UGT1A6 (B), UGT2B1 (C), SULT1A1 (D), SULT1B1 (E), Bile salt sulfotransferase (F), 3b-hydroxy-5-cholenoate sulfotransferase (G), Thiaridaminde O-sulfation (H), Piperizine derivate (DETR) N-sulfation (I), Aniline N-sulfation (J), Piperizine derivate (PTHP) N-sulfation (K), Desipramine N-sulfation (SULT2A1) (L), Androsterone O-sulfation (low activity) (M), Androsterone O-sulfation (high activity) (N), GST (O), NAT1 (P), GSH reductase (Q), and GSH peroxidase (R). The symbols represent the relative activity in each age group, and the dotted line indicates the adult value defined as $100 \%$. If multiple values were obtained for the same age group, the symbols represent the average relative activity, and the error bars show the S.D. See Table 15 for explanation on the ontogeny profiles and literature references. DETR, Piperazine derivate; PTHP, Piperidine derivative. 


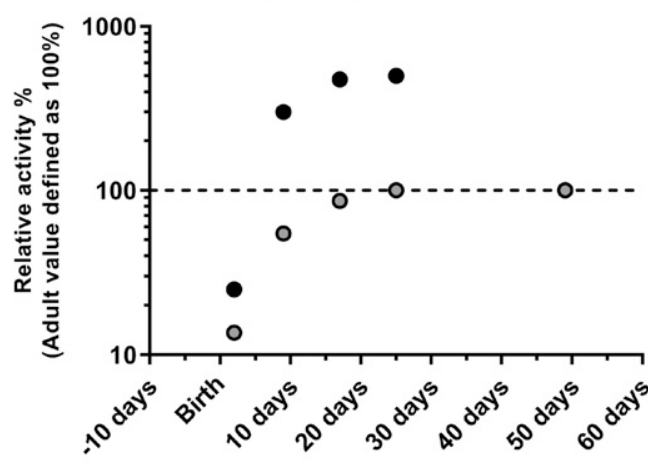

$\mathbf{K}$

Piperidine derivative

(PTHP) N-sulfation

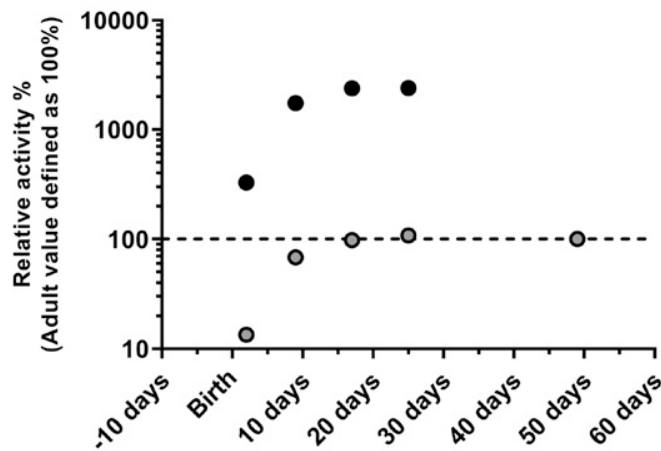

M

Androsterone O-sulfation

(Low activity)

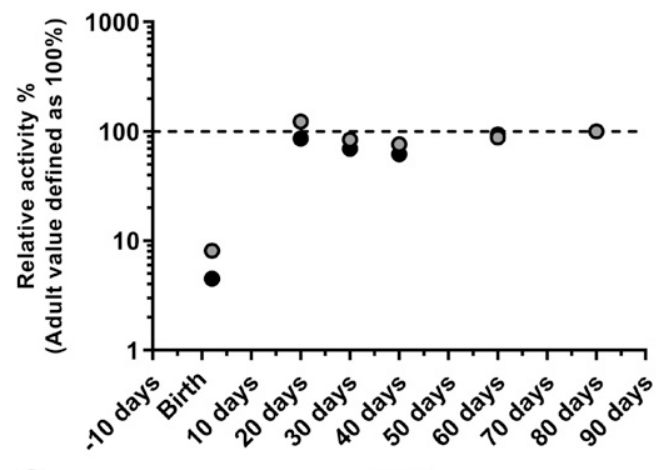

0

GST

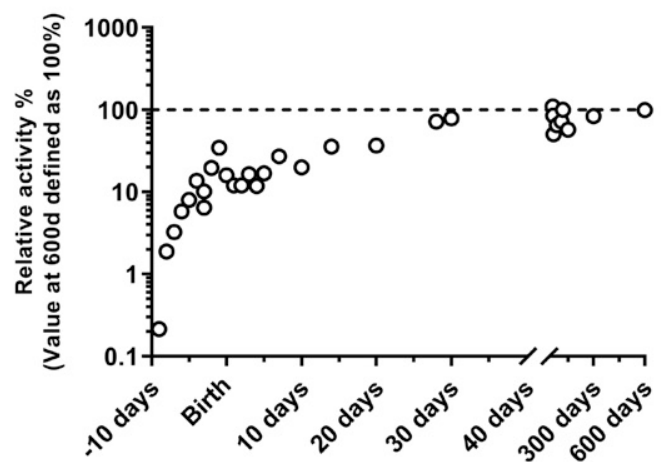

J

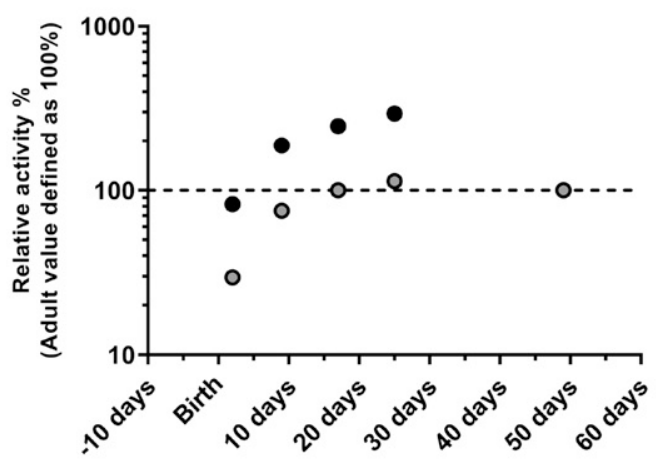

$\mathbf{L}$

Desipramine N-sulfation

(SULT2A1)

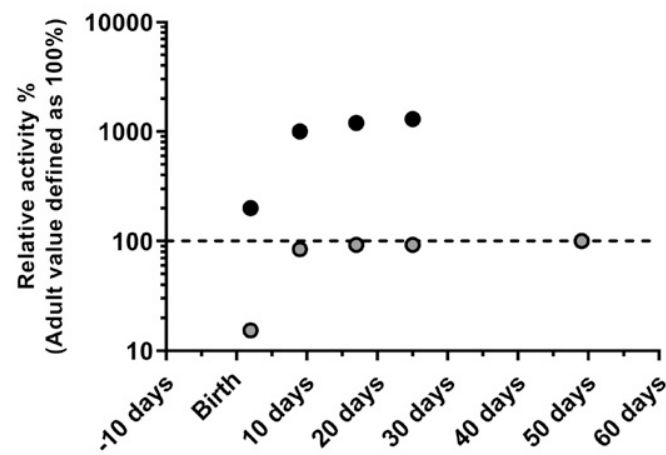

$\mathbf{N}$

Androsterone O-sulfation (High activity)

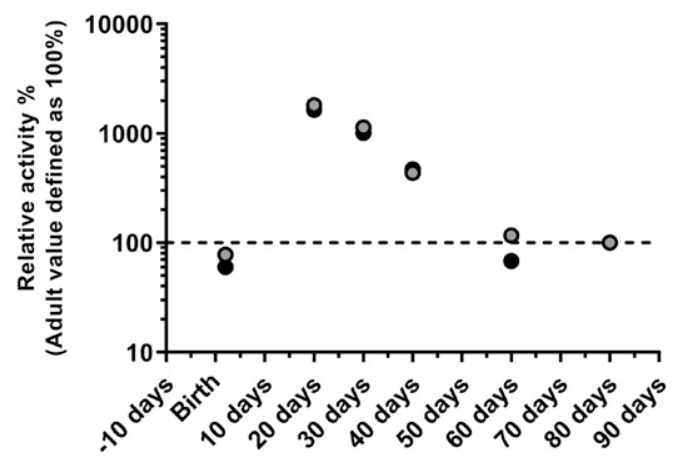

P

NAT1

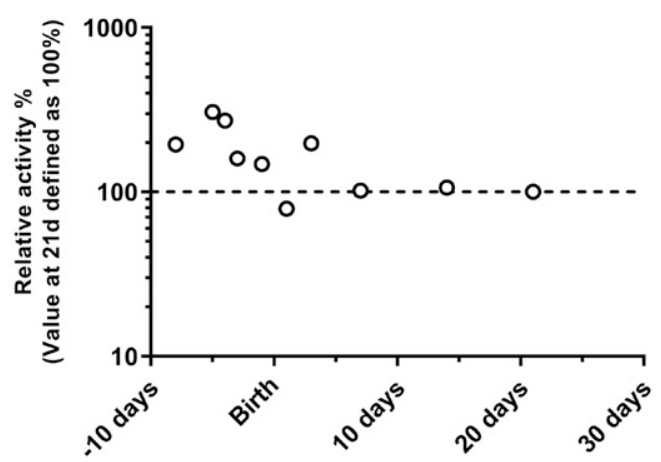

Fig. 17. Continued. 
Q

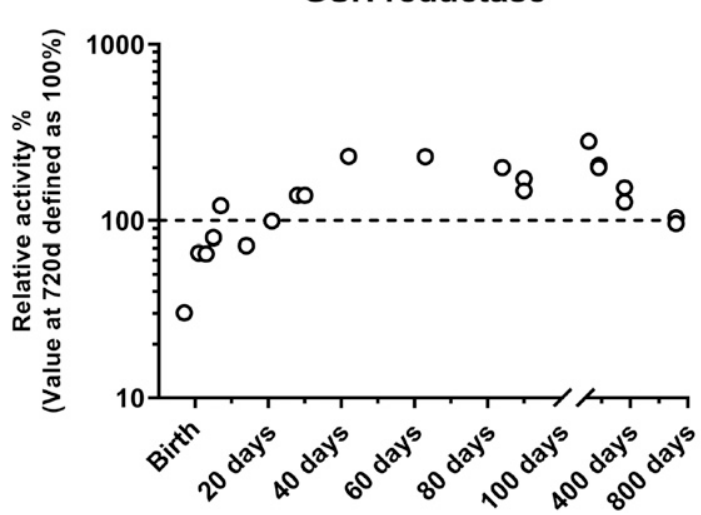

$\mathbf{R}$

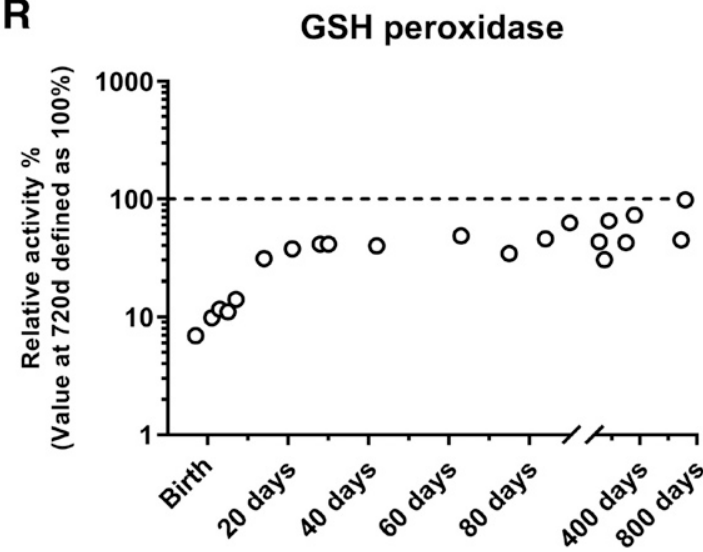

Fig. 17. Continued.

these examples of asynchronous maturation in expression and activity further demonstrate the need for crossvalidation of DT/DME ontogeny profiles for individual isoforms. Importantly, for several transporter isoforms, the prior identification and characterization of isoformselective drug/probe substrates will be required to support the generation of reliable activity data. The current review may show that mRNA expression levels could correlate quantitatively and qualitatively with protein expression levels for some DMEs and DTs (van Groen et al., 2018). However, caution is warranted for deriving quantitative maturation functions solely from mRNA expression levels. Any correlation between mRNA and protein expression levels that may come up from the current literature review could apply solely to the patient population that was studied in the original research papers. Demographic and environmental factors may affect transcription factors and
A

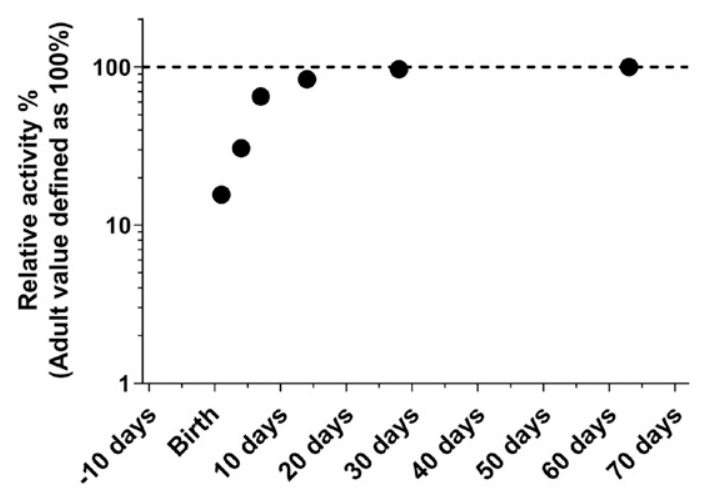

C

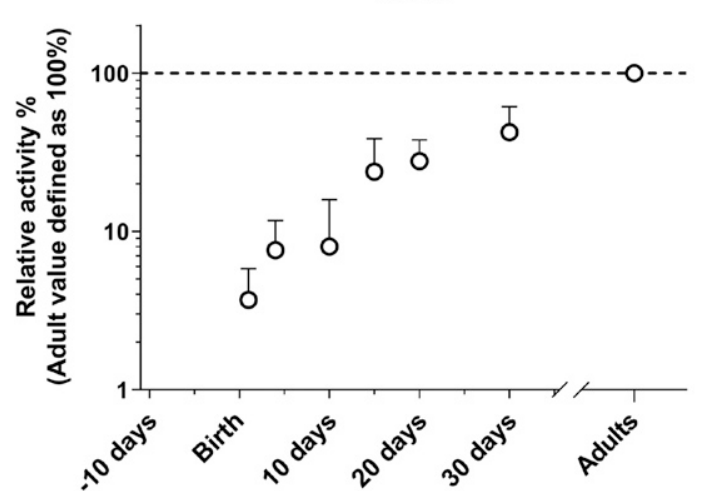

B

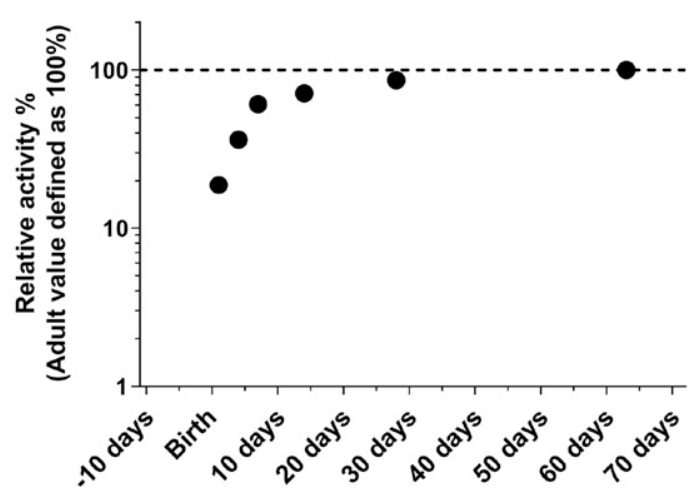

D

NAT2

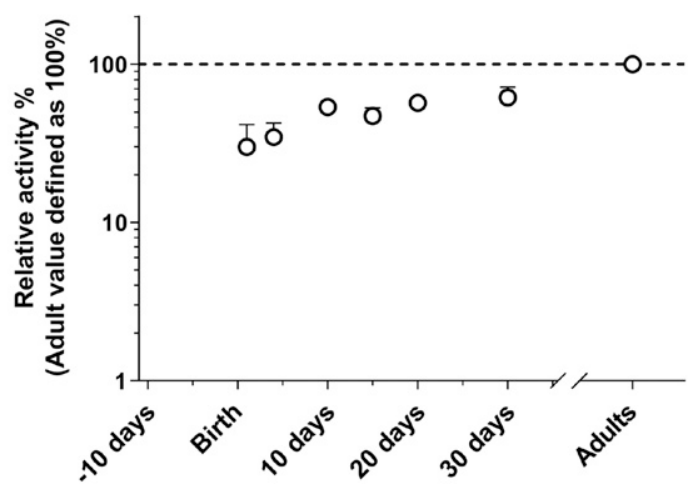

Fig. 18. Pooled literature data on the ontogeny of metabolic activity of hepatic esterases and phase II enzymes in mice: mCES1 (A), mCES2 (B), NAT1 (C), and NAT2 (D). The symbols represent the relative activity in each age group, and the dotted line indicates the adult value defined as $100 \%$. See Table 16 for explanation on the ontogeny profiles and literature references. mCES, mice carboxylesterase. 


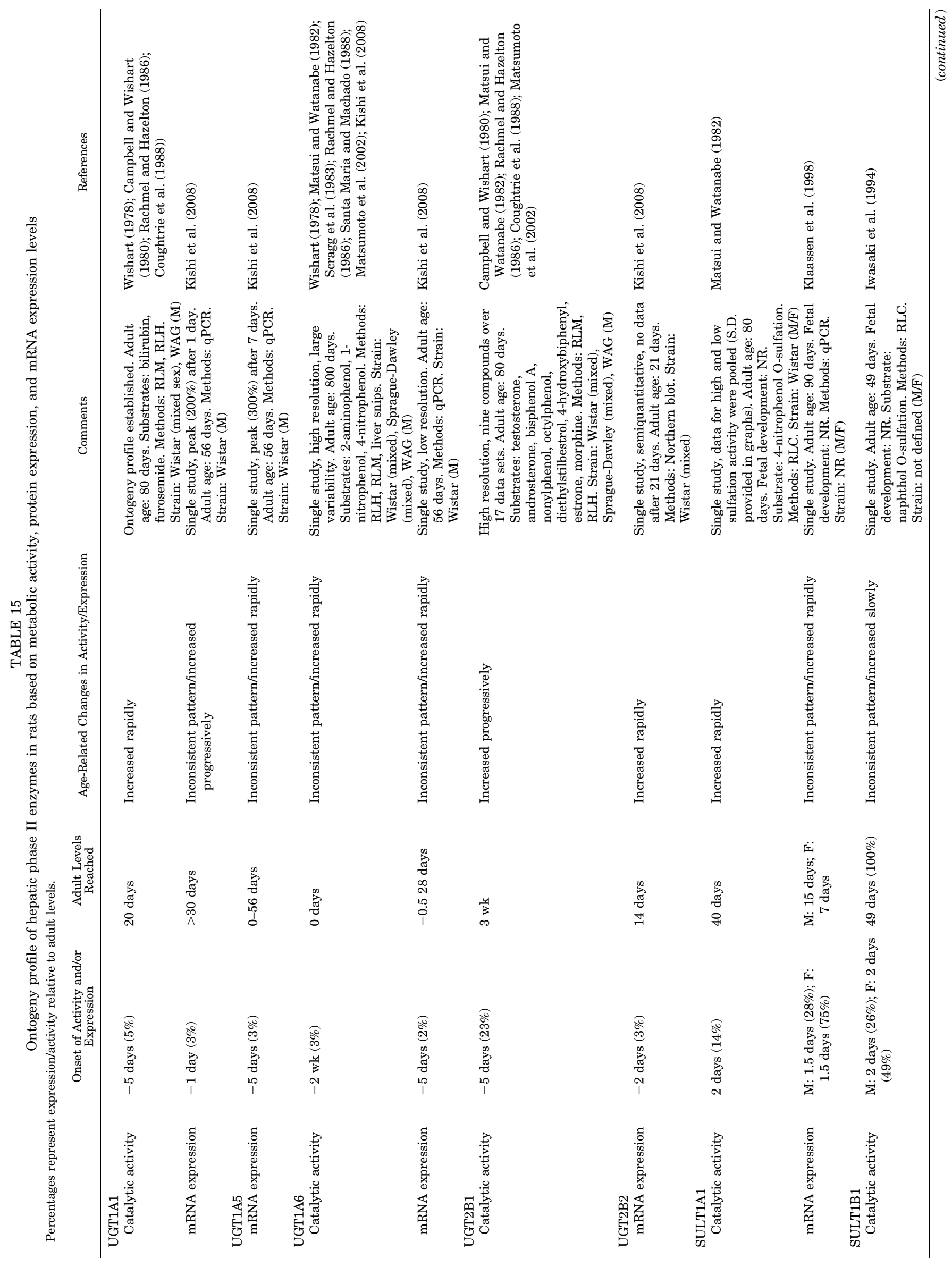

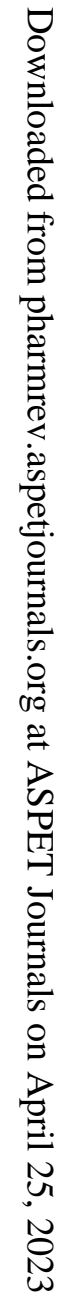




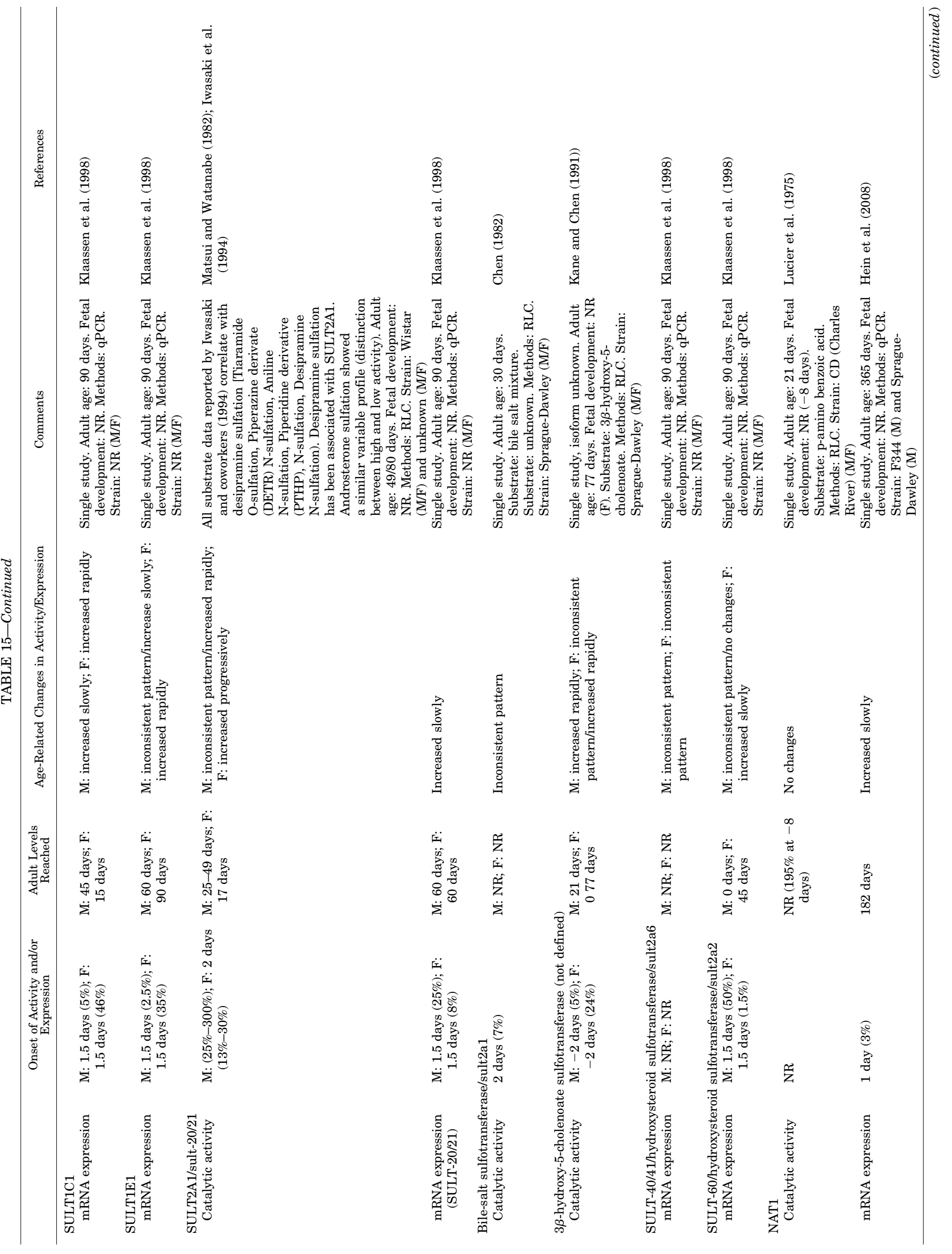




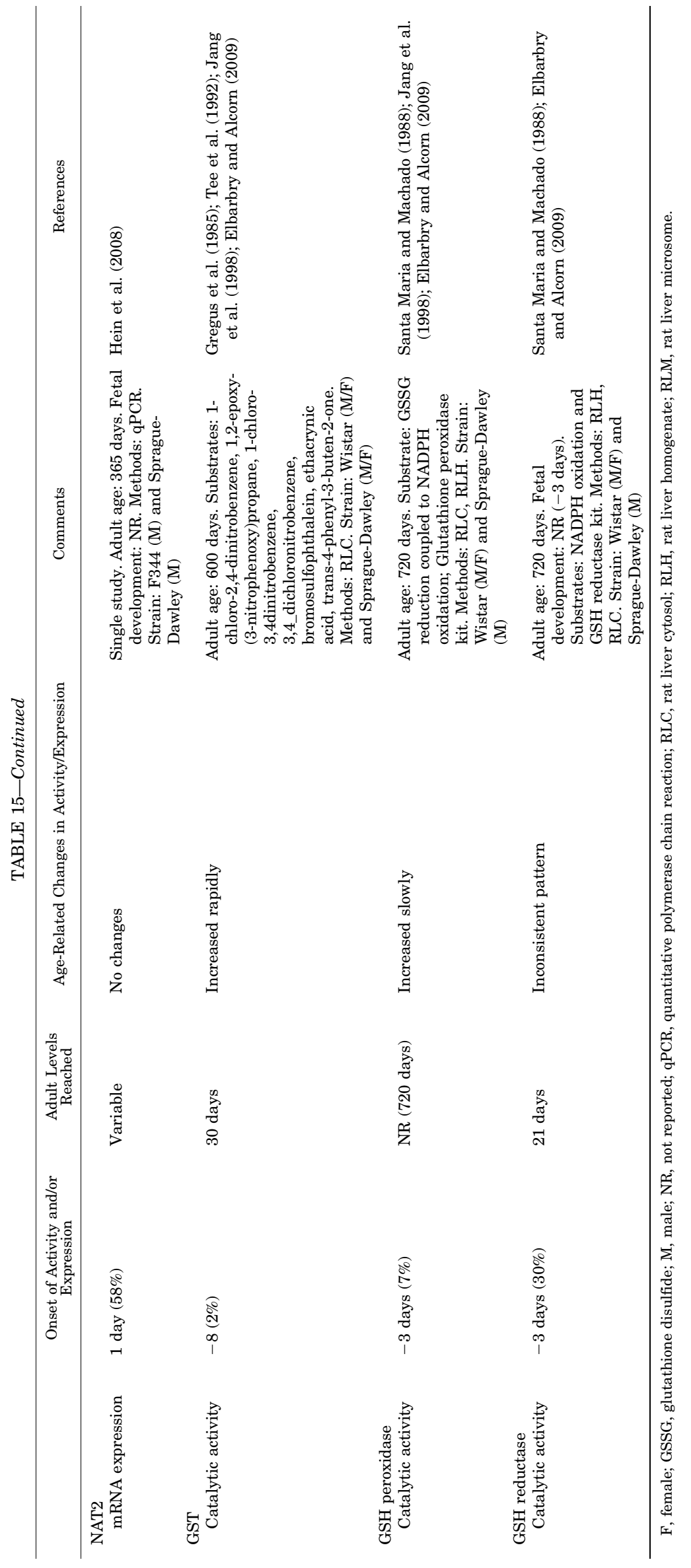




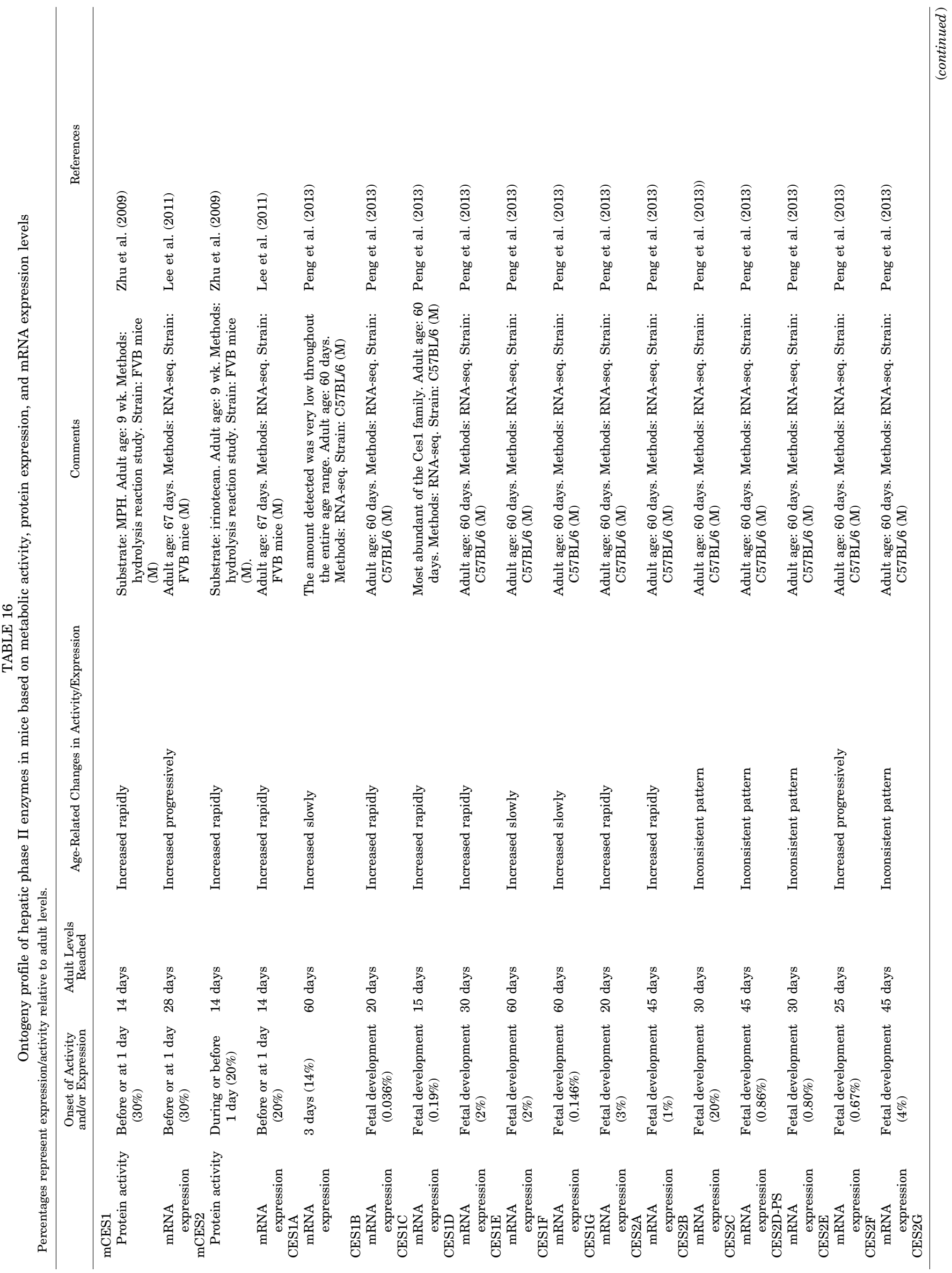




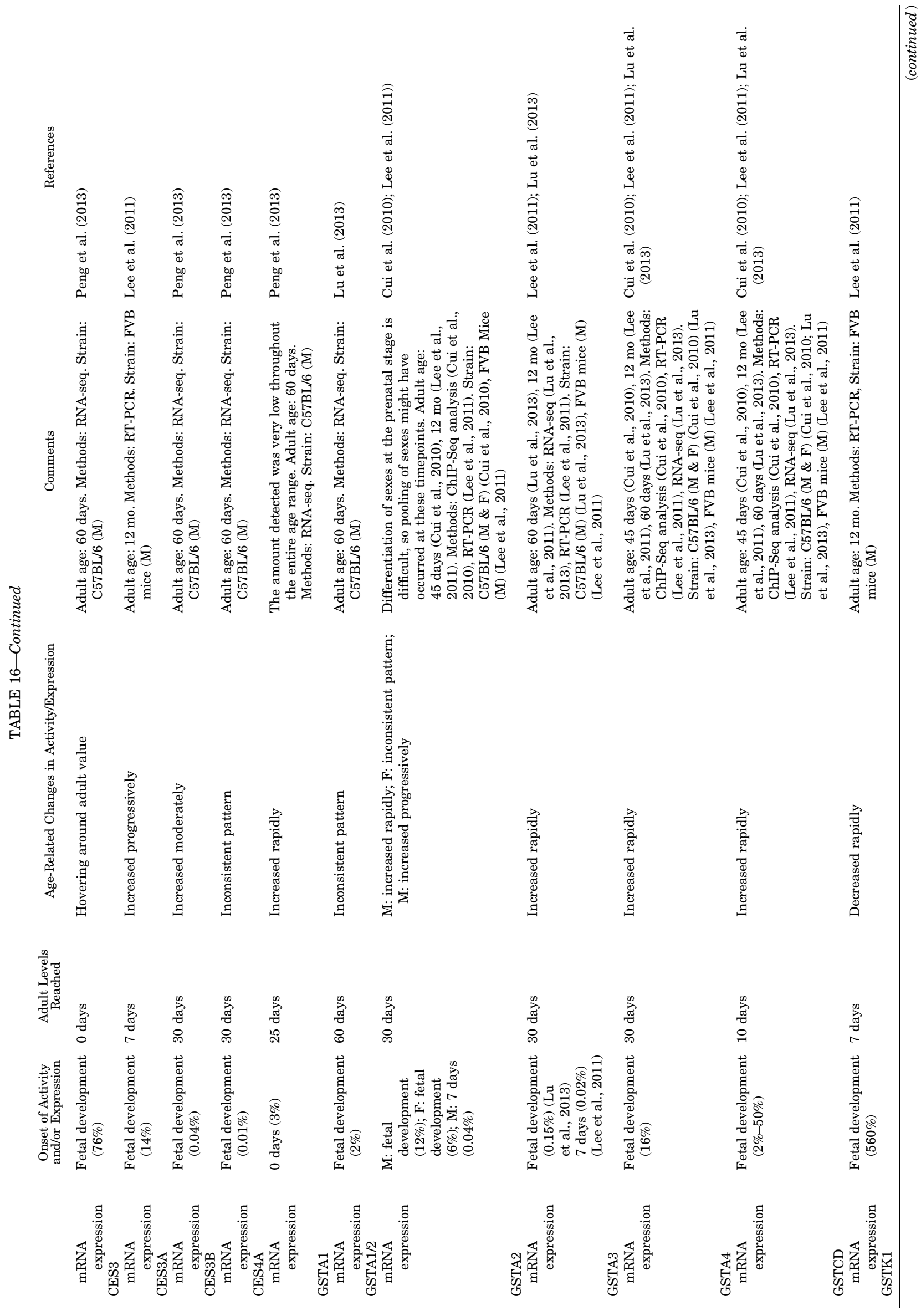




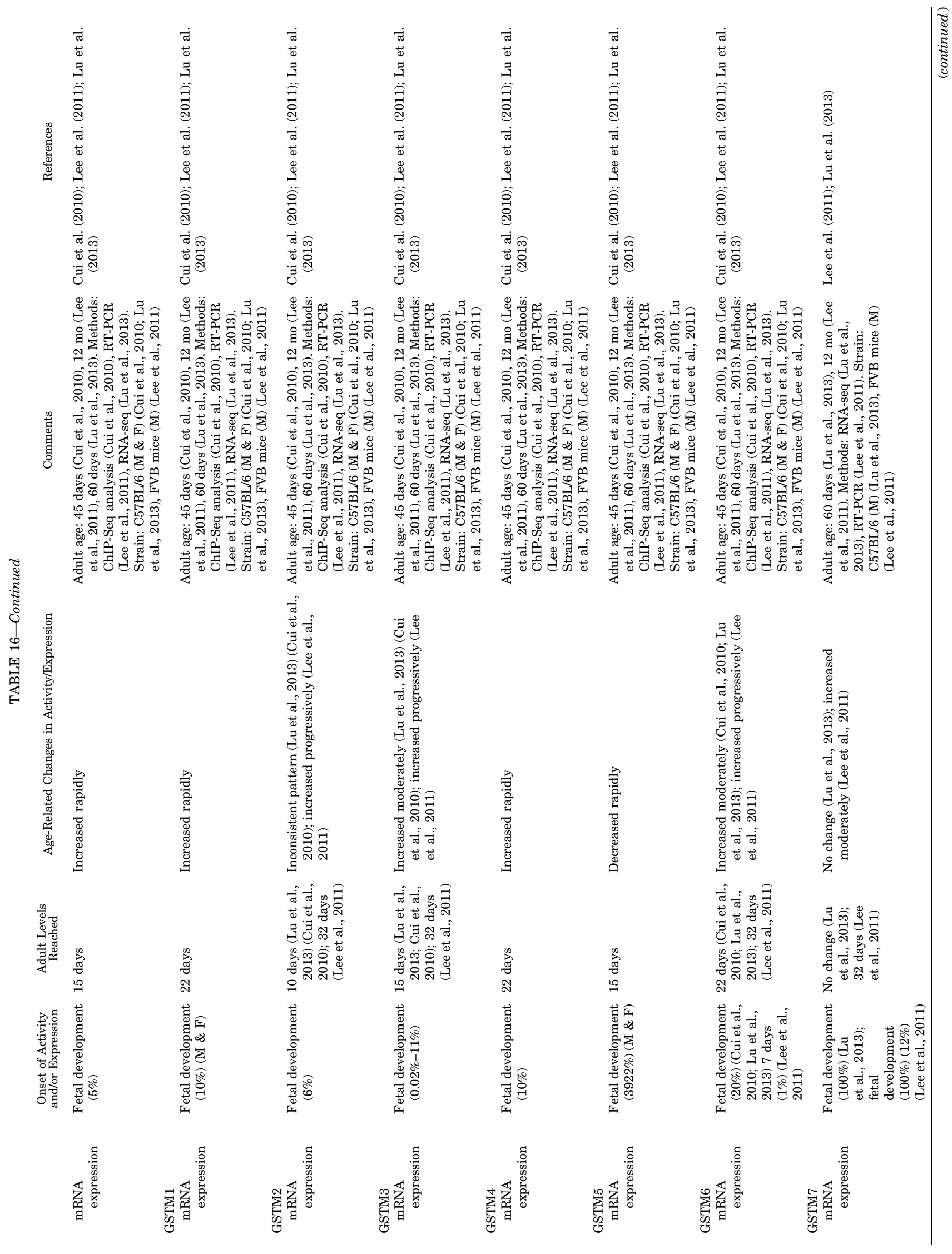




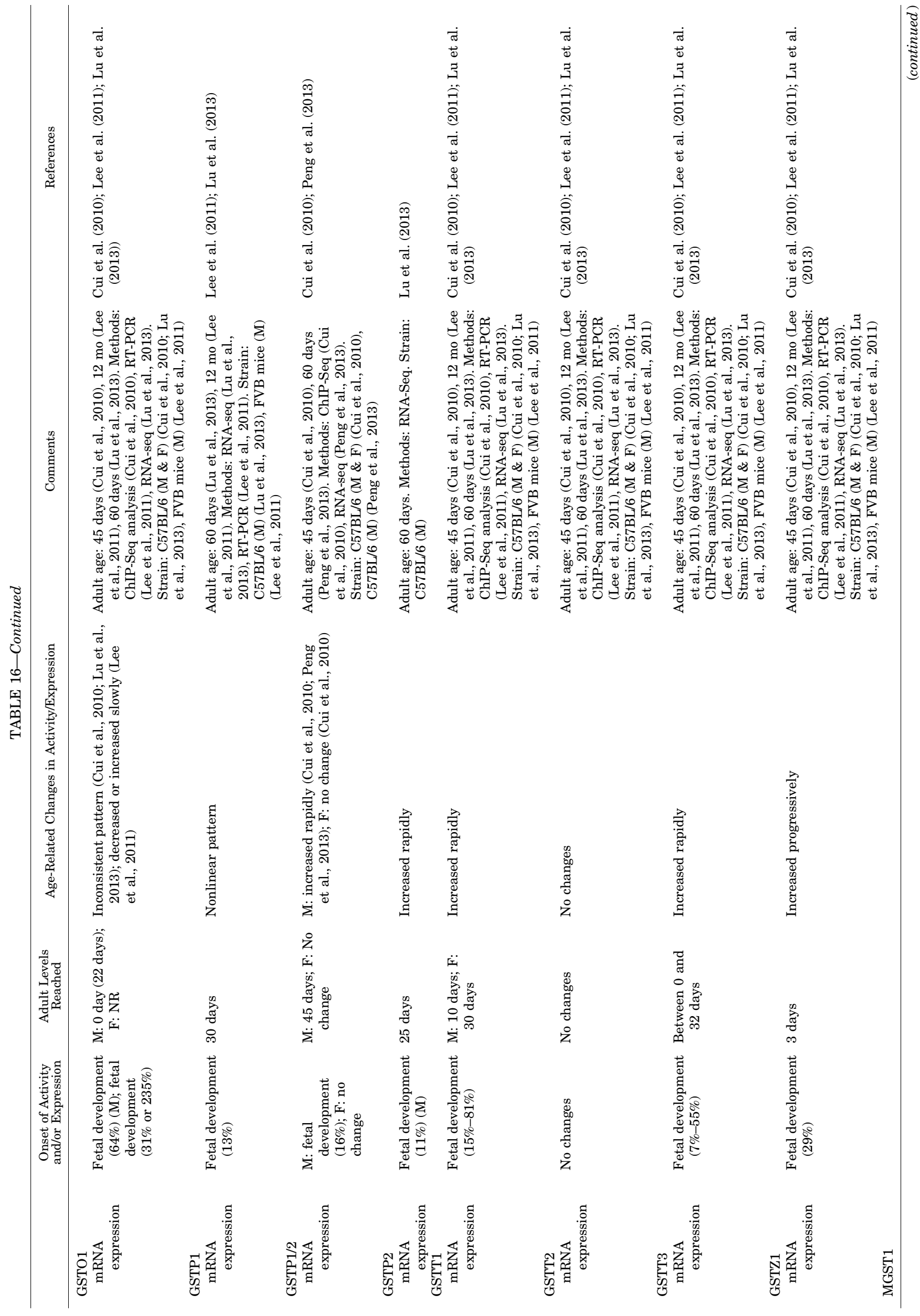




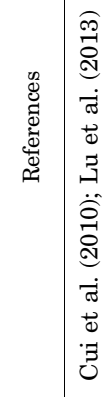

- 0

बृत्य

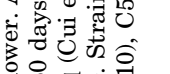

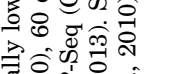

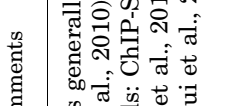

ठั

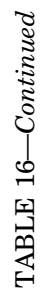

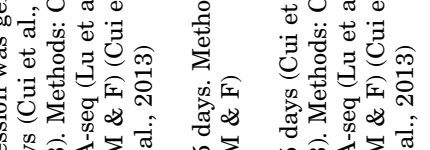

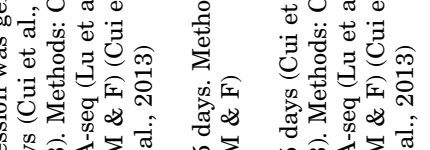

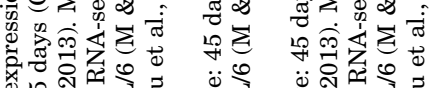

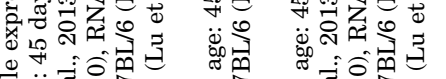

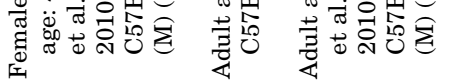

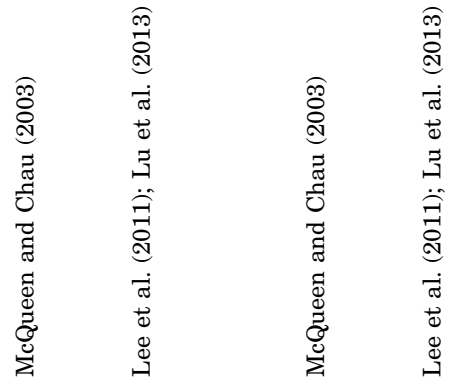

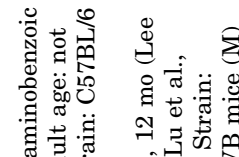

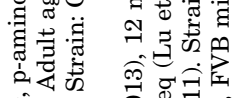

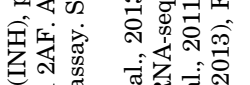

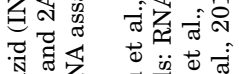

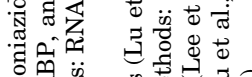

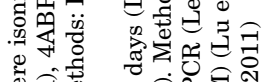

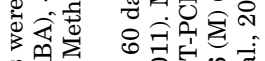

कै

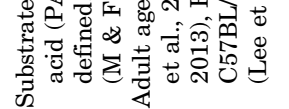

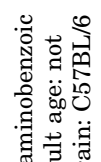

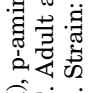

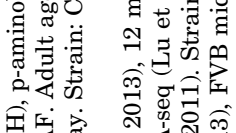

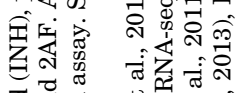

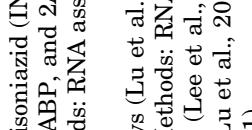

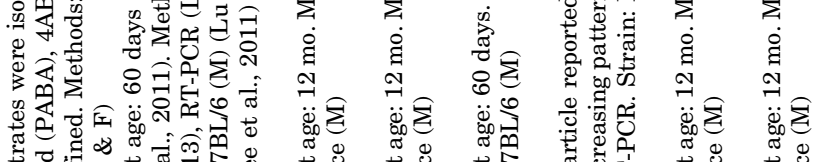

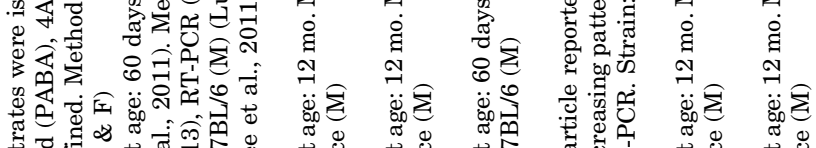

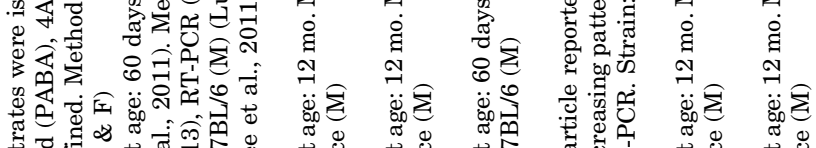

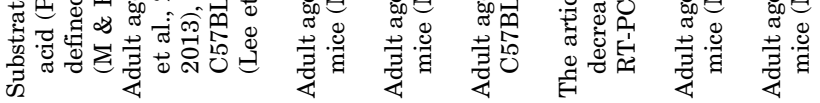
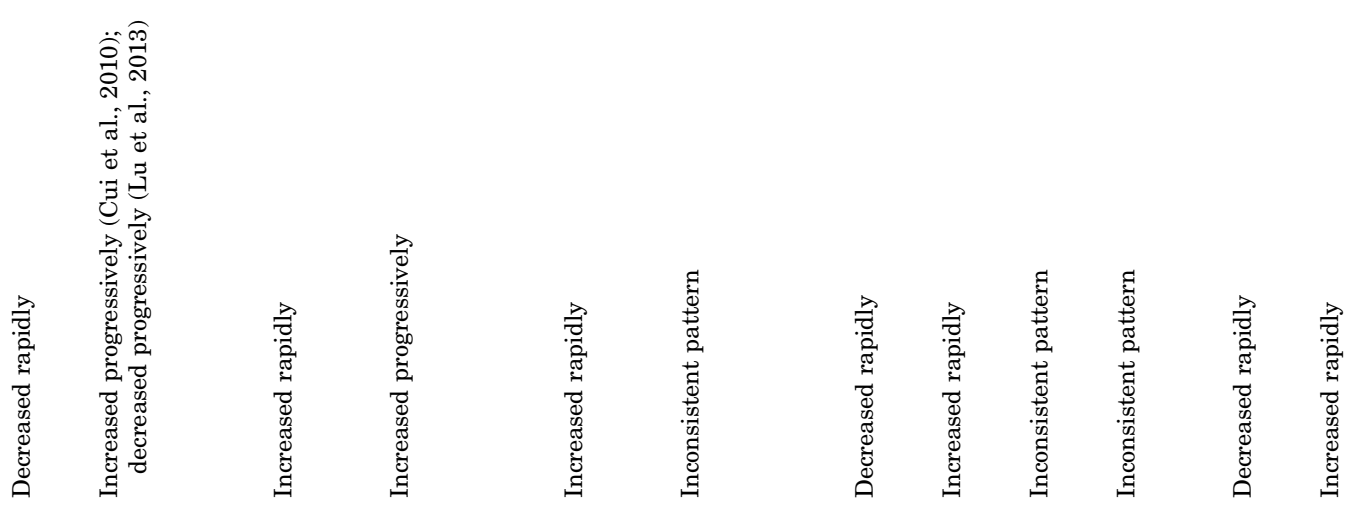

๘ี

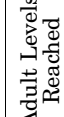

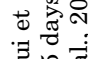

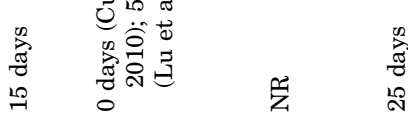

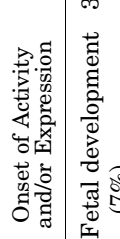

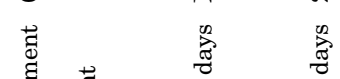

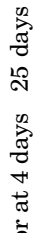

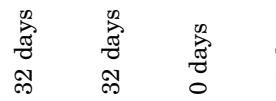

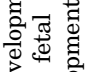

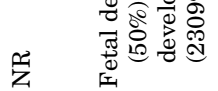

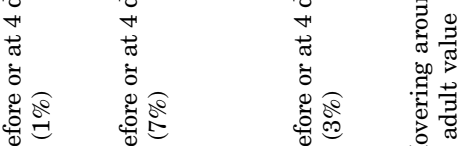

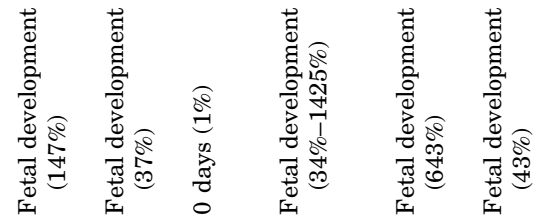

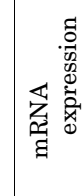

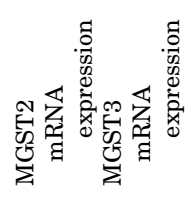

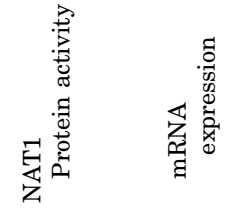

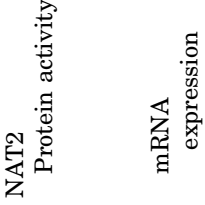

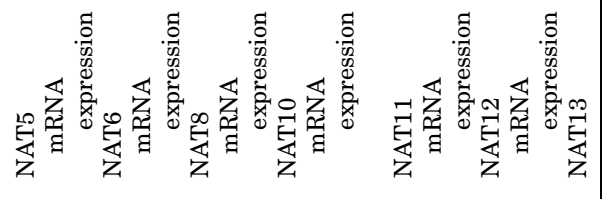




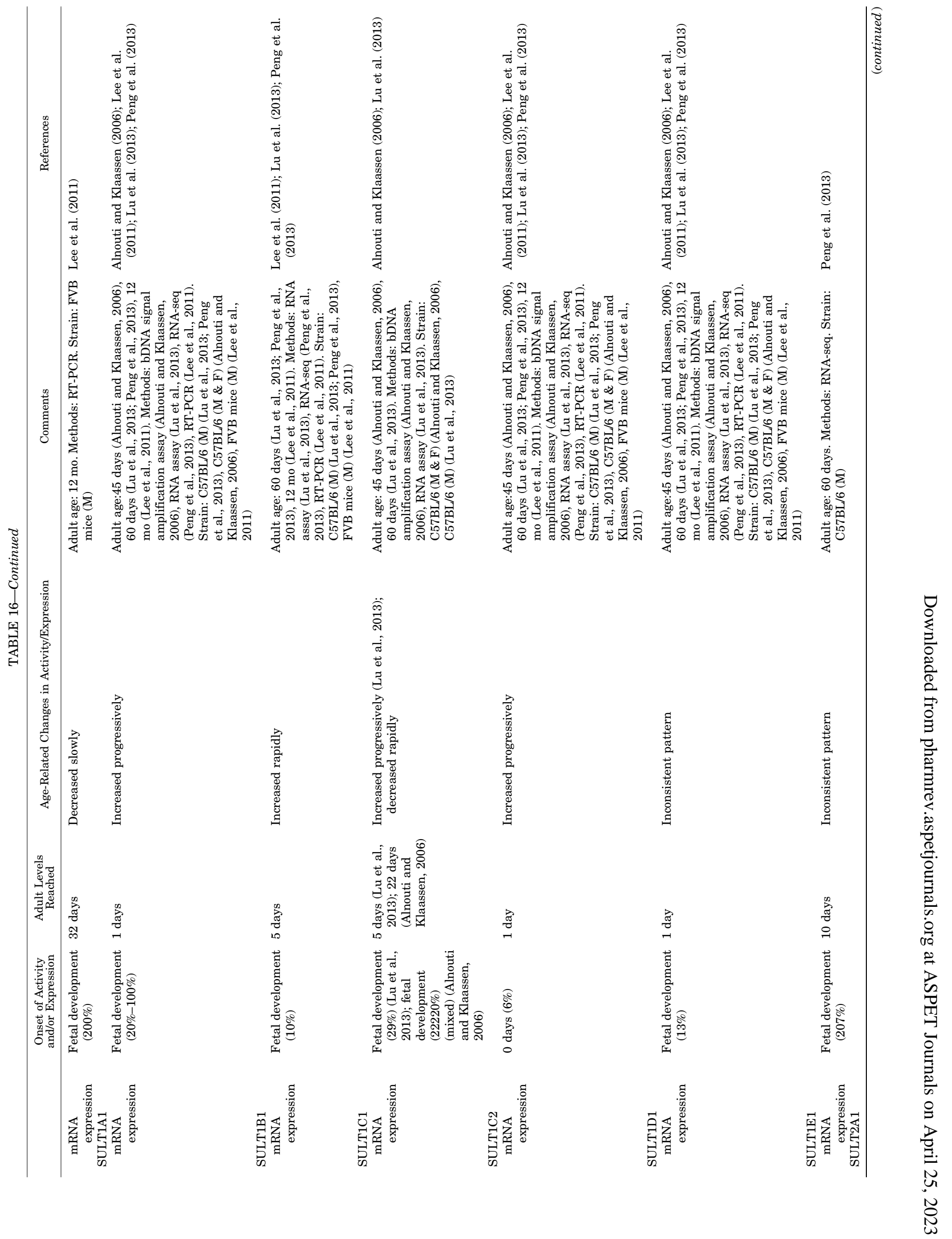




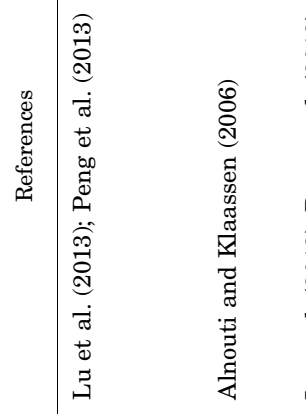

:

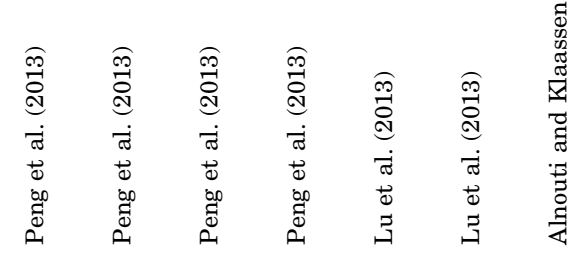

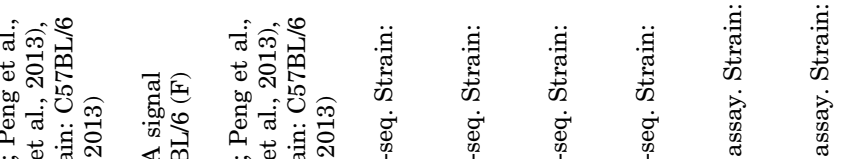

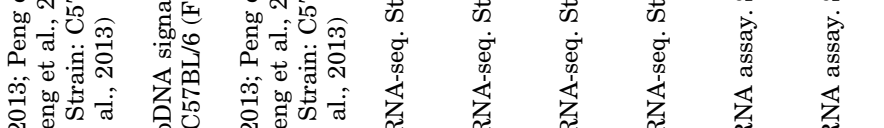

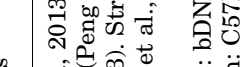

ते

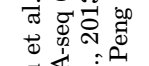

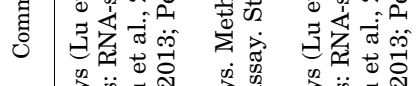

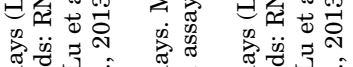

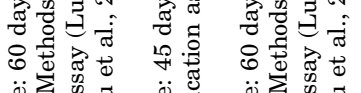

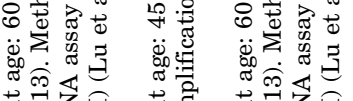

옳

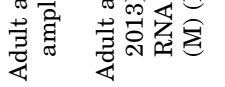

㱐

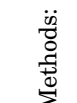

要

㲾 离

尊

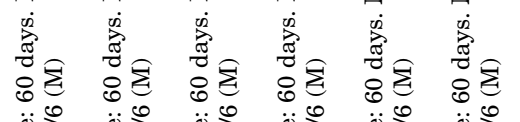

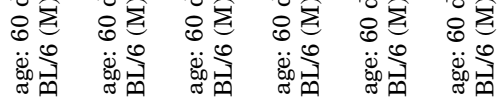

瓜

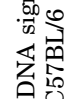

范若

究

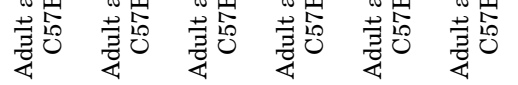

y

萨

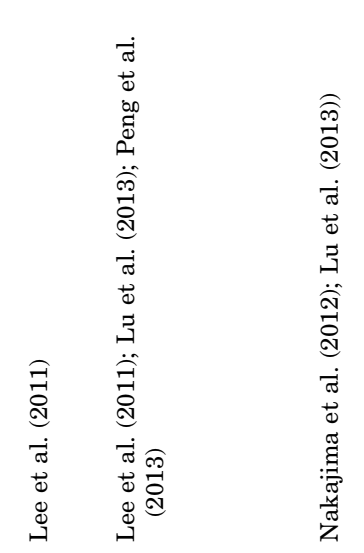

空

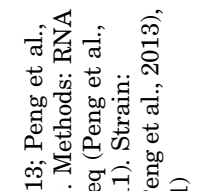

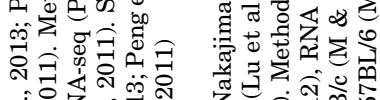

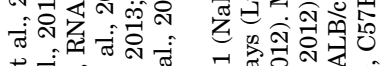

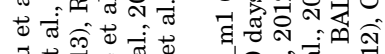

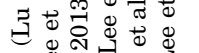

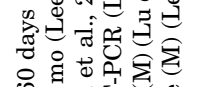

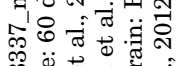

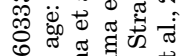

ป

范 类

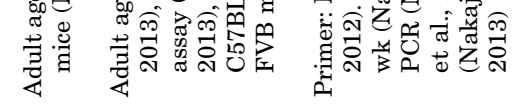

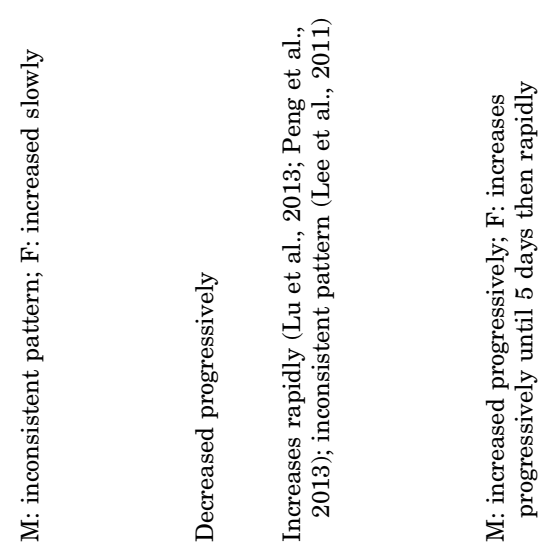

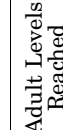

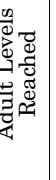

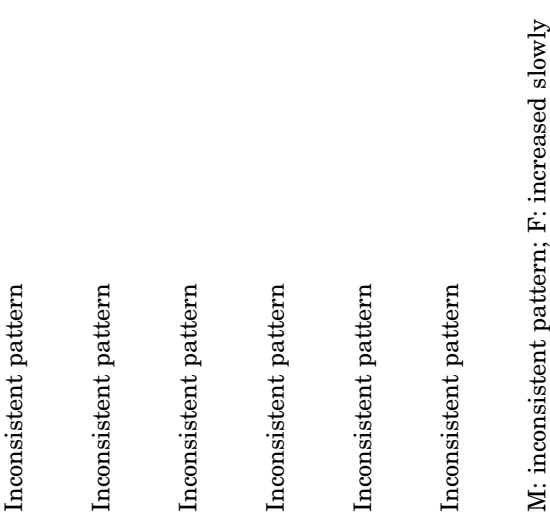

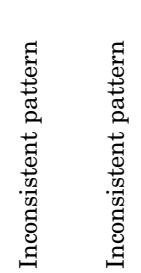

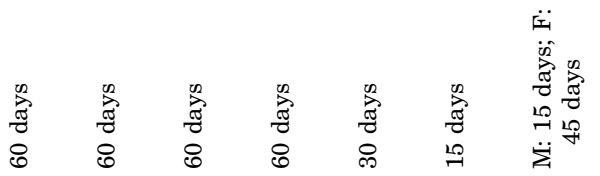

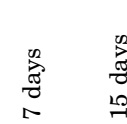

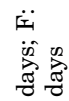

10 通

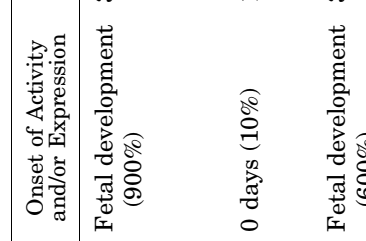

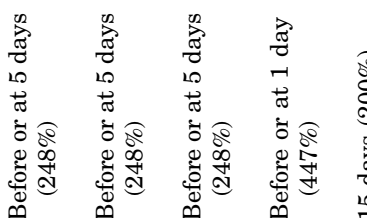

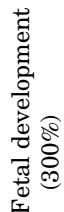

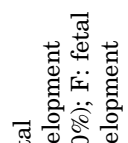

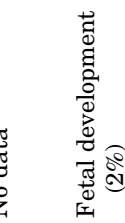

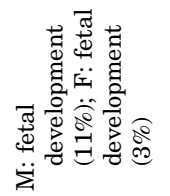

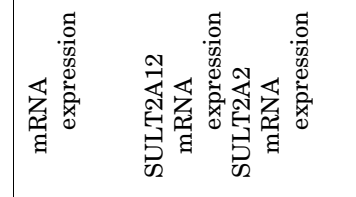
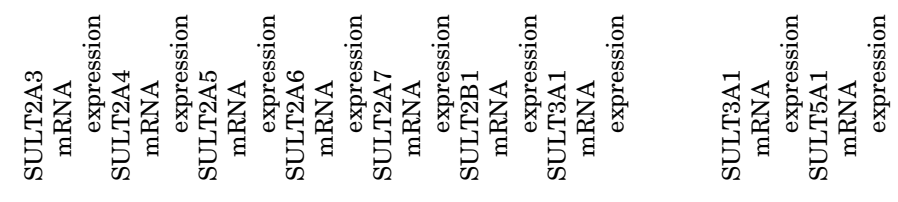

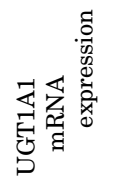


离

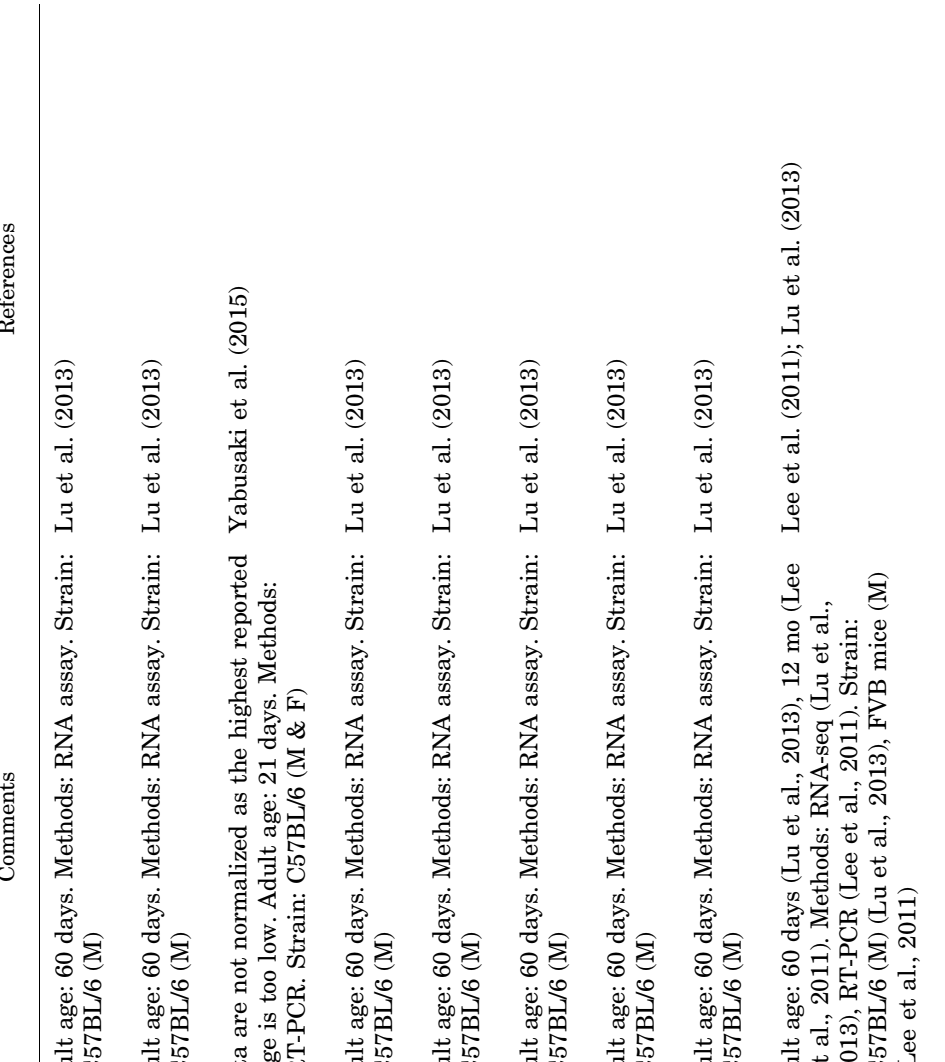

商

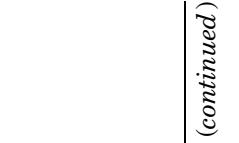

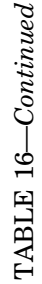

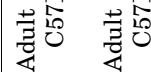

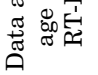
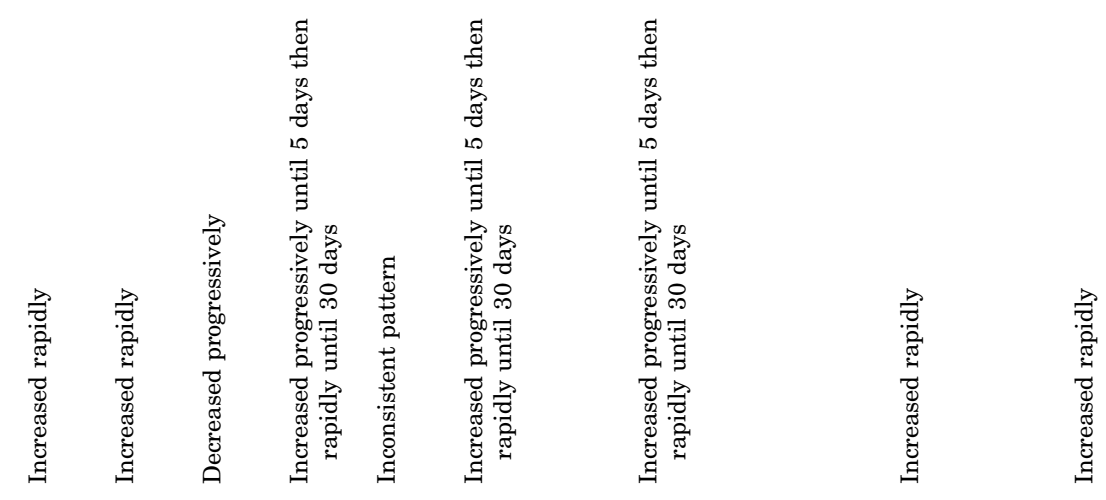

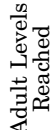

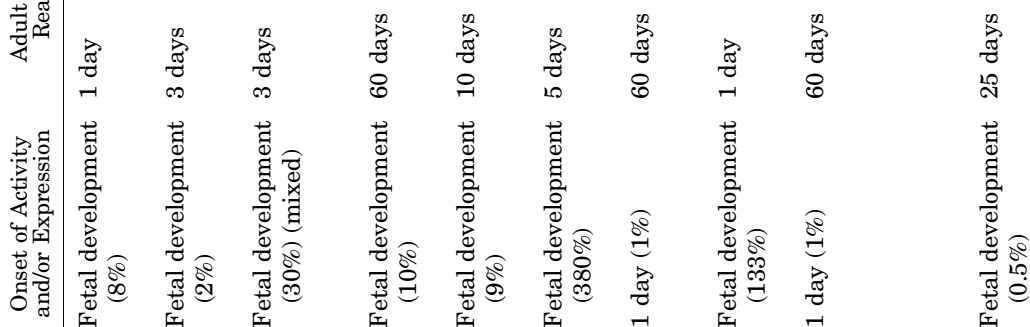

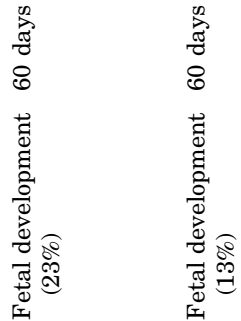

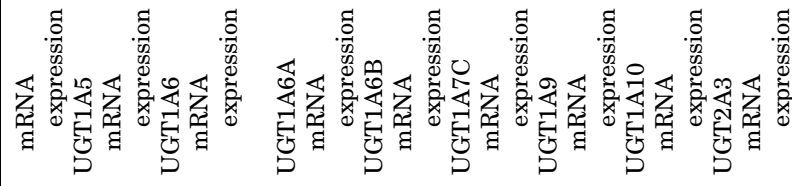<smiles>C[C@@H]1C[C@@H]1C1CC1</smiles>

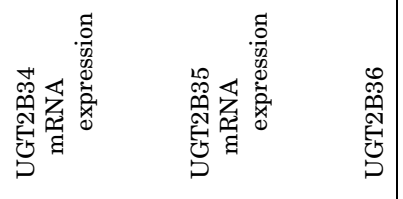




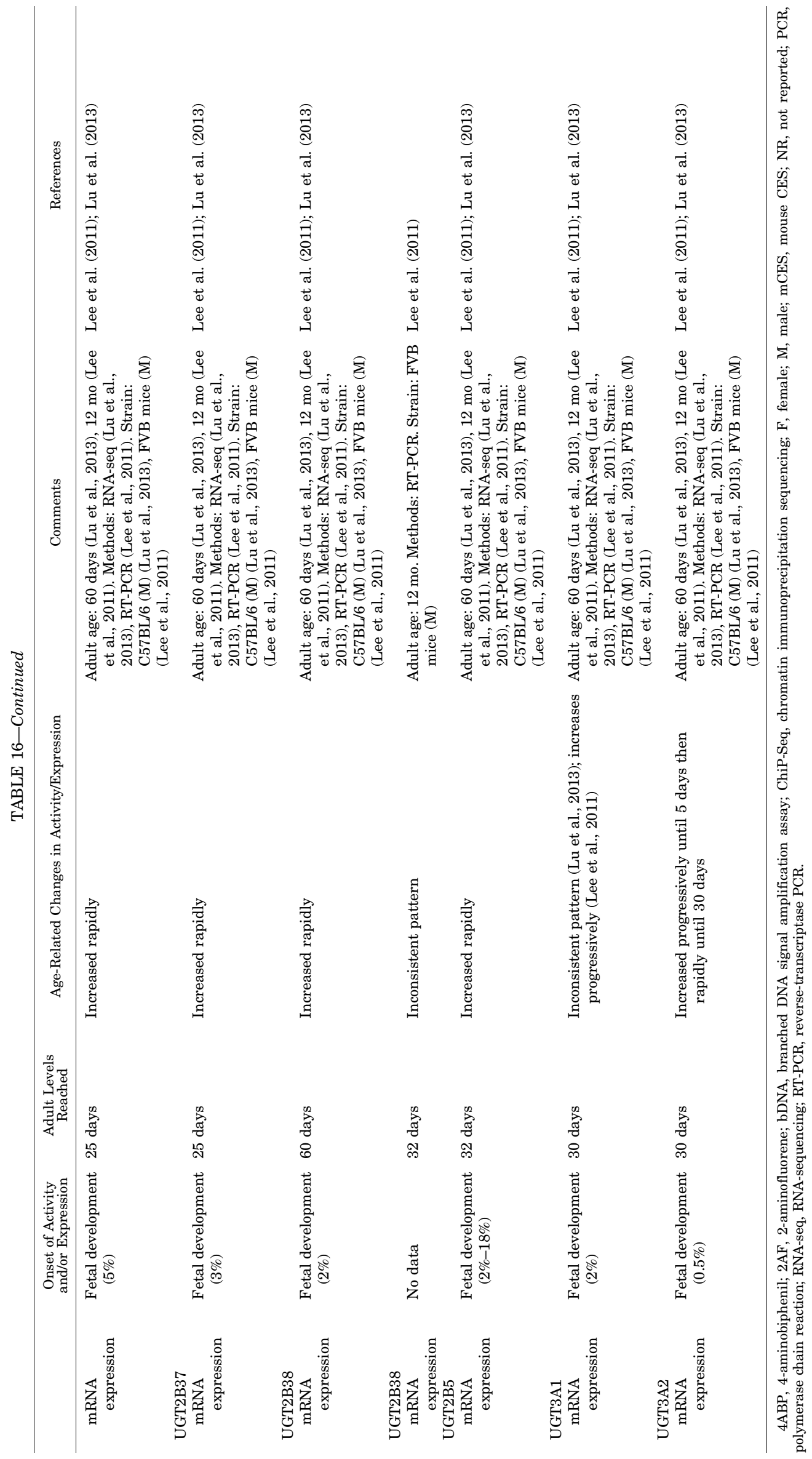




\section{UGT}

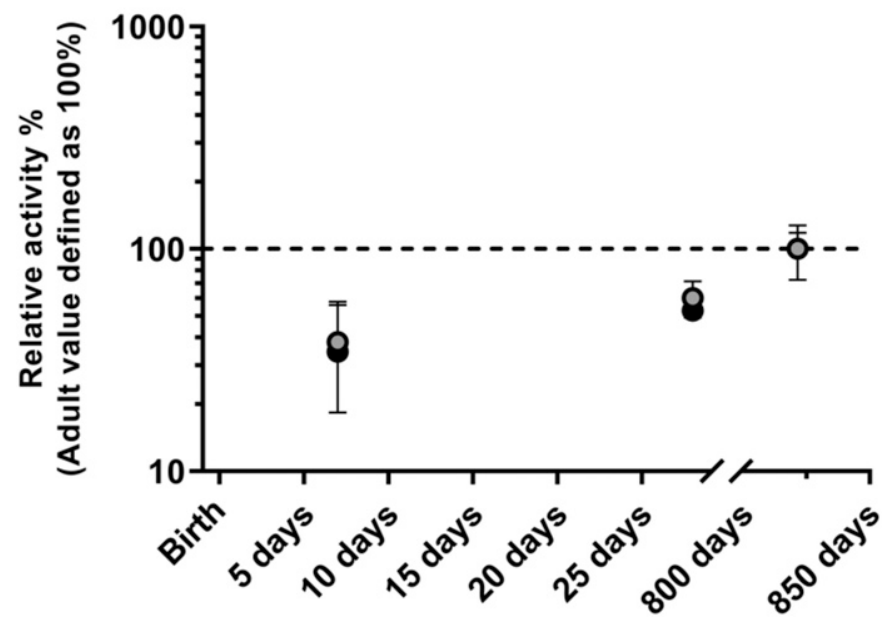

Fig. 19. Pooled literature data on the ontogeny of metabolic activity of hepatic UGT activity in Göttingen minipig. The symbols represent the relative activity in each age group, and the dotted line indicates the adult value defined as $100 \%$. If multiple values were obtained for the same age group, the symbols represent the average relative activity, and the error bars show the S.D. See Table 17 for explanation on the ontogeny profiles and literature references.

post-translational modifications, which could remove the correlation in the study populations of future research. This could lead to false conclusions. We therefore encourage future researchers to first establish the correlation between mRNA expression, protein expression, and, if possible, even protein activity for their study population interest before relying entirely on mRNA expression levels as a surrogate for protein expression or activity.

Numerous other covariates apart from age, such as sex or genotype, will also influence expression and activity of DTs and DMEs. However, because of a lack of available data and/or a limited number of individual measurements, no sex-related differences in ontogeny profile of human hepatic DTs and DMEs have been reported. In nonclinical species, including rats and mice, distinct profiles were identified between male and female animals. For instance, CYP2B13 in male mice was at adult values at birth, but in female mice adult values were only reached at 45 days (see Table 9), whereas SULT1A1 mRNA expression in 1.5-day-old rats was $28 \%$ and $75 \%$ of adults values for males and females, respectively (see Table 15).
In this review, no genetic differences in ontogeny profiles were explored. Nevertheless, for the polymorphic DME CYP2D6, for instance, both age and genotype are known to contribute to interindividual variability in CYP2D6 metabolism during human development (Stevens et al., 2008). For DTs (e.g., OATP1B1), it has been shown that some polymorphisms can influence mRNA and/or protein expression levels. Yet there are conflicting reports, as one study did not find a genotypeprotein expression relationship for OATP1B1 in human liver tissue of fetuses and children $<3$ months old (van Groen et al., 2018). Another group reported that OATP1B1 expression was associated with genotype in children $>1$ year of age (Prasad et al., 2016). Such apparent discrepancies can be explained by the interplay between genotype and ontogeny, in which a lower expression at young age may obscure an effect of genotype. Also for in vivo data, this was shown for the CYP3A5 substrate tacrolimus, in which younger age and CYP3A5 expresser genotype were independently associated with higher dosing requirements and lower tacrolimus concentration/dose ratios (Gijsen et al., 2011). Further studying the interplay between age and genotype would be of help to improve prediction of

TABLE 17

Ontogeny profile of hepatic phase II enzymes in Göttingen minipig based on metabolic activity, protein expression, and mRNA expression levels Percentages represent expression/activity relative to adult levels.

\begin{tabular}{lcccc}
\hline & $\begin{array}{c}\text { Onset of Activity and/or } \\
\text { Expression }\end{array}$ & $\begin{array}{c}\text { Adult Levels } \\
\text { Reached }\end{array}$ & $\begin{array}{c}\text { Age-Related } \\
\text { Changes in } \\
\text { Activity/ } \\
\text { Expression }\end{array}$ & Comments \\
\hline $\begin{array}{c}\text { UGT } \\
\text { Catalytic } \\
\text { activity }\end{array}$ & $\begin{array}{c}\text { M: } 7 \text { days }(35 \%) ; \text { F: } 7 \text { days } \\
(38 \%)\end{array}$ & $\begin{array}{c}\text { M: NR (52\% at 28 } 28 \\
\text { days); F: NR } \\
\text { (60\% at 28 days) }\end{array}$ & $\begin{array}{c}\text { Increased } \\
\text { rapidly }\end{array}$ & $\begin{array}{c}\text { Single study, sparse data. Adult age: 822 days. } \\
\text { Substrate: UGT-Glo. Methods: PLM. Strain: } \\
\text { Göttingen minipig (M/F) }\end{array} \quad$ Van Peer et al. \\
(2017)
\end{tabular}

F, female; M, male; NR, not reported; PLM, pig liver microsome. 
drug PK mainly when polymorphic proteins, such as CYP2D6, CYP2C19, or UGT2B10, are involved.

Several suggestions can be made for further research. Because the strength of this review lies in the fact that all raw data from available literature were extracted, normalized, and pooled, we believe that this should become standard of practice. As such, to accelerate data availability, we encourage publishing the data set as a supplementary file along with the publication and initiatives for data-sharing platforms or repositories in which all raw data of published articles are availablethe added value of this was recently shown by Ladumor et al. (2019). Scientists are encouraged to follow guidelines from initiatives like the go-FAIR initiative to make data "Findable, Accessible, Interoperable, and Reusable (FAIR)" (Wilkinson et al., 2016). Also, to further accelerate data generation, international databases with information on which samples are stored in various biobanks would have added value to overcome the scarcity of pediatric tissue. Lastly, current developments may make it possible to fill the knowledge gaps that were identified in this review. These include the use of organoids (Nantasanti et al., 2016) and exosomes (Rodrigues and Rowland, 2019) to study DT and DME activity and the interplay between DTs and DMEs. However, these techniques are currently hampered by the lack of knowledge regarding whether organoids and exosomes retain age-specific properties, which is a prerequisite for studying age-related changes in expression/activity of DTs and DMEs. Moreover, although this review is limited to ontogeny in the liver, DTs and/or DMEs are also abundant in other major organs, such as the kidney and gastrointestinal tract, and sanctuary sites, including the central nervous system (DeGorter et al., 2012). Developmental patterns of isoforms appear to be organ-dependent (Drozdzik et al., 2018; Li et al., 2019). However, for other organs, a quantitative approach as presented in this comprehensive review is not available but is highly needed. Once this is available, integration of ontogeny profiles in multiple tissues via a PBPK framework could provide a more holistic systems approach on the development of an entire organism (Smits et al., 2013).

In conclusion, we anticipate that our expedition to compile these hepatic ontogeny data across human and various nonclinical species will help us understand the developmental patterns of DTs and DMEs in human and nonclinical species and provide an excellent framework to support and trigger improvement in predicting drug disposition in pediatric and juvenile populations.

\section{Acknowledgments}

The authors would like to acknowledge the scientific and organizational support by Connie Chen and Oscar Bermudez at the Health and Environmental Sciences Institute (HESI). This manuscript was realized as one of the deliverables of the HESI Developmental and
Reproductive Toxicology (DART) working group on neonatal pediatrics (neonatal physiology subsection).

\section{Authorship Contributions}

Participated in research design: van Groen, Nicolaï, Van Cruchten, Smits, Schmidt, de Wildt, Allegaert, De Schaepdrijver, Annaert, Badée.

Performed data analysis: van Groen, Nicolaï, Kuik, Van Cruchten, van Peer, Annaert, Badée.

Wrote or contributed to the writing of the manuscript: van Groen, Nicolaï, Kuik, Van Cruchten, van Peer, Smits, Schmidt, de Wildt, Allegaert, De Schaepdrijver, Annaert, Badée.

\section{References}

Abanda NN, Riches Z, and Collier AC (2017) Lobular distribution and variability in hepatic ATP binding cassette protein B1 (ABCB1, P-gp): ontogenetic differences and potential for toxicity. Pharmaceutics $\mathbf{9} \cdot 8$.

Achour B, Dantonio A, Niosi M, Novak JJ, Fallon JK, Barber J, Smith PC, RostamiHodjegan A, and Goosen TC (2017) Quantitative characterization of major hepatic UDP-glucuronosyltransferase enzymes in human liver microsomes: comparison of two proteomic methods and correlation with catalytic activity. Drug Metab Dispos 45:1102-1112.

Aebersold R, Burlingame AL, and Bradshaw RA (2013) Western blots versus selected reaction monitoring assays: time to turn the tables? Mol Cell Proteomics 12 $2381-2382$

Agathopoulos A, Nicolopoulos D, Matsaniotis N, and Papadatos C (1971) Biochemical changes of catechol-O-methyltransferase during development of human liver. $\mathrm{Pe}$ diatrics 47:125-128.

Alcorn J, Elbarbry FA, Allouh MZ, and McNamara PJ (2007) Evaluation of the assumptions of an ontogeny model of rat hepatic cytochrome P450 activity. Drug Metab Dispos 35:2225-2231.

Alnouti Y and Klaassen CD (2006) Tissue distribution and ontogeny of sulfotransferase enzymes in mice. Toxicol Sci 93:242-255.

Alnouti Y and Klaassen CD (2008) Tissue distribution, ontogeny, and regulation of aldehyde dehydrogenase (Aldh) enzymes mRNA by prototypical microsomal enzyme inducers in mice. Toxicol Sci 101:51-64.

Alnouti Y, Petrick JS, and Klaassen CD (2006) Tissue distribution and ontogeny of organic cation transporters in mice. Drug Metab Dispos 34:477-482.

Asaoka Y, Sakai H, Sasaki J, Goryo M, Yanai T, Masegi T, and Okada K (2010) Changes in the gene expression and enzyme activity of hepatic cytochrome P450 in juvenile Sprague-Dawley rats. $J$ Vet Med Sci 72:471-479.

Badée J, Fowler S, de Wildt SN, Collier AC, Schmidt S, and Parrott N (2019) The ontogeny of UDP-glucuronosyltransferase enzymes, recommendations for future profiling studies and application through physiologically based pharmacokinetic modelling. Clin Pharmacokinet 58:189-211.

Barker EV, Hume R, Hallas A, and Coughtrie WH (1994) Dehydroepiandrosterone sulfotransferase in the developing human fetus: quantitative biochemical and immunological characterization of the hepatic, renal, and adrenal enzymes. Endocrinology 134:982-989.

Belknap WM, Balistreri WF, Suchy FJ, and Miller PC (1981) Physiologic cholestasis II: serum bile acid levels reflect the development of the enterohepatic circulation in rats. Hepatology 1:613-616.

Berthou F, Ratanasavanh D, Alix D, Carlhant D, Riche C, and Guillouzo A (1988) Caffeine and theophylline metabolism in newborn and adult human hepatocytes; comparison with adult rat hepatocytes. Biochem Pharmacol 37:3691-3700.

Bhatt DK, Basit A, Zhang H, Gaedigk A, Lee SB, Claw KG, Mehrotra A, Chaudhry AS, Pearce RE, Gaedigk R, et al. (2018) Hepatic abundance and activity of androgen- and drug-metabolizing enzyme UGT2B17 are associated with genotype, age, and sex. Drug Metab Dispos 46:888-896.

Bhatt DK, Gaedigk A, Pearce RE, Leeder JS, and Prasad B (2017) Age-dependent protein abundance of cytosolic alcohol and aldehyde dehydrogenases in human liver. Drug Metab Dispos 45:1044-1048.

Bhatt DK, Mehrotra A, Gaedigk A, Chapa R, Basit A, Zhang H, Choudhari P, Boberg M, Pearce RE, Gaedigk R, et al. (2019) Age- and genotype-dependent variability in the protein abundance and activity of six major uridine diphosphateglucuronosyltransferases in human liver. Clin Pharmacol Ther 105:131-141.

Boberg M, Vrana M, Mehrotra A, Pearce RE, Gaedigk A, Bhatt DK, Leeder JS, and Prasad B (2017) Age-dependent absolute abundance of hepatic carboxylesterases (CES1 and CES2) by LC-MS/MS proteomics: application to PBPK modeling of oseltamivir In Vivo pharmacokinetics in infants. Drug Metab Dispos 45:216-223.

Brouwer KL, Aleksunes LM, Brandys B, Giacoia GP, Knipp G, Lukacova V, Meibohm B, Nigam SK, Rieder M, and de Wildt SN; Pediatric Transporter Working Group (2015) Human ontogeny of drug transporters: review and recommendations of the pediatric transporter working group. Clin Pharmacol Ther 98:266-287.

Burchell B, Coughtrie M, Jackson M, Harding D, Fournel-Gigleux S, Leakey J, and Hume R (1989) Development of human liver UDP-glucuronosyltransferases. Dev Pharmacol Ther 13:70-77.

Campbell MT and Wishart GJ (1980) The effect of premature and delayed birth on the development of UDP-glucuronosyltransferase activities towards bilirubin, morphine and testosterone in the rat. Biochem $J$ 186:617-619.

Cappiello M, Giuliani L, Rane A, and Pacifici GM (1991) Dopamine sulphotransferase is better developed than p-nitrophenol sulphotransferase in the human fetus. Dev Pharmacol Ther 16:83-88. 
Carpenter SP, Lasker JM, and Raucy JL (1996) Expression, induction, and catalytic activity of the ethanol-inducible cytochrome P450 (CYP2E1) in human fetal liver and hepatocytes. Mol Pharmacol 49:260-268.

Cazeneuve C, Pons G, Rey E, Treluyer JM, Cresteil T, Thiroux G, D'Athis P, and Olive G (1994) Biotransformation of caffeine in human liver microsomes from foetuses, neonates, infants and adults. Br J Clin Pharmacol 37:405-412.

Chen HL, Chen HL, Liu YJ, Feng CH, Wu CY, Shyu MK, Yuan RH, and Chang MH (2005) Developmental expression of canalicular transporter genes in human liver. J Hepatol 43:472-477.

Chen LJ (1982) Bile salt sulfotransferase in Guinea pig liver. Biochim Biophys Acta 717:316-321.

Chen Y, Jin JY, Mukadam S, Malhi V, and Kenny JR (2012) Application of IVIVE and PBPK modeling in prospective prediction of clinical pharmacokinetics: strategy and approach during the drug discovery phase with four case studies. Biopharm Drug Dispos 33:85-98.

Cheng X, Buckley D, and Klaassen CD (2007) Regulation of hepatic bile acid transporters Ntcp and Bsep expression. Biochem Pharmacol 74:1665-1676.

Cheng X, Maher J, Chen C, and Klaassen CD (2005) Tissue distribution and ontogeny of mouse organic anion transporting polypeptides (Oatps). Drug Metab Dispos 33: 1062-1073.

Cherala G, Shapiro BH, and D'mello AP (2007) Effect of perinatal low protein diets on the ontogeny of select hepatic cytochrome p450 enzymes and cytochrome p450 reductase in the rat. Drug Metab Dispos 35:1057-1063.

Cheung KWK, van Groen BD, Burckart GJ, Zhang L, de Wildt SN, and Huang SM (2019) Incorporating ontogeny in physiologically based pharmacokinetic modeling to improve pediatric drug development: what we know about developmental changes in membrane transporters. J Clin Pharmacol 59 (Suppl 1):S56-S69.

Chow T, Imaoka S, Hiroi T, and Funae Y (1999) Developmental changes in the catalytic activity and expression of CYP2D isoforms in the rat liver. Drug Metab Dispos 27:188-192.

Cizkova D, Mokry J, Micuda S, Osterreicher J, and Martinkova J (2005) Expression of MRP2 and MDR1 and other hepatic markers in hepatocytes in situ and WRL 68 cells in vitro. Basic Clin Pharmacol Toxicol 96:249-250.

Coughtrie MW, Burchell B, Leakey JE, and Hume R (1988) The inadequacy of perinatal glucuronidation: immunoblot analysis of the developmental expression of individual UDP-glucuronosyltransferase isoenzymes in rat and human liver microsomes. Mol Pharmacol 34:729-735.

Csanaky IL, Lu H, Zhang Y, Ogura K, Choudhuri S, and Klaassen CD (2011) Organic anion-transporting polypeptide $1 \mathrm{~b} 2$ (Oatp1b2) is important for the hepatic uptake of unconjugated bile acids: studies in Oatp1b2-null mice. Hepatology 53:272-281.

Cuesta de Juan S, Monte MJ, Macias RIR, Wauthier V, Calderon PB, and Marin JJG (2007) Ontogenic development-associated changes in the expression of genes involved in rat bile acid homeostasis. J Lipid Res 48:1362-1370.

Cui JY, Choudhuri S, Knight TR, and Klaassen CD (2010) Genetic and epigenetic regulation and expression signatures of glutathione S-transferases in developing mouse liver. Toxicol Sci 116:32-43.

Cui JY, Gunewardena SS, Yoo B, Liu J, Renaud HJ, Lu H, Zhong XB, and Klaassen CD (2012a) RNA-Seq reveals different mRNA abundance of transporters and their alternative transcript isoforms during liver development. Toxicol Sci 127:592-608.

Cui JY, Renaud HJ, and Klaassen CD (2012b) Ontogeny of novel cytochrome P450 gene isoforms during postnatal liver maturation in mice. Drug Metab Dispos 40 1226-1237.

Cui YJ, Cheng X, Weaver YM, and Klaassen CD (2009) Tissue distribution, genderdivergent expression, ontogeny, and chemical induction of multidrug resistance transporter genes (Mdr1a, Mdr1b, Mdr2) in mice. Drug Metab Dispos 37:203-210.

DeGorter MK, Xia CQ, Yang JJ, and Kim RB (2012) Drug transporters in drug efficacy and toxicity. Annu Rev Pharmacol Toxicol 52:249-273.

del Santo B, Tarafa G, Felipe A, Casado FJ, and Pastor-Anglada M (2001) Developmental regulation of the concentrative nucleoside transporters CNT1 and CNT2 in rat liver. J Hepatol 34:873-880.

Deo AK, Prasad B, Balogh L, Lai Y, and Unadkat JD (2012) Interindividual variability in hepatic expression of the multidrug resistance-associated protein 2 (MRP2/ABCC2): quantification by liquid chromatography/tandem mass spectrometry. Drug Metab Dispos 40:852-855.

de Peretti E and Forest MG (1978) Pattern of plasma dehydroepiandrosterone sulfate levels in humans from birth to adulthood: evidence for testicular production. J Clin Endocrinol Metab 47:572-577.

de Wildt SN, Ito S, and Koren G (2009) Challenges for drug studies in children: CYP3A phenotyping as example. Drug Discov Today 14:6-15.

de Wildt SN, Kearns GL, Leeder JS, and van den Anker JN (1999) Glucuronidation in humans. Pharmacogenetic and developmental aspects. Clin Pharmacokinet 36: 439-452.

de Zwart L, Scholten M, Monbaliu JG, Annaert PP, Van Houdt JM, Van den Wyngaert I, De Schaepdrijver LM, Bailey GP, Coogan TP, Coussement WC, et al (2008) The ontogeny of drug metabolizing enzymes and transporters in the rat. Reprod Toxicol 26:220-230.

Divakaran K, Hines RN, and McCarver DG (2014) Human hepatic UGT2B15 developmental expression. Toxicol Sci 141:292-299.

Drozdzik M, Busch D, Łapczuk J, Müller J, Ostrowski M, Kurzawski M, and Oswald S (2018) Protein abundance of clinically relevant drug transporters in the human liver and intestine: a comparative analysis in paired tissue specimens. Clin Pharmacol Ther 105:1204-1212.

Duanmu Z, Weckle A, Koukouritaki SB, Hines RN, Falany JL, Falany CN, Kocarek TA, and Runge-Morris M (2006) Developmental expression of aryl, estrogen, and hydroxysteroid sulfotransferases in pre- and postnatal human liver. J Pharmacol Exp Ther 316:1310-1317.

Ekström L and Rane A (2015) Genetic variation, expression and ontogeny of sulfotransferase SULT2A1 in humans. Pharmacogenomics $J$ 15:293-297.

Elbarbry F and Alcorn J (2009) Ontogeny of glutathione and glutathione-related antioxidant enzymes in rat liver. Res Vet Sci 87:242-244.
Elbarbry FA, McNamara PJ, and Alcorn J (2007) Ontogeny of hepatic CYP1A2 and CYP2E1 expression in rat. J Biochem Mol Toxicol 21:41-50.

Elmorsi Y, Barber J, and Rostami-Hodjegan A (2016) Ontogeny of hepatic drug transporters and relevance to drugs used in pediatrics. Drug Metab Dispos 44: 992-998.

Emoto C, Johnson TN, Neuhoff S, Hahn D, Vinks AA, and Fukuda T (2018) PBPK model of morphine incorporating developmental changes in hepatic OCT1 and UGT2B7 proteins to explain the variability in clearances in neonates and small infants. CPT Pharmacometrics Syst Pharmacol 7:464-473.

European Medicines Agency (2012) Guideline on the investigation of drug interactions, Committee for Human Medicinal Products.

Fakhoury M, de Beaumais T, Guimiot F, Azougagh S, Elie V, Medard Y, Delezoide AL, and Jacqz-Aigrain E (2009) mRNA expression of MDR1 and major metabolising enzymes in human fetal tissues. Drug Metab Pharmacokinet 24:529-536.

Fattah S, Augustijns P, and Annaert P (2015) Age-dependent activity of the uptake transporters Ntcp and Oatp1b2 in male rat hepatocytes: from birth till adulthood. Drug Metab Dispos 43:1-8.

Fattah S, Augustijns P, and Annaert P (2016) Effect of age on the hepatocellularity number for wistar rats. Drug Metab Dispos 44:366-369

Food and Drug Administration (2020) Clinical Drug Interaction Studies - Cytochrome P450 Enzyme- and Transporter-Mediated Drug Interactions, Guidance for Industry, U.S. Department of Health and Human Services, Food and Drug Administration, Center for Drug Evaluation and Research

Gebremichael A, Chang AM, Buckpitt AR, Plopper CG, and Pinkerton KE (1995) Postnatal development of cytochrome P4501A1 and 2B1 in rat lung and liver: effect of aged and diluted sidestream cigarette smoke. Toxicol Appl Pharmacol 135: 246-253.

Giacomini KM and Huang SM (2013) Transporters in drug development and clinical pharmacology. Clin Pharmacol Ther 94:3-9.

Gijsen V, Mital S, van Schaik RH, Soldin OP, Soldin SJ, van der Heiden IP, Nulman I, Koren G, and de Wildt SN (2011) Age and CYP3A5 genotype affect tacrolimus dosing requirements after transplant in pediatric heart recipients. J Heart Lung Transplant 30:1352-1359.

Gilissen RA, Hume R, Meerman JH, and Coughtrie MW (1994) Sulphation of N-hydroxy-4-aminobiphenyl and N-hydroxy-4-acetylaminobiphenyl by human foetal and neonatal sulphotransferase. Biochem Pharmacol 48:837-840.

Gregus Z, Varga F, and Schmelás A (1985) Age-development and inducibility of hepatic glutathione S-transferase activities in mice, rats, rabbits and Guinea-pigs. Comp Biochem Physiol C Comp Pharmacol Toxicol 80:85-90.

Guo GL, Johnson DR, and Klaassen CD (2002) Postnatal expression and induction by pregnenolone-16alpha-carbonitrile of the organic anion-transporting polypeptide 2 in rat liver. Drug Metab Dispos 30:283-288.

Hahn D, Emoto C, Euteneuer JC, Mizuno T, Vinks AA, and Fukuda T (2019) Influence of OCT1 ontogeny and genetic variation on morphine disposition in critically ill neonates: lessons from PBPK modeling and clinical study. Clin Pharmacol Ther 105:761-768.

Hahn D, Emoto C, Vinks AA, and Fukuda T (2017) Developmental changes in hepatic organic cation transporter OCT1 protein expression from neonates to children Drug Metab Dispos 45:23-26.

Hakkola J, Pasanen M, Purkunen R, Saarikoski S, Pelkonen O, Mäenpää J, Rane A and Raunio H (1994) Expression of xenobiotic-metabolizing cytochrome P450 forms in human adult and fetal liver. Biochem Pharmacol 48:59-64.

Hakkola J, Tanaka E, and Pelkonen O (1998) Developmental expression of cytochrome P450 enzymes in human liver. Pharmacol Toxicol 82:209-217.

Hein DW, Bendaly J, Neale JR, and Doll MA (2008) Systemic functional expression of $\mathrm{N}$-acetyltransferase polymorphism in the F344 Nat2 congenic rat. Drug Metab Dispos 36:2452-2459.

Hines RN, Simpson PM, and McCarver DG (2016) Age-dependent human hepatic carboxylesterase 1 (CES1) and carboxylesterase 2 (CES2) postnatal ontogeny. Drug Metab Dispos 44:959-966.

Hou WY, Xu SF, Zhu QN, Lu YF, Cheng XG, and Liu J (2014) Age- and sex-related differences of organic anion-transporting polypeptide gene expression in livers of rats. Toxicol Appl Pharmacol 280:370-377.

Imaoka S, Fujita S, and Funae Y (1991) Age-dependent expression of cytochrome P450s in rat liver. Biochim Biophys Acta 1097:187-192.

International Council for Harmonisation (2000) ICH Harmonised Tripartite Guideline Clinical Investigation of medicinal products in the pediatric population E11.

Ise R, Kondo S, Kato H, Imai N, Akiyama H, Iwasaki K, Yamazaki H, and Uno Y (2011) Expression of cytochromes p450 in fetal, infant, and juvenile liver of cynomolgus macaques. Drug Metab Pharmacokinet 26:621-626.

Iwasaki K, Tokuma Y, Noda K, and Noguchi H (1994) Age- and sex-related changes of sulfotransferase activities in the rat. Chem Biol Interact 92:209-217.

Jacqz-Aigrain E and Cresteil T (1992) Cytochrome P450-dependent metabolism of dextromethorphan: fetal and adult studies. Dev Pharmacol Ther 18:161-168.

Jang I, Jung K, and Cho J (1998) Age-related changes in antioxidant enzyme activities in the small intestine and liver from Wistar rats. Exp Anim 47:247-252.

Janmohamed A, Hernandez D, Phillips IR, and Shephard EA (2004) Cell-, tissue-, sex- and developmental stage-specific expression of mouse flavin-containing monooxygenases (Fmos). Biochem Pharmacol 68:73-83.

Johnson DR, Guo GL, and Klaassen CD (2002) Expression of rat Multidrug Resistance Protein 2 (Mrp2) in male and female rats during normal and pregnenolone-16alpha-carbonitrile (PCN)-induced postnatal ontogeny. Toxicology 178: 209-219.

Johnson TN, Rostami-Hodjegan A, and Tucker GT (2006) Prediction of the clearance of eleven drugs and associated variability in neonates, infants and children. Clin Pharmacokinet 45:931-956.

Johnson TN, Tanner MS, and Tucker GT (2000) A comparison of the ontogeny of enterocytic and hepatic cytochromes P450 3A in the rat. Biochem Pharmacol 60: $1601-1610$ 
Johnson TN, Zhou D, and Bui KH (2014) Development of physiologically based pharmacokinetic model to evaluate the relative systemic exposure to quetiapine after administration of IR and XR formulations to adults, children and adolescents. Biopharm Drug Dispos 35:341-352.

Johnsrud EK, Koukouritaki SB, Divakaran K, Brunengraber LL, Hines RN, and McCarver DG (2003) Human hepatic CYP2E1 expression during development. $J$ Pharmacol Exp Ther 307:402-407.

Kane RE and Chen LJ (1991) Hepatic bile salt sulfotransferases in the rat: sulfation of 3 beta-hydroxy-5-cholenoate during development. J Pediatr Gastroenterol Nutr 12:260-268.

Kawade N and Onishi S (1981) The prenatal and postnatal development of UDPglucuronyltransferase activity towards bilirubin and the effect of premature birth on this activity in the human liver. Biochem $J$ 196:257-260

Kawase A, Ito A, Yamada A, and Iwaki M (2015) Age-related changes in mRNA levels of hepatic transporters, cytochrome P450 and UDP-glucuronosyltransferase in female rats. Eur J Drug Metab Pharmacokinet 40:239-244.

Kishi M, Emi Y, Sakaguchi M, Ikushiro S, and Iyanagi T (2008) Ontogenic isoform switching of UDP-glucuronosyltransferase family 1 in rat liver. Biochem Biophys Res Commun 377:815-819.

Klaassen CD and Aleksunes LM (2010) Xenobiotic, bile acid, and cholesterol transporters: function and regulation. Pharmacol Rev 62:1-96.

Klaassen CD, Liu L, and Dunn RT 2nd (1998) Regulation of sulfotransferase mRNA expression in male and female rats of various ages. Chem Biol Interact 109 299-313

Knibbe CA, Krekels EH, van den Anker JN, DeJongh J, Santen GW, van Dijk M, Simons SH, van Lingen RA, Jacqz-Aigrain EM, Danhof M, et al. (2009) Morphine glucuronidation in preterm neonates, infants and children younger than 3 years. Clin Pharmacokinet 48:371-385.

Konieczna A, Erdösová B, Lichnovská R, Jandl M, Cúžková K, and Ehrmann J (2011) Differential expression of ABC transporters (MDR1, MRP1, BCRP) in developing human embryos. J Mol Histol 42:567-574.

Koukouritaki SB, Manro JR, Marsh SA, Stevens JC, Rettie AE, McCarver DG, and Hines RN (2004) Developmental expression of human hepatic CYP2C9 and CYP2C19. J Pharmacol Exp Ther 308:965-974.

Krekels EH, Johnson TN, den Hoedt SM, Rostami-Hodjegan A, Danhof M, Tibboel D, and Knibbe CA (2012) From pediatric covariate model to semiphysiological function for maturation: Part II-sensitivity to physiological and physicochemical properties. CPT Pharmacometrics Syst Pharmacol 1:e10.

Lacroix D, Sonnier M, Moncion A, Cheron G, and Cresteil T (1997) Expression of CYP3A in the human liver--evidence that the shift between CYP3A7 and CYP3A4 occurs immediately after birth. Eur J Biochem 247:625-634.

Ladumor MK, Thakur A, Sharma S, Rachapally A, Mishra S, Bobe P, Rao VK, Pammi P, Kangne H, Levi D, et al. (2019) A repository of protein abundance data of drug metabolizing enzymes and transporters for applications in physiologically based pharmacokinetic (PBPK) modelling and simulation. Sci Rep 9:9709.

Leakey JE, Hume R, and Burchell B (1987) Development of multiple activities of UDP-glucuronyltransferase in human liver. Biochem $J$ 243:859-861.

Lee JS, Ward WO, Liu J, Ren H, Vallanat B, Delker D, and Corton JC (2011) Hepatic xenobiotic metabolizing enzyme and transporter gene expression through the life stages of the mouse. PLoS One 6:e24381.

Leeder JS, Gaedigk R, Marcucci KA, Gaedigk A, Vyhlidal CA, Schindel BP, and Pearce RE (2005) Variability of CYP3A7 expression in human fetal liver. $J$ Pharmacol Exp Ther 314:626-635.

Leeder JS, Pearce RE, Gaedigk A, Modak A, and Rosen DI (2008) Evaluation of a [13C]-dextromethorphan breath test to assess CYP2D6 phenotype. J Clin Pharmacol 48:1041-1051.

Li CY, Hosey-Cojocari C, Basit A, Unadkat JD, Leeder JS, and Prasad B (2019) Optimized renal transporter quantification by using aquaporin 1 and aquaporin 2 as anatomical markers: application in characterizing the ontogeny of renal transporters and its correlation with hepatic transporters in paired human samples. AAPS J 21:88.

Li CY, Renaud HJ, Klaassen CD, and Cui JY (2016) Age-specific regulation of drugprocessing genes in mouse liver by ligands of xenobiotic-sensing transcription factors. Drug Metab Dispos 44:1038-1049.

Li N, Hartley DP, Cherrington NJ, and Klaassen CD (2002) Tissue expression, ontogeny, and inducibility of rat organic anion transporting polypeptide 4 $J$ Pharmacol Exp Ther 301:551-560.

Li W, Gu Y, James MO, Hines RN, Simpson P, Langaee T, and Stacpoole PW (2012) Prenatal and postnatal expression of glutathione transferase $\zeta 1$ in human liver and the roles of haplotype and subject age in determining activity with dichloroacetate. Drug Metab Dispos 40:232-239.

Li Y, Cui Y, Hart SN, Klaassen CD, and Zhong XB (2009) Dynamic patterns of histone methylation are associated with ontogenic expression of the Cyp3a genes during mouse liver maturation. Mol Pharmacol 75:1171-1179.

Lu H, Gunewardena S, Cui JY, Yoo B, Zhong XB, and Klaassen CD (2013) RNAsequencing quantification of hepatic ontogeny and tissue distribution of mRNAs of phase II enzymes in mice. Drug Metab Dispos 41:844-857.

Lu H and Rosenbaum S (2014) Developmental pharmacokinetics in pediatric populations. J Pediatr Pharmacol Ther 19:262-276.

Lucier GW, Sonawane BR, McDaniel OS, and Hook GE (1975) Postnatal stimulation of hepatic microsomal enzymes following administration of TCDD to pregnant rats. Chem Biol Interact 11:15-26.

Lupp A, Glöckner R, Etzrodt J, and Müller D (2008) Precision-cut liver slices from rats of different ages: basal cytochrome P450-dependent monooxygenase activities and inducibility. Anal Bioanal Chem 392:1173-1184.

Lyubimov AV and Ortiz de Montellano PR (2011) Structure and function of cytochrome P450 enzymes, Encyclopedia of Drug Metabolism and Interactions pp 1-19.

Macias RI, Hierro C, de Juan SC, Jimenez F, Gonzalez-San Martin F, and Marin J. (2011) Hepatic expression of sodium-dependent vitamin C transporters: ontogeny, subtissular distribution and effect of chronic liver diseases. $B r J$ Nutr 106: $1814-1825$

Mäenpää J, Rane A, Raunio H, Honkakoski P, and Pelkonen O (1993) Cytochrome $\mathrm{P} 450$ isoforms in human fetal tissues related to phenobarbital-inducible forms in the mouse. Biochem Pharmacol 45:899-907.

Maharaj AR and Edginton AN (2014) Physiologically based pharmacokinetic modeling and simulation in pediatric drug development. CPT Pharmacometrics Syst Pharmacol 3:e150.

Maher JM, Slitt AL, Cherrington NJ, Cheng X, and Klaassen CD (2005) Tissue distribution and hepatic and renal ontogeny of the multidrug resistance-associated protein (Mrp) family in mice. Drug Metab Dispos 33:947-955.

Mahmood B, Daood MJ, Hart C, Hansen TW, and Watchko JF (2001) Ontogeny of P-glycoprotein in mouse intestine, liver, and kidney. J Investig Med 49:250-257.

Mahmood I (2016) Prediction of drug clearance in premature and mature neonates, infants, and children $\leq 2$ Years of age: a comparison of the predictive performance of 4 allometric models. J Clin Pharmacol 56:733-739.

Mahnke A, Strotkamp D, Roos PH, Hanstein WG, Chabot GG, and Nef P (1997) Expression and inducibility of cytochrome P450 3A9 (CYP3A9) and other members of the CYP3A subfamily in rat liver. Arch Biochem Biophys 337:62-68.

Martel F, Martins MJ, Calhau C, Hipólito-Reis C, and Azevedo I (1998) Postnatal development of organic cation transport in the rat liver. Pharmacol Res 37: 131-136

Matsui M and Watanabe HK (1982) Developmental alteration of hepatic UDPglucuronosyltransferase and sulphotransferase towards androsterone and 4nitrophenol in Wistar rats. Biochem $J$ 204:441-447.

Matsumoto J, Yokota H, and Yuasa A (2002) Developmental increases in rat hepatic microsomal UDP-glucuronosyltransferase activities toward xenoestrogens and decreases during pregnancy. Environ Health Perspect 110:193-196.

Mawal Y, Paradis K, and Qureshi IA (1997) Developmental profile of mitochondrial glycine N-acyltransferase in human liver. $J$ Pediatr 130:1003-1007.

McCarver DG and Hines RN (2002) The ontogeny of human drug-metabolizing enzymes: phase II conjugation enzymes and regulatory mechanisms. J Pharmacol Exp Ther 300:361-366.

McPhail BT, White CA, Cummings BS, Muralidhara S, Wilson JT, and Bruckner JV (2016) The immature rat as a potential model for chemical risks to children: ontogeny of selected hepatic P450s. Chem Biol Interact 256:167-177.

McQueen CA and Chau B (2003) Neonatal ontogeny of murine arylamine N-acetyltransferases: implications for arylamine genotoxicity. Toxicol Sci 73:279-286.

Meier-Abt F, Faulstich H, and Hagenbuch B (2004) Identification of phalloidin uptake systems of rat and human liver. Biochim Biophys Acta 1664:64-69.

Millecam J, De Clerck L, Govaert E, Devreese M, Gasthuys E, Schelstraete W, Deforce D, De Bock L, Van Bocxlaer J, Sys S, et al. (2018) The ontogeny of cytochrome P450 enzyme activity and protein abundance in conventional pigs in support of preclinical pediatric drug research. Front Pharmacol 9:470.

Miller MS, Juchau MR, Guengerich FP, Nebert DW, and Raucy JL (1996) Drug metabolic enzymes in developmental toxicology. Fundam Appl Toxicol 34:165-175.

Ministry of Labor and Welfare (2018) Guideline on drug interaction for drug development and appropriate provision of information, notification No.0723-4, Pharmaceutical Evaluation Division, Pharmaceuticals safety and environmental Health bureau, Japan. July 23, 2018

Miyagi SJ and Collier AC (2007) Pediatric development of glucuronidation: the ontogeny of hepatic UGT1A4. Drug Metab Dispos 35:1587-1592.

Miyagi SJ and Collier AC (2011) The development of UDP-glucuronosyltransferases 1A1 and 1A6 in the pediatric liver. Drug Metab Dispos 39:912-919.

Mooij MG, Schwarz UI, de Koning BA, Leeder JS, Gaedigk R, Samsom JN, Spaans E, van Goudoever JB, Tibboel D, Kim RB, et al. (2014) Ontogeny of human hepatic and intestinal transporter gene expression during childhood: age matters. Drug Metab Dispos 42:1268-1274.

Mooij MG, van de Steeg E, van Rosmalen J, Windster JD, de Koning BA, Vaes WH, van Groen BD, Tibboel D, Wortelboer HM, and de Wildt SN (2016) Proteomic analysis of the developmental trajectory of human hepatic membrane transporter proteins in the first three months of life. Drug Metab Dispos 44:1005-1013.

Morrissey KM, Stocker SL, Wittwer MB, Xu L, and Giacomini KM (2013) Renal transporters in drug development. Annu Rev Pharmacol Toxicol 53:503-529.

Nakajima Y, Goldblum RM, and Midoro-Horiuti T (2012) Fetal exposure to bisphenol A as a risk factor for the development of childhood asthma: an animal model study. Environ Health 11:8.

Nantasanti S, de Bruin A, Rothuizen J, Penning LC, and Schotanus BA (2016) Concise review: organoids are a powerful tool for the study of liver disease and personalized treatment design in humans and animals. Stem Cells Transl Med $\mathbf{5}$ $325-330$

Naraharisetti SB, Lin YS, Rieder MJ, Marciante KD, Psaty BM, Thummel KE, and Totah RA (2010) Human liver expression of CYP2C8: gender, age, and genotype effects. Drug Metab Dispos 38:889-893.

Neumann E, Mehboob H, Ramírez J, Mirkov S, Zhang M, and Liu W (2016a) Agedependent hepatic UDP-glucuronosyltransferase gene expression and activity in children. Front Pharmacol 7:437.

Nie Y-L, He H, Li J-F, Meng X-G, Yan L, Wang P, Wang S-J, Bi H-Z, Zhang L-R, and Kan Q-C (2017) Hepatic expression of transcription factors affecting developmental regulation of UGT1A1 in the Han Chinese population. Eur J Clin Pharmacol 73:29-37.

Nigam SK (2015) What do drug transporters really do? Nat Rev Drug Discov 14:29-44

Onishi S, Kawade N, Itoh S, Isobe K, and Sugiyama S (1979) Postnatal development of uridine diphosphate glucuronyltransferase activity towards bilirubin and 2 aminophenol in human liver. Biochem $J$ 184:705-707.

Pacifici GM, Franchi M, Colizzi C, Giuliani L, and Rane A (1988) Sulfotransferase in humans: development and tissue distribution. Pharmacology 36:411-419.

Pacifici GM, Franchi M, Giuliani L, and Rane A (1989) Development of the glucuronyltransferase and sulphotransferase towards 2-naphthol in human fetus. Dev Pharmacol Ther 14:108-114. 
Pacifici GM, Kubrich M, Giuliani L, de Vries M, and Rane A (1993) Sulphation and glucuronidation of ritodrine in human foetal and adult tissues. Eur J Clin Pharmacol 44:259-264.

Pacifici GM, Mogavero S, Giuliani L, and Rane A (1991a) Conjugation of benzoic acid with glycine in the human fetal and adult liver and kidney. Dev Pharmacol Ther 17:52-62.

Pacifici GM, Romiti P, Giuliani L, and Rane A (1991b) Thiopurine methyltransferase in humans: development and tissue distribution. Dev Pharmacol Ther 17:16-23.

Pacifici GM, Säwe J, Kager L, and Rane A (1982) Morphine glucuronidation in human fetal and adult liver. Eur J Clin Pharmacol 22:553-558.

Parrott N, Davies B, Hoffmann G, Koerner A, Lave T, Prinssen E, Theogaraj E, and Singer T (2011) Development of a physiologically based model for oseltamivir and simulation of pharmacokinetics in neonates and infants. Clin Pharmacokinet 50:613-623.

Peng L, Cui JY, Yoo B, Gunewardena SS, Lu H, Klaassen CD, and Zhong XB (2013) RNA-sequencing quantification of hepatic ontogeny of phase-I enzymes in mice. Drug Metab Dispos 41:2175-2186.

Peng L, Yoo B, Gunewardena SS, Lu H, Klaassen CD, and Zhong XB (2012) RNA sequencing reveals dynamic changes of mRNA abundance of cytochromes P450 and their alternative transcripts during mouse liver development. Drug Metab Dispos 40:1198-1209.

Petzinger E and Geyer J (2006) Drug transporters in pharmacokinetics. Naunyn Schmiedebergs Arch Pharmacol 372:465-475.

Petzinger E, Ziegler K, and Frimmer M (1979) Inhibition of 3H-demethylphalloin uptake in isolated rat hepatocytes under various experimental conditions. Naunyn Schmiedebergs Arch Pharmacol 307:275-281.

Piekos SC, Chen L, Wang P, Shi J, Yaqoob S, Zhu HJ, Ma X, and Zhong XB (2018) Consequences of phenytoin exposure on hepatic cytochrome P450 expression during postnatal liver maturation in mice. Drug Metab Dispos 46: 1241-1250.

Pope CN, Karanth S, Liu J, and Yan B (2005) Comparative carboxylesterase activities in infant and adult liver and their in vitro sensitivity to chlorpyrifos oxon. Regul Toxicol Pharmacol 42:64-69.

Powis G, Jardine I, Van Dyke R, Weinshilboum R, Moore D, Wilke T, Rhodes W, Nelson R, Benson L, and Szumlanski C (1988) Foreign compound metabolism studies with human liver obtained as surgical waste. Relation to donor characteristics and effects of tissue storage. Drug Metab Dispos 16:582-589.

Prasad B, Achour B, Artursson P, Hop CECA, Lai Y, Smith PC, Barber J, Wisniewski JR, Spellman D, Uchida Y, et al. (2019) Toward a consensus on applying quantitative liquid chromatography-tandem mass spectrometry proteomics in translational pharmacology research: a white paper. Clin Pharmacol Ther 106:525-543.

Prasad B, Evers R, Gupta A, Hop CE, Salphati L, Shukla S, Ambudkar SV, and Unadkat JD (2014) Interindividual variability in hepatic organic aniontransporting polypeptides and P-glycoprotein (ABCB1) protein expression: quantification by liquid chromatography tandem mass spectroscopy and influence of genotype, age, and sex. Drug Metab Dispos 42:78-88.

Prasad B, Gaedigk A, Vrana M, Gaedigk R, Leeder JS, Salphati L, Chu X, Xiao G Hop C, Evers R, et al. (2016) Ontogeny of hepatic drug transporters as quantified by LC-MS/MS proteomics. Clin Pharmacol Ther 100:362-370.

Prasad B, Lai Y, Lin Y, and Unadkat JD (2013) Interindividual variability in the hepatic expression of the human breast cancer resistance protein (BCRP/ABCG2): effect of age, sex, and genotype. J Pharm Sci 102:787-793.

Rachmel A and Hazelton GA (1986) The inducibility and ontogeny of rat liver UDPglucuronyltransferase toward furosemide. Biochem Pharmacol 35:3777-3782.

Ratanasavanh D, Beaune P, Morel F, Flinois JP, Guengerich FP, and Guillouzo A (1991) Intralobular distribution and quantitation of cytochrome P-450 enzymes in human liver as a function of age. Hepatology 13:1142-1151.

Richard K, Hume R, Kaptein E, Stanley EL, Visser TJ, and Coughtrie MW (2001) Sulfation of thyroid hormone and dopamine during human development: ontogeny of phenol sulfotransferases and arylsulfatase in liver, lung, and brain. J Clin Endocrinol Metab 86:2734-2742.

Rodrigues D and Rowland A (2019) From endogenous compounds as biomarkers to plasma-derived nanovesicles as liquid biopsy; has the golden age of translationa pharmacokinetics-absorption, distribution, metabolism, excretion-drug-drug interaction science finally arrived? Clin Pharmacol Ther 105:1407-1420.

Santa Maria C and Machado A (1988) Changes in some hepatic enzyme activities related to phase II drug metabolism in male and female rats as a function of age. Mech Ageing Dev 44:115-125.

Schuetz JD, Beach DL, and Guzelian PS (1994) Selective expression of cytochrome P450 CYP3A mRNAs in embryonic and adult human liver. Pharmacogenetics 4: $11-20$.

Scragg I, Pollard M, Burchell B, and Dutton GJ (1983) The temporary postnatal decline in glucuronidation of certain phenols by rat liver. Biochem $J \mathbf{2 1 4}$ $533-537$

Selwyn FP, Cheng SL, Bammler TK, Prasad B, Vrana M, Klaassen C, and Cui JY (2015) Developmental regulation of drug-processing genes in livers of germ-free mice. Toxicol Sci 147:84-103

Sharma S, Ellis EC, Gramignoli R, Dorko K, Tahan V, Hansel M, Mattison DR, Caritis SN, Hines RN, Venkataramanan R et al. (2013) Hepatobiliary disposition of 17-OHPC and taurocholate in fetal human hepatocytes: a comparison with adult human hepatocytes. Drug Metab Dispos 41:296-304.

Shephard EA, Palmer CN, Segall HJ, and Phillips IR (1992) Quantification of cytochrome P450 reductase gene expression in human tissues. Arch Biochem Biophys 294:168-172.

Shi S and Li Y (2014) Interplay of drug-metabolizing enzymes and transporters in drug absorption and disposition. Curr Drug Metab 15:915-941.

Shimada T, Yamazaki H, Mimura M, Inui Y, and Guengerich FP (1994) Interindividual variations in human liver cytochrome P-450 enzymes involved in the oxidation of drugs, carcinogens and toxic chemicals: studies with liver microsomes of 30 Japanese and 30 Caucasians. J Pharmacol Exp Ther 270:414-423.
Shimada T, Yamazaki H, Mimura M, Wakamiya N, Ueng YF, Guengerich FP, and Inui Y (1996) Characterization of microsomal cytochrome P450 enzymes involved in the oxidation of xenobiotic chemicals in human fetal liver and adult lungs. Drug Metab Dispos 24:515-522.

Smits A, Annaert P, and Allegaert K (2013) Drug disposition and clinical practice in neonates: cross talk between developmental physiology and pharmacology. Int $J$ Pharm 452:8-13.

Song G, Sun X, Hines RN, McCarver DG, Lake BG, Osimitz TG, Creek MR, Clewell HJ, and Yoon M (2017) Determination of human hepatic CYP2C8 and CYP1A2 age-dependent expression to support human health risk assessment for early ages. Drug Metab Dispos 45:468-475.

Sonnier M and Cresteil T (1998) Delayed ontogenesis of CYP1A2 in the human liver. Eur J Biochem 251:893-898.

St-Pierre MV, Stallmach T, Freimoser Grundschober A, Dufour JF, Serrano MA Marin JJ, Sugiyama Y, and Meier PJ (2004) Temporal expression profiles of organic anion transport proteins in placenta and fetal liver of the rat. Am J Physiol Regul Integr Comp Physiol 287:R1505-R1516.

Stevens JC, Hines RN, Gu C, Koukouritaki SB, Manro JR, Tandler PJ, and Zaya MJ (2003) Developmental expression of the major human hepatic CYP3A enzymes. $J$ Pharmacol Exp Ther 307:573-582.

Stevens JC, Marsh SA, Zaya MJ, Regina KJ, Divakaran K, Le M, and Hines RN (2008) Developmental changes in human liver CYP2D6 expression. Drug Metab Dispos 36:1587-1593.

Strange RC, Howie AF, Hume R, Matharoo B, Bell J, Hiley C, Jones P, and Beckett G.J (1989) The development expression of alpha-, mu- and pi-class glutathione S-transferases in human liver. Biochim Biophys Acta 993:186-190.

Strassburg CP, Strassburg A, Kneip S, Barut A, Tukey RH, Rodeck B, and Manns MP (2002) Developmental aspects of human hepatic drug glucuronidation in young children and adults. Gut 50:259-265.

Szabo DT, Richardson VM, Ross DG, Diliberto JJ, Kodavanti PRS, and Birnbaum LS (2009) Effects of perinatal PBDE exposure on hepatic phase I, phase II, phase III, and deiodinase 1 gene expression involved in thyroid hormone metabolism in male rat pups. Toxicol Sci 107:27-39.

Tanaka E, Narisawa C, Nakamura $\mathrm{H}$, Sawa $\mathrm{Y}$, Etoh $\mathrm{H}$, Tadano K, Horie T, Ohkawa H, and Misawa S (1998) Changes in the enzymatic activities of beagle liver during maturation as assessed both in vitro and in vivo. Xenobiotica 28: $795-802$.

Tang L (2007) Age-associated hepatic drug transporter expression and its implications for pediatric pharmacotherapyflexibility affect DNA topoisomerase I function. Doctor of Philosophy dissertation, University of Tennessee Health Science Center. Tateishi T, Nakura H, Asoh M, Watanabe M, Tanaka M, Kumai T, Takashima S, Imaoka S, Funae Y, Yabusaki Y, et al. (1997) A comparison of hepatic cytochrome P450 protein expression between infancy and postinfancy. Life Sci 61:2567-2574.

Tee LB, Gilmore KS, Meyer DJ, Ketterer B, Vandenberghe Y, and Yeoh GC (1992 Expression of glutathione S-transferase during rat liver development. Biochem $J$ 282:209-218.

Thomson MM, Hines RN, Schuetz EG, and Meibohm B (2016) Expression patterns of organic anion transporting polypeptides 1B1 and 1B3 protein in human pediatric liver. Drug Metab Dispos 44:999-1004.

Tomer G, Ananthanarayanan M, Weymann A, Balasubramanian N, and Suchy FJ (2003) Differential developmental regulation of rat liver canalicular membrane transporters Bsep and Mrp2. Pediatr Res 53:288-294.

Treluyer JM, Cheron G, Sonnier M, and Cresteil T (1996) Cytochrome P-450 expression in sudden infant death syndrome. Biochem Pharmacol 52:497-504.

Treluyer JM, Gueret G, Cheron G, Sonnier M, and Cresteil T (1997) Developmenta expression of CYP2C and CYP2C-dependent activities in the human liver: in-vivo/ in-vitro correlation and inducibility. Pharmacogenetics 7:441-452.

Treluyer JM, Jacqz-Aigrain E, Alvarez F, and Cresteil T (1991) Expression of CYP2D6 in developing human liver. Eur J Biochem 202:583-588.

Upreti VV and Wahlstrom JL (2016) Meta-analysis of hepatic cytochrome P450 on togeny to underwrite the prediction of pediatric pharmacokinetics using physiologically based pharmacokinetic modeling. J Clin Pharmacol 56:266-283.

van Groen BD, van de Steeg E, Mooij MG, van Lipzig MMH, de Koning BAE, Verdijk RM, Wortelboer HM, Gaedigk R, Bi C, Leeder JS, et al. (2018) Proteomics of human liver membrane transporters: a focus on fetuses and newborn infants. Eur J Pharm Sci 124:217-227.

van Kalken CK, Giaccone G, van der Valk P, Kuiper CM, Hadisaputro MM, Bosma SA, Scheper RJ, Meijer CJ, and Pinedo HM (1992) Multidrug resistance gene (P-glycoprotein) expression in the human fetus. Am J Pathol 141:1063-1072.

Van Peer E, De Bock L, Boussery K, Van Bocxlaer J, Casteleyn C, Van Ginneken C, and Van Cruchten S (2015) Age-related differences in CYP3A abundance and activity in the liver of the göttingen minipig. Basic Clin Pharmacol Toxicol 117: 350-357.

Van Peer E, Jacobs F, Snoeys J, Van Houdt J, Pijpers I, Casteleyn C, Van Ginneken C, and Van Cruchten S (2017) In vitro phase I- and phase II-drug metabolism in the liver of juvenile and adult göttingen minipigs. Pharm Res 34:750-764.

Van Peer E, Verbueken E, Saad M, Casteleyn C, Van Ginneken C, and Van Cruchten S (2014) Ontogeny of CYP3A and P-glycoprotein in the liver and the small intestine of the Göttingen minipig: an immunohistochemical evaluation. Basic Clin Pharmacol Toxicol 114:387-394.

Vieira I, Sonnier M, and Cresteil T (1996) Developmental expression of CYP2E1 in the human liver. Hypermethylation control of gene expression during the neonatal period. Eur J Biochem 238:476-483.

Warrington JS, Greenblatt DJ, and von Moltke LL (2004) Age-related differences in CYP3A expression and activity in the rat liver, intestine, and kidney. J Pharmacol Exp Ther 309:720-729.

Wegler C, Gaugaz FZ, Andersson TB, Wiśniewski JR, Busch D, Gröer C, Oswald S, Norén A, Weiss F, Hammer HS, et al. (2017) Variability in mass spectrometrybased quantification of clinically relevant drug transporters and drug metabolizing enzymes. Mol Pharm 14:3142-3151. 
Weiss CF, Glazko AJ, and Weston JK (1960) Chloramphenicol in the newborn infant. A physiologic explanation of its toxicity when given in excessive doses. $N$ Engl J Med 262:787-794.

Weiss MD, Donnelly WH, Rossignol C, Varoqui H, Erickson JD, and Anderson KJ (2005) Ontogeny of the neutral amino acid transporter SNAT1 in the developing rat. J Mol Histol 36:301-309.

Wilkinson MD, Dumontier M, Aalbersberg IJ, Appleton G, Axton M, Baak A Blomberg N, Boiten JW, da Silva Santos LB, Bourne PE, et al. (2016) The FAIR Guiding Principles for scientific data management and stewardship [published correction appears in Sci Data (2019) 6:6]. Sci Data 3:160018.

Wishart GJ (1978) Functional heterogeneity of UDP-glucuronosyltransferase as indicated by its differential development and inducibility by glucocorticoids. Demonstration of two groups within the enzyme's activity towards twelve substrates. Biochem J 174:485-489.

Wright AF, Rudan I, Hastie ND, and Campbell H (2010) A 'complexity' of urate transporters. Kidney Int 78:446-452.

Wright MC, Edwards RJ, Pimenta M, Ribeiro V, Ratra GS, Lechner MC, and Paine AJ (1997) Developmental changes in the constitutive and inducible expression of cytochrome P450 3A2. Biochem Pharmacol 54:841-846.

Wrighton SA, Brian WR, Sari MA, Iwasaki M, Guengerich FP, Raucy JL, Molowa DT, and Vandenbranden M (1990) Studies on the expression and metabolic capabilities of human liver cytochrome P450IIIA5 (HLp3). Mol Pharmacol 38:207-213.

Xu M, Bhatt DK, Yeung CK, Claw KG, Chaudhry AS, Gaedigk A, Pearce RE, Broeckel U, Gaedigk R, Nickerson DA, et al. (2017) Genetic and nongenetic factors associated with protein abundance of flavin-containing monooxygenase 3 in human liver. J Pharmacol Exp Ther 363:265-274.

Xu SF, Hu AL, Xie L, Liu JJ, Wu Q, and Liu J (2019) Age-associated changes of cytochrome P450 and related phase-2 gene/proteins in livers of rats. PeerJ 7:e7429.

Yabusaki R, Iwano H, Tsushima S, Koike N, Ohtani N, Tanemura K, Inoue H, and Yokota $\mathrm{H}$ (2015) Weak activity of UDP-glucuronosyltransferase toward Bisphenol analogs in mouse perinatal development. J Vet Med Sci 77:1479-1484.
Yamazaki H (2014) Fifty Years of Cytochrome P450 Research. Springer Japan, Chiyoda-ku, Japan.

Yang HY, Lee QP, Rettie AE, and Juchau MR (1994) Functional cytochrome P4503A isoforms in human embryonic tissues: expression during organogenesis. Mol Pharmacol 46:922-928.

Yang HY, Namkung MJ, and Juchau MR (1995) Expression of functional cytochrome P4501A1 in human embryonic hepatic tissues during organogenesis. Biochem Pharmacol 49:717-726.

Yanni SB, Smith PB, Benjamin DK Jr, Augustijns PF, Thakker DR, and Annaert PP (2011) Higher clearance of micafungin in neonates compared with adults: role of age-dependent micafungin serum binding. Biopharm Drug Dispos 32: $222-232$.

Zaya MJ, Hines RN, and Stevens JC (2006) Epirubicin glucuronidation and UGT2B7 developmental expression. Drug Metab Dispos 34:2097-2101.

Zhang H, Basit A, Wolford C, Chen KF, Gaedigk A, Lin YS, Leeder JS, and Prasad B (2020) Normalized testosterone glucuronide (TG/AG) as a potential urinary biomarker for highly variable UGT2B17 in children 7-18 years. Clin Pharmacol Ther 107:1149-1158

Zhou W, Johnson TN, Bui KH, Cheung SYA, Li J, Xu H, Al-Huniti N, and Zhou D (2018) Predictive performance of physiologically based pharmacokinetic (PBPK) modeling of drugs extensively metabolized by major cytochrome P450s in children Clin Pharmacol Ther 104:188-200.

Zhu HJ, Appel DI, Jiang Y, and Markowitz JS (2009) Age- and sex-related expression and activity of carboxylesterase 1 and 2 in mouse and human liver. Drug Metab Dispos 37:1819-1825.

Zhu QN, Hou WY, Xu SF, Lu YF, and Liu J (2017) Ontogeny, aging, and genderrelated changes in hepatic multidrug resistant protein genes in rats. Life Sci 170: 108-114.

Zinchuk VS, Okada T, Akimaru K, and Seguchi H (2002) Asynchronous expression and colocalization of Bsep and Mrp2 during development of rat liver. Am J Physiol Gastrointest Liver Physiol 282:G540-G548. 